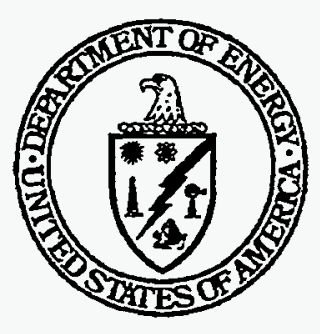

\title{
ASSESSMENT OF COSTS AND BENEFITS OF FLEXIBLE AND ALTERNATIVE FUEL USE IN THE U.S. TRANSPORTATION SECTOR
}

\section{TECHNICAL REPORT FOURTEEN:}

MARKET POTENTIAL AND IMPACTS OF ALTERNATIVE FUEL USE IN LIGHT-DUTY VEHICLES:

\section{A 2000/2010 ANALYSIS}

January 1996

United States Department of Energy Office of Policy and Office of Energy Efficiency and Renewable Energy Washington, DC 20585

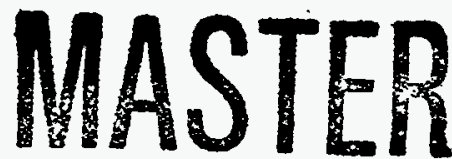
DISTRIBUTION 
This report is based on analysis performed by the Center for Transportation Analysis, Energy Division, Oak Ridge National Laboratory, and Energy and Environmental Analysis, Inc. Principal investigators were Paul Leiby (affiliated with the Center for Transportation Analysis), David L. Greene (affiliated with the Centerfor Transportation Analysis), and Harry Vidas (Energy and Environmental Analysis, Inc.). Additional analysis was provided by Margaret Singh (Argonne National Laboratory, Center for Transportation Studies), Kevin Stork (Argonne National Laboratory, Center for Transportation Studies), K.G. Duleep (Energy and Environmental Analysis, Inc.), and Rich Bechtold (EA Engineering, Inc.) 
ASSESSMENT OF COSTS AND BENEFITS OF FLEXIBLE AND ALTERNATIVE FUEL USE IN THE U.S. TRANSPORTATION SECTOR
TECHNICAL REPORT FOURTEEN: MARKET POTENTIAL AND IMPACTS OF ALTERNATIVE FUEL USE IN LIGHT-DUTY VEHICLES: A 2000/2010 ANALYSIS

\section{CONTENTS}

LIST OF ACRONYMS AND ABBREVIATIONS ............................................................................

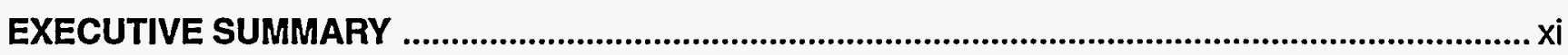

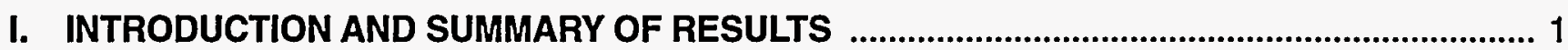

Purpose and Scope of Report ................................................................................................ 1

Analysis Overview ……...................................................................................................................... 1

Year 2000: Results ........................................................................................................................... 3

Year 2010: Methodology and Results ....................................................................................... 4

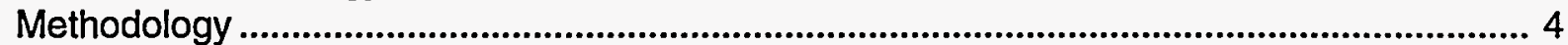

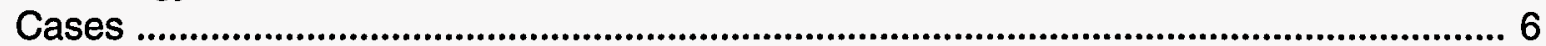

Oil Price and Motor-Fuel Tax Assumptions ........................................................................ 6

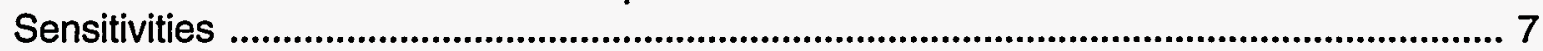

Results for Primary Cases ......................................................................................... 7

Motor-Fuel Use ..................................................................................................... 7

Motor-Fuel Prices .................................................................................................... 8

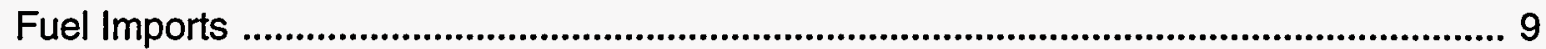

Economic Benefits and Costs .......................................................................................... 11

Greenhouse Gas Emissions ....................................................................................... 12

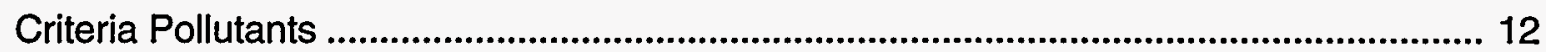

Transition Costs ......................................................................................................... 12

Results for Partially Constrained Cases ........................................................................ 12

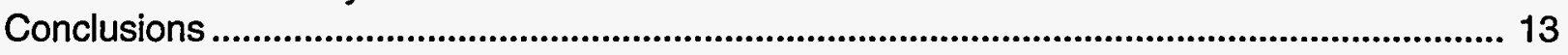

II. GASOLINE DISPLACEMENT BY REPLACEMENT FUELS IN THE YEAR 2000 ..................... 19

Alternative Motor-Fuel Use ...................................................................................... 19

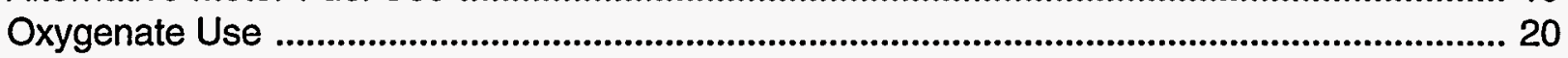

Use of Other Replacement-Fuel Components in Gasoline ...................................................... 21

Total Replacement-Fuel Use in the Year 2000 .......................................................................... 22

III. ANALYTICAL FRAMEWORK FOR THE YEAR-2010 ANALYSIS: THE AFTM MODEL ............ 25

Optimization Framework of the AFTM .................................................................................. 26

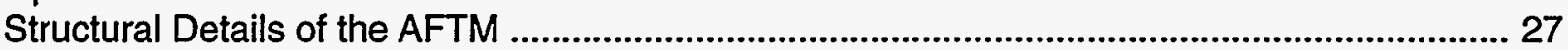

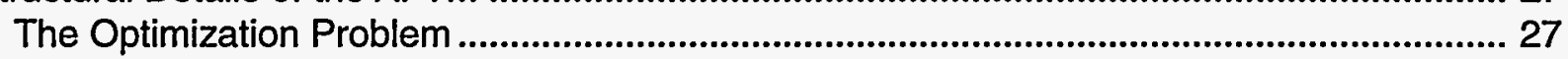

Regional Disaggregation ........................................................................................................ 28

Primary Resource Supply Curves .......................................................................................... 29

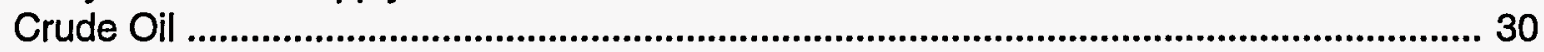

Natural Gas .................................................................................................................... 30

Biomass Feedstock Supply for Ethanol ................................................................................. 35

Energy Product Demand ............................................................................................................... 36

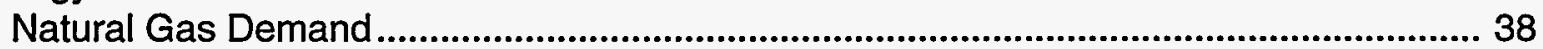

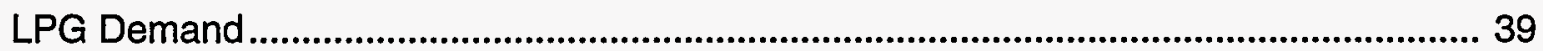




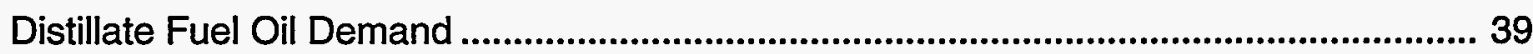

Residual Fuel Oil Demand ..................................................................................... 39

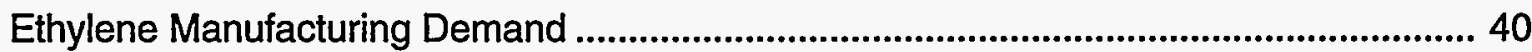

Boiler Fuel Demand ................................................................................................................ 40

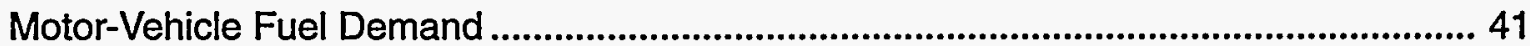

Fuel-Processing (Conversion) Activities .............................................................................. 43

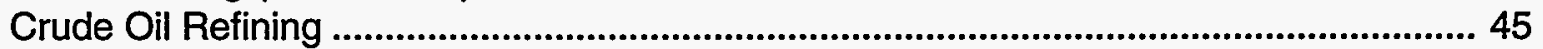

Gas Processing ................................................................................................................... 47

LNG, Methanol, and Ethanol Manufacturing ....................................................................... 48

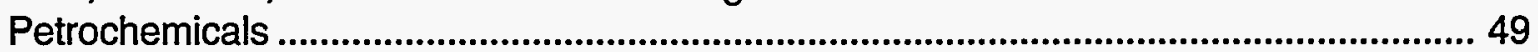

Fuel Distribution and Retail Markups ........................................................................... 50

Motor-Vehicle Fuel Consumption ........................................................................................ 51

Motor-Vehicle Capital Costs .............................................................................................. 52

Transportation Costs ....................................................................................................... 52

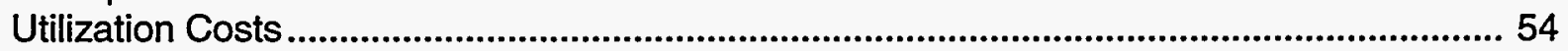

Derivation of Logit Sharing Function ..................................................................................... 55

Benchmarking ...................................................................................................................... 56

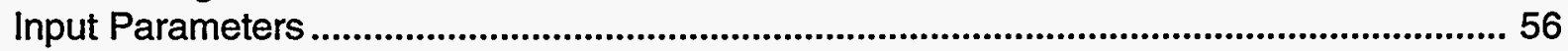

Alternative-Fuel Use in 2010: AFTM Benchmark Case ....................................................... 62

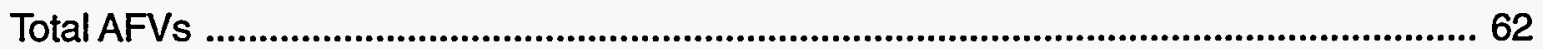

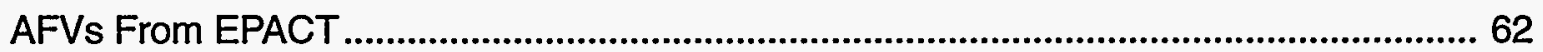

AFVs From State Programs ........................................................................................... 64

AFVs From the California ZEV Mandate ......................................................................... 64

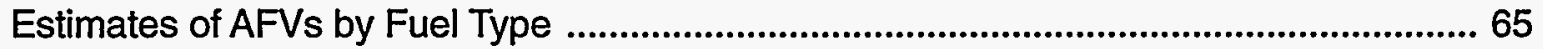

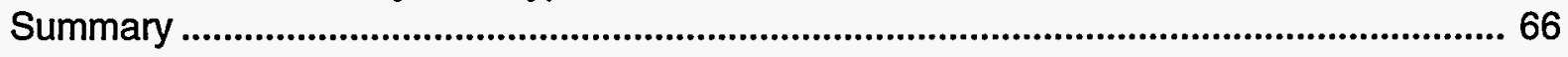

IV. DESCRIPTION OF SCENARIOS AND DETAILS OF RESULTS ...............................................6 67

Oil Price and Fuel-Tax Assumptions.................................................................................. 67

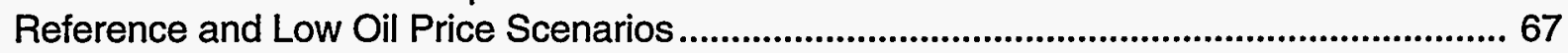

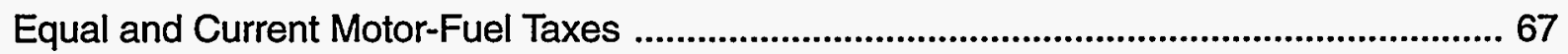

Case Descriptions ......................................................................................................................... 68

Benchmark Case (Case 0) .................................................................................................... 68

Unconstrained (Case 1) .......................................................................................................... 70

U.S. Greenhouse Gas Emissions Limited (GHG 90) (Case 2) ............................................. 71

U.S. Greenhouse Gas Emissions Limited (GHG 80) (Case 3) ........................................... 71

U.S. Energy Imports Limited (Case 4) …………………...................................................... 71

Light-Duty Vehicle Replacement-Fuel Use 30 Percent of Total LDV Fuel Use

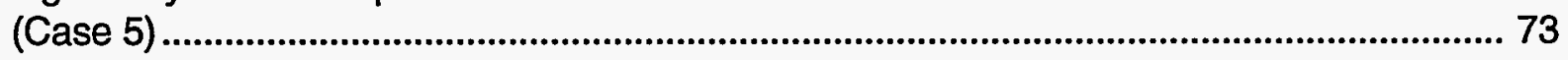

U.S. Replacement Fuel Imports Limited (Case 6) ................................................................... 73

Sensitivities .................................................................................................................................... 74

High Ethylene Demand (Sensitivity B) ................................................................................... 74

Higher Methanol Manufacturing Cost (Sensitivity C) ............................................................... 74

More Optimistic U.S. and Canada Natural Gas Supplies (Sensitivity D) ............................... 74

More Pessimistic Non-OECD Natural Gas Supplies (Sensitivity E) ...................................... 75

Current Motor-Fuel Taxes and Greater U.S.-Canada Natural Gas Supplies

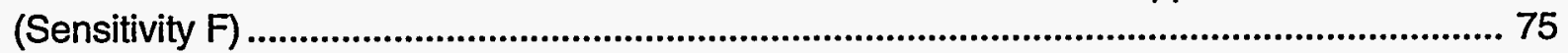

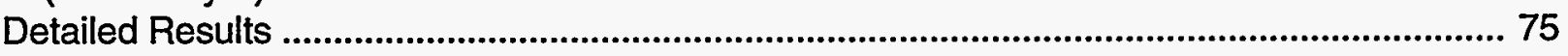

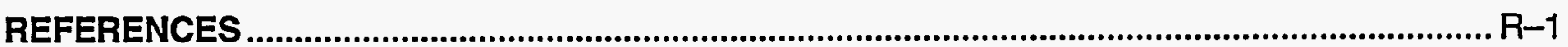




\section{APPENDICES}

APPENDIX A. FUELS AND CONVERSION PROCESSES USED IN THE

ALTERNATIVE FUELS TRADE MODEL

A-1

APPENDIX B. OPEC OIL SUPPLY CURVES

B-1

APPENDIX C. ALTERNATIVE FUELS AND VEHICLES CHOICE MODEL

C-1

APPENDIX D. ESTIMATES OF GREENHOUSE GAS EMISSIONS

FROM ALTERNATIVE TRANSPORTATION FUELS AND INDUSTRIAL FUELS

D-1

TABLES

1-1 Replacement and Alternative-Fuel Use in Light-Duty Vehicles, 1990 and 2000 .......... 3

I-2 AFTM Cases Presented in This Report ...................................................................... 8

I-3 Summary of Modeling Results for All Cases Under the Reference Oil

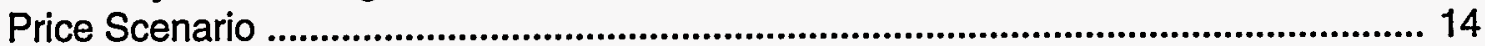

1-4 Summary of Modeling Results for All Cases Under the Low Oil Price Scenario ......... 15

II-1 Gasoline and Diesel Fuel Displaced by AFVs, Year-2000 Base Case ....................... 19

II-2 Light-Duty and Heavy-Duty AFV Vehicle and Fuel Use, Year-2000 Base Case.......... 20

II-3 Details on Oxygenate Use in the Year 2000 .............................................................. 20

II-4 Replacement-Fuel Use in the Year 2000 ................................................................... 22

II-5 Per-Gallon Gasoline Displacement for Various Fuels, Year-2000 Base Case ............ 23

III-1 AFTM Regions .......................................................................................................... 29

III-2 AFTM Crude Oil Supply Curve Reference Points ................................................... 32

III-3 AFTM Raw Gas Supply Curve Reference Points ....................................................... 36

III-4 AFTM Natural Gas Demand Curve Reference Points ................................................ 39

III-5 AFTM LPG Demand Curve Reference Points........................................................... 40

III-6 AFTM Distillate and Light Product Demand Curve Reference Points ......................... 40

III-7 AFTM Ethylene Demand Curve Reference Points ..................................................... 41

III-8 AFTM Boiler Fuel Demand Curve Reference Points .................................................. 42

III-9 AFTM Motor-Vehicle Service Demand Curve Reference Points .................................. 45

III-10 AFTM Refinery Conversions for High-Complexity Refineries .................................... 47

III-11 AFTM Gas-Processing Conversions .......................................................................... 48

III-12 AFTM LNG Conversions for All Regions ................................................................. 49

III-13 AFTM LNG Conversion Costs .............................................................................. 49

III-14 AFTM Methanol/Ethanol Manufacturing Conversions for All Regions.......................... 50

III-15 AFTM Methanol/Ethanol Manufacturing Conversion Costs ...................................... 50

III-16 AFTM Ethylene Manufacturing Conversions .......................................................... 51

III-17 Distribution and Retail Motor-Fuel Markups ............................................................ 51

III-18 Motor-Fuel Taxes ................................................................................................ 52

III-19 Alternative-Fuel Vehicle Incremental Capital Cost ................................................... 53

III-20 Total Alternative-Fuel Vehicles by Program in the 2010 Benchmark Case ................. 63

III-21 Gasoline and Diesel Fuel Replaced by Alternative-Fuel Vehicles in the 2010 Benchmark Case ...................................................................................................6 63

III-22 Alternative-Fuel Vehicle Types and Fuel Use in the 2010 Benchmark Case .............. 64

IV-1 Motor-Fuel Taxes Applied to Alternative Fuels ......................................................... 68

IV-2 State Gallonage Taxes on Motor Fuels, as of April 1994 .......................................... 69

IV-3 Cases and Sensitivities Examined Using Alternative Fuels Trade Model ................... 70 
IV-4 Greenhouse Gas Emissions From Fuel Production and Distribution, Vehicle Operation, and Vehicle Manufacturing

IV-5 Greenhouse Gas Emissions of Industrial Fuels ................................................... 73

IV-6 Assumed Demand for Ethylene ........................................................................... 75

IV-7 Assumed U.S. Natural Gas Supplies ................................................................... 75

IV-8 Reference Oil Price Scenario Retail Motor-Fuel Prices .............................................. 77

IV-9 Reference Oil Price Scenario Light-Duty-Vehicle Fuel Use ......................................... 78

IV-10 Reference Oil Price Scenario Energy Imports (From Outside NAFTA) ........................ 79

IV-11 Reference Oil Price Scenario Greenhouse Gas Emissions ......................................... 80

IV-12 Reference Oil Price Scenario Composition of U.S. Economic Benefits and Costs ..... 81

IV-13 Reference Oil Price Scenario Federal and State Motor-Fuel Taxes ........................... 82

IV-14 Reference Oil Price Scenario U.S. Environmental Benefits

From Alternative-Fuel Vehicles ................................................................................ 83

IV-15 Reference Oil Price Scenario Crude Oil Production and Price .................................. 8. 84

IV-16 Reference Oil Price Scenario Natural Gas Production and Price (Wet Basis) ............ 85

IV-17 Reference Oil Price Scenario U.S. End-Use Prices for Natural Gas, LPG,

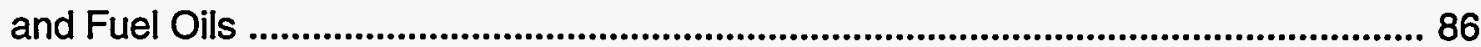

IV-18 Reference Oil Price Scenario U.S. Natural Gas Balance (Dry Basis) ......................... 87

IV-19 Reference Oil Price Scenario U.S. LPG Balance .................................................... 88

IV-20 Reference Oil Price Scenario U.S. Light-Duty-Vehicle Fleet in 2010 ........................... 89

IV-21 Low Oil Price Scenario Retail Motor-Fuel Prices ..................................................... 90

IV-22 Low Oil Price Scenario Light-Duty-Vehicle Fuel Use.............................................. 91

IV-23 Low Oil Price Scenario Imports (From Outside NAFTA) .......................................... 92

IV-24 Low Oil Price Scenario Greenhouse Gas Emissions ................................................. 93

IV-25 Low Oil Price Scenario Composition of U.S. Economic Benefits and (Costs) ............ 94

IV-26 Low Oil Price Scenario Federal and State Motor-Fuel Taxes ...................................... 95

IV-27 Low Oil Price Scenario U.S. Environmental Benefits From Alternative-Fuel

Vehicles ............................................................................................................... 96

IV-28 Low Oil Price Scenario Crude Oil Production and Price ............................................. 97

IV-29 Low Oil Price Scenario Natural Gas Production and Price (Wet Basis) ..................... 98

IV-30 Low Oil Price Scenario U.S. End-Use Prices for Natural Gas, LPG, and Fuel Oils .... 99

IV-31 Low Oil Price Scenario U.S. Natural Gas Balance (Dry Basis) ................................ 100

IV-32 Low Oil Price Scenario U.S. LPG Balance ............................................................. 101

IV-33 Low Oil Price Scenario U.S. Light-Duty-Vehicle Fleet in 2010 ................................ 102

A-1 Fuels Included in the Alternative Fuels Trade Model .............................................. A-1

A-2 Conversion Processes in the Alternative Fuels Trade Model ................................... A-2

A-3 Conversion Factors Used in the Alternative Fuels Trade Model:

Standard Physical Unit Assumptions ...................................................................... A-4

A-4 Conversion Factors Used in the Alternative Fuels Trade Model: Processing

Conversion Assumptions for Motor-Vehicle Fuels ................................................... A-5

A-5 Conversion Factors Used in the Alternative Fuels Trade Model:

Processing Conversion Assumptions for Non-Motor-Vehicle Fuels ........................ A-6

B-1 Discounted Cash Flow Analysis of Average OPEC Oil

Development Costs for 1 Barrel per Day of Oil Production Capacity ....................... B-2

B-2 Solve for Monopolistic Percent of OPEC (Based on 1994 AEO Oil Price, etc.) ........ B-4

B-3 Assume Monopolistic Fraction of OPEC Is 50 Percent of Potential Capacity ........... B-6

B-4 World Oil Demand Reduced 2 MMBOPD (Based on 1994 AEO Oil Price, etc.) ....... B-7

C-1 Fuel and Vehicle Choices .................................................................................. C-12

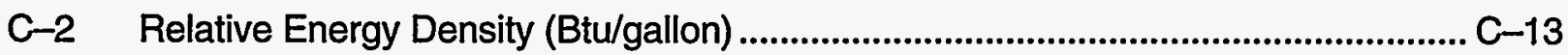

C-3 Estimation of Characteristics of Battery-Electric Vehicles ....................................... C-18

C-4 Alternative-Fuel Vehicle Onboard Fuel Storage Capacities and Refueling Times .. C-19 
C-5 Variation and Correlation Among Fuel Prices, 1978-1992 .................................... C-22

C-6 Estimated Option Values for Pairs of Alternative Fuels and Gasoline ..................... C-23

C-7 Incremental Initial Cost Estimates for AFVs .......................................................... C-25

C-8 Power-to-Weight Changes for Alternative-Fuel Vehicles ............................................25

C-9 Loss of Cargo Capacity to Energy Storage ......................................................... C-26

C-10 AFTM Fuel and Vehicle Choice Scenario ....................................................... C-31

C-11 Calculation of Value of Range and Refueling Time ............................................... C-33

C-12 Calculation of Value of Lost Cargo Space ................................................................ C-34

C-13 Calculation of Performance Values .......................................................................... C-36

C-14 AFTM Vehicle- and Fuel-Choice Market Shares-Conventional Gasoline ............. C-38

C-15 AFTM Vehicle- and Fuel-Choice Market Shares-Reformulated Gasoline ............. C-40

C-16 Fuel Price and Vehicle Economics ...................................................................... C-43

C-17 Alternative Elasticity Assumptions for Vehicle and Fuel Choices ............................ C-43

C-18 Alternate Values for Vehicle Attributes and Refueling Time .................................... C-46

D-1 Global Warming Potential of Non- $\mathrm{CO}_{2}$ Greenhouse Gases .................................... D-2

D-2 Greenhouse Gas Emissions for Light-Duty Vehicles .............................................. D-3

D-3 Greenhouse Gas Emissions for Heavy-Duty Vehicles ........................................... D-3

D-4 Final Estimates of Greenhouse Gas Emissions, by Fuel and Stage ........................... D-4

D-5 Delucchi's Revised Base-Case Estimates of Greenhouse Gas Emissions,

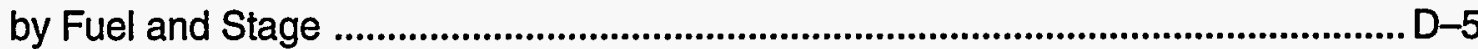

D-6 Greenhouse Gas Emissions of Industrial Fuels ................................................. D-5

DA-1 Recent Estimates of the Global Warming Potential (GWP)

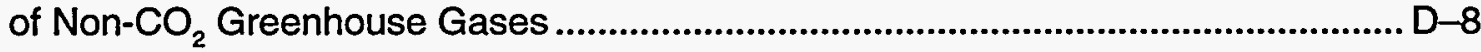

\section{FIGURES}

1-1 Basic Structure of the Alternative Fuels Trade Model .............................................. 5

1-2 AFTM Assumptions About Demand for Motor-Vehicle Fuels in 2010 .......................... 5

I-3 Light-Duty-Vehicle Fuel Use in the Primary Cases Under the Reference Oil Price

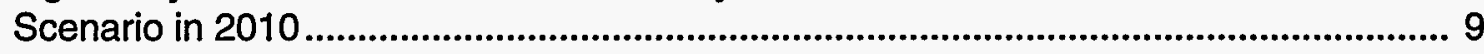

1-4 Retail Motor-Fuel Prices in the Primary Cases Under the Reference Oil Price Scenario in 2010

1-5 U.S. Fuel Imports in the Primary Cases Under the Reference Oil Price Scenario

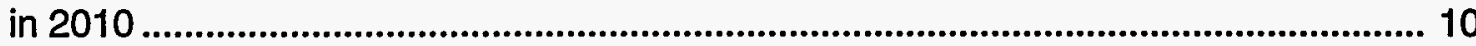

III-1 Crude Oil Supply Curves Under the Reference Oil Price Scenario............................. 31

III-2 Crude Oil Supply Curves Under the Low Oil Price Scenario.......................................... 32

III-3 Wet-Gas Production Capacity Curves for the Main AFTM Demand Regions ............. 33

III-4 Volumes and Costs of Remote Gas Discoveries....................................................... 34

III-5 Wet-Gas Supply Curves for Remote AFTM Regions ............................................... 35

III-6 Feedstock Production Capacity Curves for Corn and Wood Ethanol ........................... 37

III-7 U.S. Energy Demand Curves Used by the AFTM ..................................................... 38

III-8 Vehicle and Fuel Choice in the Alternative Fuels Trade Model .................................. 44

III-9 Flow of Raw Fuel to Final End-Use in the Alternative Fuels

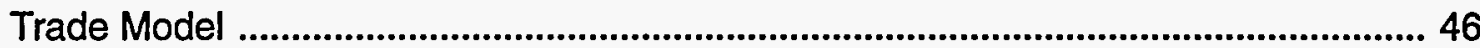

III-10 Boiler Fuel Logit Functions for Gas Versus Residual Fuel Oil in AFTM ....................... 55

III-11 Annual Energy Outlook 1994 Reference Case Projections for U.S. Energy Supply ... 57

III-12 Annual Energy Outlook 1994 Reference Case Projections for U.S. Energy Consumption .................................................................................... 58

III-13 Annual Energy Outlook 1994 Reference Case Projections for U.S. End-Use Energy Prices. 60

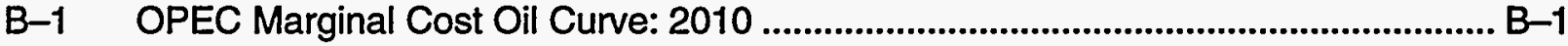


B-2 Oil Price Versus Participation in OPEC Monopoly ..................................................... B-5

C-1 Alternative Fuels and Vehicles Choice Model Flowchart of Calibration Process .....................................................................................................

C-2 Nested Structure of Alternative-Fuel and Vehicle Choice Decisions ........................... C-8

C-3 Fuel Prices 1978-1992 ................................................................................................ C-22

C-4 Sensitivity of Vehicle-Type Market Shares to Elasticity Assumptions ......................... C-44

C-5 Sensitivity of Fuel-Type Market Shares to Elasticity Assumptions ............................ C-45

C-6 Fuel-Type Market Shares Reformulated Gasoline and Option Value ........................ C-46

C-7 Sensitivity of Vehicle-Type Market Shares to Hedonic Values .................................. C-47 
AEO EIA Annual Energy Outlook

AF Alternative fuel

AFFV Alcohol flexible-fuel vehicle

AFTM Alternative Fuels Trade Model

AFV Alternative-fuel vehicle

AFVC Alternative Fuels and Vehicles Choice

AFVPERBGD Number of vehicles required

to provide 1 barrel per day

Alcohol FV Alcohol-fueled vehicle

ANL Argonne National Laboratory

bbl Barrel

Bcf Billion cubic feet

Bcfd Billion cubic feet per day

BD Barrels per day

BGE Barrel of gasoline-energy-equivalent

BGS Barrel of gasoline service

BGSE Barrel of gasoline-service-equivalent

BiFLPG Bifuel liquefied petroleum gases

BiFLPGV Bifuel liquefied petroleum gas

vehicle

BiFNGV Bifuel natural gas vehicle

Btu British thermal unit

C5 Pentane compounds

CAA Clean Air Act

CARB California Air Resources Board

CEC California Energy Commission

CEV Combustion engine vehicle

CFC Chlorofluorocarbon

CG Conventional gasoline

$\mathrm{CH}_{4}$ Methane

CNG Compressed natural gas

CO Carbon monoxide

$\mathrm{CO}_{2}$ Carbon dioxide

Ded Dedicated

DFV Dual-fuel vehicle

DOE Department of Energy

E85 A mixture of 85 percent ethanol and 15 percent gasoline

E100 100 percent ethanol

EEA Energy and Environmental Analysis,

Inc.

EIA Energy Information Administration

EPA Environmental Protection Agency

EPACT Energy Policy Act of 1992

ETBE Ethyl tertiary-butyl ether

EtOH Ethanol

ETSU Energy Technology Support Unit

EV Electric vehicle
FFV Flexible-fuel vehicle

g Gram

gal Gallon

GAMS General Algebraic Modeling System

Gaso Gasoline

GEG Gasoline-equivalent gallon

GGE Gallon of gasoline-equivalent

GHG Greenhouse gas

$\mathrm{g} / \mathrm{mi}$ Grams per mile

GSE Gasoline-service-equivalent

GWP Global warming potential

HD Heavy-duty

HDT Heavy-duty truck

HDV Heavy-duty vehicle

HHV Higher heat value

HP Horsepower

hr Hour

ICE Internal combustion engine

ICEV Internal combustion engine vehicle

IEA International Energy Agency

IEO EIA International Energy Outlook

IPCC Intergovernmental Panel on Climate

Change

kg Kilogram

kWh Kilowatthour

I Liter

Ib Pound

LD Light-duty

LDT Light-duty truck

LDV Light-duty vehicle

LEV Low-emission vehicle

LHV Lower heat value

LNG Liquefied natural gas

LPG Liquefied petroleum gas

LPGV Liquefied petroleum gas vehicle

M85 A mixture of 85 percent methanol and

15 percent gasoline

M100 100 percent methanol

MBD Thousand barrels per day

Mcf Thousand cubic feet

$\mathrm{MeOH}$ Methanol

mi Mile

min Minute

MM Million

MMBD Million barrels per day

MMBGE/D Million barrels per day of gasoline-

equivalent 
MMBGSE Million barrels of gasoline-serviceequivalent

MMBGSE/D Million barrels per day of gasoline-service-equivalent

MMBtu Million British thermal units

MNL Multinomial logit

mpg Miles per gallon

MPGEG Miles per gasoline-equivalent gallon

MTBE Methyl tertiary-butyl ether

MVMA Motor Vehicle Manufacturers

Association

N/A Not applicable

$\mathrm{N}_{2} \mathrm{O}$ Nitrous oxide

NAFTA North American Free Trade Agreement

Nat Gas Natural Gas

NE Not estimated

NEB National Energy Board

NGBiF Natural gas bifuel

NGL Natural gas liquid

NGV Natural gas vehicle

NMHC Nonmethane hydrocarbon

NMNL Nested multinomial logit
NMOC Nonmethane organic compound

$\mathrm{NO}_{\mathrm{x}}$ Nitrogen oxides

NPV Net present value

OECD Organization for Economic

Cooperation and Development

OPEC Organization of Petroleum Exporting

Countries

ORNL-RYM Oak Ridge National Laboratory

Refinery Yield Model

psig Pounds per square inch gauge

quad 1 quadrillion Btu

Rel Eff Relative efficiency

RFG Reformulated gasoline

ROR Rate of return

ROS Renewable Oxygenate Standard

ROW Rest of world

SCF Standard cubic feet

ULEV Ultra-low emission vehicle

Veh Vehicle

W Watt

wt Weight

yr Year

ZEV Zero-emission vehicle 
ASSESSMENT OF COSTS AND BENEFITS OF FLEXIBLE AND ALTERNATIVE FUEL USE IN THE U.S. TRANSPORTATION SECTOR
TECHNICAL REPORT FOURTEEN: MARKET POTENTIAL AND IMPACTS OF ALTERNATIVE FUEL USE IN LIGHT-DUTY VEHICLES: A 2000/2010 ANALYSIS

\section{EXECUTIVE SUMMARY}

\section{Background}

Section 502(a) of the Energy Policy Act of 1992 (EPACT) requires the Secretary of Energy to establish a program to promote the development and use of domestic replacement fuels in light-duty vehicles. Section 502(b) of the act requires the Secretary, under the program established by section 502(a), to conduct a study to determine, among other things, the feasibility of producing sufficient replacement fuels to replace 10 percent of light-duty motor fuel use by the year 2000 and 30 percent by 2010, with at least half of such replacement fuels being domestic fuels. A Federal Register notice describing the methodology used to conduct this study was issued in October 1993. This is the first report in a two-part study.

This study has been conducted in two parts because a two-step approach has been used to evaluate the feasibility of widespread use of alternative transportation fuels. The first step assumes that, in a sufficiently distant future year (2010), alternative fuels and vehicles are available at costs that reflect their long-run costs of production and distribution (full economies of scale). If alternative-fuel use were not economically attractive under that assumption, we would conclude that widespread alternative-fuel use would not be feasible without continuing government subsidy or some unforeseen technological breakthrough.

As discussed below, this first part of the study does conclude that the widespread use of alternative fuels would be sustainable and would produce substantial economic and environmental benefits. Therefore, the Department has begun work on the second part of the study. We are currently assessing the barriers that could prevent the realization of the 2010 alternative-fuel potential described here, and estimating the additional costs that would have to be incurred during a transition period to widespread alternative-fuel and vehicle availability. This followup study will also address the impacts of current and potential policies for achieving this transition.

In this report, estimates are provided of the potential, by 2010 , to displace conventional light-duty vehicle motor fuels with alternative fuels-compressed natural gas (CNG), liquefied petroleum gas (LPG), methanol from natural gas, ethanol from grain and from cellulosic feedstocks, and electricity -and with replacement fuels such as oxygenates added to gasoline. The 2010 estimates include the motor fuel displacement resulting both from government programs (including the Clean Air Act and EPACT) and from potential market forces.

This report also provides an estimate of motor fuel displacement by replacement and alternative fuels in the year 2000. However, in contrast to the 2010 estimates, the year 2000 estimate is restricted to an accounting of the effects of existing programs and regulations.

\section{Methodology}

To estimate the equilibrium market share of petroleum and alternative fuels for the 2010 analysis, a static equilibrium model was developed that assumes widespread availability of fuels and of alternative-fuel vehicles. The analysis thus assumes that by 2010 the transition to widespread alternative-fuel and alternative-fuel-vehicle availability has occurred-that is, a complete refueling infrastructure for all relevant fuels has been established, and economies of scale have been achieved for fuels, refueling, and vehicles.

In the analysis, consumer demand for alternative-fuel-vehicle technologies (and fuel choice for multifuel vehicles) is estimated, with the importance of vehicle prices, fuel prices, 
vehicle range, refueling time, performance, and cargo space taken into account. The impact of light-duty vehicle fuel consumption on fuel prices (and vice versa) is accounted for by estimating the interrelationships between oil and gas markets and the global trade in those markets. The resulting modeling system is used to produce forecasts of motor fuel consumption and prices in the year 2010. The demand for and prices of fuels used in stationary applications are also estimated, as well as net petroleum and alternative-fuel imports, greenhouse gas emissions, and economic costs and benefits.

The hypothesis that the light-duty vehicle market will sustain a 30-percent market share of replacement and alternative fuels in 2010 is tested under several sets of assumptions, varying by the nature of consumer behavior and domestic and international fuels markets. $A$ benchmark case is defined in which alternative-fuel use is equal to levels required by existing legislation. A number of analysis cases and scenarios are developed relative to this benchmark case. Two primary tax cases were analyzed in which consumers may choose alternative-fuel vehicles and alternative fuels-the first under existing fuel-tax assumptions, the "current tax" case, and the second under assumptions of equal taxes for all fuels, the "equal tax" case.

\section{Results and Conclusions}

The following key results and conclusions have emerged from the analysis contained in this report:

- For the year 2000,10 percent replacement of light-duty motor fuel use with alternative and replacement fuels is feasible and appears likely with existing practices and policies.

- Displacing 30 percent of light-duty motor fuel use by 2010 also appears feasible. However, this estimated feasibility is based on a number of assumptions that may not be realized without additional alternative-fuel initiatives. With a fully established refueling infrastructure and sufficient vehicle availability, market forces would continue to support 30 percent use of alternative fuels and would sustain even higher levels as alterna- tive-fuel vehicles assume an increasingly larger share of the total light-duty vehicle population. This "steady state" result is found to hold under a wide variety of assumptions regarding alternative-fuel prices and market behavior. In addition, substantial economic benefits are estimated to accrue in most scenarios.

- However, to ensure widespread availability of vehicles and fuels, a substantial Federal effort would be required during the "transition" period. Although the transition period was not studied during this part of the analysis, it is the focus of the second part, which is now under way. The nature of this transition and its likely costs are being assessed to determine the impact of various policies and to ascertain whether its costs would offset the economic benefits that would occur after the transition is complete.

- In 2010, the fuels that appear to be most economic are methanol and propane (LPG). In the equal-tax case, these fuels would account for 2.3 million barrels per day, or more than 85 percent of the total use of alternative fuels. CNG, ethanol, and electricity account for the remainder.

- In the equal-tax case, ethanol has a small market share because of its relatively high production cost. In contrast, CNG and electric vehicles have a small market share primarily because of the cost and characteristics of these vehicles.

- However, if current fuel taxes and tax preferences are assumed to exist in 2010, the mix of fuels would change substantially. Ethanol use would reach 1.2 million barrels per day and account for more than 40 percent of alternative-fuel use. LPG and methanol use would drop to a combined 1.2 million barrels per day. CNG and electricity use would remain low.

- In both the equal-tax and current-tax cases, the use of alternative fuels results in a significant reduction in U.S. petroleum imports. Crude oil and oil product imports decrease by more than 1 million barrels per day, or about 12 percent, in both scenarios. This result takes into account increased oil use in 
other sectors due to the secondary impacts of light-duty vehicle alternative-fuel usenamely, a decline in oil prices and increases in the prices of substitute fuels, such as natural gas.

- In contrast to oil imports, total energy imports experience a smaller reduction, particularly in the equal-tax case. This market equilibrium analysis finds that, in 2010 , methanol and a large share of propane are likely to be imported, largely from the Middle East. The analysis also finds that CNG, ethanol, and electricity are not likely to be imported. On net, total energy imports would decline by 8 percent in the current-tax case and by less than 2 percent in the equal-tax case.

- In long-run equilibrium, making alternative fuels and alternative-fuel vehicles available would provide an estimated net annual economic benefit of up to $\$ 10.3$ billion in 2010 . This level of gain would be achievable in the Reference Oil Price Scenario with tax neutrality. Much of this benefit ( $\$ 4.2$ billion) consists of an increase in consumer satisfaction from the availability of new classes of vehicles and less expensive fuels; the remaining $\$ 6.1$ billion reflects dollar cost savings from alternative-fuel use, mainly through reduced cost of fuel imports. In addition, environmental benefits are estimated to be up to $\$ 3.7$ billion annually. Net benefits could be significantly higher than estimated here for several reasons, all of which are outside the scope of this report:

- Increases in the world oil price that are greater than the Energy Information Administration's reference case forecast used here.

- Reductions in the vulnerability of the economy to short-term oil supply disruptions and improvements in the capability of the economy to respond to them. ${ }^{1}$

- Advancements in alternative-fuel vehicle technologies that reduce vehicle cost or

\footnotetext{
1 See David L. Greene et al., The Outlook for U.S. Oil Dependence, Oak Ridge National Laboratory, ORNL. 6817, May 1995.
}

improve vehicle attributes beyond the levels assumed for this study.

- Use of alternative fuels in medium and heavy-duty trucks (which were not analyzed in this report).

These reasons include increases in the world oil price that are greater than the Energy Information Administration's reference case forecast used here and significant advancements in alternative-fuel vehicle technologies. On the other hand, benefits should be considered relative to the costs associated with a transition to widespread alternative-fuel and vehicle availability. Such a comparison will be possible in the second part of this study.

- Greenhouse gas emissions would not significantly change as a result of alternativefuel use, as envisioned in the equal-tax case. This is because methanol, the dominant fuel in the equal-tax case, provides little greenhouse gas reduction and because reductions from the use of CNG and LPG are partially offset by changes in other fuels markets. However, in the current-tax case, greenhouse gas emissions from light-duty vehicles would decrease by 10 percent, primarily because of the substantial use of cellulosic ethanol.

In summary, although this analysis indicates that in 2010 a competitive market could sustain a large volume of alternative-fuel use, it does not appear at present that the market will move toward such a scenario without government action. To realize any substantial use of alternative fuels by 2010 , the Federal Government or State governments would have to take steps soon to ensure that the fuels and the vehicles would be produced in relatively large volumes-many more vehicles than would be used by government and business fleets (estimated in the year 2000 reference case). Displacing a significant portion of conventional motor fuel use by 2010 would likely require a substantial commitment, probably including government-driven mandates or incentives, to ensure the availability of both fuels and vehicles. An analysis of the nature and degree of commitment required will be issued as the second part of this study. 



\section{INTRODUCTION AND SUMMARY OF RESULTS}

\section{PURPOSE AND SCOPE OF REPORT}

The Energy Policy Act of 1992 (EPACT), section 502(a), requires the Secretary of Energy to establish a program to promote the development and use of domestic replacement fuels in light-duty vehicles. Section 502(b) of EPACT requires the Secretary, under the program established by section 502(a), to review appropriate information and do the following:

(1) estimate the domestic and nondomestic production capacity for replacement fuels and alternative fueled vehicles needed to implement this section;

(2) determine the technical and economic feasibility of achieving the goals of producing sufficient replacement fuels to replace, on an energy-equivalent basis-

(A) at least 10 percent by the year 2000; and

(B) at least 30 percent by the year 2010 , of the projected consumption of motor fuel in the United States for each such year, with at least one half of such replacement fuels being domestic fuels;

(3) determine the most suitable means and methods of developing and encouraging the production, distribution and use of replacement fuels and alternative fueled vehicles in a manner that would meet the program goals described in subsection (a);

(4) identify ways to encourage the development of reliable replacement fuels and alternative fueled vehicle industries in the United States, and the technical, economic, and institutional barriers to such development and

(5) determine the greenhouse gas emissions implications of increasing the use of replacement fuels, including an estimate of the maximum feasible reduction in such emissions from the use of replacement fuels.

These requirements are being addressed in a two-part report. This first part presents the results of a feasibility study that addresses several of the issues raised by these subsections of 502(b). It provides estimates relevant to subsections (1), (2), and (5), but it does not address the policy issues related to a transition to increased alternative-fuel use discussed in subsections (3) and (4). The second part, currently being conducted by the Department of Energy's Office of Policy, will address these transition issues. When completed, the feasibility of achieving specific targets for alternative-fuel use can be more completely evaluated. Together with the analysis described in this first part, the transition analysis will assist the Department of Energy and others in evaluating the overall feasibility of moving toward large-scale production and use of alternative transportation fuels, whether existing policies are likely to bring about their use, and what additional policies, if any, may be required to achieve these goals. However, until the transition analysis is completed, the results presented here represent only a partial analysis and should not be construed as definitive assessments regarding the feasibility of using alternative fuels in the future.

\section{ANALYSIS OVERVIEW}

The analysis presented in this report assesses the feasibility of displacing specific quantities of oil in the light-duty vehicle sector with alternative and replacement fuels. EPACT defines alternative fuels to be those fuels that are substantially nonpetroleum (including fuel mixtures) and whose use will yield energy security and environmental benefits. ${ }^{1}$ The alternative fuels examined in the analysis are compressed

\footnotetext{
${ }^{1}$ Section 301 of EPACT states that "the term 'alternative fuel' means methanol, denatured ethanol, and other alcohols; mixtures ... of methanol, denatured ethanol, and other alcohols with gasoline or other fuels; natural gas; liquefied petroleum gas; hydrogen; coal-derived liquid fuels; fuels (other than alcohol) derived from biological materials; electricity (including electricity from solar energy); and any other fuel the Secretary determines, by rule, is substantially not petroleum and would yield substantial energy security benefits and substantial environmental benefits."
} 
natural gas (CNG), liquefied petroleum gases (LPG, or propane), methanol from natural gas, ethanol from grain (corn) and from cellulosic feedstocks, and electricity (that is, electric vehicles). Replacement fuels are defined as the actual portion of nonpetroleum fuels, such as oxygenates, contained in motor fuels.

This analysis focuses on the years 2000 and 2010 and specifically assesses the feasibility of displacing 10 percent of the oil used in the year 2000 and 30 percent in 2010 . The term feasibility is interpreted somewhat differently in the analyses for the year 2000 and for 2010 . For the year 2000, feasibility is interpreted to mean achieving the goal given existing laws and regulations (that is, no new laws are assumed to be enacted). Assumptions regarding implementation of existing legislation are described below. For 2010 , feasibility is construed as meaning that the oil displacement targets, if met (with or without new policies), can be sustained without continuous policy pressure and without incurring undue economic cost.

In addition, the study provides estimates of the direct costs and benefits, including environmental impacts, of significant alternative-fuel use in 2010, the types of alternative fuels and alternative-fuel vehicles likely to be used in a long-run market-driven scenario, and the likely sources of alternative fuels (domestic and nondomestic production).

The type of analysis performed for the year 2000 is different from the one performed for 2010 , though the analyses have certain elements in common. For both years, the direct impacts of Federal and State programs on alternative- and replacement-fuel use are examined, including the impacts of EPACT fleet provisions. EPACT mandates various levels of AFV use by Federal, State, fuel-provider, and municipal and private fleets of more than 50 vehicles. EPACT requires the Department of Energy to undertake rulemakings relating to AFV acquisition requirements for certain Federal, State, fuel-provider, municipal, and private fleets of more than 50 vehicles. For the purposes of this analysis, it is assumed that the acquisition schedules provided in EPACT are implemented and that the "early" acquisition requirement for private and municipal fleets is adopted. The actual implementation of EPACT depends on the outcome of the Department's rulemakings and may be different than the assumptions used here. In addition, several State programs mandate alternative-fuel-vehicle use in both fleets and personal-use vehicles-most notably, the California low-emission vehicle (LEV) mandate. The analysis assumes that no alternative-fuel vehicles, other than the minimum zeroemission vehicle (ZEV) requirements under the LEV program, are used in response to Clean Air Act (CAA) requirements.

In the analysis for the year 2000 , the examination of oil displacement potential is restricted to existing industry practice and current and planned government programs. No additional (market-driven) substitution of motor fuels is assumed. Estimates include petroleum displacement from replacement- and alternativefuel use that is expected to occur in the year 2000 , including both the nonpetroleum inputs that are used in current refinery and gasolineblending practices and the additional oil displacement resulting from the incremental impacts of existing and planned government programs for alternative fuels. Because a substantial amount of this displacement comes from practices that predate the EPACT or CAA, 42 U.S.C. 7401 et seq., requirements, 1990 levels of displacement are provided for comparison.

For 2010, a more detailed analysis is undertaken. Estimates for 2010 include both the direct petroleum displacement effects of government programs and the potential marketdriven substitution of alternative fuels for conventional motor fuels. The analysis assumes that consumers can choose alternative fuels and alternative-fuel vehicles at prices that reflect sales volumes that are high enough to achieve full-scale economies. The market analysis for 2010 focuses on the private lightduty vehicle market and, more specifically, on those vehicles that are not part of fleets. The analysis assumes that fleets will purchase no more alternative-fuel vehicles than required under government programs.

By characterizing the light-duty vehicle market in this manner, this analysis presupposes a successful transition from the current situation 
of low availability of alternative fuels and alternative-fuel vehicles, and it does not address questions concerning the likely nature and costs of such a transition nor the nature of the policies needed for this transition to occur. Therefore, the results of this analysis should not be interpreted as a full cost/benefit analysis of achieving the 30-percent oil displacement goal, or even of moving toward increased use of alternative fuels. Furthermore, because achieving the 10-percent and 30-percent goals by 2010 heavily depends on the timing, intensity, and duration of the transition, this study does not fully address this practicability issue or consider whether the goals should be modified.

The analysis does, however, indicate what the implications of reaching such a posttransition world may be-whether, once established, widespread availability of alternative fuels and alternative-fuel vehicles would provide ongoing energy, environmental, and economic benefits. It also indicates whether these benefits appear sufficient to justify investigating the nature of the policies and costs associated with the transition period.

Although this study presents results that include estimates of market shares for specific alternative fuels and alternative-fuel vehicles, these estimates are included primarily to support conclusions regarding the market share of all alternative fuels taken together. Market share estimates for alternative fuels as a group should be considered more reliable than market share estimates for specific alternative fuels and vehicles, because the latter are more sensitive to specific assumptions regarding fuel and vehicle attributes.

\section{YEAR 2000: RESULTS}

The analysis of year-2000 replacement-fuel use indicates that the 10-percent motor-fuel replacement goal will likely be met without additional policies, primarily through the use of replacement fuels in gasoline. This study estimates that 0.73 million barrels per day of gasoline equivalent (MMBGE/D) of replacement fuels-that is, 10 percent of estimated year2000 light-duty fuel demand of 7.3 million barrels per day (MMBD) - will be used as a result of current industry gasoline production and blending practices and the oxygenates requirements of the CAA reformulated gasoline (RFG) program. Alternative-fuel vehicles are expected to play a relatively minor role, adding 0.04 MMBGE/D, or 0.5 percent, to the displacement goal. These results compare to the 0.4 MMBGE/D, or 6.1 percent, of light-duty motorfuel use accounted for by replacement fuels in 1990 before the CAA or EPACT programs. These results are summarized in Table $1-1$.

These results-that is, achievement of the 10-percent goal-are particularly sensitive to the assumptions that oxygenated RFG will make up 50 percent of the gasoline market and that NGLs and ether-based oxygenates will be included in the group of fuels known as

\section{Table I-1 - Replacement and Alternative-Fuel Use in Light-Duty Vehicles, 1990 and 2000}

\begin{tabular}{lccccc}
\hline & \multicolumn{2}{c}{1990} & & \multicolumn{2}{c}{2000 (estimated) } \\
\cline { 2 - 3 } \cline { 5 - 6 } & MMBGE/D & Percent & & MMBGE/D & Percent \\
\hline Total Light-Duty Vehicle Fuel Use & & & & & \\
Gasoline Blends & 0.60 & & & 7.30 & NA \\
Alternative Fuels & 0.40 & 6.1 & & 0.73 & 10.0 \\
$\quad$ Total & 0.00 & 0.0 & & 0.04 & 0.5 \\
& 0.40 & 6.1 & & 0.77 & 10.5 \\
\hline
\end{tabular}

a Source: EIA 1994.

MMBGE/D = million barrels per day of gasoline-equivalent. 
"replacement fuels."2 A significant part of the nonalcohol portion of ethers is derived from petroleum (refinery) sources. It is worth noting that virtually all ether-based fuels are included in the EPACT statutory definition of replacement fuels. The relative importance of these assumptions can be seen in Section II of this report, where the year-2000 analysis is detailed.

\section{YEAR 2010: METHODOLOGY AND RESULTS}

\section{Methodology}

The methodology used to evaluate the feasibility of widespread alternative-fuel use in 2010 relied on the Alternative Fuels Trade Model (AFTM). ${ }^{3}$ Briefly, the AFTM is a long-run static equilibrium model that estimates prices and quantities that balance the interrelated world oil and gas markets, given assumptions about supply, demand, and costs. The model is structured to provide estimates for two primary cases. In one, called the benchmark case, there exists no well-developed infrastructure for alternative transportation fuels. In the other, called the unconstrained case, a welldeveloped infrastructure exists. The AFTM estimates changes to fuel prices, fuel consumption, fuel imports, international trade flows, greenhouse gas emissions, and other variables of interest that result from moving from the scenario with no alternative-fuel infrastructure to the scenario that has that infrastructure. By comparing the two cases, it is possible to estimate the costs and benefits of alternative-fuel use.

The model features interrelated oil and gas markets for 6 main regions of the world (plus 25 "remote" natural gas regions, for a total of 31 regions). For each region, there are primary resource supply curves for crude oil, natural gas, and cellulosic feedstocks; processes to

\footnotetext{
2 According to EPACT requirements, NGLs other than propane are not designated as replacement fuels unless deemed so by Department of Energy rulemaking.

${ }^{3}$ A report describing the AFTM and the proposed methodology for this study was published in September 1993, and public comment was requested in a Federal Register notice published in October 1993.
}

represent energy conversion activities (petroleum refinery activities, natural gas plants, and conversion of feedstocks to ethanol and methanol); energy product demand curves for petroleum products, natural gas, propane, boiler fuels, and motor fuels; and substitution between oil and natural gas in boilers and among propane, ethane, and naphtha used to produce ethylene. Interregional fuel transportation costs are also specified. Figure $1-1$ shows the basic AFTM structure.

The model also characterizes the manner in which individuals choose between conventional vehicles and an assortment of alternative-fuel vehicles. For motorists with multifuel vehicles (that is, vehicles that can use more than one type of fuel), choice of fuel types used is estimated simultaneously with the choice of vehicle type. Vehicle choice is based on vehicle prices (initial cost), fuel prices, and an evaluation of several key nonprice attributes of vehicles and fuels (such as range, performance, refueling time, and whether the vehicle has a multifuel option). Fuel choice is based on fuel prices and the nonprice attributes of the fuels. For both vehicles and fuels, a logit probability function is specified to depict choices. The AFTM simulates the operation of the market by minimizing the net costs of fuel production, conversion, transportation, and demand subject to constraints imposed on the system.

Even if a transition to a world of widespread alternative-fuel and alternative-fuel-vehicle availability were complete by 2010 , not all vehicles on the road in that year would have been purchased under such conditions. In fact, many vehicles held by households would have been purchased at least 5 years earlier. To account for "pre-equilibrium" purchases, a fraction of the 2010 vehicle stock is removed from the logit modeling framework. An analysis of light-duty motor vehicle production and stock turnover rates suggests that, by 2010 , no more than 50 percent of the light-duty vehicle fleet could consist of alternative-fuel vehicles. Therefore, 50 percent of the fleet is limited to conventionally fueled vehicles. ${ }^{4}$ The remaining

\footnotetext{
${ }^{4} \mathrm{~A}$ small part of the reformulated gasoline market is assumed to be penetrated by the alternative-fuel-vehicle fleet mandates mentioned earlier.
} 


\section{Figure I-1 - Basic Structure of the Alternative Fuels Trade Model}

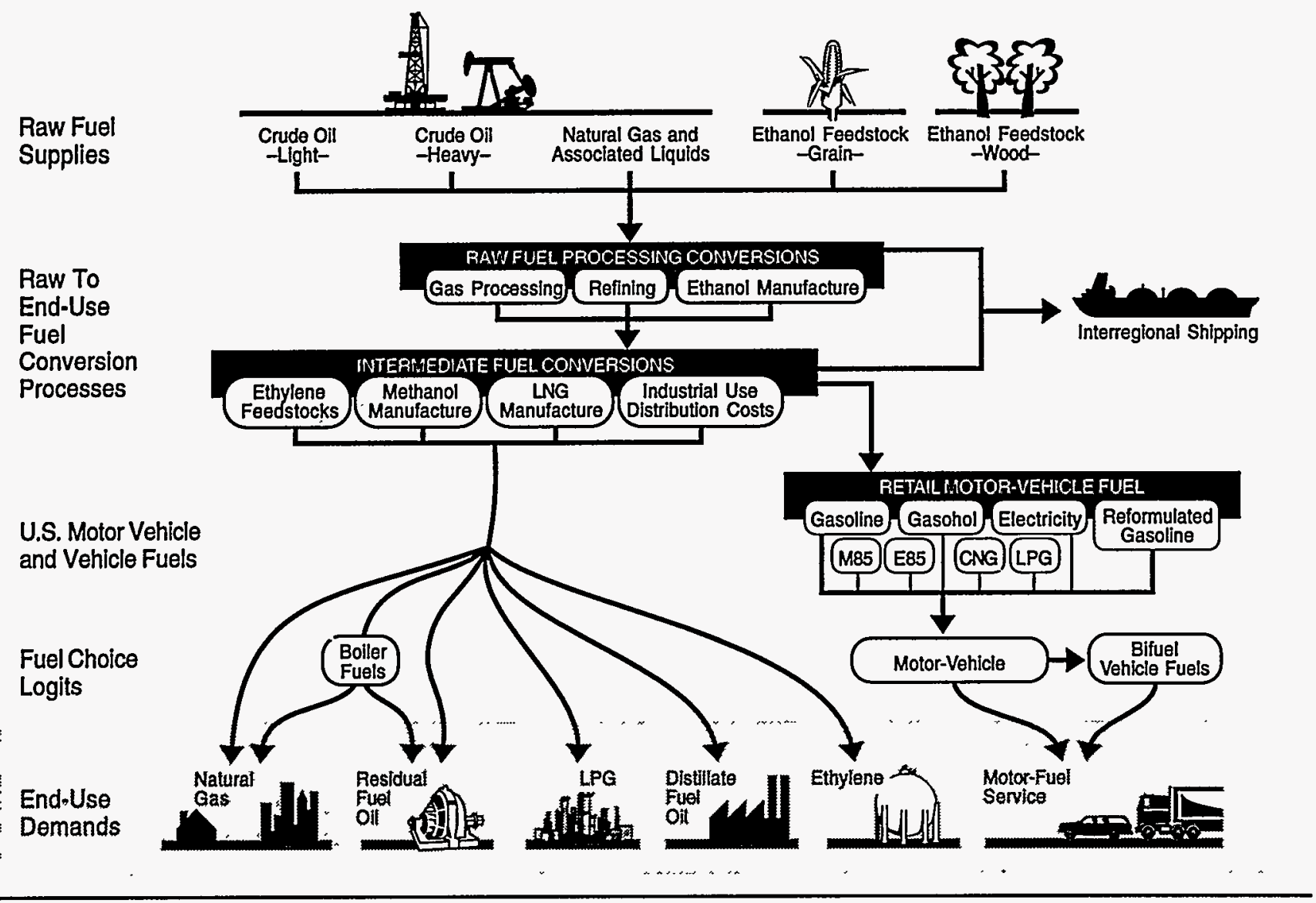

50 percent of the light-duty-vehicle fuel market is determined by the AFTM logit analysis, which determines the vehicle/fuel mix.

Figure 1-2 depicts the breakdown of 2010 light-duty motor vehicle fuel demands that are within and outside of the vehicle/fuel choice logit analysis in the model.

The estimates of incremental initial costs and vehicle attributes of light-duty vehicles in 2010 are based on the assumption that the best technology existing today would become the standard, widely available technology at that time. This analysis does not account for the development of more advanced alternativefuel-vehicle technologies that may emerge by 2010. Reductions in per-vehicle costs are assumed to result from significant economies of scale in production achieved because of larger markets. These costs are substantially below the costs of producing comparable vehicles today with much smaller production runs.
Figure 1-2 - AFTM Assumptions About Demand for Motor-Vehicle Fuels in 2010

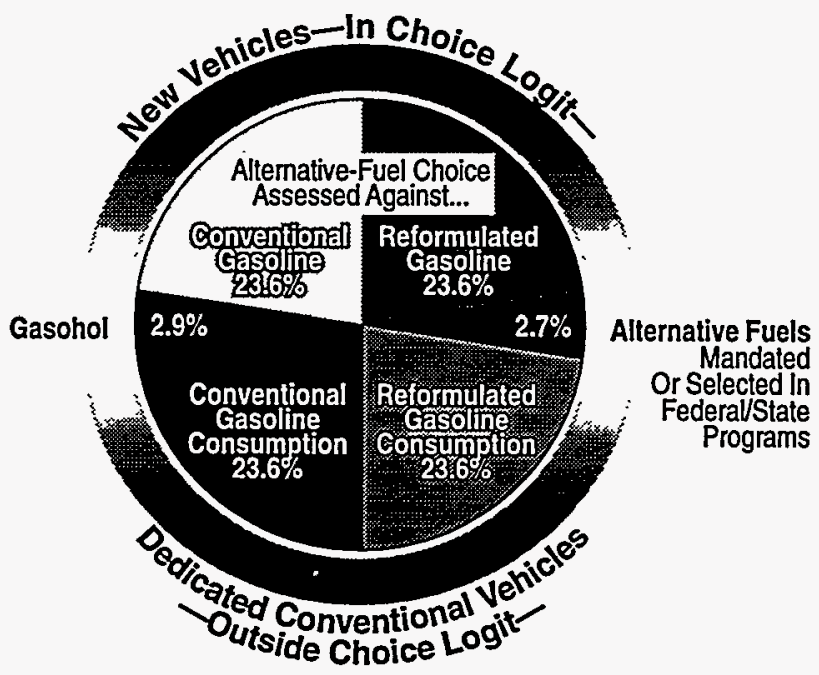

Note: Total light-duty vehicle fuel demand in 2010 is assumed to be 8.1 million barrels of gasoline service equivalent per day. 


\section{Cases}

Several cases have been defined for the 2010 analysis. These cases differ in their assumptions regarding the availability of alternative fuels and alternative-fuel vehicles, as well as the specific characteristics of fuel markets. Two of these cases bracket the analysis and are considered the primary cases. The firstthe benchmark case (Case 0) -includes estimated replacement-fuel use resulting from EPACT fleet requirements and State mandates, but also assumes that no significant sales of alternative-fuel vehicles to households occur. This reflects the assumption that no large-scale alternative-fuel infrastructure has been developed to allow nonfleet motorists to refuel alternative-fuel vehicles, except at a limited number of locations. ${ }^{5}$ The benchmark case essentially "constrains" the nonfleet market to use gasoline vehicles. It is thus defined in a manner similar to the base case for the year 2000 . The second primary case-the unconstrained case (Case 1) assumes widespread availability of alternative fuels and alternative-fuel vehicles. Because consumers are assumed to be able to choose among gasoline and alternative-fuel vehicles, this case is referred to as an "unconstrained case."

In a series of additional cases (Cases 2 through 6), the market constraints are relaxed to varying degrees, intermediate between the benchmark case and the primary unconstrained case. Partial constraints in model runs relate to meeting specific policy goals of oil displacement and greenhouse gas reduction. These partially constrained cases, as well as the unconstrained case, are then compared to the benchmark case and to each other to estimate their economic and environmental impacts.

In particular, EPACT requires the Department of Energy to examine a case in which 50 percent of alternative-fuel use is from domestically produced fuel. To comply with this requirement, two variations of the partially constrained vehicle choice cases are analyzed:

\footnotetext{
5 An exception here are electric vehicles, assumed to have at-home recharge capabilities.
}

- A case in which total imports of all fuels are reduced by 50 percent of the EPACT target use of alternative fuels in 2010.

- A case in which no more than 50 percent of the EPACT target alternative-fuel volume in the motor-fuel sector is from incremental imports, regardless of the level of total fuel imports.

\section{Oil Price and Motor-Fuel Tax Assumptions}

These different alternative-fuel cases are analyzed relative to two different sets of assumptions regarding underlying world oil prices in 2010. These sets of assumptions are called oil price scenarios. The Reference Oil Price Scenario assumes a starting world oil price of $\$ 25.82$ per barrel in 2010 . (All prices and costs are in 1990 dollars.) This price is based on the year 2010 reference case contained in the Annual Energy Outlook 1994 (EIA 1994), prepared by the Energy Information Administration, and it assumes that the Organization of Petroleum Exporting Countries (OPEC) exerts partial monopoly control over the pricing of crude oil. For this scenario, the AFTM contains oil and gas supply curves that correspond to the Annual Energy Outlook. ${ }^{6}$ It also contains projections of fuel demands based on the $A n$ nual Energy Outlook forecasts, as well as forecasts prepared by Argonne National Laboratory.

A second scenario, the Low Oil Price Scenario, corresponds to this study's estimate of what the world oil price would be if OPEC were not able to exert monopoly control over crude-oil pricing in 2010. Assuming no effective OPEC monopoly power, the 2010 world oil price is estimated to be $\$ 20.60$ per barrel. This

\footnotetext{
6 The Annual Energy Outlook 1994 projects that OPEC will produce 62 percent of the world's crude oil supplies in 2010. According to the Energy and Environmental Analysis, Inc., (EEA) estimates of the long-term incremental cost of expanding the world's crude oil production capacity, this price implies that countries constituting 72 percent of potential OPEC capacity act as revenuemaximizing monopolists. The same assumptions regarding monopoly power are used in estimating OPEC behavior in supplying alternative fuels.
} 
is similar to the price of oil in the low oil price case in the Annual Energy Outlook 1994.

In addition to examining the different alternative-fuel cases under two different oil price scenarios, the analysis also examines the effects of two different motor-fuel tax rates on alternative-fuel use-namely, an "equal" tax rate and a "current" tax rate. The equal-tax rate, which is used in conjunction with most of the cases examined, assumes that all motor fuels are taxed, on a British thermal unit (Btu) equivalent basis, at a rate equal to the sum of 1994 Federal and State excise tax rates on gasoline. It also assumes that there are no subsidies on motor fuels. For cases with the current tax rate, it is assumed that Federal and State excise and other motor-fuel taxes and subsidies remain at 1994 rates. In these runs, ethanol is subsidized, CNG is taxed at a lower rate than gasoline on a Btu-equivalent basis, and methanol and LPG are taxed at higher rates than gasoline on a Btu-equivalent basis.

\section{Sensitivities}

Finally, several sensitivities are run to test the robustness of key assumptions used in the modeling-such as increased petrochemical feedstock demands (Sensitivity B), increased methanol production costs (Sensitivity $C$ ), and different assumptions regarding long-term natural gas supplies (Sensitivities D, E, and F).

These sensitivity cases are considered relative to the primary cases only, and most are also relative to the equal-tax case. The Reference Oil Price Scenario is run with all sensitivities. The Low Oil Price Scenario is run with selected sensitivities.

Table 1-2 provides a matrix summarizing the cases and scenarios run in this analysis, including oil price scenarios, motor-fuel tax cases, fuel market constraints, and supply or demand parameter sensitivities prepared for use in this study.

The reference input parameters are described in detail in Section III. More detailed descriptions of the various sensitivities are in Section IV.

\section{Results for Primary Cases}

\section{Motor-Fuel Use}

Figure 1-3 presents estimates of motor-fuel use in light-duty vehicles in 2010 under the Reference Oil Price Scenario. In the primary unconstrained vehicle/fuel choice cases, replacement fuel (nonpetroleum components in gasoline and alternative fuels) makes up more than 30 percent of the light-duty motor fuel used both in the current-tax case and the equal-tax case; and in each case, this holds for both oil price scenarios. The change in tax assumption does, however, change the mix of alternative fuels. With tax neutrality, the principal alternative fuels used are LPG and methanol; but under current taxes, the principal alternative fuels used are LPG and ethanol, with methanol use down sharply. This result indicates that fuel tax policy would have a substantial impact on fuel choice under conditions of widespread availability of alternative fuels.

With equal taxes, CNG use in the unconstrained case represents about 3 percent of total light-duty fuel use, and ethanol use is less than 1 percent. With these low usage volumes, the assumptions of widespread fuel availability, large vehicle production runs, and high-volume retail fuel sales may not be realized. In this event, the cost of these fuels may be higher than estimated, and their market share therefore may be less than estimated. However, it is possible that CNG would be used in geographically concentrated markets and specific vehicle segments, in which case its small market share may be consistent with this study's assumptions about fuel and vehicle costs. As for E85 (a mixture of 85 percent ethanol and 15 percent gasoline), because it is used in either dedicated alcohol vehicles (which can also use M85, a mixture of 85 percent methanol and 15 percent gasoline) or in flexible-fuel vehicles (which can use both M85 and gasoline), its small market share would not pose a problem with respect to search time for finding fuel, to distribution costs, or to vehicle costs. Were E85 available at comparatively few retail outlets, motorists would have the option of using a substitute fuel. 
Table I-2 - AFTM Cases Presented in This Report

\begin{tabular}{|c|c|c|c|c|c|}
\hline \multicolumn{3}{|c|}{ Motor- } & & \multicolumn{2}{|c|}{ Scenarios } \\
\hline $\begin{array}{l}\text { Case/ } \\
\text { Sensitivity }\end{array}$ & Fuel & Fuel Choice & Sencitivity & $\frac{\text { Reference }}{\text { Oil Price }}$ & Low \\
\hline
\end{tabular}

Primary Cases

\begin{tabular}{|c|c|c|c|c|c|}
\hline EO & Equal & Benchmark & - & $x$ & $x$ \\
\hline E1 & Equal & Unconstrained & - & $x$ & $x$ \\
\hline Co & Current & Benchmark & 一 & $\mathrm{x}$ & $\mathrm{x}$ \\
\hline C1 & Current & Unconstrained & - & $x$ & $\mathrm{x}$ \\
\hline \multicolumn{6}{|c|}{ Partially Constrained Cases } \\
\hline E2 & Equal & GHG Emissions $90 \%$ & - & $x$ & $x$ \\
\hline E3 & Equal & GHG Emissions $80 \%$ & - & $x$ & $\mathrm{x}$ \\
\hline E4 & Equal & $\begin{array}{l}\text { Total U.S. Energy Imports } \\
\text { Limited }\end{array}$ & - & $x$ & $x$ \\
\hline E5 & Equal & Alternative-Fuel Use $30 \%$ & - & $x$ & $x$ \\
\hline E6 & Equal & $\begin{array}{l}\text { Alternative-Fuel Imports } \\
\text { Limited }\end{array}$ & - & $x$ & $x$ \\
\hline \multicolumn{6}{|c|}{ Sensitivity Cases } \\
\hline EO-B & Equal & Benchmark & Higher Ethylene Demand & $x$ & \\
\hline E1-B & Equal & Unconstrained & Higher Ethylene Demand & $x$ & \\
\hline EO-C & Equal & Benchmark & Higher Methanol Costs & $x$ & \\
\hline $\mathrm{E} 1-\mathrm{C}$ & Equal & Unconstrained & Higher Methanol Costs & $x$ & \\
\hline EO-D & Equal & Benchmark & More North American Gas & $x$ & \\
\hline E1-D & Equal & Unconstrained & More North American Gas & $x$ & \\
\hline EO-E & Equal & Benchmark & Less Foreign Gas & $x$ & \\
\hline E1-E & Equal & Unconstrained & Less Foreign Gas & $x$ & \\
\hline CO-F & Current & Benchmark & More North American Gas & $x$ & $x$ \\
\hline$C_{1-F}$ & Current & Unconstrained & More North American Gas & $x$ & $x$ \\
\hline
\end{tabular}

Use of electric vehicles does not increase in any primary or other case relative to its use of 0.09 million barrels per day of gasolineservice-equivalent (MMBGSE/D) in the benchmark case. This lack of market adoption reflects both the high initial vehicle costs and the vehicle characteristics.

\section{Motor-Fuel Prices}

Figure $1-4$ presents estimates of 2010 retail motor-fuel prices for the primary cases examined under the Reference Oil Price Scenario. Each retail price represents the AFTM esti- mate of a market-balancing wholesale fuel price plus transportation and distribution costs and retail price markups consistent with current gasoline marketing practices. With taxes equal, LPG, methanol, and CNG are all price competitive at the pump with gasoline (especially with RFG), while the retail price of ethanol is significantly higher than that of the other fuels. ${ }^{7}$ Electricity prices are about half the prices of other fuels.

7 Only cellulosic ethanol is included in AFTM solution sets; ethanol produced from corn is estimated to have a higher cost than cellulosic ethanol and is assumed not to be used in 2010 . 
CNG and ethanol prices are lower under current tax rates than under equal tax treatment, reflecting the favorable tax treatment currently accorded these fuels by both the Federal Government and State governments. As a result, with current tax rates ethanol is competitive with gasoline, and on a Btu basis, CNG is the least expensive motor fuel, not counting vehicle costs. At the same time, the prices of both methanol and LPG rise to reflect the higher Federal and State taxes on these fuels.

Electricity prices vary little across cases, mainly because electric vehicle sales do not change across cases.

A comparison of fuel prices in the benchmark case and the unconstrained cases reveals that the shift toward the use of alternative fuels leads to increased prices for these fuels and to a price decrease for gasoline. After equilibrating across all sectors, in the Reference Oil
Price Scenario the net decline in U.S. petroleum demand yields a reduction in the world oil price of approximately $\$ 0.60$ per barrel, or about 2 percent. This translates into a 2 -centper-gallon decrease in the price of gasoline. In the Low Oil Price Scenario, the decline in world oil price is about $\$ 0.40$, with slightly less than a 2-cent-per gallon-decrease in the price of gasoline.

\section{Fuel Imports}

Figure 1-5 presents estimates of motor-fuel imports for the primary cases under the Reference Oil Price Scenario. This report defines imports as those fuel volumes coming into the United States from outside of the North American Free Trade Agreement (NAFTA) countries.

The increased use of alternative fuels in the equal-tax case (relative to the benchmark case) yields a decline in petroleum imports,

\section{Figure 1-3 - Light-Duty-Vehicle Fuel Use in the Primary Cases Under the Reference Oil Price Scenario in $\mathbf{2 0 1 0}$}

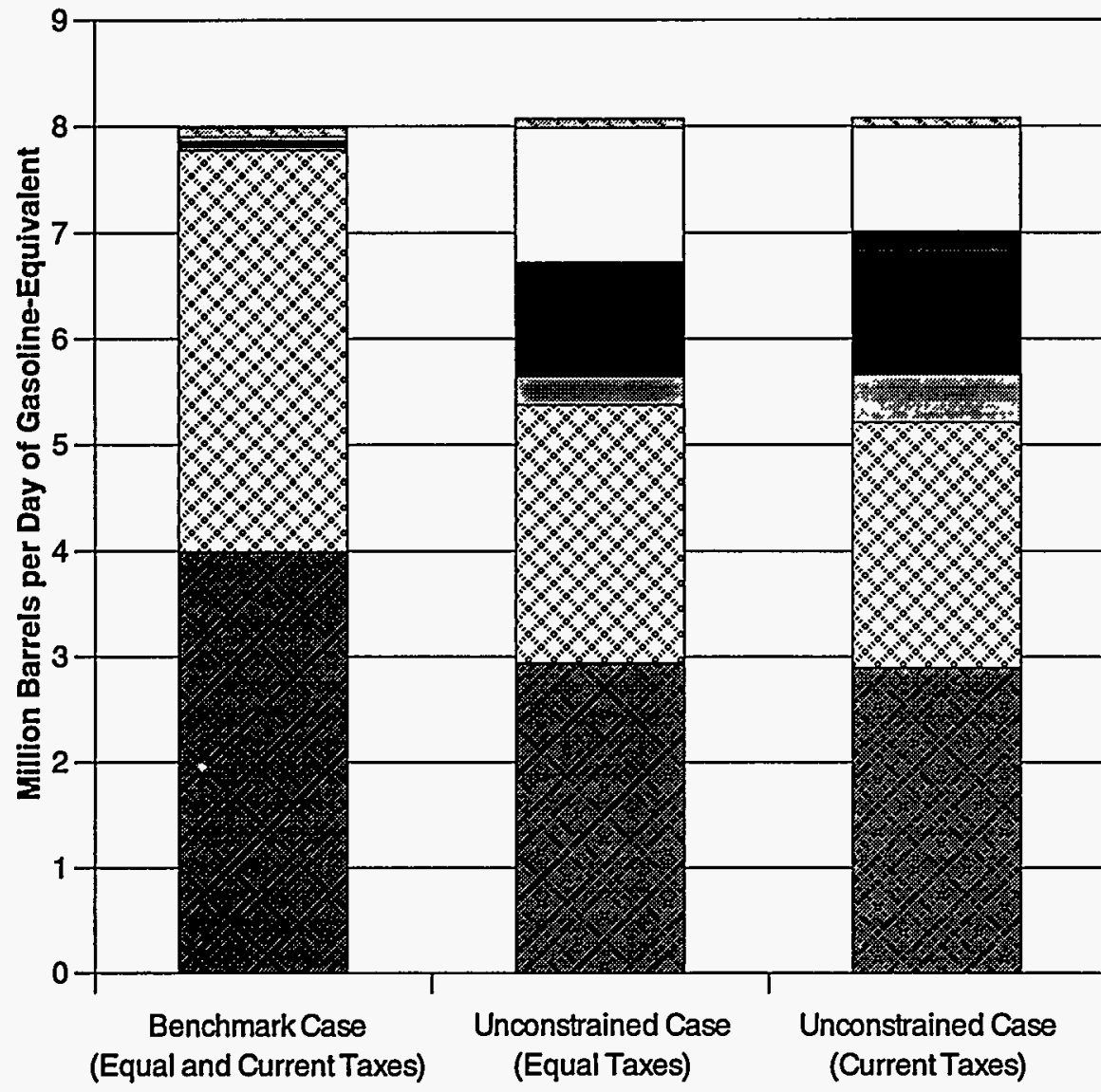

Electricity

LPG

Methanol (M85)

Ethanol (E85)

CNG

Reformulated Gasoline

Conventional Gasoline 
Figure I-4 - Retail Motor-Fuel Prices in the Primary Cases

Under the Reference Oil Price Scenario in 2010

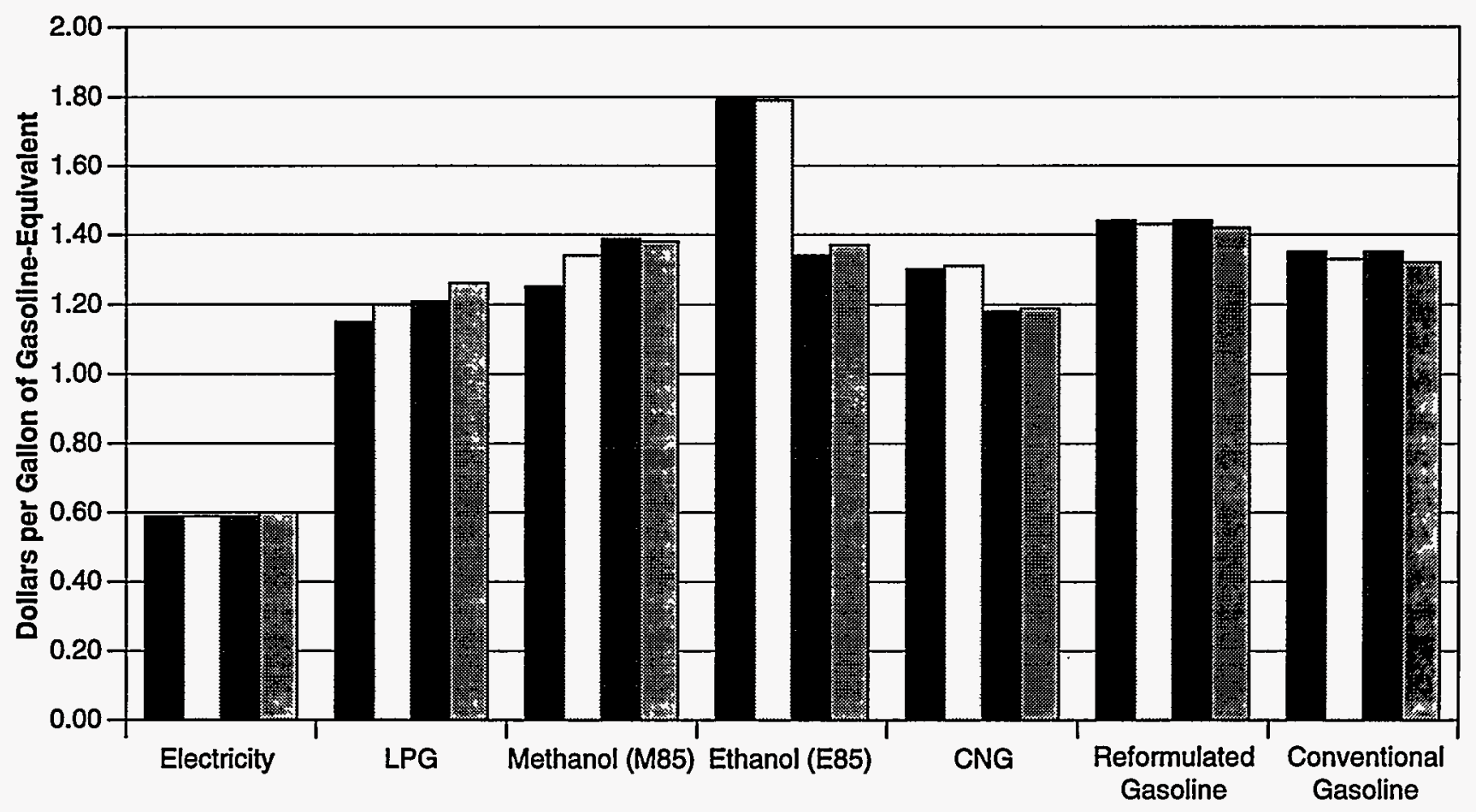

Constrained $\square$ Unconstrained

Equal-Tax Cases

Constrained Unconstrained

Current-Tax Cases

Figure I-5 - U.S. Fuel Imports in the Primary Cases

Under the Reference Oil Price Scenario in $\mathbf{2 0 1 0}$

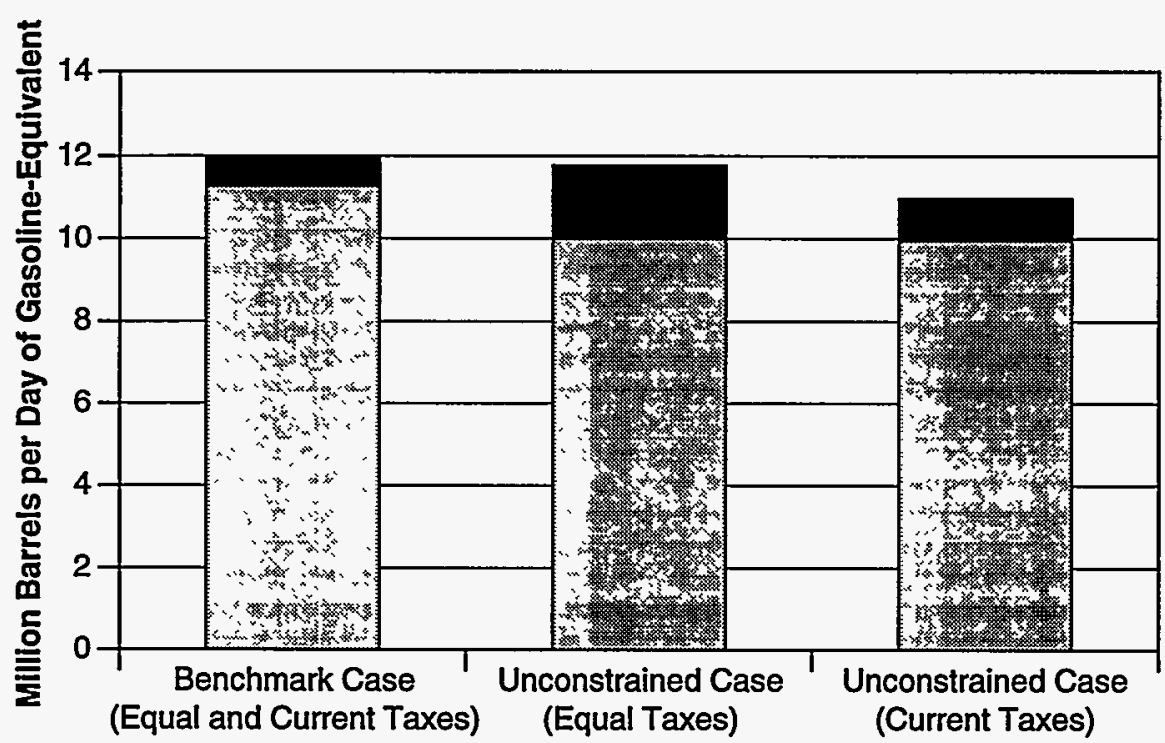

Propane

Methanol

Crude Oil and

Petroleum Products 
but by considerably less than the drop in lightduty vehicle consumption. This is primarily due to the increased use of oil in nontransportation sectors because of the price decrease resulting from lower transportation demand, but it also reflects a slight decrease in U.S. oil production. For each barrel of oil displaced in transportation, net oil imports are estimated to decline by 0.6 barrel.

As mentioned above, the impact of this decline in imports on world oil price is about $\$ 0.60$ per barrel ( $\$ 0.40$ per barrel in the Low Oil Price Scenario). Therefore, under an assumption of modest OPEC monopoly power (used in the Reference Oil Price Scenario), a 10-percent decline in U.S. oil imports results in a 2-percent decrease in the world oil price. Under an assumption of no OPEC monopoly power (used in the Low Oil Price Scenario), this decrease is closer to 1 percent.

Despite the decline in oil imports brought about by the increased use of alternative fuels in the equal-tax case, there is almost no decline in total fuel imports. This is because much of the methanol and LPG, the principal alternative fuels used, is imported from outside of NAFTA. Increased imports of these two fuels offset the reduction in imports of crude oil and petroleum products.

Of the propane that is not imported from outside of NAFTA, nearly half is from incremental production (from natural gas plants and petroleum refineries) in the United States and Canada, and the remainder is from propane released by petrochemical plants that switch to other feedstocks, mainly ethane and naphtha/ gasoil. About half the imported propane is produced at natural gas plants, and the remainder is from petroleum refineries. The methanol is all produced from natural gas.

In the current-tax case, the net reduction in U.S. petroleum imports is similar to the equaltax case-about 1.3 MMBD. However, in contrast to the equal-tax case, total fuel imports drop significantly, by about 1.0 MMBD of crude-oil-equivalent relative to the benchmark case. This difference from the equal-tax case result reflects the greater use of domestically produced ethanol that would occur under the current-tax scheme. As with the equal-tax case, similar results are obtained under the Reference and Low Oil Price Scenarios, except that the decline in world oil price resulting from lower imports is greater in the Reference Oil Price Scenario than in the Low Oil Price Scenario.

\section{Economic Benefits and Costs}

For each unconstrained case, the costs and benefits are calculated relative to the benchmark case. The costs and benefits are divided between fuel factors and consumption factors. The fuel-related benefits and costs consist of differences in the economic costs of fuels and fuel conversion between the unconstrained cases and the constrained, benchmark case. The consumption factors, which consist of vehicle costs and consumer surplus values, are estimates of the net gains to consumers (measured by their willingness to pay) from the opportunity to purchase the broader range of vehicles and fuels than is assumed to be available in the benchmark case. Impacts on external costs, such as the costs to society from pollution, greenhouse gas emissions, and energy security, are not included in these estimates. ${ }^{8}$

The total annual (private) economic benefits are greatest when tax rates are equal. In the unconstrained equal-tax case under the Reference Oil Price Scenario, the net annual gain (relative to the benchmark case) is $\$ 10.3$ billion in $2010 .^{9}$ Most of this gain is in lower cost fuels and noncost consumer benefits from the use of alternative-fuel vehicles. For the Low Oil Price Scenario, the net annual gain is $\$ 7.1$ billion; the smaller gain reflects the fact that the gains from substituting alternative fuels for gasoline are reduced if gasoline is cheaper. The gains are positive but smaller in the current-tax cases, reflecting the nature of the model structure in which higher cost results from uneven taxes and subsidies across

\footnotetext{
${ }^{8}$ Some economic benefits of oil import reduction are included in these estimates. These include reductions in the world oil price and reductions in import costs. Import-related impacts that are neglected are those directly associated with a supply disruption, such as macroeconomic adjustment costs.

9 This is an undiscounted estimate in 1993 dollars.
} 
fuels. (Because these costs reflect private costs only, and not social costs such as greenhouse gas (GHG) emissions, net social costs may be lower under different tax structures than those assessed here.)

\section{Greenhouse Gas Emissions}

Unless a constraint is imposed on carbon dioxide $\left(\mathrm{CO}_{2}\right)$ emissions, $\mathrm{GHG}$ emissions are virtually unaffected by alternative-fuel use when motor-fuel taxes are equal. This is true in both the Reference and Low Oil Price Scenarios. However, significant reductions occur under current taxes-about a 10-percent reduction in light-duty vehicle GHG emissions, and a net 4-percent reduction in U.S. GHG emissions. This is due primarily to the use of cellulosic ethanol, a fuel with very low GHG emissions.

\section{Criteria Pollutants}

Estimates of the value of the reduction in emissions of criteria pollutants between the benchmark case and the unconstrained cases are based on analysis that indicates that alternative-fuel vehicles, when burning an alternative fuel, may be able to meet stricter emissions standards than conventional vehicles at the vehicle costs assumed. The estimated average annual benefit in 2010 is $\$ 2.7$ billion in the Reference Oil Price Scenario and $\$ 2.2$ billion for the Low Oil Price Scenario, assuming equal tax rates.

\section{Transition Costs}

Although in most scenarios examined there is a net gain from the use of alternative fuel in 2010 , this gain presupposes that alternative fuels and vehicles will be widely available soon enough for a substantial fleet of alternative-fuel vehicles to be in operation by 2010 . It would take a major Federal, State, or private-sector initiative for alternative-fuel vehicles and alternative fuels to become widely available in the near future. EPACT programs are an important step in this direction.

The "transition period" is the period from the beginning of such an initiative until 2010. A preliminary analysis of the transition period suggests that there are several reasons why the transition period will be characterized by smaller net gains than are estimated here for 2010:

- Fewer alternative-fuel vehicles will be in use. The number is assumed to grow gradually over time.

- Gasoline prices are projected to increase over time and to be lower in the years preceding 2010 than in 2010. Consequently, the gains from substituting for gasoline will be less.

- The costs of producing both ethanol and methanol are projected to be higher during the transition period. This study's methanol production costs assume the use of largescale plants that may not be economic until a larger market has emerged. Cost-effective cellulosic ethanol production depends on the introduction of new technology that has thus far been proven only in the laboratory.

- Fuel distribution costs will be higher until the market size reaches some critical minimum level. Capital costs at retail outlets will have to be spread over a smaller volume of fuel sold during the transition.

- Vehicle production and maintenance costs are assumed to decline over time as production volumes and experience increase.

- Motorists will incur search costs during the transition because there will be fewer retail outlets offering alternative fuels.

A full analysis of the transition period and of transition costs is the subject of work currently under way at the Department of Energy. In interpreting the material presented in this report, it is important to bear in mind that significant transition costs might be incurred, and that these costs must be compared with the gains that could be realized in 2010 and beyond.

\section{Results for Partially Constrained Cases}

In addition to the primary unconstrained case (which was analyzed under both equal-tax and current-tax assumptions), several additional cases and sensitivities were run. Several of these cases are discussed below. 
EPACT has an additional goal of supplying 50 percent of replacement fuels with domestic supplies. Thus, a case was examined (Case 4) in which total fuel imports are reduced by 50 percent of the 30-percent light-duty replacement fuel goal (1.2 MMBGSE/D). Imposing a constraint on total U.S. fuel imports reduces the level of fuel imports by the specified amount but has little effect on alternative-fuel use or imports of alternative fuels. The constraint results in substitution among fuels such that liquid petroleum fuel imports are reduced.

EPACT's language specifically refers to the domestic content of alternative motor fuels. Given the fungibility between domestic or imported sources of LPG, methanol, or any of the other alternative fuels, it is difficult to isolate the advantages or disadvantages of import constraints on alternative fuels in the motor vehicle sector. For example, increased use of LPG in motor vehicles may lead to increased substitution of ethane and naphtha in place of LPG in the petrochemical sector, with other ripple effects on total energy imports. On the other hand, increased use of domestic LPG in the motor vehicle sector may lead simply to increased imported LPG. A case was run (Case 6) with a constraint specifically limiting the increase in imports of alternative fuels. to one-half of incremental alternative-fuel use. However, this constraint was not binding, as more than 50 percent of alternative motorvehicle fuel use would be from domestic supplies when alternative-fuel use is limited to exactly 30 percent (Case 5 ).

Two cases were run limiting GHG emissions. Case 2 limits total U.S. GHG emissions to 90 percent of their 2010 level in the benchmark case. Case 3 limits GHG emissions to 80 percent of their benchmark case level. Limiting GHG emissions was accomplished using two steps. First, relative fuel prices were adjusted, leading to greater use of low-GHG fuels relative to high-GHG fuels. Second, the prices of all fuels were raised sufficiently to reach the target reductions. In this analysis, the effect of uniformly higher prices is mainly lower overall vehicle use. The net price increases are greatest for gasoline and methanol and least for ethanol (all of which is assumed to be produced from cellulosic feedstocks).

\section{CONCLUSIONS}

The results of the model runs are summarized in Table 1-3 (for the Reference Oil Price Scenario) and Table $1-4$ (for the Low Oil Price Scenario). The results suggest that, once the costs of purchasing and using alternative-fuel vehicles reflect full economies of scale and the vehicles and fuels are widely available, substantial use of alternative fuels by consumers appears economic. Sustaining a 30-percent displacement of light-duty petroleum motor fuel in 2010 , once a successful transition has been completed, is technically and economically feasible.

This analysis estimates that the market could support about 30 percent of light-duty motor fuel use as alternative fuels in 2010 . However, after 2010, as more alternative-fuel-vehicle technologies become available and as gasoline-only vehicles are retired, the market share of alternative fuels could reach as high as 60 percent, taking into account consumer demand, producer supply, and changes in market equilibria. ${ }^{10}$

Although alternative fuels, as a group, appear likely to sustain a 30-percent market share under equilibrium conditions, the estimates of market shares for individual fuels and vehicle types are less certain. Depending on the specific assumptions used, estimated market shares for each fuel vary substantially. However, in no case examined here do alternative fuels, as a group, fail to achieve a 30-percent market share.

Nevertheless, the analysis does suggest that some fuels are more likely to be successful than others, and it indicates the conditions under which different fuels can compete. The fuels that appear to be most successful under an equal-tax regime are methanol and propane. The combined vehicle and fuel costs of

\footnotetext{
10 Note that this analysis constrained the choice of alternative-fuel vehicles to 50 percent of the stock of vehicles. Over time (perhaps by 2020), virtually the total stock would be subject to this choice. The share of alternative-fuel vehicles and fuel use may not double, however, as markets respond to rising demand with increased altemative-fuel prices.
} 
Table I-3 - Summary of Modeling Results for All Cases Under the Reference Oil Price Scenario

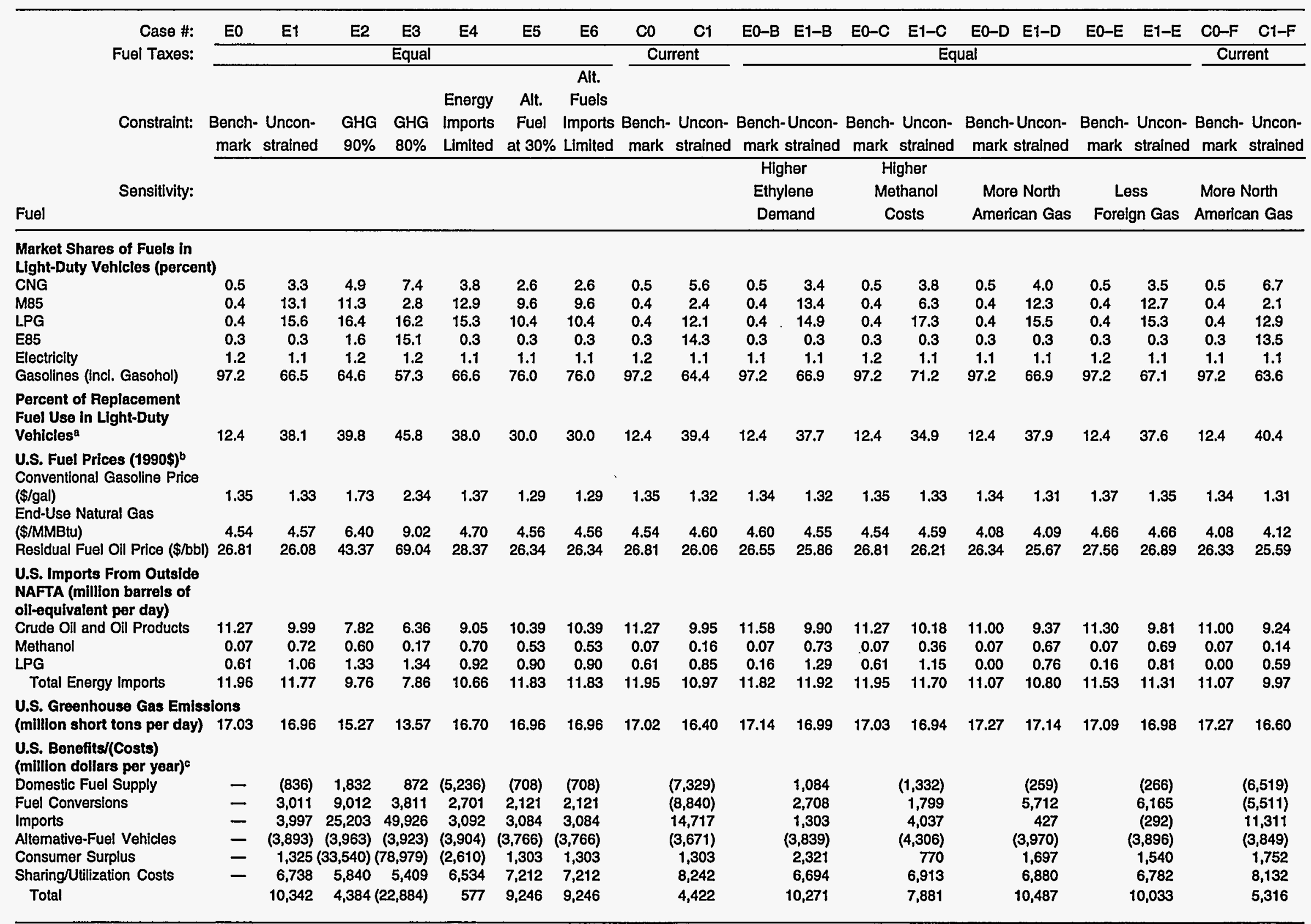

- "Replacement fuel" counts natural gas liquid feedstocks and oxygenates in gasoline and nongasoline portion of altemative fuels.

b Prices in cases with GHG emission or import constraints reflect shadow prices, not prices to producers with normal markups.

'Estimated benefits and costs are relative to the benchmark case. 
Table I-4 - Summary of Modeling Results for All Cases Under the Low Oil Price Scenario

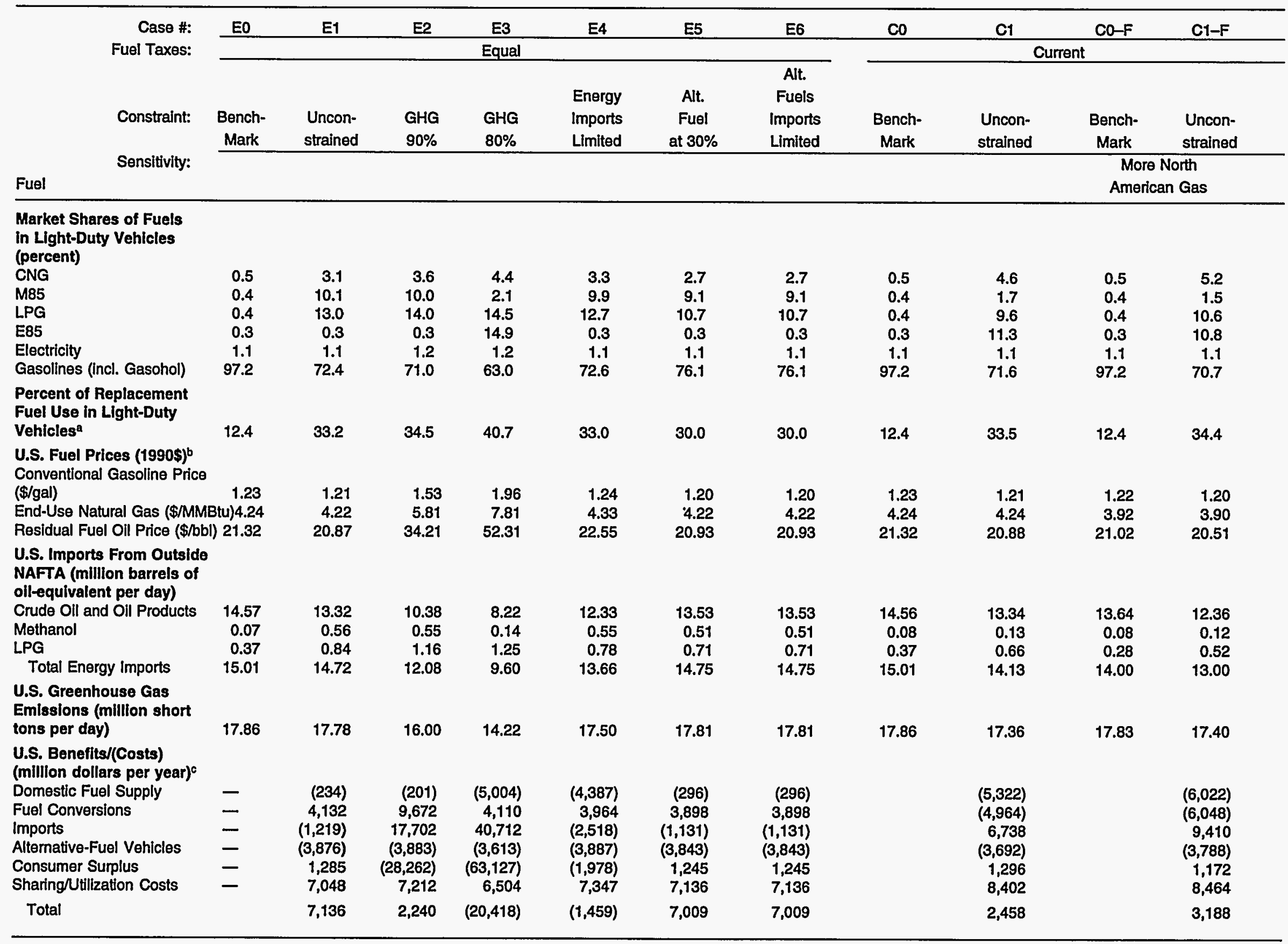

- "Replacement fuel" counts natural gas liquid feedstocks and oxygenates in gasoline and nongasoline portion of altemative fuels.

- Prices In cases with GHG emission or import constraints reflect shadow prices, not prices to producers with nomal markups.

' Estlmated benefits and costs are relative to the benchmark case. 
propane are estimated to be less than that of any other fuel; and methanol is used in a lowcost vehicle. However, both fuels are penalized relative to gasoline by current Federal and State excise taxes. These fuels might be competitive only if excise taxes were restructured to place the fuels on an equal footing (on a Btu basis) with gasoline.

Neither CNG nor ethanol appears to be very competitive in the private vehicle market $a b$ sent policies specifically designed to increase their use. Ethanol receives a small market share primarily because this fuel is costly to produce. CNG use, on the other hand, is expected to be small in the private vehicle market primarily because of the estimated incremental cost of the vehicle and the requirement for lengthy and frequent refueling.

Electric vehicles are not used in any scenario above their constrained usage of

0.09 MMBGSE/D. This is because of their high initial cost (about $\$ 5,000$ more than a conventional gasoline vehicle) and vehicle characteristics, notably low range and long refueling time. It would take a major breakthrough in their technology to make electric vehicles competitive in the private vehicle market. Should this occur, the cost and characteristics of electric vehicles could be attractive enough to result in significant market penetration.

Significant advances in different alternativefuel-vehicle technologies, would affect many of these findings because the relative cost and attractiveness of different alternative-fuel vehicles would change.

In both the equal-tax and current-tax cases, the use of alternative fuels results in a significant reduction in U.S. petroleum imports. Crude oil and oil product imports decrease by more than 1 million barrels per day, or about 12 percent, in both scenarios. This result takes into account increased oil use in other sectors due to the secondary impacts of light-duty vehicle alternative-fuel use - namely, a decline in oil prices and increases in the prices of substitute fuels, such as natural gas.

In contrast to oil imports, total energy imports experience a smaller reduction, particularly in the equal-tax case. This market equilibrium analysis finds that, in 2010, methanol and a large share of propane are likely to be imported, largely from the Middle East. The analysis also finds that $\mathrm{CNG}$, ethanol, and electricity are not likely to be imported. On net, total energy imports would decline by 8 percent in the current-tax case and by less than 2 percent in the equal-tax case.

GHG emissions are not significantly affected by alternative-fuel use except when a $\mathrm{CO}_{2}$ emission constraint is imposed. With U.S. $\mathrm{CO}_{2}$ emissions constrained to 90 percent of the unconstrained case, 20 percent of the reduction in this analysis results from a reduction in total motor fuel use and from substitution of alternative fuels (mainly cellulosic ethanol) for conventional fuels. The remainder of the reduction comes from reduced fuel consumption outside the motor vehicle market sector. This decreased activity is a result of the high fuel prices that must be imposed to satisfy the GHG emission constraint.

Imposing a constraint on GHG emissions increases social costs. If total U.S. GHG emissions were cut by 10 percent of the benchmark case level, the economy would incur a net annual social cost of $\$ 6.0$ billion in 2010 relative to the Reference Oil Price Scenario unconstrained case. This translates to a cost of $\$ 9.42$ per ton of $\mathrm{CO}_{2}$-equivalent emissions. An additional 10-percent reduction of 1.73 million tons per day would cost an additional $\$ 27$ billion annually, or $\$ 43.50$ per ton.

In long-run equilibrium, making alternative fuels and alternative-fuel vehicles available would provide an estimated net annual economic benefit of up to $\$ 10.3$ billion in 2010 . This level of gain would be achievable in the Reference Oil Price Scenario with tax neutrality. Much of this benefit ( $\$ 4.2$ billion) consists of an increase in consumer satisfaction from the availability of new classes of vehicles and less expensive fuels; the remaining $\$ 6.1$ billion reflects dollar cost savings from alternativefuel use, mainly through reduced cost of fuel imports. In addition, benefits from reduced emissions of criteria pollutants are estimated to be up to $\$ 3.7$ billion annually. Net benefits could be significantly higher than estimated here for several reasons, all of which are outside the scope of this report: 
- Increases in the world oil price that are greater than the Energy Information Administration's reference case forecast used here.

- Reductions in the vulnerability of the economy to short-term oil supply disruptions and improvements in the capability of the economy to respond to them. ${ }^{11}$

- Advancements in alternative-fuel vehicle technologies that reduce vehicle cost or improve vehicle attributes beyond the levels assumed for this study.

- Use of alternative fuels in medium and heavy-duty trucks (which were not analyzed in this report).

These reasons include increases in the world oil price that are greater than the EIA refer-

\footnotetext{
11 See David L. Greene et al., The Outlook for U.S. Oil Dependence, Oak Ridge National Laboratory, ORNL6817, May 1995.
}

ence case forecast used here and significant advancements in alternative-fuel vehicle technologies. On the other hand, benefits should be considered relative to the costs associated with a transition to widespread alternative-fuel and vehicle availability. Such a comparison will be possible in the second part of this study.

Although this analysis indicates that a free market could sustain a large volume of alternative-fuel use, it does not appear at present that the market will move toward such a scenario without government action. To realize any substantial use of alternative fuels by 2010, the Federal Government or State governments would have to take steps soon to ensure that the fuels and the vehicles would be produced in sufficient volumes. Displacing a significant portion of conventional motor fuel use by 2010 would likely require a substantial commitment, probably including governmentdriven mandates or incentives, to ensure the availability of both fuels and vehicles. An analysis of the commitment required will be issued as the second part of this study. 


\section{GASOLINE DISPLACEMENT BY REPLACEMENT FUELS IN THE YEAR 2000}

This section estimates the displacement of gasoline by replacement fuels used in lightduty vehicles (LDVs) in the year 2000. Gasoline components that are replacement fuels include liquefied petroleum gas (LPG), natural gas, hydrogen, and alcohol and ether oxygenates commonly used in gasoline. 1 These components represent almost all of the estimated replacement-fuel use by LDVs in the year 2000.

\section{ALTERNATIVE MOTOR-FUEL USE}

The Energy Policy Act of 1992 (EPACT) requires the purchase of alternative-fuel vehicles (AFVs) by specified types of fleets, . including "fuel providers" (Section 501), the Federal Government (303), State governments (507(0)), and municipal governments and private businesses (507(a)). EPACT ex-

\footnotetext{
${ }^{1}$ Natural gasoline and other natural gas liquids (NGLs) heavier than LPGs (that is, pentanes and heavier) are not explicitly listed in the EPACT definition of replacement fuels (Section 301) and therefore are not legally replacement fuels unless declared so through a rulemaking process. However, natural gasoline is considered a replacement fuel in this analysis. LPGs, which include lighter natural gas liquids such as propane and butane, are explicitly mentioned in the EPACT definition.
}

empts commercial rental cars, law enforcement vehicles, emergency vehicles, and several other vehicle types. Some States have pro-. grams requiring the purchase of AFVs in addition to those required under EPACT. All the AFVs estimated to be required as a result of existing Federal and State programs are included. AFVs that may be purchased as a result of competitive market conditions are excluded.

This report uses estimates of fleet vehicle sales based on implementation of the schedules provided in EPACT. Further, this analysis assumes an "early" rulemaking covering municipal and private fleets.

Under current requirements, approximately 890,000 light-duty AFVs will be in use in the year 2000 . Use of these vehicles will result in the displacement of 530 million gallons of gasoline per year $(35,000$ barrels per day) by alternative fuels. This represents 0.5 percent of projected gasoline demand for LDVs in the year 2000 ( 111 billion gallons, or 7.3 million barrels per day (MMBD)). ${ }^{2}$ Tables $\|-1$ and $\|-2$, which

\footnotetext{
${ }^{2}$ Energy Information Administration (EIA), Annual Energy Outlook 1994, projects total gasoline demand in the year 2000 to be approximately 120 billion gallons per year $(7.8$ million barrels per day).
}

\section{Table II-1 - Gasoline and Diesel Fuel Displaced by AFVs, Year-2000 Base Case}

(Barrels per day of gasoline-equivalent)

\begin{tabular}{|c|c|c|c|c|c|}
\hline \multirow[b]{2}{*}{ Vehicle Type } & \multirow{2}{*}{$\begin{array}{l}\text { Gasoline Used } \\
\text { by Alternative- } \\
\text { Fuel Cars } \\
\text { and LDTs }\end{array}$} & \multicolumn{3}{|c|}{$\begin{array}{c}\text { Gasoline and Diesel Replaced } \\
\text { by Alternative-Fuel Vehicles }\end{array}$} & \multirow[b]{2}{*}{$\begin{array}{c}\text { Total } \\
\text { Fuel Use }\end{array}$} \\
\hline & & $\begin{array}{l}\text { Alternative- } \\
\text { Fuel Cars } \\
\text { and LDTs }\end{array}$ & $\begin{array}{l}\text { Alternative- } \\
\text { Fuel HDTs } \\
\text { and Buses }\end{array}$ & Total & \\
\hline Federal Fleet & 633 & 2,554 & 0 & 2,554 & 3,187 \\
\hline State and Local Fleets & 985 & 3,974 & 7,224 & 11,198 & 12,183 \\
\hline Private and Fuel Provider Fleets & 6,944 & 28,030 & 1,945 & 29,975 & 36,919 \\
\hline Total Fleets & 8,562 & 34,558 & 9,169 & 43,727 & 52,289 \\
\hline Personal Vehicles & NE & NE & NE & NE & NE \\
\hline All Programs & 8,562 & 34,558 & 9,169 & 43,727 & 52,289 \\
\hline
\end{tabular}

LDTs = light-duty trucks; HDTs = heavy-duty trucks; NE = not estimated. 
Table II-2 - Light-Duty and Heavy-Duty AFV Vehicle and Fuel Use, Year-2000 Base Case

\begin{tabular}{lcr}
\hline AFV Type & $\begin{array}{c}\text { Number of } \\
\text { Vehicles }\end{array}$ & $\begin{array}{r}\text { Fuel Use: } \\
\text { (BD of } \\
\text { Gasoline- } \\
\text { Equivalent) }\end{array}$ \\
\hline Dedicated Alcohol & 4,000 & 2,300 \\
M85 & & 2,300 \\
E85 & 332,000 & 0 \\
Flex-Fuel Alcohol & & 16,700 \\
M85 & & 6,250 \\
E85 & & 6,250 \\
Gasoline & 30,000 & 4,200 \\
Dedicated CNG & 176,000 & 4,400 \\
Bifuel CNG & & 8,800 \\
CNG & & 6,600 \\
Gasoline & 29,000 & 2,200 \\
Dedicated LPG & 176,000 & 8,800 \\
Bifuel LPG & & 6,600 \\
LPG & & 2,200 \\
Gasoline & & 8,900 \\
Electric & 203,000 & 43,700 \\
Total Vehicles & 950,000 & 52,300 \\
Total Alternative Fuel & & \\
Total Fuel Used & & \\
\hline
\end{tabular}

present fuel displaced by AFVs and the number of AFVs in use, respectively, include all programmatically mandated AFVs (that is, light-duty and heavy-duty vehicles) to facilitate comparison with other estimates of AFV and alternative-fuel use.

\section{OXYGENATE USE}

The analysis of replacement-fuel components of gasoline was conducted for a base case reflecting mandated and market-driven oxygenate use. Table II-3 provides details on oxygenate use in the year 2000. In addition to the assumption about the size of the year-2000 reformulated gasoline (RFG) market, the case is based on three other assumptions about oxygenates, as follows:

- The assumed average oxygen content of the pool of RFGs is 2.2 percent by weight. ${ }^{3}$

\footnotetext{
${ }^{3}$ Reformulated gasoline" is a term of convenience in this analysis used to represent all gasolines with regulated oxygen content. These include oxygenated gasoline for carbon monoxide (CO) control and California RFG as well as Federal RFG.

The estimated average oxygen levels are not intended to be projections. While they represent a feasible range of oxygenate levels, the precision of the endpoints on the range is low. As CO nonattainment areas come into compliance, the average oxygen content could decline if those areas stop using oxygenated gasoline.
}

\section{Table II-3 - Details on Oxygenate Use in the Year 2000}

$\begin{array}{ll}\text { Total Light-Duty Fuel Demand (MMBD of gasoline-equivalent) } & 7.3 \\ \text { Gasoline Displaced by Light-Duty AFV Use (MMBD) } & 0.04 \\ \text { Light-Duty RFG Demand (MMBD of gasoline-equivalent) } & 3.6 \\ \text { Renewable Oxygenate in RFG (percent)a } & 30.0 \\ \text { Average Oxygen Content of Pool of Regulated, Oxygenated Gasolines (percent by weight) } & 2.2 \\ \text { Nonoxygenated, Light-Duty Conventional Gasoline Demand (MMBD) } & 3.5 \\ \text { Light-Duty Gasohol Demand (MMBD of gasoline-equivalent) } & 0.2 \\ \text { Ethanol Demand Due to Light-Duty Motor Fuels (billion gallons per year) } & 1.3\end{array}$

Note: Fuel volumes are subject to rounding error.

a The winter season for ethanol blending is assumed to be 6.5 months. During the other 5.5 months of the year, ethyl tertiary-butyl ether is assumed.

b This value represents the fraction of total fuel ethanol used in LDVs. The total for all vehicles is 1.4 billion gallons per year of ethanol. 
- The assumed total demand for fuel ethanol is 1.4 billion gallons per year.

- Ethanol use in RFG is at a level consistent with the proposed Renewable Oxygenate Standard (ROS), which would have required that 30 percent of the oxygen content of RFG be derived from renewable oxygenates. ${ }^{4}$ This level of ethanol use is assumed to be satisfied on a year-round basis by using ethanol during the winter and ethyl tertiary-butyl ether (ETBE) during the summer. The remainder of reformulated gasoline is assumed to be oxygenated with methyl tertiary-butyl ether (MTBE).

\section{USE OF OTHER REPLACEMENT-FUEL COMPONENTS IN GASOLINE}

Replacement-fuel components of gasoline, other than oxygenates, were estimated using data on refinery inputs from EIA's Petroleum Supply Annual 1993 (EIA 1993). The proportions of refinery inputs were assumed to remain constant, and volumes in the year 2000 were estimated based on estimated gasoline demand.

Certain refinery inputs reported by EIA have been considered as replacement fuels because they end up in the gasoline pool. These inputs include various natural gas liquids (NGLs) and "other hydrocarbons and hydro-

\footnotetext{
${ }^{4}$ If the level of ethanol use is not consistent with the proposed ROS, and all RFG is oxygenated with MTBE, the volume of gasoline displaced in the LDV pool calculated under the assumptions of this analysis would be greater (7.5 percent gasoline replaced because of RFG use in the base case, instead of 7.2 percent). This would also free up 1.1 billion gallons per year of ethanol capacity ( 80 percent of existing capacity) for other uses, such as gasohol. If gasohol is used at current levels in conventional gasoline areas and all RFG is oxygenated with MTBE, 11.1 percent of gasoline would be displaced by replacement fuels in the base case instead of 10.5 percent. There would be approximately 40 percent excess ethanol production capacity (at current ethanol production capacity) in such a case. Therefore, it is likely that some ethanol will be used in RFG whether or not the ROS is in effect.
}

gen" (as categorized by EIA). ${ }^{5}$ Finished oxygenate inputs have been excluded because the use of oxygenates was estimated by setting oxygen and ethanol levels (independent of historical refinery operations). Feedstocks to within-refinery oxygenate production in 1993 were deducted to avoid double-counting the components.

Some NGLs can be blended into gasoline directly, and some are used as feedstocks to make ethers, alkylate, and isomerate. ${ }^{6}$ The NGLs are about one-third pentanes and higher by volume (natural gasoline) and about twothirds butanes (a mixture of $n$-butane and isobutane). ${ }^{7}$ NGLs included a negligible amount of propane (less than 0.02 percent of total NGLs reported). All of the pentanes and higher NGLs have been counted as part of the gasoline pool, as were butanes, less the deduction for feedstock to within-refinery ether production in 1993.

EIA reports that the category for other hydrocarbons and hydrogen is almost exclusively hydrogen (for example, from a nominally independent, merchant hydrogen plant adjacent to a refinery) and that the balance is probably natural gas fed to steam-reforming units. This analysis assumes that the input is entirely hydrogen.

Hydrogen is a relatively complicated refinery input. It is consumed in various process units, such as hydrodesulfurization and hydrocracking. Hydrogen sulfide is produced in hydroprocessing, and the associated hydrogen is eliminated as water during sulfur recovery. In hydrocracking and hydrofining, some of the hydrogen may end up in gasoline.

\footnotetext{
${ }^{5}$ No fuels burned at refineries are classified as replacement fuels.

${ }^{6}$ Some NGLs can be used either directly or as feedstocks that produce gasoline components. $\mathrm{C} 5 \mathrm{~s}$ can be isomerized to increase octane before blending into gasoline, fed to a reformer, or blended directly into gasoline.

${ }^{7}$ On an energy basis, after netting out 1993 withinrefinery ether production (to avoid double-counting), natural gasoline displaced 36 percent of the total gasoline displaced by all NGLs.
} 
The National Petroleum Refiners Association 1989 summer gasoline survey, covering 6 summer months, reported that the U.S. average hydrocracker yield was approximately twothirds naphtha and one-third distillates. For the calculation of the replacement hydrogen component of gasolines, this relationship has been taken to be a reasonable indicator of how hydrogen enters refinery streams. ${ }^{8}$ Half the hydrogen input has been attributed to units that would not result in the replacement of gasoline with hydrogen. ${ }^{9}$ With the naphtha allocated to the gasoline pool, one-third of the refinery inputs listed under the category for other hydrocarbons and hydrogen has been credited as replacement fuel.

${ }^{8}$ Other units (for example, hydrofining and hydrotreating) use significantly less hydrogen as a fraction of their total inputs.

${ }^{9}$ The estimate of the amount of hydrogen attributed to various units is subject to revision. Attributing one-half to units that would not produce hydrogen in the motor-fuel pools may be too much. The analysis results, however, are quite insensitive to this assumption because the amount of purchased hydrogen is small.

\section{TOTAL REPLACEMENT-FUEL USE IN THE YEAR 2000}

Table II-4 summarizes replacement-fuel use in the year 2000 for the two cases considered.

These results indicate that the 10-percent replacement goal may be achievable through a combination of programs or refinery practices already in place and market incentives sufficient to sustain some use of gasohol in areas not mandated to use oxygenated fuels. AFVs will play a minor role in achieving this year2000 goal for use of replacement fuel.

Changes in the projected size of the RFG program or in refinery operations in the year 2000 could affect the replacement-fuel component of motor fuels such that this goal is easily achieved or is not achieved at all.

The results presented in Table II-4 apply to the entire gasoline pool. The per-gallon gasoline displacement for each fuel is presented in Table II-5. The per-gallon displacements can be used with volumes of the appropriate fuels as weighting factors to generate the aggregate values presented in Table II-4, or to estimate the impact of an alternative set of assumptions.

\section{Table II-4 - Replacement-Fuel Use in the Year 2000}

$\begin{array}{lr}\text { Volume of Gasoline Displaced (MBD) } & 35.0 \\ \text { By AFVs } & 352.0 \\ \text { By Oxygenates } & 379.0 \\ \text { By Other Nonpetroleum Gasoline Components } & 766.0 \\ \text { Total } & \\ \text { Gasoline Pool Displaced (percent) } & 0.5 \\ \text { By AFVs } & 4.8 \\ \text { By Oxygenates } & 5.3 \\ \text { By Other Nonpetroleum Gasoline Components } & 10.5 \\ \text { Total } & \end{array}$

Note: Percentage totals do not equal sum of components because of rounding.

$M B D=$ thousand barrels per day. 


\section{Table II-5 - Per-Gallon Gasoline Displacement}

for Various Fuels, Year-2000 Base Case

\section{Fuel}

Percent of Energy From

RFG With MTBE

Replacement Fuels

RFG With Ethanol

15.04

RFG With ETBE

9.44

Weighted Average for RFG

16.77

14.37

Gasohol ( $10 \%$ ethanol by volume)

11.82

Conventional Gasoline (Nonoxygenated)

5.58 


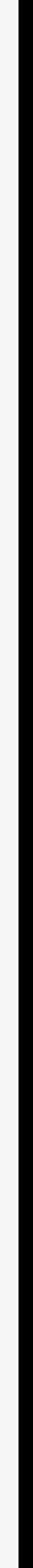




\section{ANALYTICAL FRAMEWORK FOR THE YEAR-2010 ANALYSIS: THE AFTM MODEL}

Increased use of alternative motor fuels will displace gasoline demand, initiating a series of adjustments that ultimately may lower U.S. oil imports and the world price of oil. These changes will ripple through the energy economy, providing a variety of costs and benefits to consumers and producers. This study uses the Alternative Fuels Trade Model (AFTM) to examine these market interactions and their ultimate consequences for energy supply, demand, prices, and U.S. economic welfare.

The AFTM is an integrated model that characterizes the interrelationships between oil and gas markets and the global trade in those markets. It thus provides a framework for analyzing the production and consumption of alternative motor fuels that may substitute for gasoline use in the United States. The AFTM produces a long-run equilibrium analysis of alternative-fuel vehicle (AFV) economic costs and benefits.

The AFTM approach is often called "long-run comparative statics." It compares long-run static pictures of the energy economy under alternative scenarios or policies. No explicit dynamics govern the time lags in consumers' responses to changing prices or in producers' incentives for exploration and development. In the absence of these dynamics, AFTM market outcomes are best viewed as long-run balances, which would occur if market conditions persist long enough (or change slowly enough) for needed adjustments to take place. The AFTM yields consistent solutions to the various scenarios that it examines. Although it focuses attention principally on the markets for oil and gas and their products, it includes othei fuel markets as well. The approach focuses on the following:

- Prospects for fuel substitutions (in motor fuel, switchable boiler, and basic petrochemical markets)
- Long-run effects of alternative motor-fuel use on oil and gas demand, refining, imports, and fuel prices

- Ramifications of possible monopolistic responses by oil and gas exporters-specifically, the Organization of Petroleum Exporting Countries (OPEC).

Model results are logical and easily explained based on input parameters. The AFTM determines prices and quantities that balance the interrelated world oil and gas markets given a set of assumptions regarding supply, demand, and costs. It estimates changes in prices, supplies, and demands of conventional fuels if alternative motor fuels are made available to the U.S. market. It reports the level of alternativefuel use, and tracks the market-clearing geographic trade in world energy supplies. The market costs and benefits of introducing these substitute fuels are also assessed, based on a standard "social surplus" analysis. Social surplus is defined as net economic benefits (or costs) of a particular market outcome, measured as the total benefits of fuel consumption minus the costs of domestic fuel production, fuel processing and distribution, fuel imports, and incremental vehicle capital costs.

In addition to its representation of world energy markets, the AFTM contains a vehicle- and fuel-choice component. AFV choice and motorfuel choice are endogenous and consistent in the sense that the anticipated long-run price of motor fuels is considered in the selection of either dedicated or multifuel vehicles. The multinomial logit choice framework estimates the effects of nonprice vehicle and fuel attributes. It varies vehicle and fuel shares as a function of changing relative prices, because the wide variation in consumers' situations and preferences means that a mix of vehicles may be chosen, rather than just a single best alternative. Alternative-fuel policies may be tested with the model through vehicle or fuel-use 
constraints, or through fiscal incentives including taxes and subsidies.

Through this combination of model components, the AFTM provides a consistent fuel flow accounting in the markets for oil and gas and their products. It can estimate the direct displacement of oil by alternative-fuel use in the light-duty vehicle (LDV) sector, and it can estimate and decompose the offsets to alternative-fuel use that may limit the ultimate reduction in U.S. oil imports, including fuel substitution, supply and demand responses in nonmotor-fuel markets, and changes in fuel use by intermediate conversion processes.

\section{OPIIMIZATION FRAMEWORK OF THE AFTM}

The AFTM is a numerical simulation of regional fuel supplies, production processes, demand, and transportation. Each component of fuel supply, production, and transport is assigned a cost for use in the model's optimization calculations. An additional "utilization cost" quantity is introduced into the optimization in markets that choose fuel supplies based on market share (or logit choice) functions. Demand is assigned a value based on the price consumers are willing to pay for each product; this becomes the model's valuation of the "benefit" of demand. The model seeks to minimize the sum of the costs and benefits of fuel supplies and demands under whatever constraints have been set up to describe a scenario of interest.

The model divides the world into six main regions with explicit fuel demands and domestic raw fuel supplies. In addition, the model characterizes "remote" gas discoveries in 25 regions within OPEC and within other countries that do not belong to the Organization for Economic Cooperation and Development (OECD). The AFTM's regions are the following:

- United States

- Canada

- Japan

- Western Europe
- OPEC, including remote gas discoveries in Algeria, Iran, Libya, Nigeria, Qatar, Saudi Arabia, Venezuela, and the United Arab Emirates

- Rest of world (ROW), including remote gas discoveries in Argentina, Australia, Bangladesh, Chile, China, Egypt, Indonesia, India, Malaysia, Oman, Pakistan, Papua New Guinea, Peru, Trinidad, former Soviet Union-Europe deliveries, former Soviet Union-Pacific deliveries, and Yemen

Raw fuel supplies are represented by a series of supply curves that relate production (expressed in million barrels per day for liquids and billion cubic feet per day for gas) to the cost of that production (expressed in million 1990 dollars per day). Regional supply curves are provided for the following raw fuel supplies:

- Light crudes

- Heavy crudes

- Raw gas production (distinguished by hydrocarbon liquids content)

\section{- Ethanol feedstocks}

The AFTM must find a solution that satisfies world demand for fuels derived from hydrocarbon liquids and natural gas, or replacements for these fuels. Demand is characterized by end-use demand volumes for most fuels, plus endogenous demands for fuel used in refineries and gas processing. Demand units are expressed as million barrels per day (or barrels of fuel-oil-equivalent or gasoline-serviceequivalent) and million dollars per day. Demand for the following fuels are explicitly input into the AFTM:

- Natural gas (methane)

- Liquefied petroleum gas (LPG)

- Distillate fuel oils

- Residual fuel oils 
- Switchable industrial and powergeneration fuels (residual/gas boiler fuel demand)

- Ethylene

- Fuel for dedicated gasoline vehicles (conventional and reformulated fuels are input separately)

- Fuel for light-duty motor vehicles that are free to choose gasoline or alternative motor fuels

The main supply and demand regions contain a series of "conversion processes" that process the raw fuel supplies into hydrocarbon fuel products capable of meeting the model's demands. Each conversion process is represented by fuel input requirements, a unit of activity cost, and fuel output volumes. (Volumes are expressed in millions of units per day, and costs are in million dollars per day.) These processes include the following:

- Crude oil refining to produce LPG, distillate fuel oils, residual fuel oils, conventional gasoline, and reformulated gasoline (RFG)

- Natural gas processing to produce ethane, LPG, distillates, and condensates

- Liquefied natural gas (LNG), methanol, and ethanol manufacturing

- Basic petrochemical (ethylene) manufacturing

- Distribution and retail markups on industrial and end-use fuel demands

- Motor-vehicle fuel consumption (expressed as gasoline-service-equivalent)

Transportation costs in the AFTM are incurred when fuels are transported between regions as part of the optimization of supply and demand and the minimization of the cost/benefit objective function. Costs are expressed as million dollars per million units per day.

Utilization costs are incurred when demand can be satisfied by two or more fuel choices. In these instances, additional consumer costs are calculated beyond that of fuel supply and conversions. These additional costs are considered the "utilization" costs of a particular fuel market-share mix and are described by the parameters of the AFTM multinomial logit choice functions. Both fuel prices and nonprice attributes of a fuel choice are considered in the calculation of utilization costs. Utilization costs are relevant to the analysis only when they differ between cases. Markets with choice functions include all boiler markets and the U.S. LDV fuel market. Again, costs are expressed as million dollars per million units per day.

The AFTM satisfies demand in each of the market sectors, in each region where demand is specified, by maximizing the sum of global consumer benefits less costs (the objective function). The objective function incorporates all of the costs associated with supply, conversions, demand, transportation, and utilization. Alternative scenarios can be specified by changing the supply curves, demand curves, or conversion costs, or by constraining how the model solves (for example, by limiting greenhouse gas emissions).

\section{STRUCTURAL DETAILS OF THE AFTM}

\section{The Optimization Problem}

The AFTM estimates the effects of a fuelmarket equilibrium in the United States and globally. As equilibrium is achieved, prices adjust, fuels are transported to new locations, and raw fuel supplies are converted to forms with their greatest economic value. This market-based balancing process results from cost minimization and profit maximization by the various economic agents (producers, transporters, refiners, distributors, and so forth). Consequently, the equilibrium may be calculated with an optimization framework. A standard modeling and optimization system, the General Algebraic Modeling System (GAMS), is used to define and solve the AFTM. The model includes both linear and nonlinear components. Nonlinear equations describe primary resource supplies and final fuel demands (which vary with the price of the fuel) and describe substitutions between close-substitute fuels (which vary with the price differential be- 
tween the substitutes). Linear relationships describe transportation links and fuelconversion processes (such as crude oil refining). A nonlinear model is defined to include supply, fuel processing, transportation, demand, and fuel-substitution behavior.

The AFTM solution satisfies two equilibrium conditions:

- Supply is equal to or greater than demand in all regions

- Net consumption benefits are maximized (Net Benefits = Demand (consumption benefits) - Resource Supply Costs - Conversion Costs - Transportation Costs Consumer Utilization Costs)

The AFTM objective function is constructed so that its minimum occurs at a global equilibrium of oil and gas markets. The optimization identifies that pattern of regional supplies, shipments, conversions, and demands that satisfies the market balance constraint at minimum cost. Hence, there is no market incentive remaining to reallocate goods, and the balancing allocation is at equilibrium. At the optimum, supplies and demands balance, and prices for final goods reflect the marginal costs of input supply, conversion costs, and transportation costs.

Consumption benefits are estimated from the area under the inverse-demand (marginal consumption benefit) curves; primary resource supply costs are estimated from the area under the inverse-supply (marginal cost) curves; and conversion costs and transportation costs are fixed per unit of activity. Consumer utilization costs are determined from a sharing cost function that is a discrete choice analog of consumer surplus, but depends on input market shares. The inclusion of consumer utilization costs reflects the utility derived from nonprice attributes. It also ensures that equilibrium shares for substitutable goods are consistent with the aggregate utility function.

The AFTM solves for competitive marketclearing prices and quantities for all regions. This is achieved by maximizing the measure of net benefit to the world, subject to whatever constraints are assumed in any scenario. The only constraints fixed for all model scenarios are upper limits on pipeline transport of natural gas between OPEC (Algeria) and Europe, and between ROW (Russia) and Europe.

The AFTM structure allows limits to be placed on a particular fuel choice or conversion process by simply adding a constraint equation into the model. Imposition of any constraint will move the model's solution away from its leastcost equilibrium by increasing the economic costs of raw fuel production, processing, transportation, vehicle purchases, or consumption. This study reports costs for each case or sensitivity as a difference from costs estimated in the benchmark case. This type of formulation yields a solution that estimates a "shadow" price for fuels indicative of the additional cost (for example, taxes) that must be imposed to be consistent with the constraint. For example, a carbon dioxide $\left(\mathrm{CO}_{2}\right)$ emissions constraint is expressed as a cap on emissions expressed in tons per day. The AFTM solution considers fuel price and fuel mix, as well as fuel consumption changes that yield an optimum solution to that constraint. To achieve the optimum fuel mix that satisfies the $\mathrm{CO}_{2}$ emissions constraint, the model must "shift" some of the fuel supply or demand curves. This change is reported as the marginal unit's shadow price.

\section{Regional Disaggregation}

As mentioned previously, AFTM sources of supply and demand are divided among 6 main regions and 25 regional sources of "remote" gas. Unique demand curves for each end-use product and sharing functions are described where appropriate. Unique supply curves for two crude oil types, three raw gas types, and two ethanol feedstock types are described for each region where production occurs. Conversions necessary to process raw fuel into desired end-products are described in each region. These conversion processes include liquefaction and gasification of $L N G$ and intraregion distribution markups to wholesale fuels. A matrix of fuel transportation costs allows links between regions. Table III-1 summarizes the AFTM regional descriptions.

The benefits of the introduction of alternative fuels are evaluated considering two possible scenarios of OPEC core supply behavior: mo- 
Table III-1 - AFTM Regions

\begin{tabular}{|c|c|c|c|c|c|c|c|}
\hline \multirow[b]{2}{*}{ Region } & \multicolumn{7}{|c|}{ Demand Curves } \\
\hline & Gas & LPG & Distillate & Residual & Ethylene & Boiler & Gasoline \\
\hline \multirow[t]{3}{*}{$\begin{array}{l}\text { United States } \\
\text { Canada } \\
\text { Japan } \\
\text { Western Europe } \\
\text { OPEC } \\
\text { Rest of World }\end{array}$} & $\begin{array}{l}: \\
: \\
: \\
:\end{array}$ & $\begin{array}{l}\dot{ } \\
: \\
: \\
: \\
:\end{array}$ & $\begin{array}{l} \\
\\
: \\
:\end{array}$ & $\begin{array}{l}\bullet \\
: \\
: \\
:\end{array}$ & $\begin{array}{l}\dot{\bullet} \\
\dot{\bullet} \\
\dot{\bullet} \\
\dot{\bullet}\end{array}$ & $\begin{array}{l}\dot{\bullet} \\
: \\
\dot{\bullet} \\
\dot{\bullet}\end{array}$ & $\cdot$ \\
\hline & \multicolumn{7}{|c|}{ Supply Curves } \\
\hline & $\begin{array}{l}\text { Crude } \\
\text { Light }\end{array}$ & $\begin{array}{l}\text { Crude } \\
\text { Heavy }\end{array}$ & $\begin{array}{l}\text { Low } \\
\text { NGL } \\
\text { Gas }\end{array}$ & $\begin{array}{l}\text { Medium } \\
\text { NGL } \\
\text { Gas }\end{array}$ & $\begin{array}{l}\text { High } \\
\text { NGL } \\
\text { Gas }\end{array}$ & $\begin{array}{c}\text { Grain } \\
\text { Ethanol } \\
\text { Feedstock }\end{array}$ & $\begin{array}{l}\text { Wood } \\
\text { Ethanol } \\
\text { Feeds }\end{array}$ \\
\hline $\begin{array}{l}\text { United States } \\
\text { Canada } \\
\text { Japan } \\
\text { Western Europe } \\
\text { OPEC } \\
\text { Rest of Worldc }\end{array}$ & : & $\begin{array}{l}\bullet \\
\bullet \\
\dot{\bullet} \\
\dot{\bullet}\end{array}$ & • & : & • & - & - \\
\hline
\end{tabular}

- Gasoline demand in regions outside the United States is combined with distillate demand. Products (such as gasoline) may be produced in regions without explicit demand for that product and exported to regions (such as the United States) that have demand for that product.

bOPEC oil and gas supply is further subdivided into "core" and "noncore" production capacity. Remote gas discoveries are characterized in separate curves for Algeria, Iran, Libya, Nigeria, Qatar, Saudi Arabia, Venezuela, and the United Arab Emirates.

${ }^{c}$ Rest of World remote gas discoveries are characterized in separate curves for Argentina, Australia, Bangladesh, Chile, China, Egypt, Indonesia, India, Malaysia, Oman, Pakistan, Papua New Guinea, Peru, Trinidad, former Soviet Union-Europe deliveries, former Soviet Union-Pacific deliveries, and Yemen.

nopolistic and competitive. In the monopolistic scenario, the "core countries" behave jointly to maximize their net revenue. This means that they coordinate production decisions among themselves, with full consideration of the anticipated responses of oil consumers, non-OPEC oil producers, and noncore OPEC oil producers. Each of the latter groups is then in a similar role of responding passively to the price leadership of the core OPEC producers. In the competitive scenario, the OPEC core supplies oil along a long-run competitive supply curve similar to other regions. The distinction between OPEC core and noncore is also made for natural gas production.

\section{Primary Resource Supply Curves}

The seven raw fuel types that make up all primary resources available to the AFTM are represented by a common functional form that implies a decreasing elasticity with price.

Letting $Q_{S}$ denote the quantity supplied and $P_{s}$ the associated price, all other points are extrapolated with the following nonlinear marginal cost function:

$$
P_{s}=a+b \frac{1}{c-Q_{s}}
$$

Note that this form implies high elasticities at low levels of supply and low elasticities at high 
levels. The parameter $c$ imposes an upper bound upon supplies. As $Q_{s}$ approaches this value, the supply price increases indefinitely. Conversely, parameter a represents the minimum price required for supply to be positive.

\section{Crude Oil}

In general, two crude oil types are described for each region with crude supplies: a light crude representing sweet crudes, and a heavy crude representing low-gravity and sour crudes. Each region has a unique split of crude resources between light and heavy supplies. The supply curves were benchmarked to produce an aggregate supply equal to the Energy Information Administration's (EIA) 2010 reference projection at EIA's reference price in the Annual Energy Outlook 1994. The projected fractions of light and heavy crude production, as well as the reference light-heavy price differential for each region, were determined from data sets that the Department of Energy developed for the Oil Trade Model. Each crude type yields a different slate of products (LPG, distillate fuel oils, residual fuel oils, and gasolines) during the refining process. As mentioned earlier, the crude oil supply curves are expressed as million barrels per day of production as a function of price. For each region, the supply curve passes through a "reference" price-quantity point adapted from the EIA Annual Energy Outlook 1994 reference case forecast for 2010. Prices outside the United States are based on estimated transportation price differentials to the United States. The price differential between light and heavy crudes is assumed to be $\$ 1.00$ per barrel.

OPEC crude oil supplies are handled somewhat differently. To estimate the likely behavior of OPEC "core" producers that would be required to yield a world oil price similar to that in the EIA reference forecast for 2010 , an analysis of the marginal costs of production of OPEC producers was integrated with AFTM results for world oil demand and non-OPEC supplies. This analysis, which used iterative AFTM runs that varied world crude oil supplies, yielded two sets of OPEC oil supply curves: "monopolistic behavior" curves in which approximately 70 percent of potential OPEC production behaves as a cartel (and prices that match those of the Annual Energy Outlook 1994 reference case), and "competitive behavior" curves in which all OPEC production behaves competitively.

The OPEC monopoly scenario is referred to in this report as the Reference Oil Price Scenario. Figure III-1 illustrates the AFTM input for regional crude oil supply curves under that scenario. The figure depicts total crude oil supplies. The AFTM actually uses separate production curves for light crude and heavy crude (with the \$1.00-per-barrel price differential). In the Reference Oil Price Scenario, the OPEC core restricts production, and the noncore countries increase production in response to the higher price that results.

Figure III-2 illustrates the AFTM input for regional crude oil supply curves in the Low Oil Price Scenario. In this scenario, all OPEC supply is referred to as "noncore," and the resulting oil production capacity curve has a much higher elasticity to price. The derivations of these OPEC crude oil supply curves are explained in greater detail in Appendix B. Table III-2 summarizes the reference crude oil supply capacities and prices used in the model.

\section{Natural Gas}

Natural gas supply curves are specified for the five main supply and demand regions that have domestic raw fuel supplies (Japan is excluded). Additional supplies of "remote" gas discoveries are characterized within OPEC and the ROW. The raw gas curves represent production capacities for full hydrocarbon wellstream gases and liquids. That is, the volumes of natural gas liquids (ethane, propane, butane, and pentanes plus) that are associated with the methane (dry gas) portion of natural gas production are included in the AFTM's gas supply curves. Condensate liquids related to nonassociated gas production are also included in the gas supply curves. Three different types of raw gas are described: a "dry" raw gas with very little natural gas liquid (NGL) content, a "lean" raw gas with NGL content averaging about 5 to $10 \mathrm{~mol}$ percent, and a "wet" raw gas averaging about 15 percent NGLs. Each gas supply source contains one curve that has characteristics 
Figure III-1 - Crude Oil Supply Curves Under the Reference Oil Price Scenario

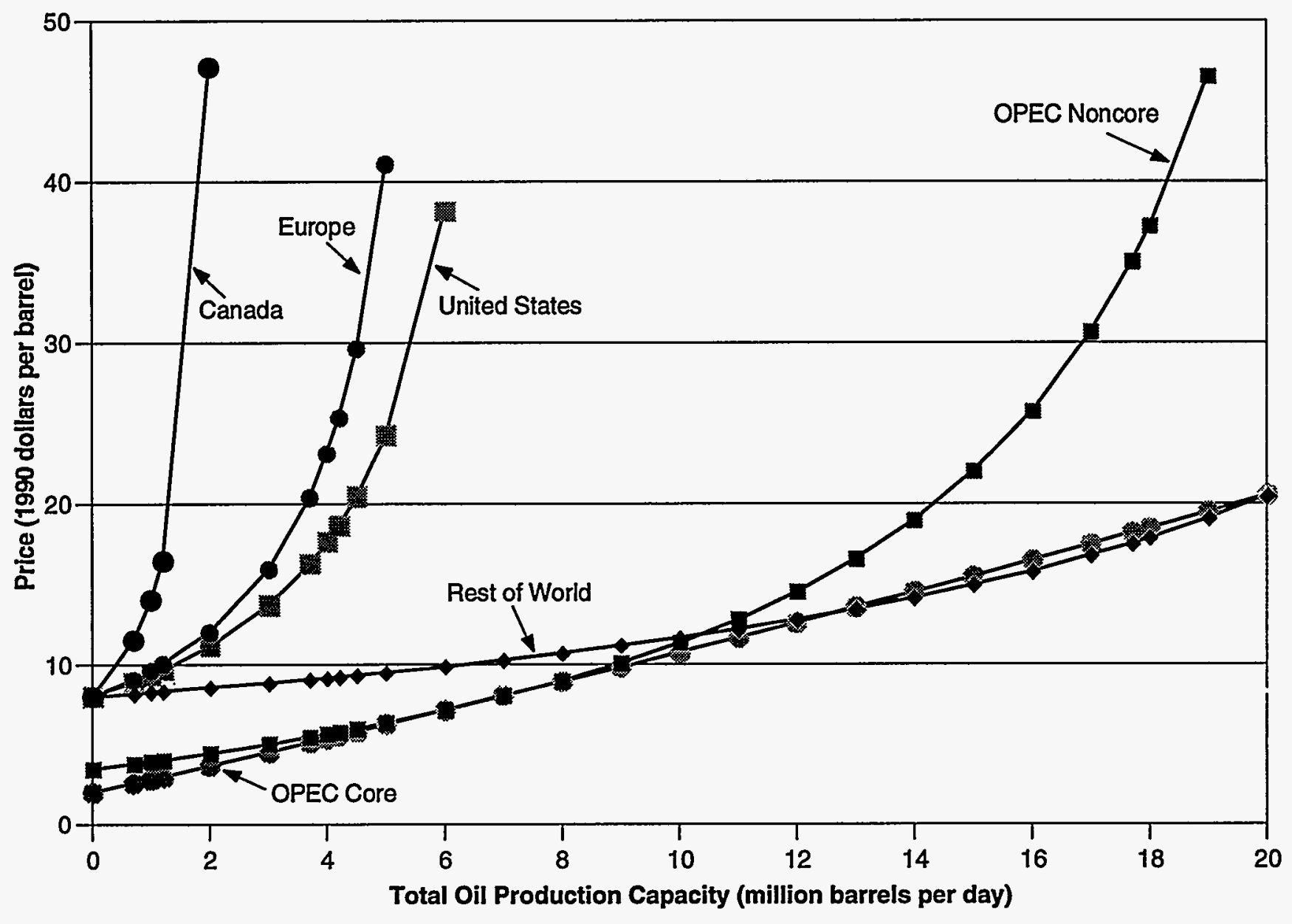

similar to one of the three raw gas types just described.

For each main region, the supply curve passes through a "reference" price-quantity point derived from gas production forecasts for 2010 in ElA's Annual Energy Outlook 1994 and International Energy Outlook 1993 and National Energy Strategy working documents. These gas forecasts include only estimates of production of processed gas for end-uses, after liquids have been extracted. Similarly, EIA's oil production forecasts include both crude oil and gas-related production of NGLs and condensate. The AFTM raw gas supply curves include both the volume and value of end-use gas as reported by EIA plus the volume and estimated value of NGLs. The AFTM crude oil supply curves include the volume of oil as reported by EIA less the estimated volume of NGLs. This reallocation of raw fuel supplies more accurately reflects the sources and economics of the various petroleum products required to satisfy demand. For example, if the model seeks to satisfy increased LPG demand, it has several choices: increased crude oil production or more intense refining, or both; or increased raw gas production or more intense gas processing, or both. In all these options, the economics of LPG production are tied directly to the economics of the main raw fuel being produced (crude oil or natural gas). Figure III-3 illustrates the wet-gas production capacity curves for each of the main AFTM regions that have gas supplies. It is important to note that the prices indicated on the graph include the wellhead value of the dry-gas production plus the gross value of associated liquids (processing and transportation costs are subtracted later by the model). 
Figure III-2 - Crude Oil Supply Curves Under the Low Oil Price Scenario

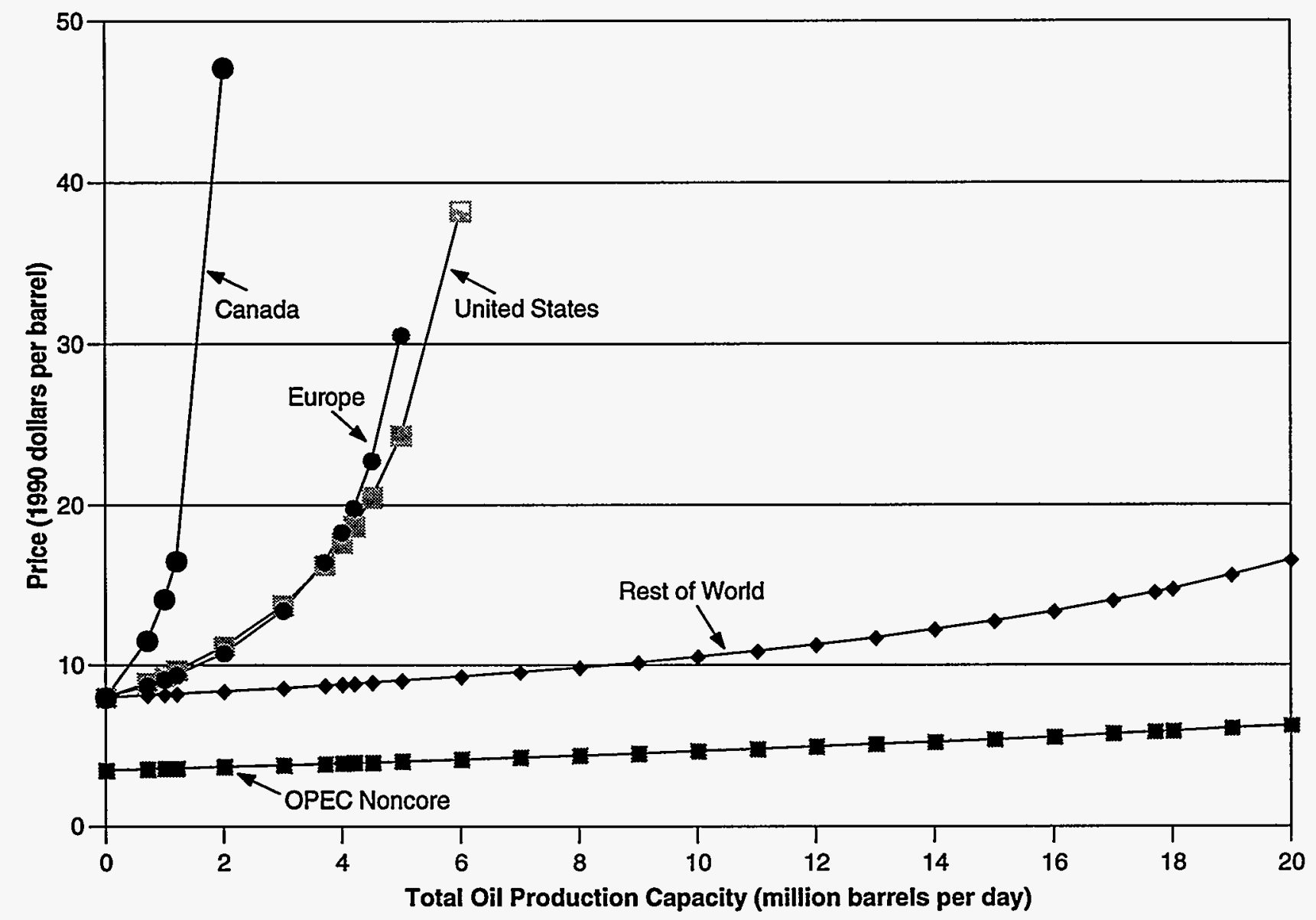

Table III-2 - AFTM Crude Oil Supply Curve Reference Points (quantities in MMBD, prices in 1990\$ per barrel)

\begin{tabular}{|c|c|c|c|c|c|c|c|c|}
\hline \multirow[b]{3}{*}{ Region } & \multicolumn{4}{|c|}{ Reference Price Scenario } & \multicolumn{4}{|c|}{ Low Price Scenario } \\
\hline & \multicolumn{2}{|c|}{ Light Crude } & \multicolumn{2}{|c|}{ Heavy Crude } & \multicolumn{2}{|c|}{ Light Crude } & \multicolumn{2}{|c|}{ Heavy Crude } \\
\hline & Qty. & Price & $\overline{\text { Qty. }}$ & Price & $\overline{\text { Qty. }}$ & Price & Qty. & Price \\
\hline United States & 1.50 & 26.54 & 3.73 & 25.54 & 1.50 & 26.54 & 3.73 & 25.54 \\
\hline Canada & 0.54 & 25.30 & 1.10 & 24.30 & 0.54 & 25.30 & 1.10 & 24.30 \\
\hline Western Europe & 3.04 & 26.17 & 1.19 & 25.17 & 3.04 & 26.17 & 1.19 & 25.17 \\
\hline Japan & - & - & - & - & - & - & - & - \\
\hline $\begin{array}{l}\text { OPEC } \\
\text { Core } \\
\text { Noncore }\end{array}$ & $\begin{array}{r}1.11 \\
12.25\end{array}$ & $\begin{array}{l}25.46 \\
25.46\end{array}$ & $\begin{array}{r}22.63 \\
3.62\end{array}$ & $\begin{array}{l}24.46 \\
24.46\end{array}$ & $\overline{16.86}$ & $\overline{19.46}$ & 33.14 & $\overline{18.46}$ \\
\hline Rest of World & 5.15 & 26.39 & 17.75 & 25.39 & 5.15 & 26.39 & 17.75 & 25.39 \\
\hline
\end{tabular}




\section{Figure III-3 - Wet-Gas Production Capacity Curves for the Main AFTM Demand Regions}

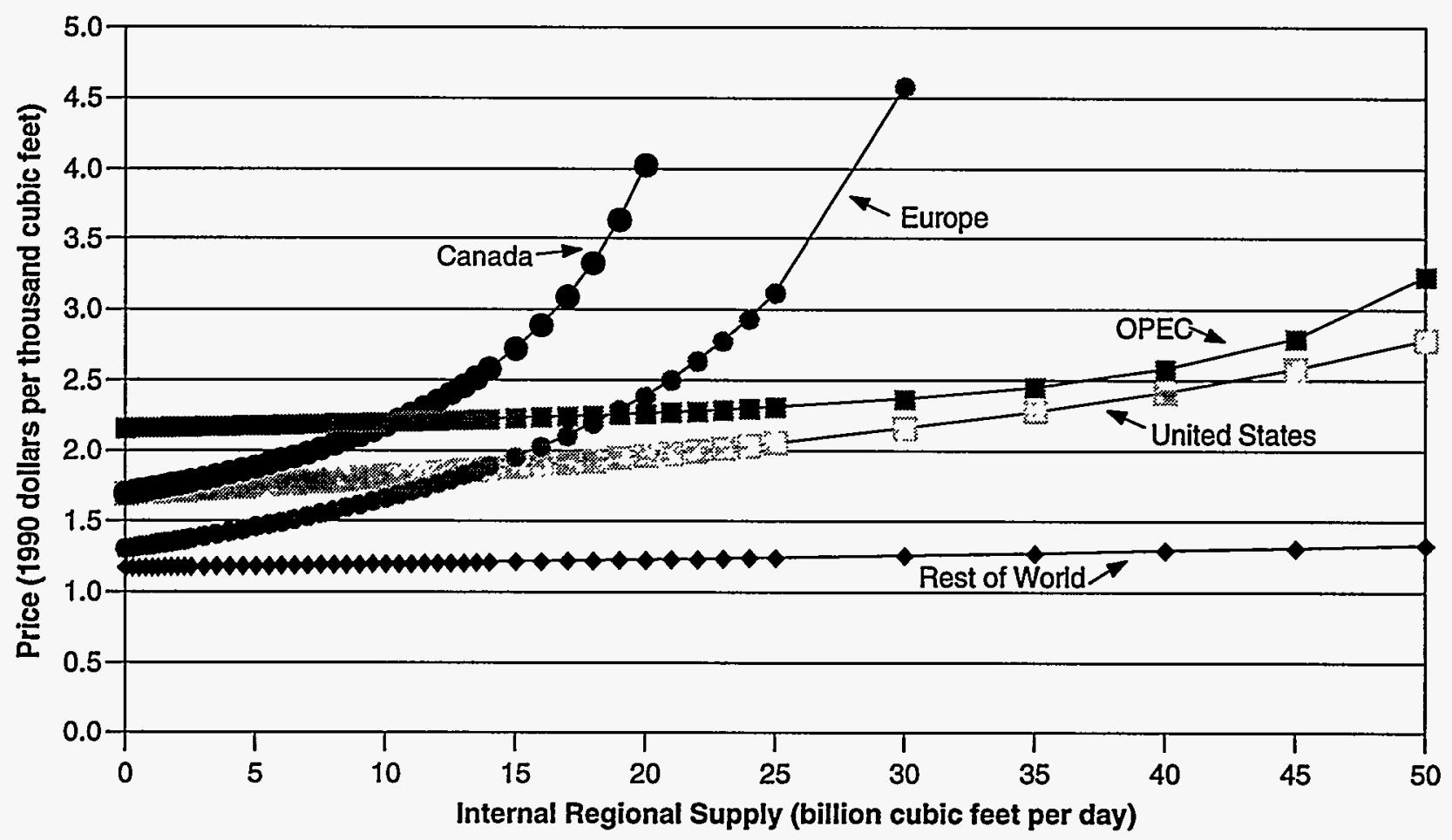

OPEC gas production is constrained in all Reference Oil Price Scenarios (the "monopolistic behavior" scenarios) to be no greater than that in the benchmark case solution (which corresponds to the EIA reference case for 2010). The Low Oil Price Scenarios ("competitive behavior" scenarios) do not impose any constraints on OPEC gas production. Unlike the crude oil production curves, the input gas production curve parameters are not changed; only the utilization of potential gas production is constrained.

Gas supplies in the AFTM main region are supplemented by a series of country-specific undeveloped nonassociated gas supply curves. These "remote" gas source supplies were evaluated in some detail in an earlier report in this series (DOE 1993). Undeveloped gas fields are defined as those in which no production has taken place, nor is any scheduled in the next few years. Estimated undeveloped, nonassociated gas resources are equivalent to about 50 percent of total reported gas reserves in the most promising countries. The undeveloped gas estimates made for the earlier study include many large deposits of natural gas that are uneconomic to develop because of high costs, distance to market, or lack of market. For these reasons, they are referred to as "remote" gas supplies in the AFTM and are linked to potential demand via LNG or methanol conversions. In the United States, these would not be classified as reserves because they do not meet economic criteria. It is unclear to what extent the AFTM estimates of undeveloped gas resources may overlap reserves reported by many countries. The EIA projections used to create gas supply curves for the AFTM's main regions do not include undeveloped nonassociated gas. Thus, the cumulative potential supply from resources in this category supplements gas supply estimates for the main regions.

For nations that are potentially important suppliers of remote gas, the volume and development costs for known nonassociated gas 
discoveries were estimated on a field-by-field basis. As Figure III-4 shows, Russia and a few countries in the Middle East dominate estimated resources in this class. Figure III-4 illustrates the estimated final cost of dry natural gas, after processing and transportation to the producing country's border (the point at which it would be converted to LNG or methanol for export). Although Russia has the largest volumes of undeveloped gas, it is relatively expensive to export. The cost of remote gas supplies was estimated by applying a standard set of investment and project assumptions to a discounted cash-flow model of each discovery's projected production. Countryspecific price-quantity supply curves were then constructed on a dollar-per-mcf-of-wet-gas basis. Some of the resulting remote gas supply curves are shown in Figure III-5. The curves in this figure are the estimated raw gas supply costs. They indicate that a substantial quantity of low-cost gas (before transportation) is avail- able from these sources, particularly in Iran, Qatar, and Russia. Algeria's reported undeveloped gas is relatively limited (the Hassi R'Mel field is excluded from the AFTM remote gas curve because the field is already developed), based on the data used to generate these curves. Although Russia appears to have a tremendous volume of undeveloped low-cost gas, the great distances the gas must be transported render Russian gas more costly than Middle East gas if exported to the United States.

Table III-3 summarizes the reference natural gas supply capacities and prices used in the model. Note that the prices and quantities reflect the full hydrocarbon wellstream, including all natural gas liquids and condensate. A "wet gas" priced at the same amount as a "lean gas" will yield much cheaper pipeline gas (primarily methane) because the high value of liquids extracted will usually act as a subsidy.

Figure III-4 - Volumes and Costs of Remote Gas Discoveries

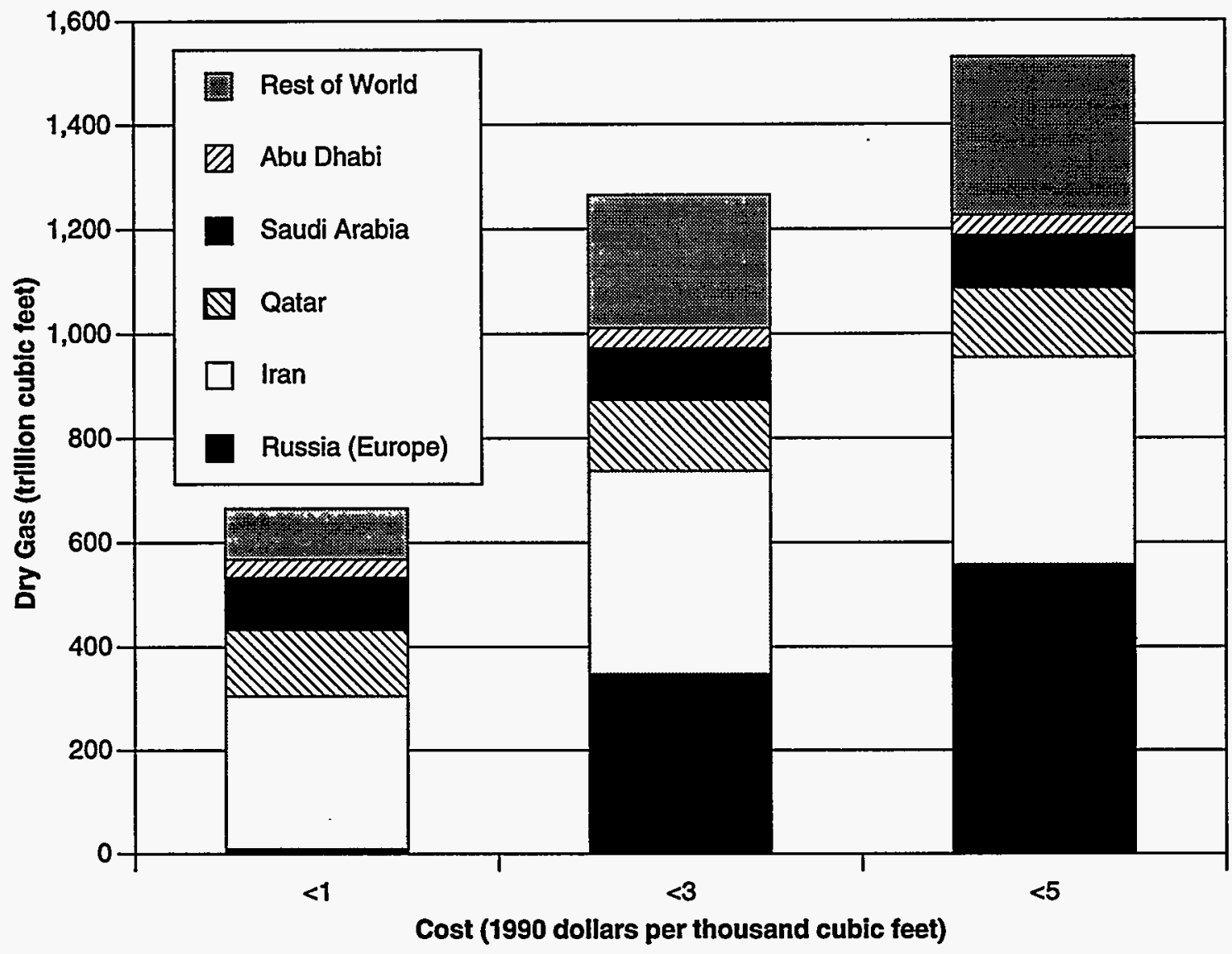


Figure III-5 - Wet-Gas Supply Curves for Remote AFTM Regions

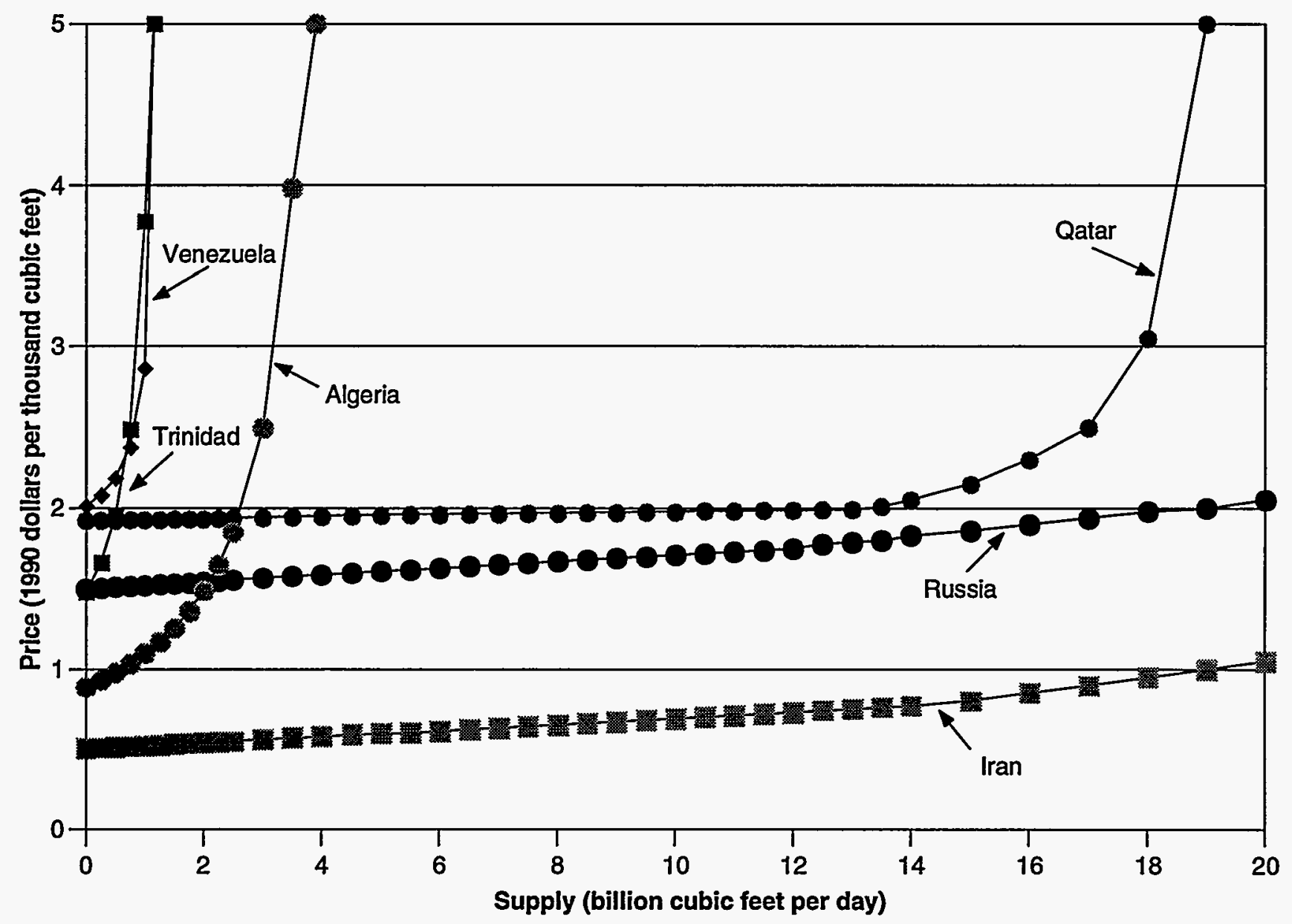

The main region reference points are benchmarked to the Annual Energy Outlook 1994 and International Energy Outlook 1993. The "remote" discovery reference points roughly mark the points on the supply capacity curves at which increased production begins to rapidly increase in costs.

\section{Biomass Feedstock Supply for Ethanol}

A simple variable-elasticity supply curve for grain-ethanol feedstock materials was fit to data on the response of corn supplies, which were nearly linear in price. The estimates were based on published reports and experiments with large agricultural-economic models such as the Agricultural Simulation Model and the Agricultural Resources Interregional Modeling System. The supply curves indicated a rising cost of ethanol supply from corn. The compet- ing uses for corn, corn byproducts, and farmland all contribute to model results that suggest a fairly steep corn feedstock supply curve. As production of feedstock increases from 50,000 to 1 million barrels of ethanol per day, feedstock costs (excluding the oil and gas fuels needed) rise from $\$ 0.49$ to $\$ 1.14$ per gallon ( $\$ 20.58$ to $\$ 47.88$ per barrel).

A similar analysis was performed to estimate a supply curve for cellulosic-based feedstock. The National Renewable Energy Laboratory has worked on improving the ethanol lignocellulosic wood process. The most likely sources of ethanol feedstock in this process are hardwoods with greater than 40 percent cellulose content.

The cost estimates used in the AFTM for ethanol from wood are based on experimental data 


\section{Table III-3 - AFTM Raw Gas Supply Curve Reference Points}

(quantities in Bcf per day, prices in $1990 \$$ per Mcf)

\begin{tabular}{|c|c|c|c|c|c|c|}
\hline \multirow[b]{2}{*}{ Region } & \multicolumn{2}{|c|}{ Wet Gas } & \multicolumn{2}{|c|}{ Lean Gas } & \multicolumn{2}{|c|}{ Dry Gas } \\
\hline & Quantity & Price & Quantity & Price & Quantity & Price \\
\hline United States & - & - & 65.6 & 3.79 & - & - \\
\hline Canada & - & - & 18.1 & 3.35 & - & - \\
\hline Western Europe & - & - & - & - & 26.59 & 3.47 \\
\hline Japan & 一 & - & - & - & - & - \\
\hline \multicolumn{7}{|l|}{ OPEC } \\
\hline Core & 24.80 & 2.57 & - & - & - & - \\
\hline Noncore & 14.89 & 2.57 & 一 & - & - & - \\
\hline Rest of World & - & - & 190.97 & 2.65 & - & - \\
\hline \multicolumn{7}{|l|}{ Remote Areas } \\
\hline Abu Dhabi & 4.837 & 2.49 & - & - & - & - \\
\hline Algeria & 2.13 & 1.56 & - & - & - & 一 \\
\hline Iran & - & - & - & - & 35.50 & 2.49 \\
\hline Indonesia & - & - & 1.93 & 1.56 & - & - \\
\hline Nigeria & 1.53 & 2.49 & - & - & - & 一 \\
\hline Oman & 0.52 & 2.49 & - & - & - & - \\
\hline Russia (Europe) & - & - & - & - & 63.76 & 6.27 \\
\hline Saudi Arabia & 13.09 & 2.49 & - & - & - & - \\
\hline Trinidad & - & - & 0.13 & 1.56 & - & - \\
\hline Venezuela & 0.84 & 2.49 & - & - & - & - \\
\hline
\end{tabular}

extrapolated to a large-scale production plant. Feedstock costs for the ethanol process are referenced at $\$ 0.33$ per gallon $(\$ 13.86$ per barrel) at feedstock demand of 1.1 million barrels per day. At the range of demands being considered by the AFTM, this feedstock cost does not vary significantly. Demand would have to increase to more than 3 million barrels per day before even a 10-percent increase in cost could be projected.

Both ethanol feedstock production capacity curves are illustrated in Figure III-6.

\section{Energy Product Demand}

The AFTM models the final demand for each end-product with downward-sloping constantelasticity demand curves, with the following form:

$$
Q_{d}=Q_{d R e f}\left(\frac{P}{P_{\text {Ref }}}\right)^{e}
$$

Regional demands are specified separately for natural gas (methane), LPG, distillate fuel oils, residual fuel oils, switchable industrial/power generation fuels (residual/gas boiler fuel demand), ethylene, dedicated gasoline vehicles (conventional and reformulated gasoline are input separately), and LDVs free to choose gasoline or alternative motor fuels.

AFTM demand curves for most fuels are specified by a reference point $\left(Q_{d R e f}, P_{\text {Ref }}\right)$ based on EIA forecasts for 2010. With few exceptions, U.S. demand forecasts are taken from the 1994 Annual Energy Outlook 1994, and non-U.S. demand forecasts are taken from the 1993 International Energy Outlook 1993. The solution demand volume and price are determined by the elasticity of demand, $e$. Demand curves for end-use fuels that are not explicitly forecast by EIA (that is, ethylene, boiler, and light-duty motor vehicles) were derived using assumed price elasticities of around -0.3 . 
Figure III-6 - Feedstock Production Capacity Curves for Corn and Wood Ethanol

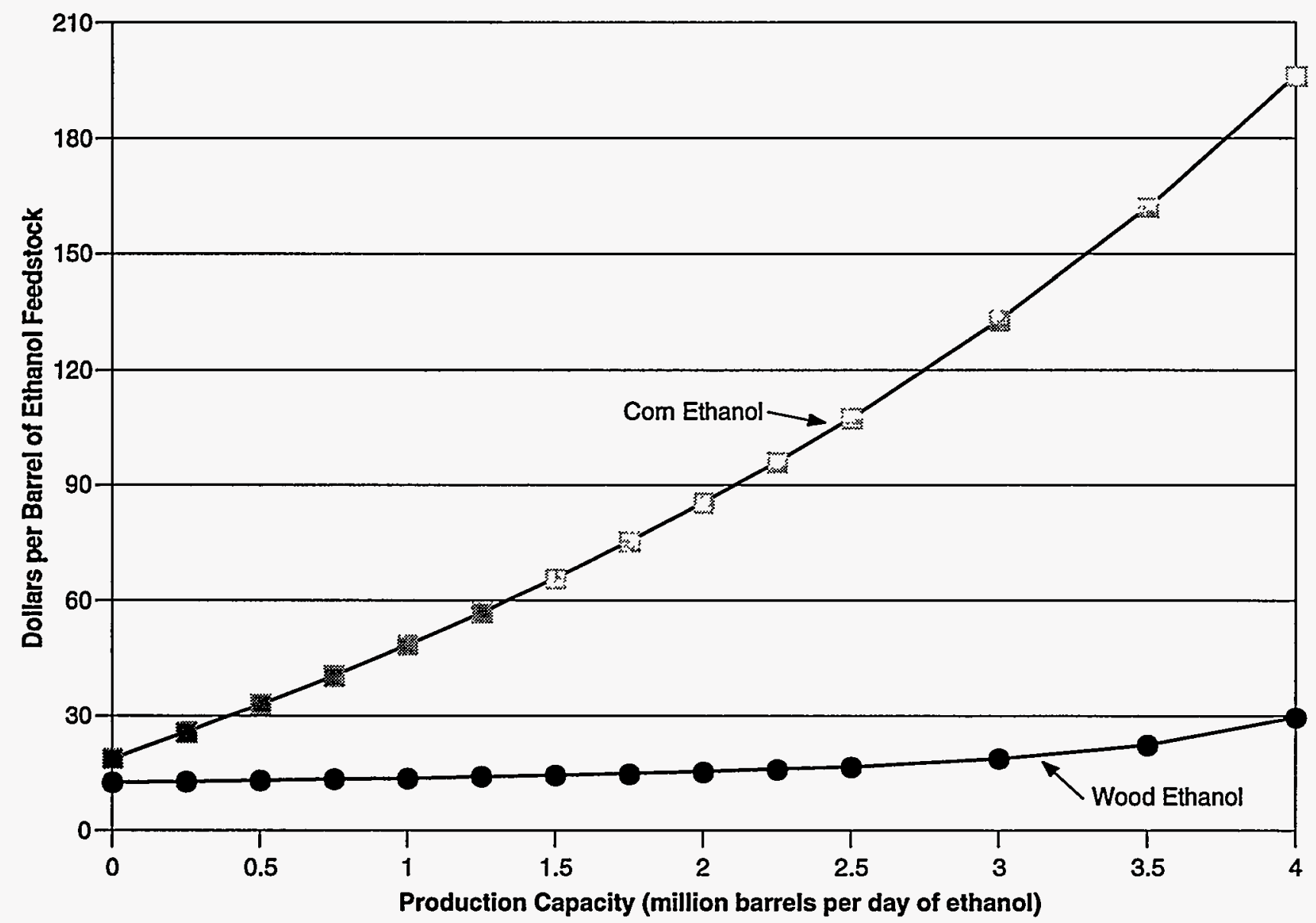

Most fuel-demand curves are a combination of a particular fuel's demand in several market sectors (for example, natural gas demand includes industrial, commercial, residential, and utility uses). In some cases, inputs to the demand curve are a combination of several fuels serving a particular market sector (ethylene manufacturing demand is made up of and met by ethane, LPG, and naphtha feedstocks). The AFTM also creates several endogenous demands as part of conversion process activity. These internal demands occur in two areas: demands for refinery boiler fuel, and demands for gas-processing fuel. Fuel demands in these activities are dependent on the model solution. Refinery boiler-fuel demands are not distinguished from input industrial and powergeneration end-use boiler demand in the solution process. Gas-processing fuel de- mands (including methanol and LNG manufacturing losses) may be met only by natural gas.

End-use fuel demands may be met only by processed fuels (no raw fuel supply is capable of satisfying a model demand curve directly). To satisfy the demand, the model may choose to process a raw fuel or fuels through a combination of several conversion process choices. For example, LPG demand is met by the combined output of several refining conversion processes and several gas-processing conversions. If an end-use fuel demand is actually met by multiple fuels, such as in the case of boiler fuels and light-duty vehicle services, the solution is influenced by the fuel's "sharing cost" (fuel cost and other attributes) function. Boiler fuel demand may be satisfied with either residual fuel oil or natural gas. LDV demand 
may be satisfied with gasoline, RFG, compressed natural gas (CNG), LPG, M85 (a mixture of 85 percent methanol and 15 percent gasoline), E85 (a mixture of 85 percent ethanol and 15 percent gasoline), or electricity.

Reference demand prices were most thoroughly benchmarked in the U.S. region of the AFTM. Outside the United States, prices were based on transportation differentials to the United States or the most likely end-use market (Western Europe or Japan) if appropriate. Figure III-7 illustrates several input demand curves used by the AFTM in determining the solution to U.S. fuel demands. All curves actually have similar elasticities at their respective reference demand points, but the different levels of reference volume and price for each fuel create different demand curves.

\section{Natural Gas Demand}

Every main region of the AFTM has end-use natural gas demand. In the United States, this demand is made up of residential, commercial, industrial, and electric utility demand. Half of the EIA forecast for industrial and electric utility gas demand was separated from the input end-use gas demand and placed in AFTM boiler demand. A similar estimate of the "switchable boiler" fuel portion of forecasted natural gas demand was made for non-U.S. regions as well. Some additional natural gas is consumed in CNG vehicles in the United States. This volume is selected by the AFTM as part of the LDV logit choice function solution.

Figure III-7 - U.S. Energy Demand Curves Used by the AFTM

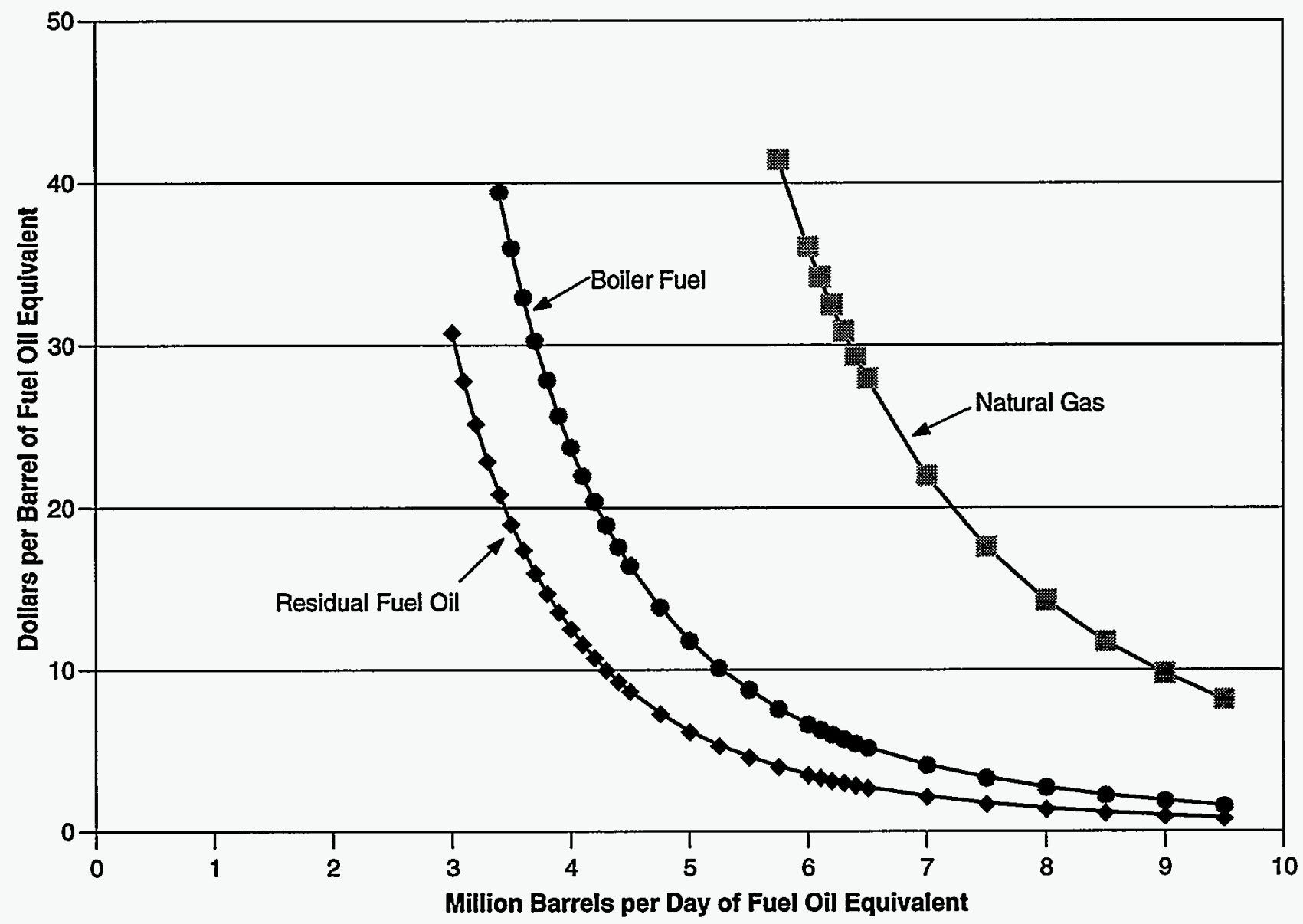


In the solution process, the AFTM estimates the volume of natural gas that is consumed by boiler demand, including refinery fuel. The model also generates natural gas demand as part of total gas processing, methanol manufacturing, and LNG manufacturing and conversions in the solution. In the Reference Oil Price Scenario benchmark case solution, about 1 quadrillion Btu (quad) per year of natural gas is consumed in these processes, over half of which occur in the United States.

Natural gas in the AFTM is derived from processing of raw gas supplies. It may be either supplied directly from a regional gas plant (after distribution markups) or via LNG conversion and transportation.

Table III-4 summarizes the reference end-use natural gas demands included in the AFTM runs performed as part of this analysis. Natural gas consumption in boiler fuels, motor vehicles, and in natural gas processing (including LNG and methanol conversions) is estimated by the AFTM.

\section{LPG Demand}

End-use LPG demand is input to the AFTM for each main region. In the United States, AFTM end-use LPG demand is made up of residential and industrial demands. For Canada, estimated LPG demand was taken from National Energy Board (NEB) forecasts. Outside the United States and Canada, LPG demand was

\section{Table III-4 - AFTM Natural Gas Demand Curve Reference Points}

\begin{tabular}{lcc}
\hline Region & $\begin{array}{c}\text { Quantity } \\
\text { (MMBD }\end{array}$ & $\begin{array}{c}\text { Price } \\
(1990 \$ \text { per } \\
\text { barrel) }\end{array}$ \\
\hline United States & 6.278 & 29.16 \\
Canada & 1.068 & 26.02 \\
Western Europe & 7.308 & 29.16 \\
Japan & 0.922 & 35.45 \\
OPEC & 1.790 & 10.25 \\
Rest of World & 19.208 & 22.87
\end{tabular}

a In the AFTM, a "barrel" of natural gas is defined to be 6.287 MMBtu. estimated from United Nations statistics on world liquid petroleum product consumption (United Nations 1992).

Additional LPG use as petrochemical feedstock is determined by the model's solution for ethylene manufacturing demand. LPG demand in light-duty motor vehicles is also selected by the AFTM.

There is no LPG supply curve input to the AFTM. LPG is produced by refinery conversions of crude oil and as a product of gas processing conversions.

Table III-5 summarizes the reference end-use LPG demands included in every sensitivity run of the AFTM performed as part of this analysis. LPG consumption in motor vehicles and ethylene manufacturing is estimated by the AFTM.

\section{Distillate Fuel Oil Demand}

Distillate demand in the AFTM includes distillate fuel oils, jet fuels, and naphtha. Nontransportation market sectors contributing to distillate demand include residential, commercial, industrial, and electric utilities. Outside the United States, distillate demand also includes diesel and gasoline demand (and is referred to as "light product" demand). Additional distillate use as petrochemical feedstock (as naphtha) is determined by the model's solution for ethylene manufacturing demand.

There is no distillate supply curve input to the AFTM. Distillate is primarily produced by refinery conversions of crude oil with some additional supply from gas-processing conversions.

Table III-6 summarizes the reference end-use distillate and "light product" fuel demands included in the AFTM runs performed as part of this analysis. Distillate consumption in ethylene manufacturing (mainly naphtha) is estimated by the AFTM.

\section{Residual Fuel Oil Demand}

Residual fuel demand in the AFTM includes residual fuel oils, kerosene, petrochemical feedstocks other than ethylene feeds, and miscellaneous other petroleum products classified 
Table III-5 - AFTM LPG Demand Curve Reference Points

\begin{tabular}{lcc}
\hline Region & $\begin{array}{c}\text { Quantity } \\
\left(\text { MMBD }^{\mathrm{a}}\right)\end{array}$ & $\begin{array}{c}\text { Price } \\
(1990 \$ \text { per } \\
\text { barrel) }\end{array}$ \\
\hline United States & 1.740 & 36.57 \\
Canada & 0.157 & 32.77 \\
Western Europe & 1.093 & 35.12 \\
Japan & 1.121 & 34.68 \\
OPEC & 0.546 & 29.81 \\
Rest of World & 2.127 & 31.67 \\
\hline
\end{tabular}

a In the AFTM, a barrel of LPG is defined to be 4.011 MMBtu.

as fuels. Market sectors contributing to residual fuel demand include commercial, industrial, transportation (locomotive and marine diesel), and electric power generation. In the United States, half of the EIA forecast for industrial fuel oil demand and all electric utility fuel oil demand was separated from the input end-use demand for residual oil and placed in AFTM boiler demand. A similar estimate of the "switchable boiler" fuel portion of forecasted demand for residual oil was made for non-U.S. regions as well. The AFTM estimates the volume of residual oil that is consumed by boiler demand, including demand for refinery fuel, in the solution process.

There is no supply curve for residual fuel oil input to the AFTM. Residual fuel oil is primarily produced by refinery conversions of crude oil with some additional supply from gasprocessing conversions.

\section{Ethylene Manufacturing Demand}

Ethylene (and the related olefin products propylene and butylene) is one of the basic petrochemical raw materials, with ethylene manufacturing accounting for more than 30 percent (by weight) of secondary petrochemical feedstock demand today. Ethylene is forecast to rise to 35 percent of petrochemical demand by 2010 . When both methanol and ammonia (which consume mainly natural gas in their manufacture) production are excluded

\section{Table III-6 - AFTM Distillate and Light Product Demand Curve Reference Points}

\begin{tabular}{lcc}
\hline Region & $\begin{array}{c}\text { Quantity } \\
\left(\text { MMBD }^{\mathrm{a}}\right)\end{array}$ & $\begin{array}{c}\text { Price } \\
\text { (1990\$ per } \\
\text { barrel) }\end{array}$ \\
\hline United States & 4.374 & 36.06 \\
Canada & 1.188 & 37.04 \\
Western Europe & 10.637 & 36.76 \\
Japan & 4.396 & 36.76 \\
OPEC & 5.190 & 37.04 \\
Rest of World & 21.640 & 36.70 \\
\hline
\end{tabular}

${ }^{a}$ In the AFTM, a barrel of distillate is defined to be 5.763

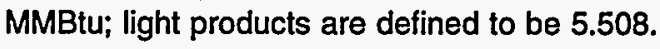

from the sum of petrochemical feedstocks, ethylene manufacturing accounts for more than 45 percent of petrochemical manufacturing. Forecasted 2010 ethylene demand in the AFTM is a composite estimate derived from current worldwide ethylene plant capacities and utilization rates and forecasts of regional growth to 2010 (Oil and Gas Journal 1994).

Ethylene manufacturing inputs are ethane, propane, butane, and naphtha/gasoil. Ethylene demand is incorporated into the AFTM because of its importance as a competing consumer of LPG, which is one of the primary alternative motor fuels included in the AFTM. The AFTM inputs to ethylene manufacture are ethane, LPG, and naphtha. Ethane and LPG are products of gas processing. LPG and naphtha are also available from refineries.

Table III-7 summarizes the reference ethylene demands included in all AFTM runs performed as part of this analysis, with the exception of the High Ethylene Demand sensitivity. For reference, the estimated ethylene manufacturing feedstock mix used to calibrate demand for ethane, LPG, and naphtha is also reported in the table. The AFTM determines the final mix of ethylene feedstocks in its solution process.

\section{Boiler Fuel Demand}

Boiler fuel in the AFTM includes both industrial and electric generation demand as well as 


\section{Table III-7 - AFTM Ethylene Demand Curve Reference Points}

\begin{tabular}{lccrrr}
\hline & Quantity & Price & \multicolumn{3}{c}{ Feedstock (percent) } \\
\cline { 3 - 6 } & (MMBD) & $(1990$ \$ per barrel) & Ethane & LPG & Naphtha \\
\hline United States & 1.210 & 28.49 & 40 & 32 & 28 \\
Canada & 0.137 & 28.49 & 49 & 9 & 42 \\
Western Europe & 1.104 & 28.49 & 19 & 17 & 64 \\
Japan & 0.363 & 28.49 & 0 & 0 & 100 \\
OPEC & 0.221 & 28.49 & 89 & 10 & 1 \\
Rest of World & 0.735 & 28.49 & 19 & 17 & 64 \\
\hline
\end{tabular}

supplemental refinery fuel demands. These "switchable" boiler fuel demands are able to choose between residual fuel oil and natural gas. Total input boiler fuel demand for the United States is about 25 percent of total input natural gas and residual fuel demand. Outside the United States, boiler fuel demand was estimated from a review of OECD fuel consumption data (IEA 1992a, IEA 1992b, IEA 1993). In Europe, Canada, and Japan, potentially switchable fuel demands make up about 20, 18 , and 9 percent, respectively, of total demand for residual fuel oil and natural gas. The OPEC and ROW regions of the AFTM were assumed to have 20 percent switchable boiler fuel demands. Because of a lack of data, the former Soviet Union's boiler fuel demand was excluded from ROW in estimating switchable boiler fuel demand.

Additional boiler fuel demand is generated by the AFTM as part of refinery conversion processes. The model solution determines the volume of "boiler" fuel that is consumed in the solution slate of refinery processes. The Reference Oil Price Scenario benchmark case solution generates about 16 quadrillion Btu per year of worldwide refinery fuel use, about 2.5 quads of which is in the United States.

Table III-8 summarizes the reference end-use "boiler" fuel demands included in the AFTM runs performed as part of this analysis. The Reference Oil Price Scenario benchmark case boiler fuel mix used to calibrate demand for natural gas and residual fuel is also reported in the table. The final mix of gas and residual fuel in boiler use is estimated by the AFTM.

\section{Motor-Vehicle Fuel Demand}

Within the AFTM, final demand for motor-vehicle fuels in the United States is expressed as vehicle service demands, which are based on the Annual Energy Outlook 1994 forecast of fuel usage in 2010. The standard unit of motor-vehicle fuel demand is a barrel of gasoline-service-equivalent (BGSE) - the energy required to provide the same transportation service as a standard light-duty gasoline-powered vehicle. (Vehicle fuel demands are expressed as barrels of gasolineservice-equivalent because different fuels have varying capacities to replace a barrel of gasoline depending on Btu content and combustion efficiencies.) A standard gasoline vehicle is assumed to have an efficiency of 21.3 miles per gallon and travel about 11,400 miles per year. A "BGSE" therefore is roughly equivalent to 895 miles of travel.

LDV demand in 2010 in the Annual Energy Outlook 1994 forecast is 8.1 million barrels of gasoline-service-equivalent per day (MMBGSE/D). In the AFTM, gasoline and alternative-fuel dedicated and multifuel vehicles are assumed to be available to satisfy this motor-vehicle demand.

The number of vehicles and supplies of motor fuels are, effectively, intermediate demands chosen to satisfy the vehicle service demands where consumer preferences influence the distribution of market shares of different vehicles and fuels. Certain segments of the demand for vehicle services have been separated out in the AFTM to allow for greater 
Table III-8 - AFTM Boiler Fuel Demand Curve Reference Points

\begin{tabular}{lcccc}
\hline & Quantity & Price & \multicolumn{2}{c}{ Feedstock (percent) } \\
\cline { 5 - 5 } & (MMBD) & $(1990 \$$ per barrel) & Natural Gas & Residual \\
\hline United States & 3.905 & 25.62 & 90 & 10 \\
Canada & 0.179 & 25.86 & 90 & 10 \\
Western Europe & 1.878 & 28.85 & 57 & 43 \\
Japan & 0.436 & 32.63 & 79 & 21 \\
OPEC & 1.434 & 10.40 & 99 & 1 \\
Rest of World & 3.999 & 27.20 & 90 & 10 \\
\hline
\end{tabular}

Note: In the AFTM a barrel of boiler fuel is defined to be 6.287 MMBtu.

detail in modeling the types of vehicles and fuels used in the LDV service market and to reflect recent national and State legislation regarding vehicle and alternative-fuel mandates.

Motor-vehicle fuel demand is divided into different driving markets to separate the heavyduty and commercial demands from the 8.1 MMBGSE/D of LDV service demands. The competitiveness of AFVs depends in part on the type of gasoline displaced. The AFTM therefore employs two parallel, yet distinct, "regions," designated as the conventional gasoline region and the RFG region. As shown in Figure $1-2$, each motor-vehicle-fuel demand region is expected to satisfy roughly 50 percent of the light-duty vehicle service demand. (A small part of the RFG market is assumed to be penetrated by the AFV fleet mandates.)

Within the conventional gasoline region, at least half of the fleet is limited to conventional gasoline (including gasohol) vehicles. Within the RFG region, at least half the fleet is limited to RFG vehicles. These restrictions take into account the continuing production of conventional-fuel vehicles during the analysis period (under the assumption that total lightduty fleet turnover by 2010 is not possible). Specifically, the analysis assumes that 50 percent of the 2010 light-duty vehicle fleet would be purchased before any new policy to promote alternative fuels could be fully implemented. These dedicated conventionally fueled vehicles are placed outside the vehicle- and fuel-choice logits-that is, the model is not allowed to make a choice of vehicles.

The other 50-percent of light-duty vehicle fuel demand is placed in vehicle- and fuel-choice logits in which the model chooses the vehicle and fuel and their quantities. Here the LDV service demand can be satisfied by combinations of vehicles and fuels, including M85, E85, CNG, LPG, electricity, and (depending on the "region") either conventional gasoline or RFG.

Each choice function is specified multinomial logit to simulate consumer choices (specifically, through an estimate of market share) of several fuels or vehicles. The logit function is described through a series of parameters that describe nonprice attributes of each choice and market share as a function of each choice's price. Fuel and vehicle service demand in the logits may be satisfied by either conventional gasoline vehicles or AFVs-the AFTM makes that choice as part of the optimization calculations.

The selection of vehicles and fuels used to satisfy vehicle service demands is greatly influenced by consumer preferences for vehicle and fuel attributes. The AFTM employs two levels of choice logits in each gasoline region-one for vehicles and one for fuels. In both sets of logits, the market-share distribution of choices is determined by exogenous parameters reflecting consumer prefererices for vehicle and fuels attributes and fuel prices. In the vehicle logit, consumers choose from an 
array of dedicated (single-fuel) and multifuel cars. As the vehicles are chosen, the model selects the types and amounts of fuels that are consumed. The model then chooses the longterm equilibrium solution by determining vehicle and fuel market shares simultaneously. The logits' function and interaction in the model are discussed in greater detail in Appendix $C$.

Figure III-8 illustrates the underlying structural logic used to construct logits that satisfy the LDV service demand with vehicle-fuel combinations in the conventional gasoline region. (The RFG region logic is identical to that shown here.) The ellipses in the diagram reflect logit choices, and the rectangles reflect conversion processes in the AFTM. The demand for vehicle service (variable VALLG in the model) is the input variable driving this choice process. The AFTM chooses vehicles by type and volume of service (measured in BGSE) to be met from all of the dedicated and alternative-fuel vehicles available in the model (taking into account any scenario-specific restrictions on availability of vehicles). The model estimates the amount of vehicle services provided by dedicated vehicles-conversion processes for gasoline-only vehicles

(SI_VGASO), dedicated CNG vehicles

(SI_VCNGDG), dedicated LPG vehicles

(SI_VLPGDG), and electric vehicles

(SI_VELEG) - and by bifuel vehicles: dedicated alcohol vehicles (SI_VALCDG), flexiblefuel alcohol vehicles (SI_VALCFG), bifuel CNG vehicles (SI_VCNGFG), and bifuel LPG vehicles (SI_VLPGFG). A parallel set of conversions adds vehicle capital costs. Bifuel vehicles are involved in another level of logit choice in which consumers decide the percentage breakdown of fuel usage within a vehicle choice. These "nested" fuel-choice logits are part of the alcohol-dedicated vehicle, alcohol flexible-fuel vehicle, CNG bifuel vehicle, and LPG bifuel vehicle choices. The choice of fuel in turn adds to the amounts of total fuels consumed. The bottom row of the diagram contains the set of six motor-vehicle fuels (M85, E85, gasoline, CNG, LPG, and electricity) that may satisfy the demand for fuels initiated by the input demand for motor-vehicle services. Because both the vehicle and the fuel logit choice equations depend on fuel prices, the market-share equations for vehicles and fuels are solved simultaneously.

Table III-9 summarizes the reference U.S. motor-vehicle service demand used in the model benchmark case. The column headings "conventional" and "reformulated" refer to the two gasoline "regions" used in the AFTM to represent U.S. fuel choices. The same reference prices, $\$ 55.87$ per BGSE in the conventional gasoline region and $\$ 59.65$ per BGSE in the RFG region, are used for all motor-vehiclefuel demand curves. The reference prices are taken from the Annual Energy Outlook 1994. Benchmark case quantities are based on the Annual Energy Outlook 1994 and work done by Argonne National Laboratory. The last section in this chapter explains the work done in estimating benchmark case alternative motorfuel demands.

In the AFTM, motor-vehicle fuel demands are set in the benchmark case with a series of constraints on vehicle and fuel choices. These constraints are lifted outside the benchmark case, and the vehicle service demands in the logits VALLG (demand for all vehicles in areas using conventional gasoline) and VALLR (demand for light-duty vehicles in areas using reformulated gasoline) may be satisfied by any motor vehicle or fuel combination. The LPG, CNG, M85, E85, and electricity demands noted in the unconstrained cases are the minimum volumes set in the model. Additional volumes of these alternative fuels may also be selected in the unconstrained cases within the VALLG and VALLR demands.

\section{Fuel-Processing (Conversion) Activities}

The AFTM end-use demand curves are not satisfied directly by raw fuel supplies. All raw fuels must pass through a series of "conversion" processes that refine, process, and distribute fuel supplies into a form suitable for end-use. AFTM conversion processes include activities that physically transform a fuel, such as crude oil refining, LNG liquefaction, and methanol manufacturing. These conversion processes also add costs to the raw fuel supply. Other conversion activities redefine the efficiency or cost of a fuel to the end-user. These are usually conversions that represent the distribution costs of a fuel within a region 


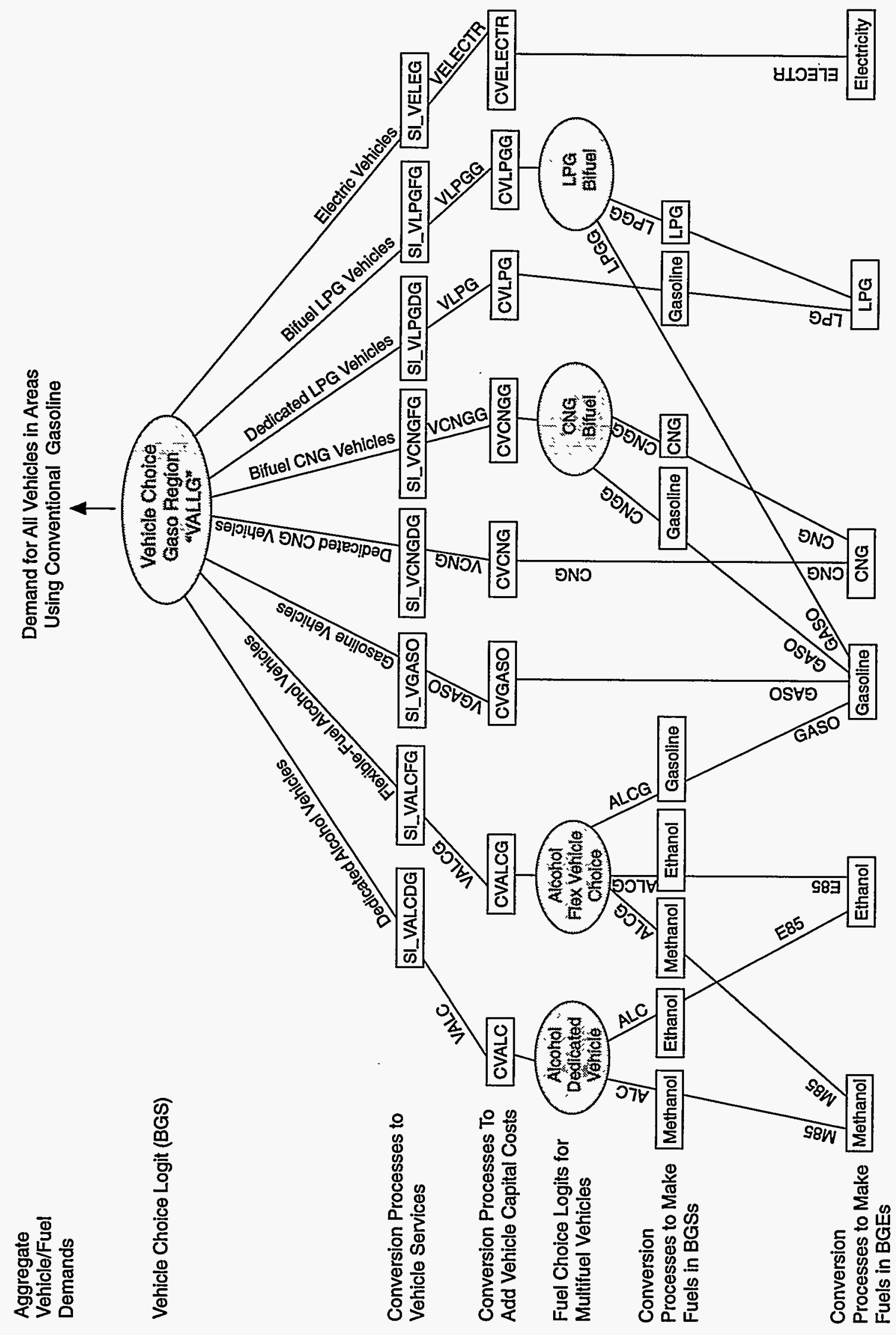




\section{Table III-9 - AFTM Motor-Vehicle Service Demand Curve Reference Points}

(million barrels of gasoline-service-equivalent per day)

\begin{tabular}{lccccc}
\hline & \multicolumn{2}{c}{ Benchmark Case } & & \multicolumn{2}{c}{ Unconstrained Cases } \\
\cline { 2 - 3 } \cline { 5 - 6 } Fuel & Conventional & Reformulated & & Conventional & Reformulated \\
\hline Unconstrained Fuel & & & & & \\
$\quad$ Choice (VALLGNALLR) & - & & & 1.920 & 1.920 \\
Light-Duty Gasoline & 3.840 & 3.840 & & 1.920 & 1.920 \\
Heavy-Duty Gasoline & 0.275 & 0.275 & & 0.275 & 0.275 \\
LPG & 0.015 & 0.015 & & 0.015 & 0.015 \\
CNG & 0.020 & 0.020 & & 0.020 & 0.020 \\
M85 & 0.017 & 0.017 & & 0.017 & 0.017 \\
E85 & 0.012 & 0.012 & & 0.012 & 0.012 \\
Electricity & 0.046 & 0.046 & & 0.046 & 0.046 \\
Gasohol & 0.236 & - & 0.236 & - \\
\hline
\end{tabular}

(for example, the transformation of wholesale LPG to petrochemical or retail LPG use) or describe the capacity of a fuel to fit the final demand curve.

Conversion processes in the AFTM are described as a series of physical input/output quantity ratios and a cost per unit of conversion activity. They are all linear relationships. Each region of the model with raw fuel supply curves contains a suite of conversion activities that allow fuels to be processed into end-use or intermediate fuels capable of satisfying model demands. In the U.S. region, additional conversion processes allow the creation of end-use motor-vehicle-fuel supplies. Conversion activities in the AFTM may be broadly grouped into the following categories: crude oil refining, gas processing, LNG and methanol manufacturing, petrochemicals, fuel distribution, and retail fuel markups.

Figure III-9 is an example of the AFTM's flow of a raw fuel through various conversion processes to its final use in satisfying end-use demands. Wholesale LPG (WLPG) is created in refineries and gas processing plants and is available for use as a fuel in industrial and residential markets (ENDLPG), in ethylene manufacturing (CHEMLPG), and in light-duty vehicles (VLPG).

\section{Crude Oil Refining}

A refinery submodel within the AFTM estimates the costs of producing gasoline and other refinery products. The model is a simplified representation of several refining scenarios developed to bound anticipated real-world refinery conditions. The original basis of the refinery submodel is the large and detailed Oak Ridge National Laboratory Refinery Yield Model (ORNL-RYM).

ORNL-RYM was run to characterize refinery operations at several extreme points. These results were then modified to suit the demands of the AFTM. The refinery submodel can process two crude oils: a composite light-sweet crude and a composite heavy-sour crude. There are three basic refinery configurations, ranging from a simple topping-reforming refinery to a highly complex cracking- coking refinery. For each configuration, several modes of operation are possible to vary the product mix, representing the flexibility refiners have to meet changing market demands. The refinery product mix is represented by LPG, conventional gasoline, RFG, distillate fuel oil (which includes kerosene, jet fuel, and distillate oil), and residual fuel oil (which includes residual fuel and miscellaneous products such as lube oils and waxes). Within the model, boiler fuel 
Figure III-9 - Flow of Raw Fuel to Final End-Use in the Alternative Fuels Trade Model

क

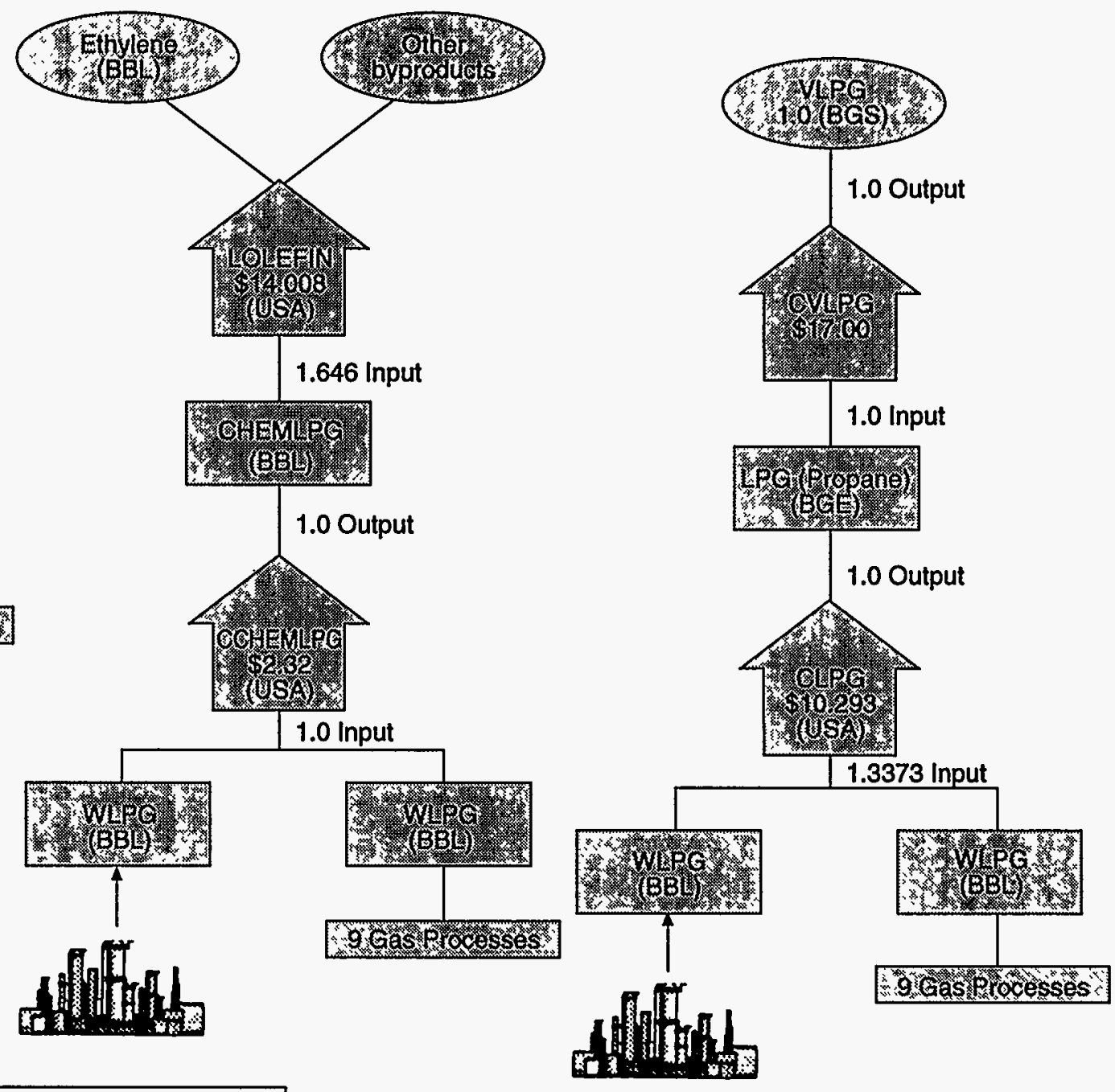

Key

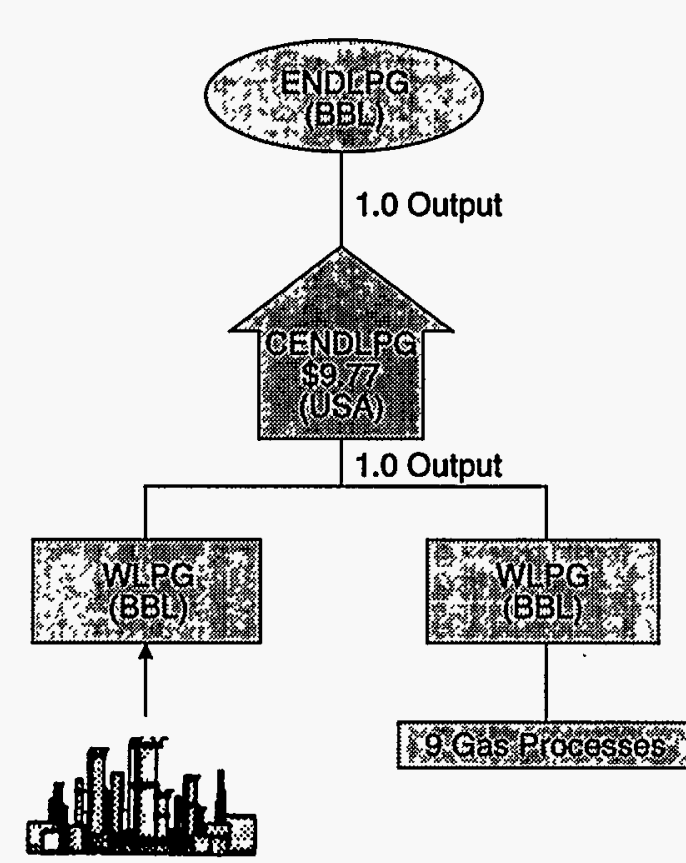

$\$$ Final demand $\cdots$ Conversion 1 process 
and refinery gas are separately tracked to allow extraction of additional LPG from refinery gas when conditions warrant. Demand for methanol associated with RFG production also is tracked.

As demand for different fuels changes within the AFTM, the refinery submodel changes the mix of operations to match the required product slate and determines a processing cost increment for each product. In addition to the LPG commonly produced in refineries, LPG extraction can take place at two levels: extracting LPG from high-pressure (450-pounds-persquare-inch-gauge (psig)) refinery gas sources at a relatively low cost or extracting additional LPG from lower pressure (10-psig) sources at a higher additional processing cost.

Table III-10 summarizes some of the refinery conversion processes most commonly selected by the AFTM. Each conversion process is represented in the model as a series of input and output coefficients and a cost for each unit of conversion activity. Coefficients are related to the units used in the AFTM for each process input and output. Costs include capital and operating costs, excluding fuel use. The same cost is assumed for refinery processes in all regions of the AFTM. Fuel use is input as a volume of input fuel, with its value determined as part of the solution process.

All types of refinery conversions are available in all of the main regions of the AFTM. Of the 60 possible combinations of refinery configuration and input fuel, only a few are selected in the solution to each scenario. Inputs to each refinery conversion are barrels of crude oil. Outputs are physical barrels of liquid refinery products.

\section{Gas Processing}

Three levels of liquids extraction severity are modeled in the AFTM gas processing module:

- Cryogenic extraction (90 percent ethane recovery, 100 percent propane plus recovery)

- Refrigeration (40 percent ethane recovery, 65 percent propane, 85 percent butane, 100 percent pentanes plus recovery)

- Dehydration only ( 0 percent ethane plus recovery)

\section{Table III-10 - AFTM Refinery Conversions for High-Complexity Refineries}

\begin{tabular}{|c|c|c|c|c|c|c|c|c|c|c|}
\hline \multirow[b]{2}{*}{ Process } & \multirow{2}{*}{$\begin{array}{c}\text { Cost } \\
\text { (1990\$ per } \\
\text { barrel of input) }\end{array}$} & \multicolumn{4}{|c|}{ Inputs (MMBD) } & \multicolumn{5}{|c|}{ Outputs (MMBD) } \\
\hline & & $\begin{array}{l}\text { Heavy } \\
\text { Crude }\end{array}$ & $\begin{array}{l}\text { Light } \\
\text { Crude }\end{array}$ & $\begin{array}{l}\text { Boiler } \\
\text { Fuel }\end{array}$ & $\begin{array}{l}\text { Methanol/ } \\
\text { Ethanol }\end{array}$ & LPG & Gaso. & RFG & Distil. & - Resid. \\
\hline \multicolumn{11}{|l|}{ Standard Configuration } \\
\hline Gasoline Maximized & 9.176 & - & 1.00 & 0.101 & - & 0.057 & 0.572 & - & 0.395 & 0.047 \\
\hline Gasoline Maximized & 8.559 & 1.00 & - & 0.119 & - & 0.054 & 0.538 & - & 0.313 & 0.188 \\
\hline RFG Maximized & 9.50 & - & 1.00 & 0.083 & 0.021 & 0.018 & 0.175 & 0.466 & 0.350 & 0.047 \\
\hline RFG Maximized & 8.618 & 1.00 & - & 0.096 & 0.020 & 0.009 & 0.094 & 0.443 & 0.314 & 0.195 \\
\hline Resid Maximized & 8.176 & - & 1.00 & 0.070 & - & 0.036 & 0.364 & - & 0.312 & 0.306 \\
\hline Resid Maximized & 8.735 & 1.00 & - & 0.069 & - & 0.022 & 0.215 & 一 & 0.268 & 0.507 \\
\hline \multicolumn{11}{|l|}{$\begin{array}{l}\text { High-Pressure } \\
\text { LPG Extraction }\end{array}$} \\
\hline Gasoline Maximized & 9.205 & - & 1.00 & 0.113 & 一 & 0.076 & 0.572 & - & 0.395 & 0.047 \\
\hline Gasoline Maximized & 8.585 & 1.00 & - & 0.130 & 一 & 0.070 & 0.538 & - & 0.313 & 0.188 \\
\hline \multicolumn{11}{|l|}{$\begin{array}{l}\text { Low-Pressure } \\
\text { LPG Extraction }\end{array}$} \\
\hline Gasoline Maximized & 9.306 & $\overline{10}$ & 1.00 & 0.131 & 一 & 0.104 & 0.572 & - & 0.395 & 0.047 \\
\hline Gasoline Maximized & 8.674 & 1.00 & - & 0.145 & - & 0.095 & 0.538 & - & 0.313 & 0.188 \\
\hline
\end{tabular}


In all gas-processing choices, full recovery of field condensates is assumed. For use in the AFTM, a matrix of NGL and condensate recovery is input, representing each combination of process type of raw gas. Propane and butane recoveries are combined into LPG. Fuel use is assumed to be all methane and is accounted for in the model as reduced output of dry natural gas from the conversion processes. The input to each gas-processing conversion is raw gas (measured in bcf per day). Outputs are physical barrels of liquid NGL products (ethane, LPG, distillates, and light crude) and natural gas (dry gas suitable for end-use). Natural gas output is measured as barrels of residual-fuel-oil-equivalent, at 6.287 million British thermal units (MMBtu) per unit. Ethane and other NGLs not recovered during processing are counted as natural gas output. Outputs are measured in millions of barrels per day.

Table III-11 summarizes the gas-processing conversions available for selection by the AFTM. Processing costs are assumed to be the same in the United States, Canada, and Europe. Costs in OPEC and ROW are 40 percent greater. Gas processing is also provided in the remote gas supply regions, at the same cost as OPEC and ROW. A more detailed tabulation of assumptions regarding extraction of liquids is contained in Appendix A.

\section{LNG, Methanol, and Ethanol Manufacturing}

The parameters used in LNG and methanol conversion processes are based on a prior report in this series (DOE 1989). That study considered the capital costs, operating costs, and feedstock requirements of methanol and LNG facilities in some detail. While the operating parameters of such facilities were estimated to vary with plant scale and design, only one set of conversion input-output coefficients was used for each process in the AFTM. A large-scale plant in a representative area was chosen to estimate the fuel conversion parameters. (For methanol, the study employed an advance scheme technology to produce fuelgrade methanol from natural gas, at 10,000 metric tons per day, with a 20-percent fixed charge rate. Methanol production with smaller scale plants of 2,500 metric tons per day would have capital and other variable costs, excluding fuel and feedstock, of as much as 70 percent higher, depending on the region and technology.) Because costs will vary substantially by plant location (with some remote foreign locations being far more expensive), a separate set of conversion cost parameters is used for each region. Across regions, capital and operating costs of methanol production (excluding feedstock and fuel costs) are estimated to vary by about a factor of two.

\section{Table III-11 - AFTM Gas-Processing Conversions}

\begin{tabular}{|c|c|c|c|c|c|c|c|}
\hline \multirow[b]{2}{*}{ Process } & \multirow{2}{*}{$\begin{array}{c}\text { U.S. } \\
\text { Cost } \\
\text { (1990 } \$ / M c f \\
\text { of input) }\end{array}$} & \multirow{2}{*}{$\begin{array}{c}\text { Input } \\
\text { Raw } \\
\text { Gas } \\
\text { (bcf per day) }\end{array}$} & \multicolumn{5}{|c|}{ Output (MMBD) } \\
\hline & & & $\begin{array}{c}\text { Natural } \\
\text { Gas }\end{array}$ & Ethane & LPG & Distil. & $\begin{array}{l}\text { Crude } \\
\text { Light }\end{array}$ \\
\hline \multicolumn{8}{|c|}{ Cryogenic Processing } \\
\hline Wet Gas Input & 0.1134 & 1.00 & 0.1303 & 0.0429 & 0.0382 & 0.0135 & 0.0150 \\
\hline Lean Gas Input & 0.0931 & 1.00 & 0.1413 & 0.0200 & 0.0178 & 0.0063 & 0.0070 \\
\hline Dry Gas Input & 0.0931 & 1.00 & 0.1454 & 0.0114 & 0.0102 & 0.0036 & 0.0040 \\
\hline \multicolumn{8}{|c|}{ Refrigeration Processing } \\
\hline Wet Gas Input & 0.0854 & 1.00 & 0.1503 & 0.0191 & 0.0277 & 0.0135 & 0.0150 \\
\hline Lean Gas Input & 0.070 & 1.00 & 0.1523 & 0.0089 & 0.0129 & 0.0063 & 0.0070 \\
\hline Dry Gas Input & 0.070 & 1.00 & 0.1531 & 0.0051 & 0.0074 & 0.0036 & 0.0040 \\
\hline \multicolumn{8}{|l|}{ Dehydration Only } \\
\hline Wet Gas Input & 0.014 & 1.00 & 0.1913 & - & 一 & - & 0.0150 \\
\hline Lean Gas Input & 0.014 & 1.00 & 0.1730 & - & - & - & 0.0070 \\
\hline Dry Gas Input & 0.014 & 1.00 & 0.1661 & - & 一 & - & 0.0040 \\
\hline
\end{tabular}


Fuel use in these conversions is assumed to be all natural gas and is taken care of in the AFTM's accounting of physical input and output for each process. In the case of LNG, an additional 10-percent loss of product is assumed as part of the transportation and liquefaction/ regasification processes. One of the few constraints placed on the AFTM solution process is LNG regasification in the United States, which is limited to constrain U.S. LNG imports.

Ethanol conversion cost estimates and inputoutput parameters for the grain-to-ethanol and wood-to-ethanol processes were constructed. The conversion parameters track feedstock use and the consumption of oil- or gas-based fuels during crop shipment and conversion. For every Btu of ethanol from corn, 0.14 Btu of natural gas and $0.06 \mathrm{Btu}$ of distillate oil are used. Coal is the principal energy fuel used, but it is not explicitly tracked by the AFTM. Rather, coal use is included as a per-unit conversion cost. A similar conversion is made for ethanol manufactured from wood feedstocks.

Tables III-12 and III-13 summarize LNG manufacturing conversions in the AFTM for the six main regions. LNG conversion processes are available in all gas supply regions, including the remote gas supply areas. LNG regasification is available only in the main consuming regions.

Tables III-14 and III-15 summarize the methanol and ethanol manufacturing conversions in the AFTM for the six main regions. Methanol conversion processes are available in all gas supply regions, including the remote gas supply areas, but ethanol conversions are available only in the United States. The ethanol feedstock volume input is measured in barrels of ethanol output (that is, the grain or cellulosic biomass feedstock supply sufficient to create 1 barrel of ethanol).

\section{Petrochemicals}

As mentioned earlier, olefin manufacturing is represented in the AFTM because of its importance as a competing demand for LPG. Specifically, ethylene manufacturing is included in the model with a choice of three feedstocks: ethane, LPG, or naphtha/gasoil. The AFTM requires intermediate conversion of these feed-

\section{Table III-12 - AFTM LNG Conversions for All Regions \\ (MMBD)}

\begin{tabular}{ccccc}
\hline \multicolumn{2}{c}{ LNG } & & \multicolumn{2}{c}{ LNG } \\
Liquefaction & & \multicolumn{2}{c}{ Regasification } \\
\cline { 5 - 6 } $\begin{array}{c}\text { Input } \\
\text { (natural gas) }\end{array}$ & $\begin{array}{c}\text { Output } \\
\text { (LNG) }\end{array}$ & & $\begin{array}{c}\text { Input } \\
\text { (LNG) }\end{array}$ & $\begin{array}{c}\text { Output } \\
\text { (natural gas) }\end{array}$ \\
\hline 1.10 & 1.00 & & 1.00 & 1.00 \\
\hline
\end{tabular}

Note: In the AFTM, a barrel of natural gas is defined to be 6.287 MMBiu.

\section{Table III-13 - AFTM LNG Conversion Costs (1990\$ per barrel of LNG)}

\begin{tabular}{lcc}
\hline Region & Liquefaction & Regasification \\
\hline United States & 9.10 & 3.30 \\
Canada & 11.20 & 3.30 \\
Western Europe & 9.10 & 3.30 \\
Japan & - & 3.30 \\
OPEC & 11.20 & - \\
Rest of World & 11.20 & - \\
\hline
\end{tabular}

stocks before use in ethylene conversions. Ethane and LPG must be transported from their sources in gas processing. Naphtha is separated from the distillate fuel stream in the AFTM, and an accounting is made for its lower Btu content per barrel.

The ethylene manufacturing process yields a variety of petrochemical outputs in addition to ethylene: propylene, butylene, butadiene, benzene, toluene, xylene, fuel oil, hydrogen, and methane. For the purposes of the AFTM, these coproducts have been grouped into ejther "gasoline" or "residual" outputs. A more detailed tabulation of processing assumptions is contained in Appendix A.

No constraints have been placed on the choices of ethylene manufacturing made by the model in its solution on the assumption that turnover of existing petrochemical plant stock will be sufficient to meet any projected 
Table III-14 - AFTM Methanol/Ethanol Manufacturing Conversions

for All Regions (MMBD)

\begin{tabular}{|c|c|c|c|c|c|}
\hline \multicolumn{2}{|c|}{ Methanol } & \multicolumn{4}{|c|}{ Ethanol } \\
\hline $\begin{array}{l}\text { Input } \\
\text { (natural gas) }\end{array}$ & $\begin{array}{c}\text { Output } \\
\text { (methanol) }\end{array}$ & $\begin{array}{l}\text { Input } \\
\text { (wood) }\end{array}$ & $\begin{array}{c}\text { Input } \\
\text { (natural gas) }\end{array}$ & $\begin{array}{c}\text { Input } \\
\text { (distillate) }\end{array}$ & $\begin{array}{c}\text { Output } \\
\text { (ethanol) }\end{array}$ \\
\hline 0.60 & 1.00 & 1.00 & 0.0163 & 0.0446 & 1.00 \\
\hline
\end{tabular}

Note: In the AFTM, a barrel of methanol is defined to contain 2.626 MMBtu. A barrel of ethanol is defined to contain 3.536 MMBtu.

\section{Table Ill-15 - AFTM Methanol/Ethanol Manufacturing Conversion Costs (1990\$ per barrel of output)}

\begin{tabular}{lccc}
\hline Region & Methanol & Ethanol from Grain & Ethanol from Wood \\
\hline United States & 7.90 & 3.54 & 25.06 \\
Canada & 7.90 & - & - \\
Western Europe & 7.90 & - & - \\
Japan & 7.90 & - & - \\
OPEC & 11.20 & - & - \\
Rest of World & 11.20 & - & \\
\hline
\end{tabular}

changes in feedstocks. In the short run, the complex evaluation of feedstock choice is influenced by the existing capital stock of plants and seasonal variations in feedstock costs. In the AFTM, the various conversions representing feedstock transportation markups, and ethylene plant costs have been modeled in an effort to depict long-run product spreads seen in ethylene manufacturing. As in the real world, AFTM scenarios that find ethane extraction and ethylene manufacturing margins too low will place ethane back into the natural gas supply and, instead, use LPG or naphtha for ethylene manufacture.

Table III-16 summarizes ethylene manufacturing conversions available for selection by the AFTM. Costs are assumed to be the same in all regions.

\section{Fuel Distribution and Retail Markups}

Movement of fuel products to their end-use demand within AFTM regions is modeled with several distribution and retail outlet markups. In most cases, these "conversions" are merely an additional cost.

The greatest distribution markup cost in the AFTM is the conversion from gas-plant tailgate to end-use (burner tip) gas. These costs in the U.S. region are based on the Annual Energy Outlook 1994 forecasted price differential from pipeline wellhead delivery price to industrial end-use. An additional retail outlet cost is added if the gas is to be used as a source of CNG for motor vehicles. Similar distribution costs are added for petrochemical demand for LPG, distillate fuel, and boiler fuelș. Distribution markups for industrial end-uses of distillate and residual fuel are included in the refinery module costs.

Motor-vehicle fuels must bear the cost of distribution, retail outlet markups, and special taxes applied to road use. To model the higher cost of gasoline reformulation not fully captured in the AFTM's refinery module, RFG is assigned 
Table III-16 - AFTM Ethylene Manufacturing Conversions

\begin{tabular}{lcccccc}
\hline & \multirow{2}{*}{$\begin{array}{c}\text { Cost } \\
\text { (1990\$ per }\end{array}$} & & \multicolumn{3}{c}{ Output (MMBD) } \\
\cline { 5 - 6 } Feedstock & barrel output) & $\begin{array}{c}\text { Input } \\
\text { (MMBD) }\end{array}$ & Ethylene & Gasoline & $\begin{array}{c}\text { Residual } \\
\text { Fuel }\end{array}$ \\
\hline Ethane & 11.04 & 1.250 & 1.000 & 0.014 & 0.070 \\
LPG & 14.01 & 1.646 & 1.000 & 0.027 & 0.658 \\
Naphtha/Gasoil & 16.13 & 1.996 & 1.000 & 0.488 & 1.136 \\
\hline
\end{tabular}

a somewhat higher markup than conventional gasoline.

Distribution markups for M85, E85, and LPG are based on estimates from EA Engineering (EA Engineering, Science and Technology, Inc. 1993). Distribution data for CNG and electricity used as a motor fuel are taken from the Annual Energy Outlook 1994 using the change in price from producer to end-user. Energy and Environmental Analysis, Inc. (EEA), provided retail markups for M85, E85, LPG, and CNG (EEA 1994). The gasoline retail markup is calculated from the Annual Energy Outlook 1994 end-user price for gasoline and a plantgate price from ElA's Petroleum Marketing Annual 1993. The gasohol markup is calculated as a weighted average of gasoline and ethanol. Table III-17 summarizes the distribution and retail markups used in AFTM for the hydrocarbon vehicle fuels.

The AFTM is also structured to account for motor-fuel taxes. The total tax for each fuel consists of a weighted State average and a Federal tax at spring 1994 levels. All hydrocar- bon fuels in the model are taxed at the same rate as gasoline on a Btu-equivalent basis. The AFTM offers the flexibility of changing the motor-fuel tax assumptions for a sensitivity scenario that reflects the current motor-fuel taxes for the different fuels as of spring 1994. Again, these taxes reflect a Federal component and a weighted average of State taxes. A more detailed explanation of the motor-fuel taxes is contained in Section IV. Table III-18 presents the two tax scenarios used in the analysis: the equal-tax case (on a Btuequivalency basis), and the existing (circa 1994) motor-vehicle fuel tax structure case.

\section{Motor-Vehicle Fuel Consumption}

The energy content of a barrel of gasoline is 5.253 MMBtu. In the AFTM, this energy content is referred to as a barrel of gasolineequivalent, or BGE. LPG, CNG, M85, and E85 fuels are brought to a common unit of measurement by a "conversion" that creates a unit of fuel equivalent to a BGE (5.253 MMBtu). The unit of electricity production in the AFTM is $1.00 \mathrm{MMBtu}$ and is not converted to BGEs.

Table III-17 - Distribution and Retail Motor-Fuel Markups

(1990\$ per barrel of gasoline-equivalent)

\begin{tabular}{lccccccc}
\hline & $\begin{array}{c}\text { Conventional } \\
\text { Gasoline }\end{array}$ & $\begin{array}{c}\text { Reformulated } \\
\text { Gasoline }\end{array}$ & M85 & E85 & CNG & LPG & Gasohol \\
\hline Distribution & 1.26 & 1.26 & 2.19 & 1.98 & 7.73 & 3.58 & 1.30 \\
Retail & 3.44 & 5.23 & 5.19 & 5.00 & 17.05 & 5.17 & 3.56 \\
Total Markup & 4.70 & 6.48 & 7.38 & 6.98 & 24.78 & 8.75 & 4.86 \\
\hline
\end{tabular}

Note: Columns may not add to totals because of rounding. 
Table III-18 - Motor-Fuel Taxes

(1990\$ per barrel of gasoline-equivalent)

\begin{tabular}{lccccccc}
\hline Case & $\begin{array}{c}\text { Conventional } \\
\text { Gasoline }\end{array}$ & $\begin{array}{c}\text { Reformulated } \\
\text { Gasoline }\end{array}$ & M85 & E85 & CNG & LPG & Gasohol \\
\hline Equal Tax & 13.90 & 13.90 & 13.90 & 13.90 & 13.90 & 13.90 & 13.90 \\
Existing Tax & 13.90 & 13.90 & 19.70 & -5.45 & 8.60 & 16.63 & 9.84 \\
\hline
\end{tabular}

Note: 1 barrel of gasoline-equivalent $=5.253 \mathrm{MMBtu}$.

An average gasoline vehicle is assumed to consume about 12.7 barrels of gasoline per year. Taking into account differences in thermal efficiency, the amount of any alternative fuel needed to displace a barrel of gasoline is referred to as a barrel of gasoline-serviceequivalent, or BGSE. LPG and CNG use in dedicated LPG or CNG vehicles is assumed to require $1 \mathrm{BGE}$ to provide $1 \mathrm{BGSE}$. LPG and CNG use in dedicated LPG or CNG vehicles is assumed to require $1 \mathrm{BGE}$ to provide $1 \mathrm{BGSE}$. That is, no efficiency improvement or loss is assumed. Bifuel vehicles capable of using gasoline as well as LPG are assumed to have only 98 percent of the efficiency of a comparable conventional gasoline vehicle. Similarly, bifuel CNG vehicles are assumed to have only 97 percent of the efficiency of a conventional gasoline vehicle. The efficiency losses in the bifuel vehicles are assumed to be due mainly to the increased weight of the bifuel systems. In the case of alcohol fuels (M85 and E85), the conversion to BGSE is made to account for increased efficiency of an engine tuned to run on alcohol fuel. If used in a dedicated alcohol vehicle, an efficiency improvement of 5 percent is assumed-it takes 0.95 BGE of M85 or E85 to produce a BGSE. If used in a flexiblefuel vehicle, an efficiency improvement of 1 percent is assumed.

Electric vehicles are assumed to have a much larger efficiency improvement. In the AFTM, the electric power required to provide a BGSE is $358 \mathrm{kWh}$ (1.224 MMBtu). This is based on an overall efficiency of 2.5 miles per $\mathrm{kWh}$. Fuel production for electric vehicles is not modeled as rigorously. To calculate electricity prices in the year 2010, the AFTM adds average capital, operating, and transmission costs of $\$ 0.0457$ per $\mathrm{kWh}$ (or $\$ 16.36$ per BGSE), based on an analysis of electric power generating mixes and estimated costs of those plants operating with coal. An additional boiler fuel input is made to represent fuel costs for those plants that use natural gas or residual fuel (similar to the conversion process assumptions made in ethanol manufacturing). The sum of these weighted costs yields a final electricity price of about $\$ 0.071$ per kWh (EIA 1994b).

The choice of motor vehicle and vehicle fuel is explained in more detail in the previous subsection on motor-vehicle demand and in the Appendix $\mathrm{C}$ description of the logit choice functions.

\section{Motor-Vehicle Capital Costs}

In the AFTM solution process, total vehicle capital costs are determined based on the demand level for vehicle services in each vehicle choice. Fixed costs of the AFV fleet are included in the AFTM energy system calculations as added markup terms to the cost of supplying a unit of BGSE with something other than a conventional gasoline vehicle (assumed to be the vehicle with the least costly capital investment requirement). The costs considered by the AFTM are estimated incremental initial purchase costs of an AFV. Table III-19 summarizes the incremental costs for nongasoline vehicles used in the AFTM runs prepared for this report.

\section{Transportation Costs}

Although each AFTM region comprises at least one entire country, for the purpose of transportation analysis each region is treated as a single point. This practical simplification 


\section{Table III-19-Alternative-Fuel Vehicle Incremental Capital Cost}

(1990\$ per AFV)

\begin{tabular}{ccccccc}
\hline M85/E85/Gasoline & M85/E85 & CNG/Gasoline & LPG/Gasoline & CNG & LPG & Gasohol \\
\hline 100 & 0 & 817 & 625 & 451 & 171 & 0 \\
\hline
\end{tabular}

Note: Total alternative-fuel vehicles (AFV) cost in objective function = (AFVPERBGD) (Capital charge rate) (Total fuel demand). AFVPERBGD = number of vehicles required to provide 1 barrel per day of gasoline-service-equivalent, given average gasoline use per vehicle of 534 gallons per year, 11,400 miles per year per vehicle, and 21.3 miles per gallon (that is, 28.7 vehicles per BGSE per day). Capital charge rate $=0.168$.

Total fuel demand = daily light-duty vehicle (LDV) demand for each vehicle type (total LDV demand is 8.1 MMBGSE/D in the benchmark case).

means, for example, that there are no transportation costs for trade between member countries of the large ROW region. However, the AFTM does distinguish between "wholesale" fuel prices at ports, wellheads, or plantgates and "retail" prices for final products after distribution to the consumer. (The average costs of transportation and distribution of motor fuels are reflected in a special markup process that adds to the cost of wholesale fuels.) Thus some intraregion transportation costs are accounted for, while each region is treated as a single demand market.

Transportation links are defined between the principal expected trading partners. All feasible transportation activities, with few exceptions, have no upper limits. It is assumed that in the 2010 long-run equilibrium, sufficient tanker, pipeline, and terminal capacity would be built to allow unrestricted fuel shipments in situations where it is cost-effective. One exception is the U.S. importation of LNG. Model assumptions limit U.S. LNG imports to 1.1 trillion cubic feet per year. ${ }^{1}$ This constraint reflects the base assumption (for the purposes of this study ${ }^{2}$ )

\footnotetext{
1 As a technical matter, it was simpler to implement the U.S. LNG import constraint as a limit on U.S. regasification of LNG. This yields the same material balances as a joint constraint on the sum of all LNG shipments to the U.S. It also implies that the potential benefits of access to the limited foreign LNG are gained by U.S. terminal and regasification facility owners, not LNG shippers.

2 The National Petroleum Council's 1992 natural gas study, The Potential for Natural Gas in the United States, makes a similar assumption regarding prospective LNG imports.
}

that a significant expansion in U.S. LNG imports is unlikely by 2010 , given the difficulties in siting LNG terminal facilities.

Explicit gas pipeline links are modeled between the United States and Canada, Europe and OPEC (Algeria), and Europe and ROW (Russia). No upper limit is placed on U.S. Canada gas trade, although the benchmark case solution yields a volume equal to the $A n-$ nual Energy Outlook 1994 forecast for U.S. gas imports in 2010. The upper bound on direct gas trade (via pipeline) between Europe and OPEC is three times the 1993 capacity of the Trans-Mediterranean pipeline. The upper bound on direct gas trade (via pipeline) between Europe and ROW is three times the 1993 capacity of the Russia-Uzhgorod pipeline. A trading link with costs based on pipeline tariffs is also available for ethane movement from Canada to the United States.

Crude oil and petroleum products trade is possible between OPEC or ROW and the four main demand regions (United States, Canada, Japan, and Western Europe). Petroleum can be traded as crude oil, LPG, distillate fuel, gasoline, or residual fuel oil. OPEC, ROW, and the remote foreign gas regions can export LNG to the United States, Japan, or Western Europe. Methanol trade between these gas supply regions and the United States is modeled as well.

The estimated costs of transportation are fixed on a per-unit basis. They are calculated based on the transportation mode and the shipping 
distance. Oil and gas trade between the United States and Canada is by pipeline. Petroleum product trade requires special tankers and is at least twice as expensive as crude shipping. LNG and methanol transport costs are based on a detailed analysis of the capital and operating costs of the associated tankers, and they reflect bunker fuel costs and the mileage between the closest major port cities.

\section{Utilization Costs}

The final cost considered by the AFTM in its optimization is the fuel-switching cost that may be incurred in markets where fuel substitution is possible. This cost is characterized as a "sharing," or "utilization," cost described by a series of logit functions. AFTM considers the opportunities for fuel substitution through vehicle type choice, fuel choice by flexible-fuel vehicles, and fuel choice in industrial or utility boilers. In each substitutable market, two or more close substitute goods compete for market share. The substitutable goods are combined to satisfy demand for a composite good. The substitutable markets are the following:

- Industrial and Utility Boilers: Natural Gas versus Residual Fuel Oil

- Passenger Motor Vehicles: Gasoline Vehicles versus Flexible-Fuel Vehicles versus Alternative-Fuel Vehicles

- Alcohol Flexible-Fuel Vehicles: Methanol (M85) versus Ethanol (E85) versus Gasoline

- CNG Flexible-Fuel Vehicles: Compressed Natural Gas versus Gasoline

- LPG Flexible-Fuel Vehicles: Propane versus Gasoline

- Alcohol-Dedicated Vehicles: Methanol (M85) versus Ethanol (E85)

Substitution between oil and gas in the industrial and utility boiler market establishes an important connection between the prices of petroleum products and gas-based products. The degree of switching by flexible-fuel vehicles determines the market penetration and success of specific alternative fuels. For substitutable-fuel markets, a logit function re- lates the market share of one fuel to its price advantage over the others. The logit function follows the commonly used "S-shaped" curve for market penetration (shown in Figure III-10), where small changes in the price advantage lead to only small changes in market shares. The logit model avoids the "penny-switching" assumption that is otherwise inherent in leastcost linear programming. Furthermore, the logit-derived market share is consistent with the aggregate outcome of least-cost fuel choices by numerous individuals, each facing slightly different fuel prices and valuing the fuels somewhat differently, provided the distribution of fuel prices follows a particular form.

Boilers may switch between natural gas and residual fuel oil, with natural gas being the preferred fuel if prices are close. Figure III-10 shows the two-input (binomial) logit function used by the AFTM to define the share of natural gas consumed in boiler fuel markets. According to the parameters used, when natural gas costs the equivalent of $\$ 8$ per barrel more than fuel oil, its market share in the United States is about 10 percent, and its market share in other regions is about 15 percent. Gas achieves 50 percent market share when it is at a \$2.50-per-barrel price disadvantage in the United States and when it is at a $\$ 3.50$ price disadvantage in other regions. (The boiler fuel price differentials are based on the industrial price of residual fuel oil and the delivered utility price of natural gas, about $\$ 1.40$ per thousand cubic feet (Mcf) above the wellhead price.)

Alcohol flexible-fuel vehicles, LPG bifuel vehicles, and CNG bifuel vehicles may switch between alternative fuels and gasoline, according to the relative fuel prices at the pump. The fuel choices of multiple-fuel vehicle owners depend upon fuel availability, vehicle performance, range, refueling convenience, and fuel price. For example, methanol and ethanol fuels may be generally less convenient than gasoline because they offer a shorter range than an equal volume of gasoline (and thus require more frequent refueling and a potentially longer search to find a refueling station), yet both offer some performance advantages, with their higher octane providing more power and more efficient fuel use. They also may be perceived by consumers as environmentally attractive. In the AFTM, the attitudes of con- 
Figure III-10 - Boiler Fuel Logit Functions

for Gas Versus Residual Fuel Oil in AFTM

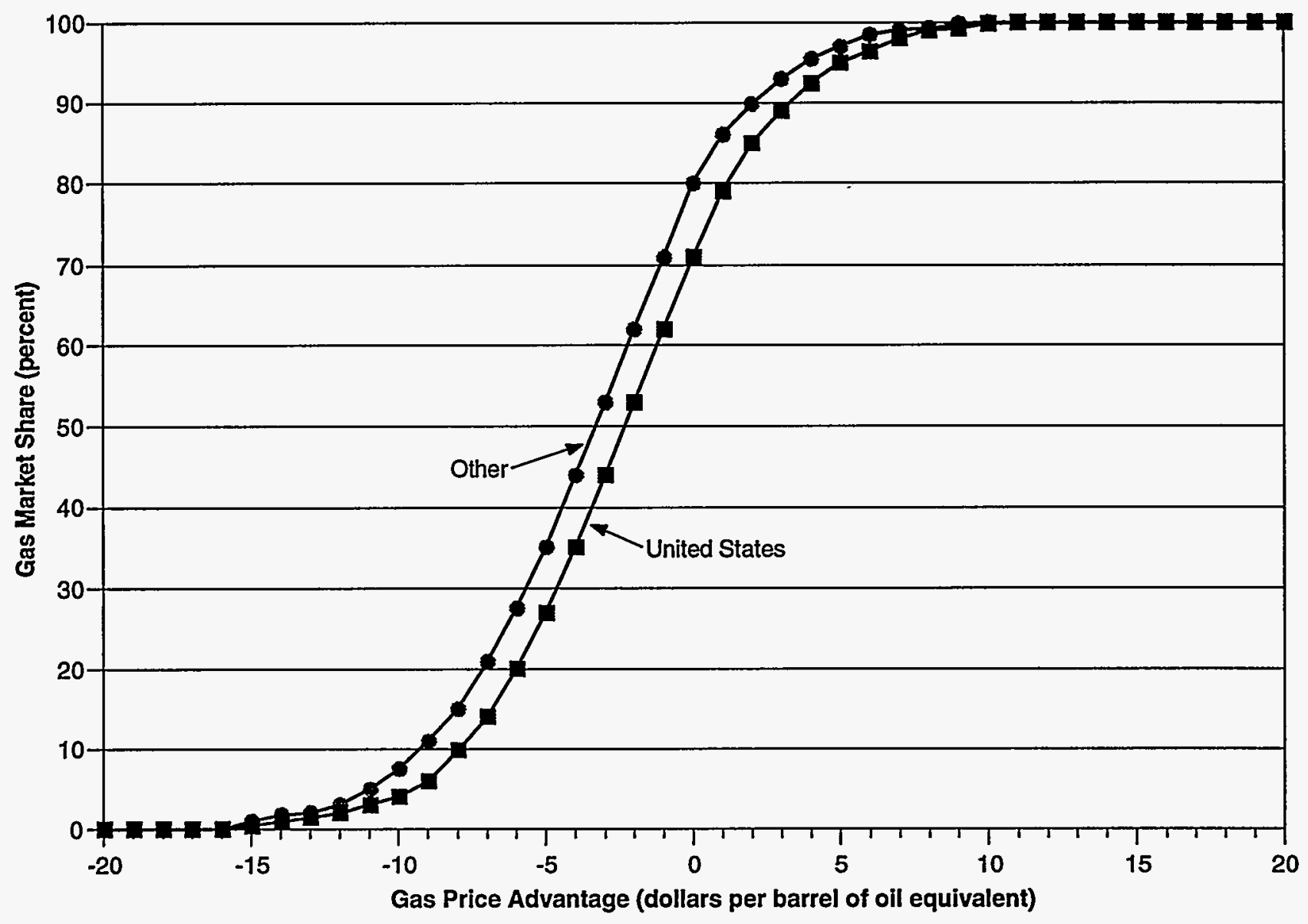

sumers toward these nonprice attributes of alternative fuels are represented in the parameters of the logit market share function. Fuel availability is essentially a transitional concern, expected to be resolved for fuels in significant demand by the year 2010 equilibrium. The approach in this study is to assume that fuel availability is not a problem, but to recognize that the AFTM may overestimate the market share of little-used fuels whose penetration is much below 5 percent.

\section{Derivation of Logit Sharing Function}

The logit function used to estimate vehicle and fuel market shares is derived as follows: Let $\sigma_{i}$ represent the quantity-based market share of a substitutable input $i, q_{i}$ its quantity, and $P_{i}$ its price (or its price advantage over some reference product, considering that only price differ- ences matter). A logit function with $n$ inputs is governed by $n+1$ constants $\alpha_{1}$ and $\beta$. The "offset" parameters $\sigma_{i}$ determine the input $i$ market share when all input prices are equal. The "steepness" parameter â determines the slope of the logit function with respect to price at that point. Therefore, the multinomial logit (MNL) sharing relationship is as follows:

$$
\begin{aligned}
\sigma_{i} & =\left(\frac{q_{i}}{\sum_{k} q_{k}}\right)=\frac{\exp \left(\alpha_{i}+\beta P_{i}\right)}{\sum_{k} \exp \left(\alpha_{i}+\beta P_{i}\right)} \\
& =\left(1+\sum_{k=i} \exp \left(\alpha_{k}-\alpha_{i}\right) \beta\left(P_{k}-P_{i}\right)\right)^{-1}
\end{aligned}
$$

where $k=i$. 
To impose this market-share relationship on the equilibrium outcome generated by the AFTM optimization approach, a sharing cost C is imposed. For each composite good, the sharing cost depends on the vector of all its inputs $q$, or rather their relative shares $\sigma$. It reflects the costs of adjusting input shares toward an unbalanced mix, or may be seen as the benefit of maintaining a diversified input mix. The sharing cost function used ensures that the competitive equilibrium market shares for substitutes vary with price differences in a manner that conforms to the desired (MNL) sharing function. To define the sharing cost function, the unit utilization or unit sharing cost $U(\sigma)$ is first defined. This is the sharing cost imposed for every unit of sharing activity (that is, per unit composite good produced), when the input shares are $\sigma$ :

$$
U(\sigma)=-\left(\beta\left(\ln \sigma_{k}-1-\sigma_{k}\right) \sigma_{k}\right)^{-1}+\gamma
$$

In the AFTM, the composite mix of fuels resulting from a sharing function is treated like any other good. For example, the total fuel demand by flexible-fuel vehicles that can switch between alcohol composite goods is like any other demand for the composite fuel "AlcG." AlcG represents the sum of fuel choices available to a flexible-fuel vehicle that is capable of using M85, E85, or conventional gasoline. The demands for the composite goods are like any other demand function in the AFTM, exhibiting a constant elasticity with respect to its price. Thus the demand curve for the composite transport fuel AlcG determines the total fuel consumed by alcohol flexible-fuel vehicles, and the logit functions determine the actual mix of fuels that is chosen to meet that aggregate demand level. Accordingly, the consumer surplus calculated from a composite fuel demand curve is used to calculate the welfare effects of a change in price of the composite fuel (from a change in the average price of inputs), while the consumer utilization cost function $C(\sigma)$ is used to calculate the welfare effects of a change in the relative prices of inputs (as reflected in input shares $\sigma$ ). The utilization cost function is estimated in the same manner as the supply costs and demand benefits-that is, it is the integral of the sharing function. Total utilization costs (or the total cost of using a composite fuel) are the sum of each composite good's unit sharing cost times the volume of that good consumed in the solution.

\section{BENCHMARKING}

\section{Input Parameters}

In the benchmark case of the AFTM Reference Oil Price Scenario, total supply and demand volumes for natural gas and petroleum products in the United States are

benchmarked to the EIA Annual Energy Outlook 1994 (AEO) Reference Case for the year 2010. Crude oil and natural gas production volumes are based on data contained in Figure III-11 (which reproduces Table A-1 of the AEO). Energy consumption data are based on data contained in Figure III-12 (Table A-2 of the AEO). Crude oil and the wellhead price of natural gas are benchmarked to prices contained in Figure III-11. End-use prices are based on data contained in Figure III-13 (Table A-3 of the AEO). Motor-vehicle demand is based on gasoline consumption forecast by EIA. The breakdown of demand for conventional gasoline and RFG and use of alternative fuels in LDVs is based on work done by Argonne National Laboratory. Total U.S. consumption of natural gas and petroleum products in the AFTM benchmark case is 67.1 quadrillion Btu.

Outside the United States, raw fuel supplies and consumption data are based on forecasts in the EIA International Energy Outlook 1993 (IEO). The International Energy Outlook demand forecasts are much less detailed than the forecasts for the United States taken from the Annual Energy Outlook. Only two commodities are forecast in the International Energy Outlook: natural gas and "oil" products. Demand for "oil" is subdivided into residual fuel oil, gasoline, LPG, and distillate fuel oil based on current splits of demand for liquid hydrocarbon fuel in the various AFTM regions and projected growth rates to 2010 . These specific fuel demands were derived from statistics reported in the United Nations' Energy Statistics Yearbook. In some areas, particularly in Canada and in worldwide ethylene demand, if specific forecasts of fuels were available, they were used in place of the estimated splits. 


\section{Figure III-1 1 - Annual Energy Ouflook 1994 Reference Case Projections for U.S. Energy Supply}

Table A1. Total Energy Supply and Disposition Summary (Quadrillion Btu per Year, Unless Otherwise Noted)

\begin{tabular}{|c|c|c|c|c|c|c|c|}
\hline \multirow{2}{*}{ Supply, Disposition, and Prices } & \multicolumn{5}{|c|}{ Reference Case } & \multirow{2}{*}{$\begin{array}{c}\text { Annual } \\
\text { Growth } \\
1990-2010 \\
\text { (percent) }\end{array}$} & \multirow{2}{*}{$\begin{array}{c}\text { Annual } \\
\text { Growth } \\
\text { 1992-2010 } \\
\text { (percent) }\end{array}$} \\
\hline & 1990 & 1992 & 2000 & 2005 & 2010 & & \\
\hline \multicolumn{8}{|l|}{ Production } \\
\hline Crude $\mathrm{Oil}$ and Lease Condensale . . . . . . . . . . . . & 15.57 & 15.22 & 11.01 & 10.25 & 10.80 & $-1.8 \%$ & $-1.9 \%$ \\
\hline Natural Gas Plant Luquds $\ldots \ldots \ldots \ldots \ldots$. . . . & 2.17 & 2.36 & 2.54 & 270 & 270 & $1.1 \%$ & $0.8 \%$ \\
\hline Nuclear Power,$\ldots \ldots \ldots \ldots \ldots \ldots \ldots \ldots$. & 6.20 & 6.64 & 7.21 & 7.30 & 6.57 & $0.3 \%$ & $-0.1 \%$ \\
\hline Renewable Energy/Other ${ }^{2} \ldots \ldots \ldots \ldots \ldots \ldots$ & 6.20 & 6.28 & 7.29 & 7.82 & 8.69 & $1.7 \%$ & $1.8 \%$ \\
\hline Total $\ldots \ldots \ldots \ldots \ldots \ldots \ldots \ldots \ldots \ldots \ldots$ & 71.08 & 70.64 & 71.06 & 73.23 & 76.12 & $0.3 \%$ & $0.4 \%$ \\
\hline \multicolumn{8}{|l|}{ Imports } \\
\hline 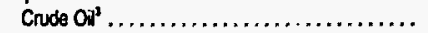 & 12.80 & 13.24 & 18.73 & 19.78 & 19.62 & $2.2 \%$ & $22 \%$ \\
\hline Petroleum Products ${ }^{4} \ldots \ldots \ldots \ldots \ldots \ldots \ldots \ldots$ & 3.40 & 2.71 & 6.90 & 8.55 & 9.81 & $5.4 \%$ & $7.4 \%$ \\
\hline \multicolumn{8}{|l|}{ Exports } \\
\hline Petroleum,$\ldots \ldots \ldots \ldots \ldots \ldots \ldots \ldots \ldots \ldots$ & 1.82 & 2.02 & 2.12 & 2.12 & 2.12 & $0.7 \%$ & $0.2 \%$ \\
\hline Natural Gas $\ldots \ldots \ldots \ldots \ldots \ldots \ldots \ldots$ & 0.09 & 0.22 & 0.24 & 0.27 & 0.30 & $6.4 \%$ & $1.7 \%$ \\
\hline 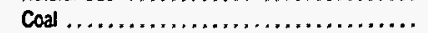 & 2.70 & 2.68 & 3.31 & 3.54 & 3.75 & $1.7 \%$ & $1.9 \%$ \\
\hline Total....$\ldots \ldots \ldots \ldots \ldots \ldots \ldots \ldots$ & 4.61 & 4.92 & 5.68 & 5.92 & 6.17 & $1.5 \%$ & $1.3 \%$ \\
\hline Discrepancy' ........................... & .0 .65 & 1.01 & 0.05 & 0.10 & 0.07 & NA & $-13.9 \%$ \\
\hline \multicolumn{8}{|l|}{ Consumption } \\
\hline Petroleum Products' ${ }^{\prime}, \ldots \ldots \ldots$. & 33.55 & 33.65 & 38.23 & 40.29 & 4200 & $1.1 \%$ & $1.2 \%$ \\
\hline Natural Gas $\ldots \ldots, \ldots \ldots \ldots \ldots \ldots \ldots \ldots$ & 19.30 & 20.15 & 22.67 & 24.31 & 24.69 & $1.3 \%$ & $1.2 \%$ \\
\hline 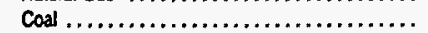 & 19.01 & 18.99 & 20.29 & 20.95 & 22.88 & $0.9 \%$ & $1.0 \%$ \\
\hline Nuclear Power $, \ldots, \ldots, \ldots, \ldots, \ldots, \ldots, \ldots$ & 620 & 6.64 & 7.21 & 7.30 & 6.57 & $0.3 \%$ & $-0.1 \%$ \\
\hline Renewable Energy/Other.............. & 6.23 & 6.37 & 7.34 & 7.94 & 8.89 & $1.8 \%$ & $1.9 \%$ \\
\hline \multicolumn{8}{|l|}{ Prices (1992 dollars per unit) } \\
\hline
\end{tabular}

'Includes synthetic gas.

'Includes uthity and non-utility electricity from hydrcelectne, geothemal, wood and wood waste, municipal solid waste, other biomass, wrnd, photovoltaic and solar thernal sources: non-electric energy from renewable sources, such as active and passive solar systerms, ground-water heat pumps, and wood; alcohol fuels from renewable sources; and, in addition to renewables, electricty from waste heat, hquid hydrogen. and methanol.

'Includes imports of crude oil for the Strategic Petroleum Reserve.

Imports of finished petroteum products. Does not inchude imports of unfinished oils or blending components.

Includes coal, coal coke (net), and electricty (net), methanol, methyl tertary butyl ether (MTBE), and imports of uninished ols.

"Bslancing item. Includes unaccounted for supply, losses, and gains.

Includes natural gas plant Irquids, crude oil consumed as a fuet, and non-petroleum based liquids for blending, such as ethanol.

includes utuly and non-ulity lectpery from hydroelectric, geothemal, wood and wood waste, municipal solid waste, other biomass, wind, photovoltaic and solar thermal sources: non-eloctnc energy from renewable sources, such as active and passive solar systems, ground-water heat pumps, and wood; akcohol fuels from renewrable sources; and, in addrion to renewables, electrcity from waste heat, plus net coal coke umports, net electricity imports, methanol, and liquid hydrogen.

Average retiner acquisition cost for umported crude ol.

"Represents Lower-48 onshore and oftshore supplies.

Btu $=$ Bntish thermal unit.

Mct a Thousand cubic teet.

$N A=$ Nol applicable.

Note: Totals may not equal sum of components due to independent rounding.

Sources: 1990: Energy Injormation Adrninistration (EIA), Arrual Energy Review 1992, DOE/EIA-0384(92) (Washington. D.C.. June 1993$) .1990$ and 1992 natural gas values: EIA. Natura/ Gas A nol 1992 Volume 1. DOE/EIA-0131(92)1 (Washington. D.C.. Novenber 1993). Figures for 1990 may differ from published data due to intemal conversion factors within the AEO 1994 National Energy Modeling System. Projections: EIA, AEO 1994 National Energy Modeling System run AEO94B.D1221934. 
Figure III-12 - Annual Energy Outlook 1994 Reference Case Projections for U.S. Energy Consumption

Table A2. Energy Consumption by End-Use Sector and Source (Quadrillion Btu per Year)

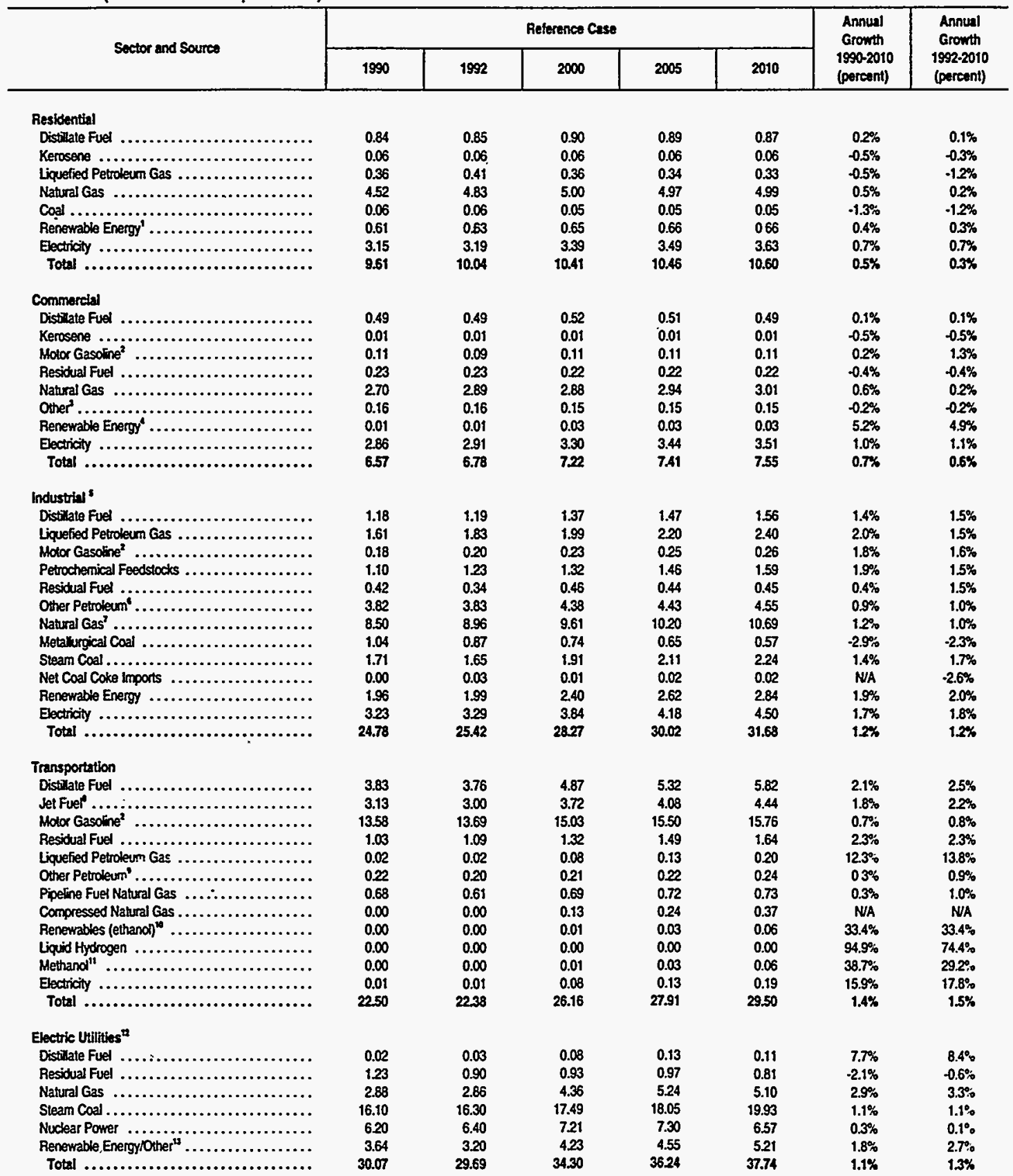




\section{Figure III-12 - Annual Energy Ouflook 1994 Reference Case Projections for U.S. Energy Consumption (continued)}

Table A2. Energy Consumption by End-Use Sector and Source (Continued) (Quadrillion Btu per Year)

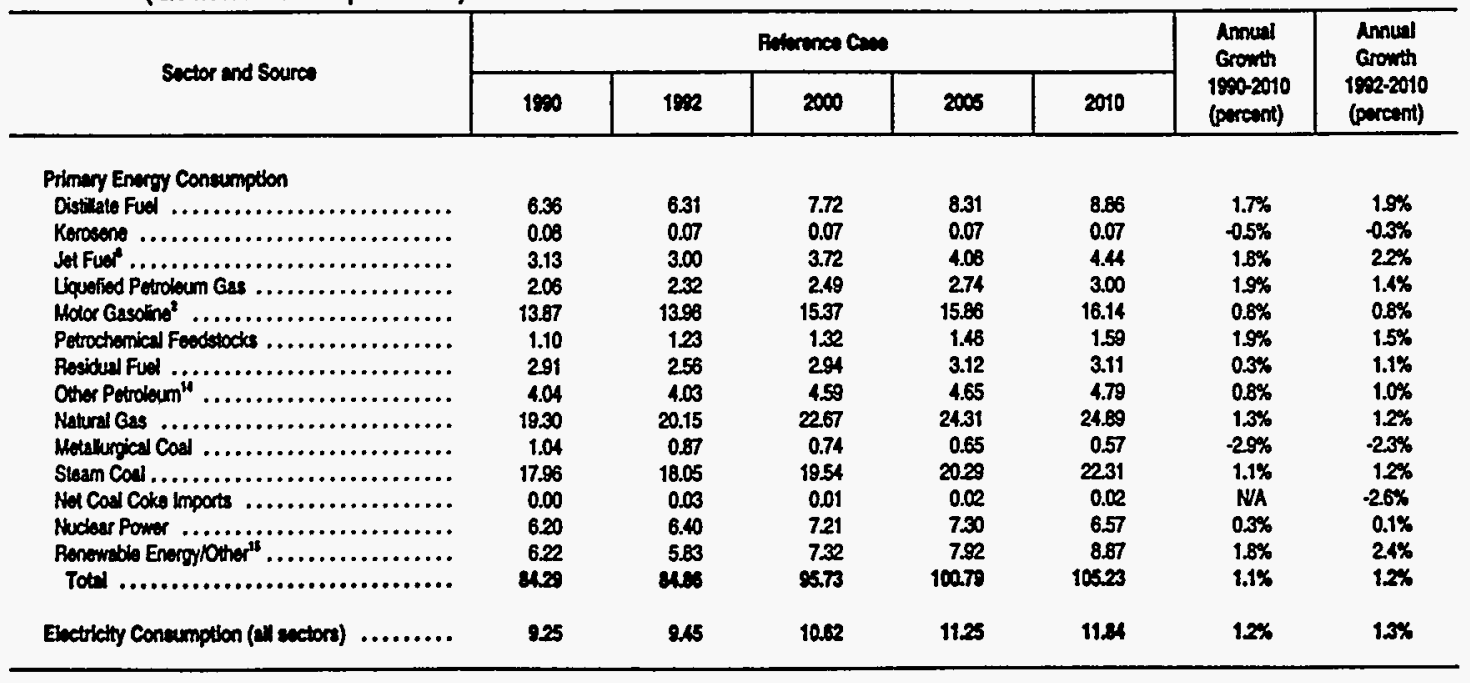

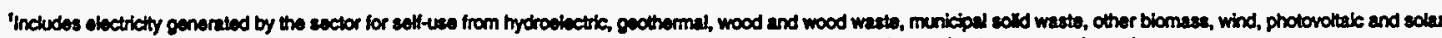
thamal eources, and non-lectric enorgy from renewablo sources, such as sciar thermal water heaters, ground-water heat pumps, and wood.

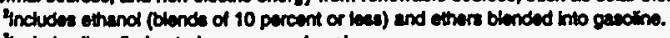

Inctudes llquefied petroleum gas and coel.

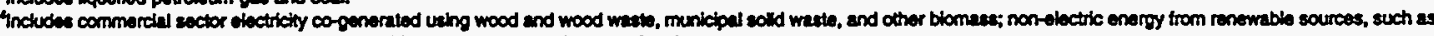

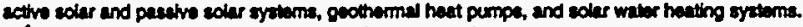

Fual conaumption includes conveumption for cogenseration.

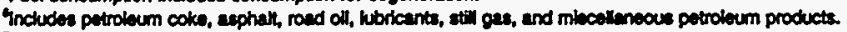

IInctuden weses and plant heo.

includes nephtha and kerosene type.

Includes aviation gas and hubricants.

"Orly ESS (85 percent ethenor).

"Orly $1 \mathrm{kS}$ (85 porcent metheno).

"Includes contumption of energy by electric utilities, incependerx power producens, and amall power producers that sell power to the grid.

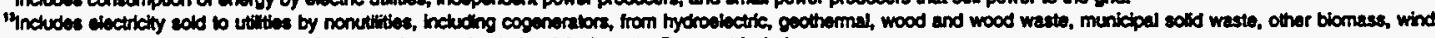
phorovolteic and solar thermal sources, plus wate heal and net electricky trporta. Doses not hatude own use.

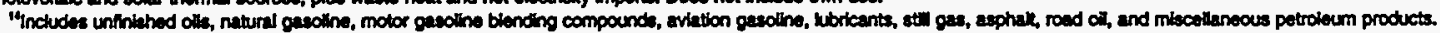

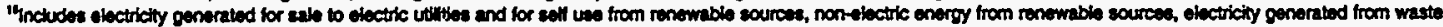
hest, net electikcty imports, liquid mydrogen, and methenol.

Btu $=$ Britten thermal unit.

NA $=$ Mot applicable.

Nots: Totik may not equal sum of componente dee to hodependent rounding.

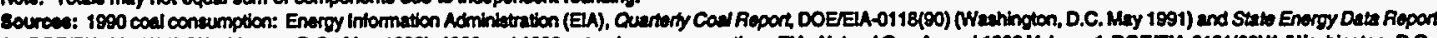

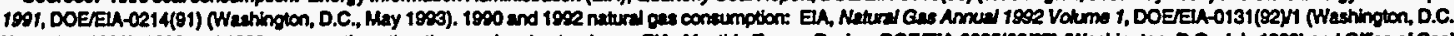

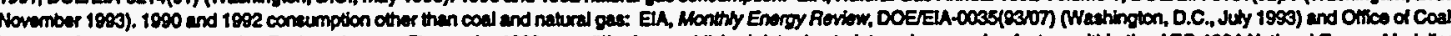

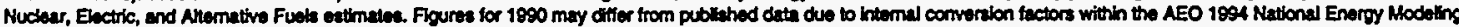
Syctem. The 1990 values are not final and may be updaled in EA pebilcatione. Projections: ElA, AEO 1994 National Energy Modeling System run AEOS4B.D1221934. 
Figure III-13 - Annual Energy Ouflook 1994 Reference Case Projections for U.S. End-Use Energy Prices

Table A3. Energy Prices by End-Use Sector and Source (1992 Dollars per Million Btu)

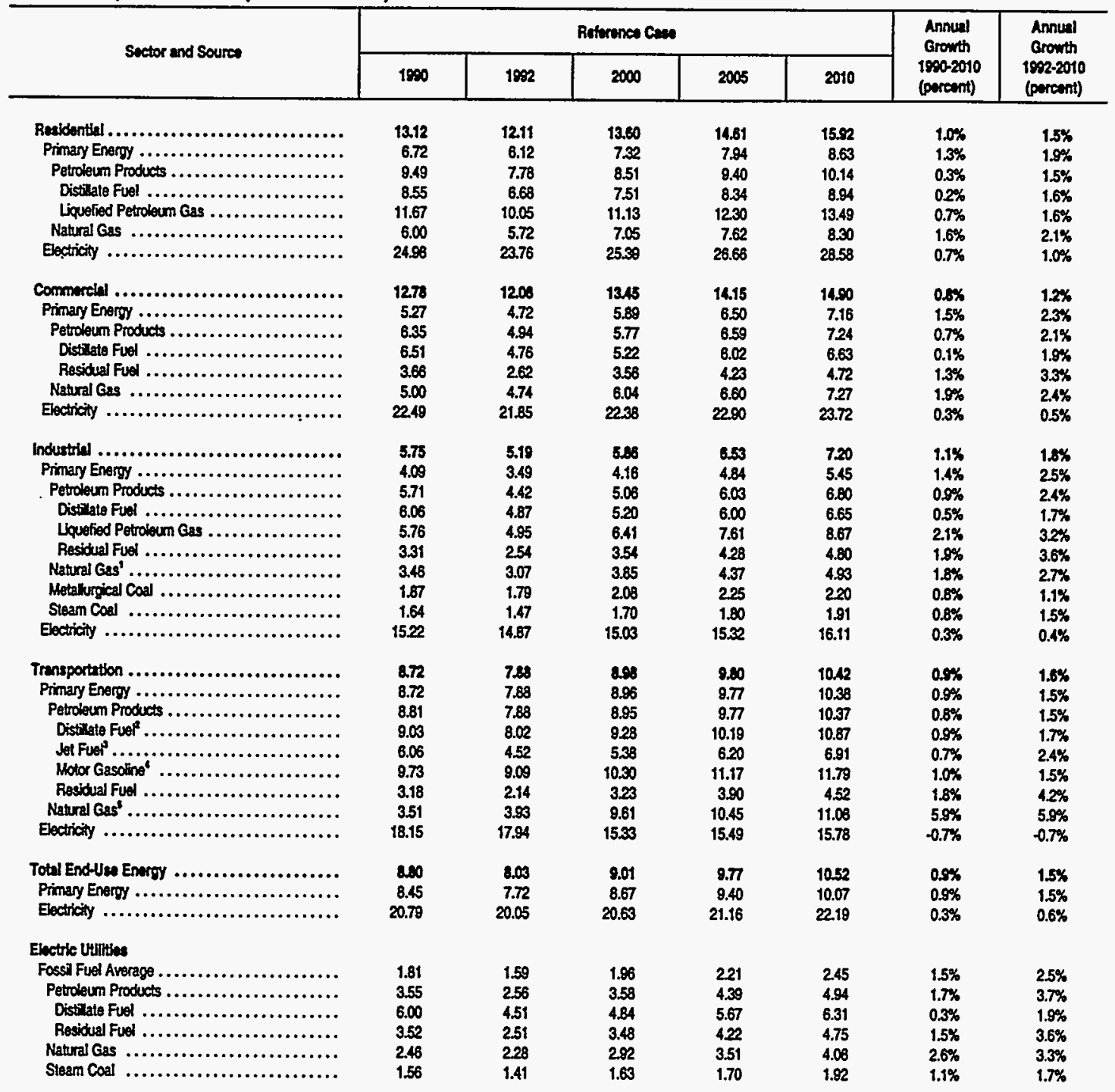




\section{Figure III-13 - Annual Energy Ouflook 1994 Reference Case Projections for U.S. End-Use Energy Prices (continued)}

Table A3. Energy Prices by End-Use Sector and Source (Continued) (1992 Dollars per Million Btu)

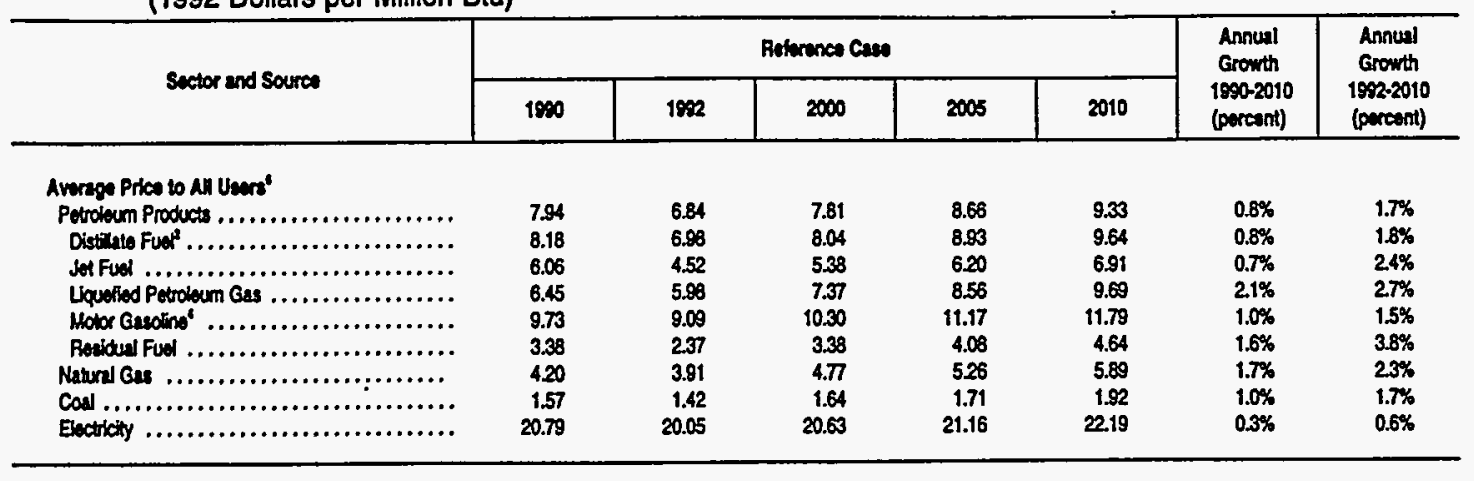

'Exctudes uses for haes and plent tuel.

Ineludel Federal and Stats taxes on diesel fuel and excludes county and beal texes.

Karovene-type ist tuat.

"Average prica for all gradec. Inctudes Foderal and stato taxes and excludes county and local taxes.

compreseed natural gas uend as a vehlile hul.

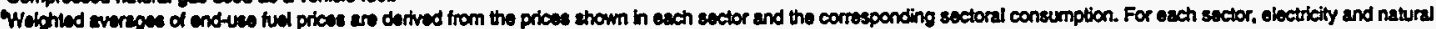

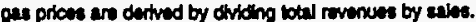

Btu $=$ Brtiteh thermal unit.

Btu = Briteh thermul uril.

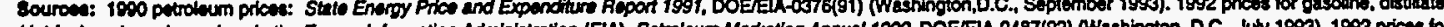

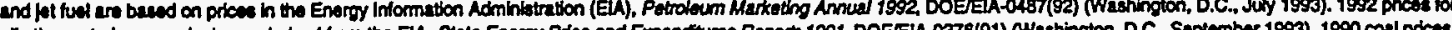

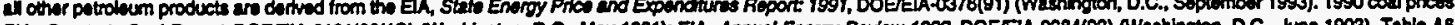

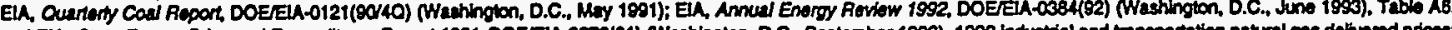

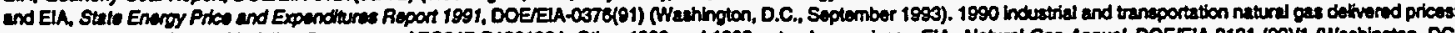

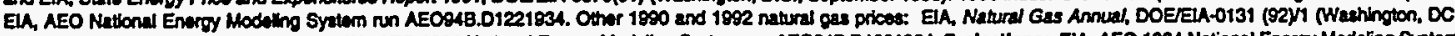
November 1903). 1900 electrlity prices: EIA, AEO 1994 Nattond Energy Modeling System run AEOg48.D1221934. Projectiona: EIA, AEO 1994 National Energy Modoling System IUn AEOS48.01221934. 
Some Canadian forecasts were taken from the National Energy Board's Canadian Energy Supply and Demand, 1990-2010. Boiler fuel estimates were derived from data reported in the International Energy Agency's Oil and Gas Information, Electricity Information, and Energy Statistics and Balances of Non-OECD Countries. Most prices outside the United States for raw fuel supplies were referenced to transportation price differentials between the production source and the most likely consumption region. Because the AFTM handles the U.S. market in much greater detail than other regions, in most cases transportation differentials to the U.S. determined the reference supply cost. Reference demand prices were also differentiated by transportation cost differences to the U.S. for end products.

To ensure consistency in the benchmarking process, the EIA forecasts were retained as the "calibration" benchmark. All forecasts external to the EIA were rolled into the AFTM, but the EIA total supply, demand, and prices were kept unchanged. Total non-U.S. consumption of natural gas and petroleum products in the AFTM benchmark case is 238.6 quadrillion Btu.

As mentioned earlier, the EIA forecasts add condensate and NGLs produced with gas to their "oil" production forecasts. During the benchmarking process, these volumes were taken out of the oil supply curves and their Btu equivalent placed into revised wet-gas supply curves. On the demand side, products such as boiler fuel and ethylene were assumed to be included in the original EIA forecasts of primary energy consumption. The greater consumption detail for these products in the AFTM was handled by reducing end-use demand for the primary fuels that make up the feedstocks for boiler fuel and ethylene. The AFTM also endogenously creates demand for boiler fuel in refinery processes and for fuel in natural gas and methanol processing. These endogenous demands were removed from input end-use demands for natural gas and residual fuel oil as well.

The AFTM benchmark case was benchmarked by first estimating the various adjustments to EIA forecasts mentioned above, making test runs and observing the solution, then recalibrating the model with further adjustments to input volumes based on the test solution. The objective of this benchmarking process was to match the production, demand, and prices reported in the EIA forecasts for 2010. Reference prices and conversion markups were adjusted when necessary to help obtain a solution that matched the desired reference volumes and prices. Imposition of solution constraints to yield desired results was avoided. The value of a model solution to a scenario differing from the benchmark case, and the reported "shadow" prices resulting from changes to the benchmark case, would be greatly reduced if constraints were applied to the benchmark case equilibrium.

\section{Alternative-Fuel Use in 2010: AFTM Benchmark Case}

\section{Total AFVs}

Benchmark case estimates of alternativemotor-fuel use in 2010 were developed for this study by Argonne National Laboratory (Singh 1993). The benchmark case assumes that alternative-fuel use in 2010 will be limited to what is mandated by various programs requiring the use of alternative motor fuels. These programs include the fleet mandates of EPACT, several State and local alternative-fuel mandates, and the California Low-Emission Vehicle (LEV) program. These programs are described in various reports, including the Final Report of the Interagency Commission on Alternative Motor Fuels (Final Report) and a more recent report by EIA entitled Alternatives to Traditional Transportation Fuels (DOE 1992; EIA 1994a).

Tables III-20 through III-22 present the benchmark case estimates of AFVs by program, by type of vehicle, by fuel type, and by fuel use. The derivation of these estimates is discussed below.

\section{AFVs From EPACT}

As discussed for the 2000 analysis (Chapter II), The Energy Policy Act of 1992 (EPACT) requires the purchase of alternative-fuel vehicles (AFVs) by specified types of fleets, including "fuel providers" (Section 501), Federal government (303), State Governments 


\section{Table III-20 - Total Alternative-Fuel Vehicles by Program in the 2010 Benchmark Case}

(thousands)

\begin{tabular}{|c|c|c|c|c|c|c|}
\hline \multirow[b]{2}{*}{ Program } & \multicolumn{5}{|c|}{ Vehicle Type } & \multirow[b]{2}{*}{ Total } \\
\hline & Car & $\begin{array}{l}\text { Light-Duty } \\
\text { Truck }\end{array}$ & $\begin{array}{l}\text { Heavy-Duty } \\
\text { Truck }\end{array}$ & $\begin{array}{l}\text { Transit } \\
\text { Bus }\end{array}$ & $\begin{array}{l}\text { School } \\
\text { Bus }\end{array}$ & \\
\hline $\begin{array}{l}\text { EPACT } \\
\text { Federal Fleet }\end{array}$ & 40 & 60 & & & & 100 \\
\hline State and Local Fleets & 174 & 79 & & 32 & & 285 \\
\hline $\begin{array}{l}\text { Private and Fuel } \\
\text { Provider Fleets }\end{array}$ & 1,440 & 550 & & & & 1,989 \\
\hline Subtotal & 1,654 & 689 & & 32 & & 2,374 \\
\hline $\begin{array}{l}\text { State and Local Programs } \\
\text { State and Local Fleets }\end{array}$ & 50 & 19 & & 3 & 52 & 125 \\
\hline $\begin{array}{l}\text { Private Fleets } \\
\text { Subtotal }\end{array}$ & $\begin{array}{l}149 \\
199\end{array}$ & $\begin{array}{l}58 \\
76\end{array}$ & $\begin{array}{l}57 \\
57\end{array}$ & 3 & 52 & $\begin{array}{l}264 \\
389\end{array}$ \\
\hline ZEV Programs & 2,218 & 195 & & & & 2,414 \\
\hline Total, All Programs & 4,071 & 960 & 57 & 35 & 52 & 5,177 \\
\hline
\end{tabular}

Note: Columns may not add to totals because of rounding.

Table III-21 - Gasoline and Diesel Fuel Replaced by Alternative-Fuel Vehicles in the 2010 Benchmark Case

(barrels per day)

\begin{tabular}{|c|c|c|c|c|c|}
\hline \multirow[b]{2}{*}{ Vehicle Type } & \multirow{2}{*}{$\begin{array}{l}\text { Gasoline Used by } \\
\text { Alternative-Fuel } \\
\text { Cars and LDTs }\end{array}$} & \multicolumn{4}{|c|}{$\begin{array}{c}\text { Gasoline and Diesel Replaced by } \\
\text { Alternative-Fuel Vehicles }\end{array}$} \\
\hline & & $\begin{array}{l}\text { Alternative-Fuel } \\
\text { Cars and LDTs }\end{array}$ & $\begin{array}{l}\text { Alternative-Fuel } \\
\text { HDTs and Buses }\end{array}$ & Total & $\begin{array}{l}\text { Total } \\
\text { Fuel Use }\end{array}$ \\
\hline Federal Fleet & 1,020 & 3,500 & & 3,500 & 4,520 \\
\hline State and Local Fleets & 2,380 & 8,400 & 26,500 & 34,900 & 37,280 \\
\hline $\begin{array}{l}\text { Private and Fuel } \\
\text { Provider Fleets }\end{array}$ & 28,305 & 99,900 & 6,500 & 106,400 & 134,705 \\
\hline Total Fleets & 31,700 & 111,800 & 33,000 & 144,800 & 176,500 \\
\hline Personal Vehicles & & 75,200 & & 75,200 & 75,200 \\
\hline All Programs & 31,700 & 187,000 & 33,000 & 220,000 & 251,700 \\
\hline
\end{tabular}




\section{Table III-22 - Alternative-Fuel Vehicle Types and Fuel Use in the 2010 Benchmark Case}

\begin{tabular}{lcr}
\hline AFV Type & $\begin{array}{c}\text { Number } \\
\text { of Vehicles }\end{array}$ & $\begin{array}{r}\text { Fuel Use } \\
\text { (BGSE } \\
\text { per day) }\end{array}$ \\
\hline Dedicated Alcohol & 18,000 & 11,500 \\
M85 & & 11,500 \\
E85 & & 0 \\
Flex-Fuel Alcohol & $1,180,000$ & 61,300 \\
M85 & & 23,000 \\
E85 & & 23,000 \\
Gasoline & 66,000 & 15,300 \\
Dedicated CNG & 635,000 & 15,700 \\
Bifuel CNG & & 32,700 \\
CNG & & 24,500 \\
Gasoline & 62,000 & 8,200 \\
Dedicated LPG & 635,000 & 32,700 \\
Bifuel LPG & & 24,500 \\
LPG & & 8,200 \\
Gasoline & $2,580,000$ & 92,000 \\
Electric Vehicles & & 220,000 \\
Total Alternative-Fuel & & 252,000 \\
Total Fuel Used & $5,180,000$ & \\
\hline
\end{tabular}

(507(0)), municipal governments, and private businesses (507(a)). Some States have programs requiring the purchase of AFVs in addition to those required under EPACT.

Table III-20 presents the estimates used in the 2010 benchmark case for the number of fleet vehicles resulting from EPACT and other programs. This report uses estimates of fleet vehicle sales based on implementation of the schedules provided in EPACT. Further, this analysis assumes an "early" rulemaking establishing requirements covering municipal and private fleets.

\section{AFVs From State Programs}

The Final Report describes several State and local alternative-fuel programs. These programs were reexamined for this analysis, and other sources were reviewed for possible additional programs. Ultimately the programs of six States, the District of Columbia, and two cities were included in the benchmark case. The State programs are those of Colorado, lowa,
Missouri, New Mexico, Texas, and Washington. The two cities are Denver and New York City. The State programs all require use of alternative fuels in State fleets, and some State and local programs require substantial use of alternative fuels in private and local fleets. By 2010, there may well be other States and localities mandating alternative-fuel use and some of the States included here may have modified their programs; but this analysis assumes that just these programs are in effect and that they are in effect as structured in the spring of 1993.

Table III-20 also presents the total number of AFVs resulting from the State and local programs by fleet type. Separate estimates were developed for each of the States and localities but are not presented here. The vehicle totals presented are in addition to the fleet vehicles that would be mandated in these areas by EPACT.

To develop the estimates of the incremental AFVs, this study first developed estimates of the number of fleet vehicles mandated in each State and locality as well as the total number of fleet vehicles in each State and locality by fleet size. The effects of the specific State and local mandates were then evaluated to estimate the number of incremental AFVs. Additional AFVs will be used in these areas because some of the State and local requirements cover smaller fleets than mandated in EPACT, cover a greater percentage of a fleet's vehicles, start their programs earlier, include smaller metropolitan areas than covered by EPACT, and so forth. As shown in Table III-20, these additional requirements might add about 400,000 AFVs by 2010 to those required by EPACT.

Assumptions about vehicle use (annual mileage, fuel economy, and percent operation on alternative fuels) are the same as those made for EPACT-required fleets.

\section{AFVs From the California ZEV Mandate}

The State programs mentioned above do not include the California LEV program, which is designed to reduce vehicle emissions. To achieve progressively more stringent fleet average emission levels, manufacturers must 
produce a combination of vehicles that meet LEV, ultra-low emission vehicle (ULEV), and zero-emission vehicle (ZEV) standards. The program mandates the sale of ZEVs, beginning with 2 percent of vehicle sales and reaching 10 percent by 2003 . The only vehicles that can meet the ZEV mandate as currently structured appear to be electric vehicles (EVs). Gasoline vehicles operating on RFG may meet the LEV and ULEV standards. This analysis assumes that the only AFVs resulting from the LEV program are electric vehicles.

Other States have expressed interest in implementing a LEV program, including the ZEV mandate. Both New York and Massachusetts have already adopted the LEV program; for the benchmark case, this study assumes that both these States have a ZEV mandate. Table III-20 presents the effect of this program in the three States on AFV use in the 2010 benchmark case. Inclusion of New York and Massachusetts should roughly double the number of EVs that would result from California alone adopting the program, for a total of approximately 2.4 million incremental EVs. Based on past analysis of potential applications of EVs to the fleet and household markets, most of the EVs are likely to be personal-use vehicles (Hamilton 1989). Fuel use by these personal use EVs is illustrated in Table III-21.

\section{Estimates of AFVs by Fuel Type}

The benchmark case also includes an estimate of the number of AFVs by type of fuel use. Table III-22 presents the results of that analysis. All the dedicated vehicles listed in Table III-22 are buses or heavy-duty trucks. All the flexible-fuel vehicles or bifuel vehicles are cars and light-duty trucks.

These estimates are based on the following assumptions:

- As indicated above, most EVs will be used in the personal-vehicle market. The EV share of the AFV fleet car market is assumed to be very low, except in States that have adopted the ZEV mandate. Similarly, the EV share of the AFV fleet truck market will be smaller than that of other AFVs (10 percent), except in those States with the ZEV mandate.

- After accounting for EVs, the AFV fleet car market will be evenly distributed between alcohol-fueled and gaseous-fueled vehicles. It is assumed that flexible-fuel vehicles will be able to use both methanol and ethanol and thus will account for 50 percent of the fleet car market. CNG and LPG will each account for 25 percent.

- After accounting for EVs, the fleet light-truck market will be similarly shared, except that there will be a slightly greater propensity to use the gaseous-fueled vehicles than the alcohol-fueled vehicles. Specifically, approximately 60 percent of the non-EV alternativefuel light-duty trucks will be gaseous-fueled vehicles and 40 percent will be flexible-fuel vehicles using alcohol.

- Only CNG and methanol will be used in transit buses.

- Only CNG and LPG will be used in school buses and heavy-duty trucks.

These assumptions are generally consistent with the assumptions made regarding the use of various fuels in the multifuel scenario developed for the Second Interim Report of the Interagency Commission on Alternative Motor Fuels (DOE 1991). That scenario was designed to achieve a 25-percent displacement of highway transportation fuel use by 2010 . This study revised at least one of the assumptions in that report. Whereas that report assumed no market penetration by alcoholfueled vehicles in the fleet light-duty truck market, this study assumed some penetration, as described above.

The above assumptions apply to all the vehicles estimated to be in operation as a result of EPACT. They are "national average" assumptions. If the price of a specific fuel in a State is lower than the national average or if a specific fuel is more readily available than on a national basis, then that fuel (and vehicle type) would be used more frequently in that State. To account for this, some variation from the national assumptions are incorporated in the 
estimates of the types of AFVs used in the various State programs. However, no one fuel ever completely dominates the vehicles required by State or local programs. Documentation of the derivation of these estimates is available in spreadsheet format (Singh 1993).

\section{Summary}

In total, approximately 5 million AFVs could be in operation in 2010 as a direct result of the various Federal and State programs. They could use approximately 220,000 barrels per day of alternative fuel, or roughly 3 percent of the highway transportation fuel use projected by EIA for 2010 (EIA 1994b).
These benchmark case estimates should not be considered firm projections. They are simply representative of what might happen in a world in which AFVs exist only because of mandates. In such a "stand alone" world, fleet AFVs are more likely than not to be flexiblefuel or bifuel vehicles because of limited fuel availability. Alternatively, where fleet AFVs are part of a fully developed AFV market, these vehicles are more likely to be dedicated. Further, there are likely to be more fleet AFVs than estimated here. 


\section{DESCRIPTION OF SCENARIOS AND DETAILS OF RESULTS}

To assess the market potential and effects of alternative-fuel use in light-duty vehicles in 2010, this study uses the Alternative Fuels Trade Model (AFTM) to examine an array of cases and scenarios that differ with respect to oil prices and motor-fuel tax rates, constraints on fuel choices and emissions, and sensitivities to parameters describing fuel supplies or demand. None of these cases are presented as forecasts of the future. Collectively, however, they present a mosaic of possible future outcomes and relate these to potential market conditions.

\section{OIL PRICE AND FUEL-TAX ASSUMPTIONS}

All of the alternative-fuel cases for 2010 are examined under specific sets of assumptions about world oil prices and U.S. tax rates on motor fuels.

\section{Reference and Low Oil Price Scenarios}

Two oil price scenarios, modeled with different assumptions regarding the Organization of Petroleum Exporting Countries (OPEC) oil production capacity and behavior, form the basic backdrop for the various forecasts:

- Reference Oil Price Scenario, in which oil prices (as well as energy production and demand) are benchmarked to the Energy Information Administration's (EIA) Annual Energy Outlook 1994 reference case. In the benchmark case (Reference Oil Price Scenario Case 0), the world oil price is $\$ 25.82$ per barrel and the U.S. oil price is $\$ 26.74$ per barrel. (All prices and costs are in 1990 dollars.) According to EIA's projection, OPEC will produce 62 percent of world crude oil supply in 2010. This study's estimates of the cost of maintaining and expanding OPEC production capacity imply that the EIA reference case oil price will be matched if countries controlling about 72 percent of potential OPEC capacity act as revenue-maximizing monopolists. As men- tioned in Section III, this group is referred to as the "OPEC core" in this study. The OPEC core is also assumed to restrict natural gas production and production of products that may be used to satisfy alternative-fuel-vehicle demands-liquefied petroleum gas (LPG) and methanol-in this scenario. Appendix $B$ contains a description of the methodology used to estimate long-run OPEC oil supply curves.

- Low Oil Price Scenario, in which the benchmark case (Low Oil Price Scenario Case 0) world oil price is $\$ 20.60$ per barrel and the U.S. oil price is $\$ 21.60$ per barrel. These oil prices are similar to, but do not directly match, the low oil price case in the Annual Energy Outlook 1994. The Low Oil Price Scenario assumes no OPEC monopoly behavior. OPEC crude oil, natural gas, $L P G$, and methanol production is not restricted in this scenario.

In both scenarios, the benchmark case demand curves for volumes of petroleum products, natural gas, and motor-vehicle fuel correspond to the Annual Energy Outlook 1994 reference case.

\section{Equal and Current Motor-Fuel Taxes}

To examine the effect of tax policy on alternative-fuel use, this analysis incorporated two different motor-fuel tax rates into the AFTM-a "current tax" rate and an "equal tax" "rate. The equal motor-fuel tax schedule assumes that taxes for all motor fuels are applied equally when measured on a dollar-per-British thermal unit (Btu) basis. The tax rate used is the same as the 1994 national average gasoline tax rate $-\$ 13.90$ per million Btu (\$0.33 per gallon). This tax estimate includes Federal excise taxes and a weighted average of State taxes.

However, motor-fuel taxes other than gasoline taxes are currently not applied uniformly by any measure (per million Btu or per gallon). The alternative fuels and alternative-fuel vehicles 
considered in this study-M85 (a mixture of 85 percent methanol and 15 percent gasoline), E85 (a mixture of 85 percent ethanol and 15 percent gasoline), compressed natural gas (CNG), LPG, and electricity-are subject to taxes applied per physical gallon and per vehicle. Therefore, in several of the cases examined, these current tax rates are applied to the use of alternative fuels in motor vehicles. As Table IV-1 illustrates, these current taxes are significantly different from the equal-tax treatment used in most cases presented in this report.

The AFTM uses total motor-fuel taxes in dollars per barrel of gasoline-equivalent as a parameter in evaluating the total costs of alternative-fuel use. The calculation of the State portion of the tax required some additional assumptions to fit the model's framework. In instances where States levied flat annual vehicle fees in lieu of gallonage taxes, the flat fees were converted into gallonage taxes by assuming number of miles traveled per year and number of miles per gallon. State sales taxes that applied to certain alternative fuels but did not apply to gasoline were added to the State portion of the taxes. The weighted State average taxes were estimated with motor-fuel excise taxes (that is, tax per gallon) and the numbers of gallons of gasoline consumed in 1992 in each State as the weights. Table IV-2 shows the individual State tax rates used to estimate the weighted average State taxes for use in the AFTM.

\section{CASE DESCRIPTIONS}

Each of the two oil price scenarios is run with a series of cases that incorporate constraints on fuel choices in the United States. The benchmark case explicitly limits alternativefuel-vehicle choice and fuel use. The unconstrained case removes those constraints. The other, partially constrained cases limit emissions and U.S. imports from outside North American Free Trade Agreement (NAFTA) countries.

Table IV-3 outlines the seven cases that are examined under both oil price scenarios, as well as the five sensitivities that test the effects of changes in supply and demand parameters on the benchmark case and the unconstrained case.

\section{Benchmark Case (Case 0)}

The Annual Energy Outlook 1994 reference price case is used to calibrate the Reference Oil Price Scenario benchmark case. Base U.S. motor-vehicle fuel demands, nonvehicle fuel demands, end-use prices, raw fuel supplies, and raw fuel prices are taken from the Annual Energy Outlook. Remaining world oil and gas production and consumption are adapted from the International Energy Outlook 1993. As discussed in Section III, vehicle-specific motorfuel demands in the United States are based on work done by Argonne National Laboratory

\section{Table IV-1 - Motor-Fuel Taxes Applied to Alternative Fuels}

\begin{tabular}{|c|c|c|c|c|c|c|}
\hline & Gasoline/RFG & M85 & E85 & CNG & LPG & Gasohol \\
\hline \multicolumn{7}{|c|}{ Current Taxes (1990ф/gallon $\left.{ }^{a}\right)$} \\
\hline $\begin{array}{l}\text { State Weighted Average } \\
\text { Renewable Tax Credit }\end{array}$ & 16.64 & 15.39 & $\begin{array}{r}15.27 \\
-41.06\end{array}$ & 15.05 & 13.86 & 11.04 \\
\hline Federal Tax & 16.46 & 11.58 & 16.41 & 5.43 & 16.37 & 11.63 \\
\hline \multicolumn{7}{|c|}{ Total Motor-Fuel Taxes (1990\$/BGEb) } \\
\hline $\begin{array}{l}\text { Current Taxes } \\
\text { Equal Taxes }\end{array}$ & $\begin{array}{l}13.90 \\
13.90\end{array}$ & $\begin{array}{l}19.70 \\
13.90\end{array}$ & $\begin{array}{l}-5.45 \\
13.90\end{array}$ & $\begin{array}{r}8.60 \\
13.90\end{array}$ & $\begin{array}{l}16.63 \\
13.90\end{array}$ & $\begin{array}{r}9.84 \\
13.90\end{array}$ \\
\hline
\end{tabular}

Note: Tax rates in the above table include weighted average State plus Federal excise taxes. The Federal taxes reflect the tax incentives and increases in the Energy Policy Act of 1992 and the Omnibus Budget Reconciliation Act of 1993.

a Liquid fuels in $1990 \varnothing$ per physical gallon, CNG in gallons of gasoline-equivalent.

b 1 BGE = 5.253 MMBtu. 


\begin{tabular}{|c|c|c|c|c|c|c|c|c|c|}
\hline State & Gasoline & Diesel & CNG & LPG & Electric & Methanol & Ethanol & Gasohol & $\begin{array}{c}1992 \\
\text { Consumption } \\
\text { (thousand gal.) }\end{array}$ \\
\hline$A L$ & 18.00 & 19.00 & 20.22 & 16.15 & None & 18.00 & 18.00 & 16.00 & $2,154,917$ \\
\hline$A K$ & 8.00 & 8.00 & 0.00 & None & None & 0.00 & 0.00 & 0.00 & 229,194 \\
\hline$A Z$ & 18.00 & 18.00 & 1.00 & 18.00 & None & 18.00 & 18.00 & 18.00 & $1,780,867$ \\
\hline$A R$ & 18.70 & 18.70 & 5.00 & 2.43 & None & 18.50 & 18.50 & 18.50 & $1,169,652$ \\
\hline$C A^{a}$ & 18.00 & 17.00 & 7.00 & 5.14 & None & 8.50 & 8.50 & 17.00 & $13,608,581$ \\
\hline CO & 22.00 & 20.50 & 20.50 & 20.50 & None & 20.50 & 20.50 & 22.00 & $1,494,089$ \\
\hline CT & 30.00 & 18.00 & 29.00 & 18.00 & None & 28.00 & 28.00 & 29.00 & $1,348,426$ \\
\hline DE & 22.00 & 19.00 & 19.00 & 19.00 & None & 19.00 & 19.00 & 19.00 & 357,257 \\
\hline DC & 20.00 & 20.00 & 20.00 & 20.00 & None & 20.00 & 20.00 & 20.00 & 182,101 \\
\hline $\mathrm{FL}^{\mathbf{a}}$ & 11.80 & 21.00 & 39.78 & 31.44 & None & 11.80 & 11.80 & 11.80 & $6,144,407$ \\
\hline GA & 7.50 & 7.50 & 7.50 & 7.50 & None & 7.50 & 7.50 & 7.50 & $3,602,759$ \\
\hline $\mathrm{HI}$ & 16.00 & 16.00 & 0.00 & 11.00 & None & 16.00 & 16.00 & 16.00 & 380,100 \\
\hline ID & 21.00 & 21.00 & 21.00 & 15.20 & None & 21.00 & 21.00 & 21.00 & 503,054 \\
\hline IL & 19.00 & 21.50 & 19.00 & 19.00 & None & 19.00 & 19.00 & 19.00 & $4,523,242$ \\
\hline IN & 15.00 & 16.00 & 18.71 & 14.29 & None & 15.00 & 15.00 & 15.00 & $2,695,015$ \\
\hline IA & 20.00 & 22.50 & 18.40 & 20.00 & None & 20.00 & 20.00 & 19.00 & $1,273,622$ \\
\hline KS & 18.00 & 20.00 & 17.00 & 17.00 & None & 20.00 & 20.00 & 18.00 & $1,165,654$ \\
\hline$K \gamma$ & 15.40 & 12.40 & 15.00 & 15.00 & None & 15.00 & 15.40 & 15.00 & $1,900,229$ \\
\hline LA & 20.00 & 20.00 & 33.32 & 26.15 & None & 20.00 & 20.00 & 20.00 & $1,939,019$ \\
\hline$M E$ & 19.00 & 20.00 & 0.00 & 18.00 & None & 18.00 & 18.00 & 18.00 & 604,701 \\
\hline MD & 23.50 & 24.75 & 23.50 & 23.50 & None & 23.50 & 23.50 & 23.50 & $2,096,228$ \\
\hline MA & 21.00 & 21.00 & 21.00 & 9.60 & None & 21.00 & 21.00 & 21.00 & $2,381,373$ \\
\hline MI & 15.00 & 15.00 & 0.00 & 15.00 & None & 15.00 & 15.00 & 15.00 & $4,227,191$ \\
\hline$M N$ & 20.00 & 20.00 & 40.62 & 32.09 & 41.97 & 20.00 & 18.00 & 18.00 & $2,029,719$ \\
\hline MS & 18.20 & 18.20 & 18.20 & 17.00 & None & 18.20 & 18.20 & 18.20 & $1,325,736$ \\
\hline MO & 13.03 & 13.00 & 14.03 & 10.72 & None & 13.00 & 13.03 & 11.00 & $2,784,211$ \\
\hline MT & 24.00 & 24.00 & 7.49 & 15.43 & None & 24.00 & 24.00 & 24.00 & 444,825 \\
\hline NE & 24.40 & 24.40 & 24.40 & 23.80 & None & 24.40 & 24.40 & 24.40 & 761,469 \\
\hline NV & 23.00 & 27.00 & 23.00 & 17.00 & None & 23.00 & 23.00 & 23.00 & 680,546 \\
\hline $\mathrm{NH}^{\mathrm{b}}$ & 18.70 & 18.70 & 18.00 & 18.00 & None & 18.00 & 0.00 & 18.00 & 516,150 \\
\hline NJ & 10.50 & 13.50 & 5.25 & 5.25 & None & 10.50 & 10.50 & 10.50 & $3,329,117$ \\
\hline NM & 23.00 & 19.00 & 23.00 & 18.00 & None & 23.00 & 22.00 & 22.00 & 840,008 \\
\hline NY & 23.03 & 25.03 & 22.84 & 8.00 & None & 22.84 & 22.84 & 22.84 & $5,422,459$ \\
\hline NC & 22.30 & 22.30 & 25.60 & 22.30 & None & 22.30 & 22.30 & 22.30 & $3,204,703$ \\
\hline ND & 17.00 & 17.00 & 17.00 & 17.00 & None & 17.00 & 17.00 & 17.00 & 325,630 \\
\hline $\mathrm{OH}$ & 22.00 & 22.00 & 22.00 & 22.00 & None & 22.00 & 22.00 & 21.00 & $4,537,831$ \\
\hline OK & 17.00 & 14.00 & 24.62 & 26.74 & None & 17.00 & 17.00 & 16.00 & $1,676,625$ \\
\hline OR & 24.00 & 24.00 & 24.00 & 24.00 & None & 24.00 & 24.00 & 19.00 & $1,368,469$ \\
\hline PA & 22.40 & 22.40 & 12.00 & 22.40 & None & 12.00 & 22.40 & 12.00 & $4,548,960$ \\
\hline RI & 28.00 & 28.00 & 28.00 & 28.00 & None & 28.00 & 28.00 & 26.00 & 376,788 \\
\hline SC & 16.00 & 16.00 & 16.00 & 16.00 & None & 16.00 & 16.00 & 16.00 & $1,845,737$ \\
\hline SD & 18.00 & 18.00 & 18.00 & 16.00 & None & 16.00 & 16.00 & 16.00 & 386,237 \\
\hline$T N$ & 21.40 & 17.00 & 13.00 & 14.00 & None & 21.40 & 21.40 & 20.00 & $2,452,857$ \\
\hline$T X$ & 20.00 & 20.00 & 13.82 & 11.66 & None & 20.00 & 20.00 & 20.00 & $8,572,288$ \\
\hline UT & 19.00 & 19.00 & 13.30 & 11.05 & None & 19.00 & 19.00 & 19.00 & 741,122 \\
\hline VT & 16.00 & 17.00 & 5.24 & 4.00 & None & 19.00 & 0.00 & 16.00 & 296,842 \\
\hline VA & 17.50 & 16.00 & 10.00 & 10.00 & 10.00 & 17.50 & 17.50 & 17.50 & $3,022,658$ \\
\hline WA & 23.00 & 23.00 & 17.07 & 13.04 & None & 23.00 & 3.45 & 23.00 & $2,372,205$ \\
\hline WV & 25.35 & 25.35 & 25.35 & 25.35 & None & 25.35 & 25.35 & 25.35 & 854,641 \\
\hline WI & 23.20 & 23.20 & 23.20 & 23.20 & None & 23.20 & 23.20 & 23.20 & $2,130,877$ \\
\hline $\begin{array}{l}\text { WY } \\
\text { Weighted }\end{array}$ & 9.00 & 9.00 & 0.00 & None & None & 5.00 & 5.00 & 5.00 & 300,935 \\
\hline Averages & 18.61 & 18.99 & 16.83 & 15.50 & 1.02 & 16.96 & 16.80 & 12.34 & $112,911,323$ \\
\hline
\end{tabular}

Notes: Boxed items indicate data derived from annual flat fees and sales taxes which do not apply to gasoline. CNG is in 1994 cents per GGE.

- Florida and Califomia sales taxes were 0 percent and 6-percent, respectively, based on conversations with individual State tax offices.

b Now Hampshire 18 centgas on CNG and LPG is based on communication with NH tax office.

Sources: Source for gallonage taxes: "The Clean Fuels Report," April 1994, p. 59. Source for sales taxes: "Disparate Impacts of Federal and State Highway Taxes on Altemallve Motor Fuels," Congressional Research Service. Table 2, David E. Gushee and Salvatore Lazarri, March 12, 1993, revised December 17, 1993. 


\section{Table IV-3 - Cases and Sensitivities Examined Using Alfernative Fuels Trade Model}

\section{Cases}

0 Benchmark case: Annual Energy Outlook 1994 reference supply/demand, constrained vehicle choices

1 Unconstrained vehicle choices

2 U.S. greenhouse gas emissions limited to 90 percent of unconstrained solution

3 U.S. greenhouse gas emissions limited to 80 percent of unconstrained solution

$4 \quad$ U.S. energy imports kept 1.215 MMBGE/D less than unconstrained solution

5 U.S. alternative-fuel use at exactly 30 percent of light-duty fuel use

6 U.S. alternative-fuel imports no more than 1.215 MMBGE/D above benchmark solution

\section{Sensitivities}

B Ethylene demand worldwide higher than reference

C Methanol production costs worldwide higher than reference

D U.S./Canadian gas supplies 25 percent greater than reference

E Non-OECD gas supplies 25 percent less than reference

F 1994 motor-fuel taxes and greater U.S./Canadian gas supplies

Note: There is no Sensitivity A.

(ANL) (Singh 1993). The number of vehicles in the United States and the mix of vehicle types take into consideration implementation of Federal and State mandates.

The benchmark case limits replacement fuel use to about 12.4 percent of total light-duty vehicle fuel use. Replacement fuel use is estimated by counting all nongasoline components of light-duty vehicle fuel demand; this includes oxygenates in reformulated gasoline and gasohol. In the benchmark case, total lightduty vehicle fuel use is 3.84 million barrelsgasoline-service-equivalent (MMBGSE) per day conventional gasoline vehicles, 3.84 MMBGSE per day reformulated gasoline vehicles, 0.236 MMBGSE per day gasohol vehicles, and 0.22 MMBGSE per day alternative-fuel vehicles.

The benchmark case assumes all motorvehicle fuels (except electric vehicles) are taxed at the same dollar-per-Btu rate and that rate is the same as 1994 gasoline taxes. This assumption has been made to eliminate any distortions to the model's fuel choices that could be caused as a result of unequal taxes on fuel energy content.

\section{Unconstrained (Case 1)}

Case 1 is intended to model the long-run equilibrium in motor-vehicle demand and global oil and gas trade under the two oil-price scenarios-this time assuming widespread availability of alternative fuels and alternative-fuel vehicles. In the unconstrained case, all model input fuel demands remain the same as the benchmark case. The same light-duty motorvehicle fuel demand of 8.1 MMBGSE per day is targeted in this case, but the mix of alternative-fuel-vehicle types and fuel choices is no longer limited. All upper constraints on alternative-fuel use by motor vehicles in the United States are removed. The capability of alternative fuels to displace gasoline service includes consideration of relative fuel efficiencies as compared to gasoline. Btu content, combustion efficiency and power output, and vehicle weight differences are all considered in the model calculation of the volume of alternative fuel required to displace gasoline. The AFTM is free to choose the lowest cost combination of fuels and vehicles. Costs considered in the solution include vehicle costs, fuel prices, an evaluation of nonprice characteristics of alternative-fuel vehicles, fuel substitution outside the motor-vehicle sector, and 
costs involved in altering raw fuel production and trading patterns.

U.S. motor-vehicle demand is but one part of the global equilibrium solved for by the AFTM. The unconstrained solution may not provide the exact same demand for total motor-vehicle services as in the benchmark case in all sensitivities.

Minimum joint constraints are left on alternative fuels in this and all subsequent cases to guarantee that at least as much alternative fuel is consumed as in the benchmark case. This minimum alternative-fuel demand precaution is not a limiting constraint in any of the cases run as part of this study. All unconstrained cases seek to use a much greater volume of alternative fuels than the benchmark case. As discussed in Section III, imposition of any constraint will move the model's solution away from its least-cost equilibrium, making the sum of costs greater than a solution with no constraints.

\section{U.S. Greenhouse Gas Emissions Limited (GHG 90) (Case 2)}

In Case 2, total U.S. greenhouse gas (GHG) emissions are constrained to be no more than 90 percent of the GHG emissions estimated in the unconstrained case. GHG emissions are measured for all U.S. fuel consumption-not just motor-vehicle fuel consumption.

Within the model, only carbon dioxide $\left(\mathrm{CO}_{2}\right)$ and $\mathrm{CO}_{2}$-equivalent emissions are included in GHG emission estimates. Emission coefficients based on full-cycle fuel production and consumption are used to estimate the total volume of $\mathrm{CO}_{2}$ and $\mathrm{CO}_{2}$-equivalent output. $\mathrm{CO}_{2}$-equivalent emissions include methane, other hydrocarbons, carbon monoxide, nitrous oxide, and nitrogen oxides. These coefficients are based on estimates developed by ANL (Singh and Delucchi 1994). For each alternative transportation fuel, ANL estimated GHG emissions from vehicle operation, vehicle manufacture, fuel production and distribution, and feedstock recovery and transport (the transportation fuel cycle). The type and amount of energy used at each stage of the fuel cycle is accounted for, as is the amount of GHG emissions at each stage. Emissions estimates take into account fuel efficiencies assumed for each combination of vehicle and fuel considered in this study. Table IV-4 summarizes the greenhouse gas coefficients used in the AFTM for motor-vehicle fuels, while Table IV- 5 summarizes the GHG coefficients used to measure emissions from non-motorvehicle fuel production and consumption.

\section{U.S. Greenhouse Gas Emissions Limifed (GHG 80) (Case 3)}

In Case 3, GHG emissions are constrained to be no more than 80 percent of the greenhouse gas emissions estimated in the unconstrained case.

\section{U.S. Energy Imports Limited (Case 4)}

Case 4 represents the "intent of the law" interpretation of the Energy Policy Act of 1992 (EPACT), which states that at least half of the target volume of alternative-fuel use in the United States should be produced from within the countries of NAFTA. This is interpreted to mean that one of the goals of increased alternative-fuel use is to reduce total U.S. energy imports. In this case, alternative-fuel use is not constrained to any maximum. However, total oil, gas, and product imports to the United States, Canada, and Mexico are limited to be no more than that in the solution to the unconstrained case less half of the target alternativefuel use set forth in EPACT. This setup ensures that 50 percent of target alternativefuel consumption (or the equivalent fuel use in other sectors) is not based on imports-that is, it is produced from within NAFTA. Imports and target alternative-fuel use are measured in Btu for the purposes of this constraint.

The sum of light-duty vehicle fuel use in the scenarios considered in this study is 8.098 MMBGSE per day. The EPACT target for 2010 would have 30 percent of this amount, or 2.43 MMBGSE per day, be from alternative fuels. Half of this target volume is $\mathbf{1 . 2 1 5}$ MMBGSE per day. A barrel of gasoline is as- 


\section{Table IV-4 - Greenhouse Gas Emissions From Fuel Production and Distribution, Vehicle Operation, and Vehicle Manufacturing}

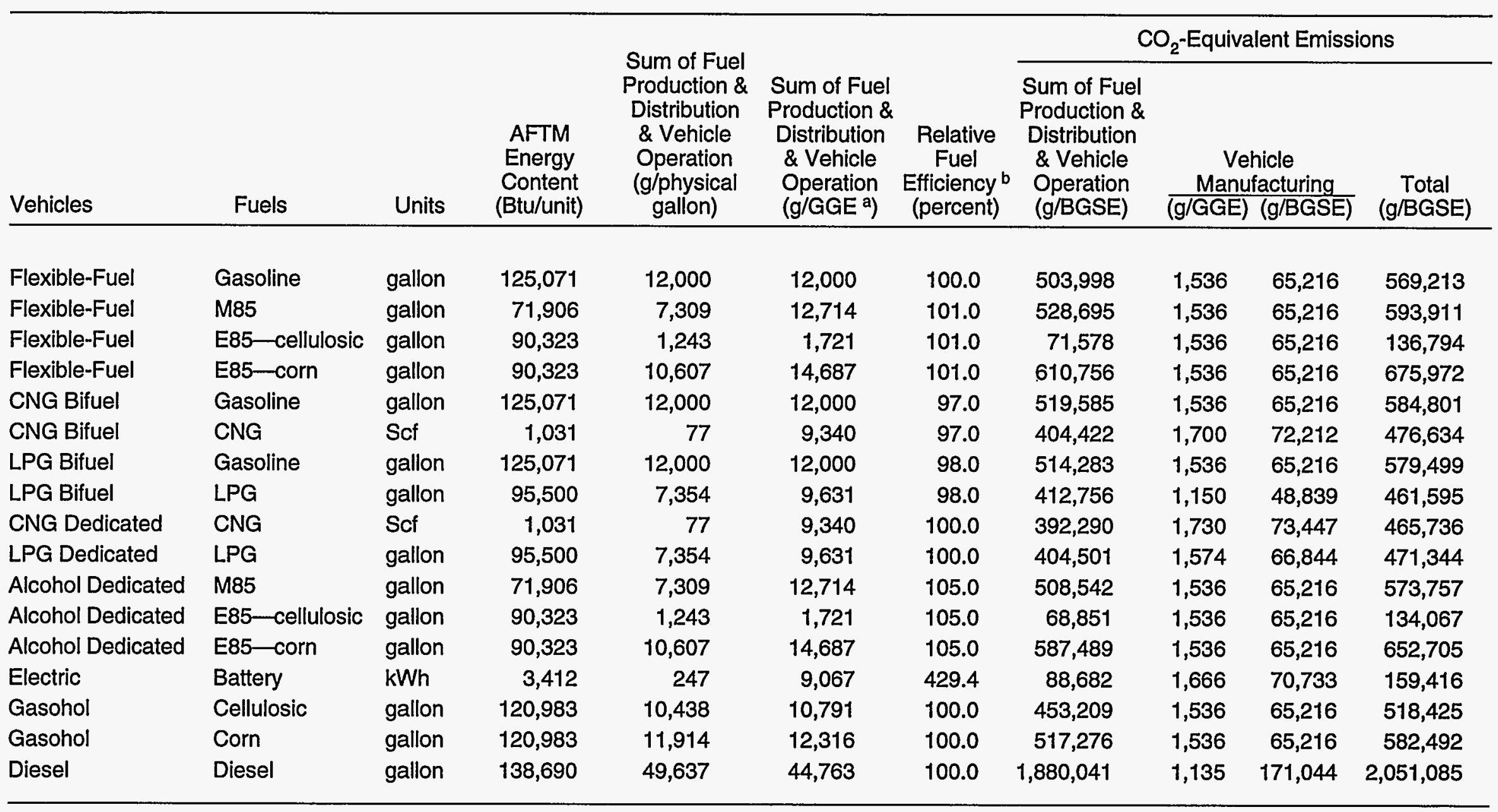

Note: Mileage assumption is $21.3 \mathrm{mpg}$.

a $\mathrm{GGE}=125,071 \mathrm{Btu}$

b Relative fuel efficiency refers to different efficiencies related to fuel economy and vehicle operation. The alcohol fuels in flex-fuel vehicles achieve a gain of 1 percent; the alcohols in dedicated vehicles gain 5 percent. The CNG and LPG bifuel vehicles incur efficiency losses related to increased weights of the engines (relative to a traditional gasoline engine). 
Table IV-5 - Greenhouse Gas Emissions of Industrial Fuels
(grams of $\mathrm{CO}_{2}$-equivalent per million Btu of net final product)

\begin{tabular}{lcccc}
\hline & Natural Gas & Fuel Oil & LPG & Distillate \\
\hline Total & 63,917 & 90,598 & 73,409 & 91,599 \\
\hline
\end{tabular}

sumed to contain 5.253 million British thermal units (MMBtu) in the model. Total U.S. and Canada energy imports are constrained in this case to be no more than 6.38 trillion Btu per day [(1.215 million barrels per day) $(5.253$ MMBtu per barrel)] less than in Case 1 (the unconstrained fuel and vehicle choice case). ${ }^{1}$

\section{Light-Duty Vehicle Replacement-Fuel Use 30 Percent of Total LDV Fuel Use (Case 5)}

In Case 5, total light-duty vehicle (LDV) replacement fuel use is constrained to equal exactly 30 percent of all light-duty motorvehicle fuel use. Fuels that are available to meet this constraint (which, again, is 2.43 MMBGSE per day) are the 1.57 MMBGSE per day in the conventional gasoline logit and 1.81 MMBGSE per day in the reformulated gasoline logit, the ethanol component of gasohol use, and the oxygenates in reformulated gasoline. The remaining light-duty motor-vehicle fuel demands outside the logit are fixed as either conventional gasoline or reformulated gasoline and are unavailable to switch to alternative fuels to satisfy the 30-percent replacement constraint. In the benchmark case, only 12.4 percent of LDV fuel demand is met by replacement fuels, a large portion of which is in noncrude oil inputs to reformulated gasoline and gasohol. Case 5

\footnotetext{
${ }^{1}$ As noted in Section III, all motor-vehicle fuel use targets, whether they be input consumption forecasts or constraints on fuel/vehicle choices, are expressed in MMBGSE per day. Because the benchmark case assumes nearly all of this demand to be satisfied by gasolines, gasoline consumption is the benchmark to which import reductions are compared. If satisfied by conventional gasoline, a barrel of gasoline senvice may be met by a physical barrel of gasoline. The model accounting does consider that if met by a fuel other than gasoline, the equivalent physical volume of the alternative fuel will not be the same because of Btu content and efficiency differences.
}

therefore requires increased alternative-fuel use of about 1.44 MMBGSE per day out of a pool of 3.38 MMBGSE per day that is available to switch.

\section{U.S. Replacement Fuel Imports Limited (Case 6)}

Case 6 is the "letter of the law" interpretation of EPACT (as opposed to the "intent of the law" interpretation represented by Case 4. EPACT states a goal of replacement motorfuel usage to be at least 30 percent of all lightduty motor-vehicle fuel use and a goal of supplying that replacement-fuel use with at least 50 percent domestic supplies. In addition, increased imports of any fuel products into the United States in a final form that could be used as an alternative motor-vehicle fuel are restricted. Because this constraint could satisfy increased demand of alternative fuels in the motor-vehicle market by displacing fuel use in other sectors in the United States, imports of fuels outside the motor-vehicle sector could still increase. For example, increased LPG demand in motor vehicles could affect the use of $L P G$ in petrochemicals. The rise in LPG demand could be accommodated by increased imports of naphtha.

This case is structured to limit direct imports of fuels suitable for use in motor vehicles. Methanol and LPG imports are limited. Natural gas imports are not constrained because the United States and Canada are treated as one region for domestic imports accounting. Liquefied natural gas (LNG) imports are too costly to displace any potential increase in Canadian gas imports.

The level of LPG and methanol imports is constrained to that of the benchmark case plus half of the target replacement-fuel use set forth in EPACT. As in Case 4, this constraint is equivalent to 1.215 MMBGSE per day. This 
setup ensures that 50 percent of target replacement fuel supplies are produced within NAFTA. Methanol and LPG imports and target replacement fuel use are measured in Btu for the purposes of this constraint.

\section{SENSITIVITIES}

To test the robustness of model solutions to changes in key assumptions used in the modeling, the benchmark case and the unconstrained case were both run with a series of sensitivities. Each sensitivity incorporates changes to AFTM model parameters describing regional supply (production capacity of raw fuels), regional demand, or an element of the cost structure of a fuel. The sensitivities examine oil and gas market responses to policies that restrict U.S. imports or GHG emissions, market responses to U.S. tax policies on motor-vehicle fuels, and different assumptions regarding raw fuel supplies and costs, fuel processing costs, and demands for nonmotor fuels. Each sensitivity case is set up independent of the parameters used to model the Reference Oil Price Scenario and the Low Oil Price Scenario. The AFTM has been constructed so that it is possible to run each sensitivity with each oil price scenario without changing the scenarios' original assumptionsexcept for alteration of whatever parameter needs to be altered for the particular sensitivity analysis.

\section{High Ethylene Demand (Sensitivity B)}

Because of ethylene manufacturing's importance as a competing consumer of increased motor-vehicle demand for LPG, Sensitivity B was created to explore the sensitivity of model results to increased worldwide demand for ethylene. Ethylene is a primary petrochemical product, and its production is forecast to rise to 35 percent (by weight) of basic petrochemical production in the United States by 2010 (GRI 1993). Worldwide demand is increasing more rapidly than in the United States (Rhodes 1994, Oil and Gas Journal 1994; Poten and Partners, Inc. 1992; International Butane/Propane Newsletter 1993; and Zanetti 1993). Ethylene manufacturing feedstocks are ethane,
LPG, and naphtha/gasoil, with LPG currently providing about one-third of U.S. ethylene feedstocks.

In Sensitivity B, 2010 ethylene demand is 3.77 MMBD, which is about 63 percent higher than the forecasted demand of 6.13 MMBD in the benchmark case in the Reference Oil Price Scenario. The majority of the more rapid growth in this case is in countries not in the Organization for Economic Cooperation and Development (OECD). Table IV-6 summarizes AFTM assumptions for ethylene demand.

\section{Higher Methanol Manufacturing Cost (Sensitivity C)}

Results from the Reference Oil Price Scenario unconstrained case (Case l) appear to find methanol an attractive alternative motor fuel. Sensitivity $\mathrm{C}$ considers the possibility that methanol conversion costs do not decrease from today's standard plant costs. The steps involved in bringing M85 to the retail pump are numerous: raw gas production and processing, methane conversion to methanol, methanol transport (including overseas shipping by product carriers if the source is outside the United States), distribution, and retail outlet markup. In the reference case, methanol conversion costs are based on cost estimates of very large-scale advanced-technology plants (DOE 1989). Sensitivity $C$ uses cost estimates for methanol conversion based on current stateof-the-art technology and smaller scale plants. Sensitivity $C$ cost estimates for methanol conversion are about 60 percent higher than in the Reference Oil Price Scenario benchmark case. Fuel consumption during the methanol manufacturing process is about 10 percent higher than in the benchmark case (DOE 1989).

\section{More Optimistic U.S. and Canada Natural Gas Supplies (Sensitivity D)}

Sensitivity $D$ assumes that gas production capacity in both the United States and Canada is 25 percent greater than in the Reference Oil Price Scenario benchmark case. In the unconstrained reference case (Case 1), LPG imports increase to supply increased motor-vehicle demand for LPG. Sensitivity D tests the attrac- 
Table IV-6 - Assumed Demand for Ethylene

(MMBD)

\begin{tabular}{lccccccc}
\hline Case & United & Canada & Japan & $\begin{array}{c}\text { Western } \\
\text { Europe }\end{array}$ & OPEC & ROW & World \\
\hline Reference & 1.210 & 0.137 & 0.363 & 1.104 & 0.221 & 0.735 & 3.700 \\
Sensitivity B & 1.459 & 0.194 & 0.477 & 1.155 & 0.767 & 2.080 & 6.132
\end{tabular}

\section{Table IV-7 - Assumed U.S. Nałural Gas Supplies}

\begin{tabular}{lccc}
\hline Case & Wet gas $(\mathrm{bcfd})$ & Dry gas $(\mathrm{bcfd})$ & Dry gas $(\$ / \mathrm{Mcf})$ \\
\hline Reference & 65.6 & 55.6 & 3.26 \\
Sensitivity D & 82.0 & 69.4 & 3.26 \\
\hline
\end{tabular}

tiveness of increasing LPG imports if greater domestic supplies of natural gas and associated LPG are available. In the AFTM structure, this is accomplished by increasing the input reference production capacity on the raw gas supply curves. The two U.S. gas supply scenarios are summarized in Table IV-7.

\section{More Pessimistic Non-OECD Natural Gas Supplies (Sensitivity E)}

Sensitivity $E$ assumes gas production capacity outside the United States, Canada, and Western Europe is 25 percent less than in the Reference Oil Price Scenario. Raw gas supply curves representing OPEC, rest of world (ROW), and all of the remote gas regions have been reduced 25 percent. Changes to the AFTM structure are made to input reference production capacity quantities in each region, while costs are kept the same, similar to the changes made in Sensitivity D.

\section{Current Mołor-Fuel Taxes and Greater U.S.-Canada Natural Gas Supplies (Sensitivity F)}

Sensitivity $\mathrm{F}$ combines the current motorvehicle fuel tax schedule with the assumptions of increased natural gas supplies in the United States and Canada in Sensitivity D.

\section{DETAILED RESULTS}

The following tables summarize model solution values for many of the key global and U.S. fuel and vehicle parameters under study. Results for both the Reference Oil Price Scenario (Tables IV-8 through IV-20) and the Low Oil Price Scenario (Tables IV-21 through IV-33) are presented. Results shown include the following:

- Retail motor-fuel prices in the United States for gasoline and alternative fuels in dollars per gallon of gasoline-equivalent (see Appendix $A$ for physical unit conversion factors)

- Light-duty vehicle fuel use in million barrelsgasoline-equivalent per day (this is the model's standard unit of gasoline-serviceequivalent satisfied)

- Imports from outside NAFTA in million barrels of crude oil equivalent per day (a crude

- oil barrel heat content of 5.8 MMBtu is the standard measure)

- GHG emissions in million short tons per day (emissions counted are $\mathrm{CO}_{2}$ and $\mathrm{CO}_{2}^{-}$ equivalent) 
- Composition of U.S. economic benefits and costs in million dollars per year relative to the corresponding benchmark case (this table summarizes the costs and benefits estimates made by the model in its optimization of global supply, processing, shipping, vehicle manufacturing, fuel sharing (utilization), and demand functions)

- Federal and State motor-fuel taxes

- U.S. environmental benefits from alternative-fuel vehicles in million dollars per year

- Crude oil production and price by region
- Natural gas production and price by region (note that prices are estimated full wellstream value of methane and all liquids)

- U.S. end-use prices for natural gas, LPG, and fuel oils

- U.S. natural gas balance (supply-and-demand disposition of dry gas)

- U.S. LPG balance

- U.S. light-duty vehicle fleet in the year 2010 


\section{Table IV-8 - Reference Oil Price Scenario Retail Motor-Fuel Prices \\ (dollars per gallon of gasoline-equivalent)}

\begin{tabular}{|c|c|c|c|c|c|c|c|c|c|c|c|c|c|c|c|c|c|c|c|}
\hline Case \#: & EO & E1 & E2 & E3 & E4 & E5 & E6 & CO & ct & EO-B & E1-B & EO-C & $E 1-C$ & EO-D & $E 1-D$ & EO-E & E1-E & $\mathrm{CO}-\mathrm{F}$ & C1-F \\
\hline Fuel Taxes: & \multicolumn{7}{|c|}{ Equal } & \multicolumn{2}{|c|}{ Current } & \multicolumn{8}{|c|}{ Equal } & \multicolumn{2}{|c|}{ Current } \\
\hline Constraint: & $\begin{array}{c}\text { Bench- } \\
\text { mark }\end{array}$ & $\begin{array}{l}\text { Uncon- } \\
\text { strained }\end{array}$ & $\begin{array}{l}\text { GHG } \\
90 \%\end{array}$ & $\begin{array}{l}\text { GHG } \\
80 \%\end{array}$ & $\begin{array}{l}\text { Energy } \\
\text { Imports } \\
\text { Limited }\end{array}$ & $\begin{array}{c}\text { Alt. } \\
\text { Fuel } \\
\text { at } 30 \%\end{array}$ & $\begin{array}{c}\text { Alt. } \\
\text { Fuels } \\
\text { Imports } \\
\text { Limited }\end{array}$ & $\begin{array}{c}\text { Bench- } \\
\text { mark }\end{array}$ & $\begin{array}{l}\text { Uncon- } \\
\text { strained }\end{array}$ & \multicolumn{2}{|c|}{$\begin{array}{l}\text { Bench-Uncon- } \\
\text { mark strained }\end{array}$} & $\begin{array}{l}\text { Bench- } \\
\text { mark }\end{array}$ & $\begin{array}{l}\text { Uncon- } \\
\text { strained }\end{array}$ & $\begin{array}{l}\text { Bench-1 } \\
\text { mark s }\end{array}$ & $\begin{array}{l}\text { Uncon- } \\
\text { strained }\end{array}$ & $\begin{array}{l}\text { Bench- } \\
\text { mark }\end{array}$ & $\begin{array}{l}\text { Uncon- } \\
\text { strained }\end{array}$ & $\begin{array}{l}\text { Bench- } \\
\text { mark }\end{array}$ & $\begin{array}{l}\text { Uncon- } \\
\text { strained }\end{array}$ \\
\hline Sensitivity: & & & & & & & & & & \multicolumn{2}{|c|}{$\begin{array}{l}\text { Ethylene } \\
\text { Demand }\end{array}$} & \multicolumn{2}{|c|}{$\begin{array}{l}\text { Methanol } \\
\text { Costs }\end{array}$} & \multicolumn{2}{|c|}{$\begin{array}{l}\text { More North } \\
\text { American Gas }\end{array}$} & \multicolumn{2}{|c|}{$\begin{array}{l}\text { Less } \\
\text { Foreign Gas }\end{array}$} & \multicolumn{2}{|c|}{$\begin{array}{l}\text { More North } \\
\text { American Gas }\end{array}$} \\
\hline & \multicolumn{19}{|c|}{ Absolute Price } \\
\hline $\begin{array}{l}\text { Conventional } \\
\text { Gasoline }\end{array}$ & 1.35 & 1.33 & 1.73 & 2.34 & 1.37 & 1.29 & 1.29 & 1.35 & 1.32 & 1.34 & 1.32 & 1.35 & 1.33 & 1.34 & 1.31 & 1.37 & 1.35 & 1.34 & 1.31 \\
\hline Reformulated & & & & & & & & & & & & & & & & & & & \\
\hline Gasoline & 1.44 & 1.43 & 1.86 & 2.50 & 1.47 & 1.40 & 1.40 & 1.44 & 1.42 & 1.44 & 1.42 & 1.44 & 1.43 & 1.42 & 1.41 & 1.46 & 1.44 & 1.42 & 1.41 \\
\hline CNG & 1.30 & 1.31 & 1.63 & 2.10 & 1.32 & 1.31 & 1.31 & 1.18 & 1.19 & 1.31 & 1.31 & 1.30 & 1.31 & 1.25 & 1.25 & 1.32 & 1.32 & 1.12 & 1.13 \\
\hline Ethanol (E85) & 1.80 & 1.79 & 1.89 & 2.33 & 1.80 & 1.79 & 1.79 & 1.34 & 1.37 & 1.80 & 1.79 & 1.80 & 1.79 & 1.79 & 1.79 & 1.80 & 1.80 & 1.33 & 1.36 \\
\hline Methanol (M85) & 1.25 & 1.34 & 1.78 & 2.33 & 1.39 & 1.32 & 1.32 & 1.39 & 1.38 & 1.24 & 1.34 & 1.49 & 1.54 & 1.25 & 1.34 & 1.27 & 1.37 & 1.38 & 1.38 \\
\hline LPG & 1.15 & 1.20 & 1.59 & 2.12 & 1.26 & 1.19 & 1.19 & 1.21 & 1.26 & 1.21 & 1.22 & 1.15 & 1.21 & 1.12 & 1.19 & 1.18 & 1.23 & 1.19 & 1.23 \\
\hline \multirow[t]{2}{*}{ Electricity } & 0.59 & 0.59 & 1.99 & 4.01 & 0.60 & 0.59 & 0.59 & 0.59 & 0.60 & 0.59 & 0.59 & 0.59 & 0.60 & 0.58 & 0.58 & 0.60 & 0.60 & 0.58 & 0.58 \\
\hline & \multicolumn{19}{|c|}{ Difference From Corresponding Benchmark Case } \\
\hline $\begin{array}{l}\text { Conventional } \\
\text { Gasoline }\end{array}$ & & $(0.02)$ & 0.38 & 0.99 & 0.02 & $(0.06)$ & $(0.06)$ & & $(0.03)$ & & $(0.02)$ & & $(0.02)$ & & $(0.03)$ & & $(0.02)$ & & $(0.03)$ \\
\hline $\begin{array}{l}\text { Reformulated } \\
\text { Gasoline }\end{array}$ & & $(0.01)$ & 0.42 & 1.06 & 0.03 & $(0.04)$ & $(0.04)$ & & $(0.02)$ & & $(0.02)$ & & $(0.01)$ & & $(0.01)$ & & $(0.02)$ & & $(0.01)$ \\
\hline CNG & & 0.01 & 0.33 & 0.80 & 0.02 & 0.01 & 0.01 & & 0.01 & & 0.00 & & 0.01 & & 0.00 & & 0.00 & & 0.01 \\
\hline Ethanol (E85) & & $(0.01)$ & 0.09 & 0.53 & 0.00 & $(0.01)$ & $(0.01)$ & & 0.03 & & $(0.01)$ & & $(0.01)$ & & 0.00 & & 0.00 & & 0.03 \\
\hline Methanol (M85) & & 0.09 & 0.53 & 1.08 & 0.14 & 0.07 & 0.07 & & $(0.01)$ & & 0.10 & & 0.05 & & 0.09 & & 0.10 & & 0.00 \\
\hline LPG & & 0.05 & 0.44 & 0.97 & 0.11 & 0.04 & 0.04 & & 0.05 & & 0.01 & & 0.06 & & 0.07 & & 0.05 & & 0.04 \\
\hline Electricity & & 0.00 & 1.40 & 3.42 & 0.01 & 0.00 & 0.00 & & 0.01 & & 0.00 & & 0.01 & & 0.00 & & 0.00 & & 0.00 \\
\hline
\end{tabular}


Table IV-9 - Reference Oil Price Scenario Light-Duty-Vehicle Fuel Use

(million barrels of gasoline-equivalent per day)

\begin{tabular}{|c|c|c|c|c|c|c|c|c|c|c|c|c|c|c|c|c|c|c|c|}
\hline Case \#: & EO & E1 & $\mathrm{E2}$ & E3 & E4 & E5 & E6 & $\mathrm{CO}$ & C1 & $\mathrm{EO}-\mathrm{B}$ & $E 1-B$ & EO-C & $\mathrm{E} 1-\mathrm{C}$ & EO-D & $E 1-D$ & EO-E & E1-E & CO-F & C1-F \\
\hline Fuel Taxes: & \multicolumn{7}{|c|}{ Equal } & \multicolumn{2}{|c|}{ Current } & \multicolumn{8}{|c|}{ Equal } & \multicolumn{2}{|c|}{ Current } \\
\hline Constraint: & $\begin{array}{c}\text { Bench- } \\
\text { mark }\end{array}$ & $\begin{array}{l}\text { Uncon- } \\
\text { strained }\end{array}$ & $\begin{array}{l}\text { GHG } \\
90 \% \\
\end{array}$ & $\begin{array}{l}\text { GHG } \\
80 \% \\
\end{array}$ & $\begin{array}{l}\text { Energy } \\
\text { Imports } \\
\text { Limited }\end{array}$ & $\begin{array}{c}\text { Alt. } \\
\text { Fuel } \\
\text { at } 30 \%\end{array}$ & $\begin{array}{c}\text { Alt. } \\
\text { Fuels } \\
\text { Imports } \\
\text { Limited }\end{array}$ & $\begin{array}{c}\text { Bench- } \\
\text { mark }\end{array}$ & $\begin{array}{l}\text { Uncon- } \\
\text { strained }\end{array}$ & $\begin{array}{l}\text { Bench- } \\
\text { mark s }\end{array}$ & $\begin{array}{l}\text { Uncon- } \\
\text { strained }\end{array}$ & $\begin{array}{l}\text { Bench- } \\
\text { mark }\end{array}$ & $\begin{array}{l}\text { Uncon- } \\
\text { strained }\end{array}$ & $\begin{array}{l}\text { Bench- } \\
\text { mark }\end{array}$ & $\begin{array}{l}\text { Uncon- } \\
\text { strained }\end{array}$ & $\begin{array}{l}\text { Bench- } \\
\text { mark }\end{array}$ & $\begin{array}{l}\text { Uncon- } \\
\text { strained }\end{array}$ & $\begin{array}{l}\text { Bench- } \\
\text { mark }\end{array}$ & $\begin{array}{l}\text { Uncon- } \\
\text { strained }\end{array}$ \\
\hline Sensitivity: & & & & & & & & & & $\begin{array}{l}\text { High } \\
\text { Ethyl } \\
\text { Dem }\end{array}$ & $\begin{array}{l}\text { her } \\
\text { lene } \\
\text { nand }\end{array}$ & $\begin{array}{r}\text { Hig } \\
\text { Met } \\
\text { Co }\end{array}$ & $\begin{array}{l}\text { gher } \\
\text { thanol } \\
\text { osts }\end{array}$ & $\begin{array}{l}\text { More } \\
\text { Americ }\end{array}$ & $\begin{array}{l}\text { North } \\
\text { can Gas }\end{array}$ & $\begin{array}{r}\text { Le } \\
\text { Foreic }\end{array}$ & gns Gas & $\begin{array}{l}\text { More } \\
\text { Americe }\end{array}$ & $\begin{array}{l}\text { North } \\
\text { an Gas }\end{array}$ \\
\hline $\begin{array}{l}\text { Conventional } \\
\text { Gasoline }\end{array}$ & 3.994 & 2.940 & 2.828 & 2.396 & 2.942 & 3.328 & 3.328 & 3.991 & 2.896 & 3.996 & 2.961 & 3.995 & 3.055 & 3.997 & 2.954 & 3.987 & 2.953 & 3.993 & 2.844 \\
\hline Reformulated Gasoline & 3.783 & 2.429 & 2.250 & 1.988 & 2.421 & 2.807 & 2.807 & 3.786 & 2.309 & 3.785 & 2.444 & 3.782 & 2.687 & 3.789 & 2.456 & 3.780 & 2.457 & 3.792 & 2.298 \\
\hline CNG & 0.041 & 0.270 & 0.385 & 0.566 & 0.305 & 0.206 & 0.206 & 0.041 & 0.449 & 0.041 & 0.273 & 0.041 & 0.304 & 0.041 & 0.321 & 0.041 & 0.284 & 0.041 & 0.546 \\
\hline Ethanol (E85) & 0.023 & 0.023 & 0.129 & 1.158 & 0.023 & 0.023 & 0.023 & 0.023 & 1.157 & 0.023 & 0.023 & 0.023 & 0.023 & 0.023 & 0.023 & 0.023 & 0.023 & 0.023 & 1.094 \\
\hline Methanol (M85) & 0.035 & 1.059 & 0.890 & 0.213 & 1.037 & 0.774 & 0.774 & 0.035 & 0.197 & 0.035 & 1.085 & 0.035 & 0.511 & 0.035 & 0.991 & 0.035 & 1.020 & 0.035 & 0.171 \\
\hline LPG & 0.031 & 1.263 & 1.290 & 1.239 & 1.229 & 0.838 & 0.838 & 0.031 & 0.978 & 0.031 & 1.200 & 0.031 & 1.392 & 0.031 & 1.252 & 0.031 & 1.233 & 0.031 & 1.045 \\
\hline Electricity & 0.092 & 0.092 & 0.092 & 0.092 & 0.092 & 0.092 & 0.092 & 0.092 & 0.092 & 0.092 & 0.092 & 0.092 & 0.092 & 0.092 & 0.092 & 0.092 & 0.092 & 0.092 & 0.092 \\
\hline LD Total & 7.999 & 8.076 & 7.864 & 7.652 & 8.049 & 8.068 & 8.068 & 7.999 & 8.078 & 8.003 & 8.078 & 7.999 & 8.064 & 8.008 & 8.089 & 7.989 & 8.062 & 8.007 & 8.090 \\
\hline LD Replacement Fuel \% & 12.4 & 38.1 & 39.8 & 45.8 & 38.0 & 30.0 & 30.0 & 12.4 & 39.4 & 12.4 & 37.7 & 12.4 & 34.9 & 12.4 & 37.9 & 12.4 & 37.6 & 12.4 & 40.4 \\
\hline Total Incl. HDV & 10.513 & 10.590 & 10.305 & 10.014 & 10.554 & 10.583 & 10.583 & 10.510 & 10.590 & 10.518 & 10.594 & 10.513 & 10.578 & 10.525 & 10.605 & 10.499 & 10.574 & 10.520 & 10.605 \\
\hline
\end{tabular}

Note: "Replacement fuel" counts natural gas liquild feedstocks and oxygenates in gasoline and nongasoline portion of alternative fuels. 
Table IV-10 - Reference Oil Price Scenario Energy Imports (From Outside NAFTA)

(million barrels of crude-oil-equivalent per day)

\begin{tabular}{|c|c|c|c|c|c|c|c|c|c|c|c|c|c|c|c|c|c|c|c|}
\hline \multirow{2}{*}{$\begin{array}{r}\text { Case \#: } \\
\text { Fuel Taxes: }\end{array}$} & E0 & E1 & E2 & E3 & E4 & E5 & E6 & $\mathrm{CO}$ & C1 & EO-B & $E 1-B$ & EO-C & $E 1-C$ & EO-D & $E 1-D$ & EO-E & $E 1-E$ & $\mathrm{CO}-\mathrm{F}$ & C1-F \\
\hline & \multicolumn{7}{|c|}{ Equal } & \multicolumn{2}{|c|}{ Current } & \multicolumn{8}{|c|}{ Equal } & \multicolumn{2}{|c|}{ Current } \\
\hline Constraint: & $\begin{array}{l}\text { Bench- } \\
\text { mark }\end{array}$ & $\begin{array}{l}\text { Uncon- } \\
\text { strained }\end{array}$ & $\begin{array}{l}\text { GHG } \\
90 \%\end{array}$ & $\begin{array}{l}\text { GHG } \\
80 \%\end{array}$ & $\begin{array}{l}\text { Energy } \\
\text { Imports } \\
\text { Limited }\end{array}$ & $\begin{array}{c}\text { Alt. } \\
\text { Fuel } \\
\text { at } 30 \%\end{array}$ & $\begin{array}{c}\text { Alt. } \\
\text { Fuels } \\
\text { Imports } \\
\text { Limited }\end{array}$ & $\begin{array}{l}\text { Bench- } \\
\text { mark }\end{array}$ & $\begin{array}{l}\text { Uncon- } \\
\text { strained }\end{array}$ & $\begin{array}{l}\text { Bench- } \\
\text { mark }\end{array}$ & $\begin{array}{l}\text { Uncon- } \\
\text { strained }\end{array}$ & $\begin{array}{l}\text { Bench- } \\
\text { mark }\end{array}$ & $\begin{array}{l}\text { Uncon- } \\
\text { strained }\end{array}$ & $\begin{array}{l}\text { Bench- } \\
\text { mark }\end{array}$ & $\begin{array}{l}\text { Uncon- } \\
\text { strained }\end{array}$ & $\begin{array}{l}\text { Bench- } \\
\text { mark }\end{array}$ & $\begin{array}{l}\text { Uncon- } \\
\text { strained }\end{array}$ & $\begin{array}{l}\text { Bench- } \\
\text { mark }\end{array}$ & $\begin{array}{l}\text { Uncon- } \\
\text { strained }\end{array}$ \\
\hline Sensitivity: & & & & & & & & & & \multicolumn{2}{|c|}{$\begin{array}{l}\text { Higher } \\
\text { Ethylene } \\
\text { Demand }\end{array}$} & \multicolumn{2}{|c|}{$\begin{array}{l}\text { Higher } \\
\text { Methanol } \\
\text { Costs }\end{array}$} & \multicolumn{2}{|c|}{$\begin{array}{c}\text { More North } \\
\text { American Gas }\end{array}$} & \multicolumn{2}{|c|}{$\begin{array}{l}\text { Less } \\
\text { Foreign Gas }\end{array}$} & \multicolumn{2}{|c|}{$\begin{array}{l}\text { More North } \\
\text { American Gas }\end{array}$} \\
\hline \multicolumn{20}{|l|}{ Crude and } \\
\hline Methanol (M100) & 0.07 & 0.72 & 0.60 & 0.17 & 0.70 & 0.53 & 0.53 & 0.07 & 0.16 & 0.07 & 0.73 & 0.07 & 0.36 & 0.07 & 0.67 & 0.07 & 0.69 & 0.07 & 0.14 \\
\hline Propane & 0.61 & 1.06 & 1.33 & 1.34 & 0.92 & 0.90 & 0.90 & 0.61 & 0.85 & 0.16 & 1.29 & 0.61 & 1.15 & 0.00 & 0.76 & 0.16 & 0.81 & 0.00 & 0.59 \\
\hline LNG & 0.00 & 0.00 & 0.00 & 0.00 & 0.00 & 0.00 & 0.00 & 0.00 & 0.00 & 0.00 & 0.00 & 0.00 & 0.00 & 0.00 & 0.00 & 0.00 & 0.00 & 0.00 & 0.00 \\
\hline Total & 11.96 & 11.77 & 9.76 & 7.86 & 10.66 & 11.83 & 11.83 & 11.95 & 10.97 & 11.82 & 11.92 & 11.95 & 11.70 & 11.07 & 10.80 & 11.53 & 11.31 & 11.07 & 9.97 \\
\hline
\end{tabular}


Table IV-11 - Reference Oil Price Scenario Greenhouse Gas Emissions

(million short tons per day)

\begin{tabular}{|c|c|c|c|c|c|c|c|c|c|c|c|c|c|c|c|c|c|c|c|}
\hline \multirow{2}{*}{$\begin{array}{r}\text { Case \#: } \\
\text { Fuel Taxes: }\end{array}$} & EO & E1 & E2 & E3 & E4 & E5 & E6 & Co & C1 & $E 0-B$ & $E 1-B$ & EO-C & $E_{1}-\mathrm{C}$ & EO-D & E1-D & EO-E & $E 1-E$ & $\mathrm{CO}-\mathrm{F}$ & $\mathrm{C} 1-\mathrm{F}$ \\
\hline & & & & Equal & & & & \multicolumn{2}{|c|}{ Current } & \multicolumn{8}{|c|}{ Equal } & \multicolumn{2}{|c|}{ Current } \\
\hline Constraint: & $\begin{array}{l}\text { Bench- } \\
\text { mark }\end{array}$ & $\begin{array}{l}\text { Uncon- } \\
\text { strained }\end{array}$ & $\begin{array}{l}\text { GHG } \\
90 \%\end{array}$ & $\begin{array}{l}\text { GHG } \\
80 \%\end{array}$ & $\begin{array}{l}\text { Energy } \\
\text { Imports } \\
\text { Limited }\end{array}$ & $\begin{array}{c}\text { Alt. } \\
\text { Fuel } \\
\text { at } 30 \%\end{array}$ & $\begin{array}{c}\text { Alt. } \\
\text { Fuels } \\
\text { Imports } \\
\text { Limited }\end{array}$ & $\begin{array}{c}\text { Bench- } \\
\text { mark }\end{array}$ & $\begin{array}{l}\text { Uncon- } \\
\text { strained }\end{array}$ & $\begin{array}{l}\text { Bench- } \\
\text { mark }\end{array}$ & $\begin{array}{l}\text { Uncon- } \\
\text { strained }\end{array}$ & $\begin{array}{l}\text { Bench- } \\
\text { mark }\end{array}$ & $\begin{array}{l}\text { Uncon- } \\
\text { strained }\end{array}$ & $\begin{array}{c}\text { Bench-1 } \\
\text { mark s }\end{array}$ & $\begin{array}{l}\text { Uncon- } \\
\text { strained }\end{array}$ & $\begin{array}{c}\text { Bench- } \\
\text { mark }\end{array}$ & $\begin{array}{l}\text { - Uncon- } \\
\text { strained }\end{array}$ & $\begin{array}{l}\text { - Bench- } \\
\text { d mark }\end{array}$ & $\begin{array}{l}\text { - Uncon- } \\
\text { strained }\end{array}$ \\
\hline Sensitivity: & & & & & & & & & & \multicolumn{2}{|c|}{$\begin{array}{l}\text { Ethylene } \\
\text { Demand }\end{array}$} & \multicolumn{2}{|c|}{$\begin{array}{c}\text { Methanol } \\
\text { Costs }\end{array}$} & \multicolumn{2}{|c|}{$\begin{array}{l}\text { More North } \\
\text { American Gas }\end{array}$} & \multicolumn{2}{|c|}{$\begin{array}{l}\text { Less } \\
\text { Foreign Gas }\end{array}$} & \multicolumn{2}{|c|}{$\begin{array}{l}\text { More North } \\
\text { American Gas }\end{array}$} \\
\hline U.S. Motor-Vehicle Fuels & 6.64 & 6.53 & 6.29 & 5.60 & 6.51 & 6.58 & 6.58 & 6.63 & 6.00 & 6.64 & 6.54 & 6.64 & 6.50 & 6.64 & 6.54 & 6.63 & 6.53 & 6.64 & 6.02 \\
\hline U.S. Nonmotor Fuels & 10.39 & 10.43 & 8.98 & 7.97 & 10.19 & 10.38 & 10.38 & 10.39 & 10.40 & 10.50 & 10.45 & 10.39 & 10.44 & 10.63 & 10.60 & 10.46 & 10.45 & 10.63 & 10.58 \\
\hline Total U.S. & 17.03 & 16.96 & 15.27 & 13.57 & 16.70 & 16.96 & 16.96 & 17.02 & 16.40 & 17.14 & 16.99 & 17.03 & 16.94 & 17.27 & 17.14 & 17.09 & 16.98 & 17.27 & 16.60 \\
\hline Total World & 76.36 & 76.64 & 75.46 & 74.06 & 76.50 & 76.52 & 76.52 & 76.35 & 76.04 & 76.66 & 76.78 & 76.36 & 76.61 & 76.72 & 76.83 & 75.67 & 75.74 & 76.72 & 76.29 \\
\hline
\end{tabular}

Note: Calculated only for oil- and natural-gas-derived fuels covered in AFTM and U.S. ethanol. Excludes all coal use. 


\section{Table IV-12 - Reference Oil Price Scenario Composition of U.S. Economic Benefits and Costs}

(million dollars per year relative to corresponding benchmark case)

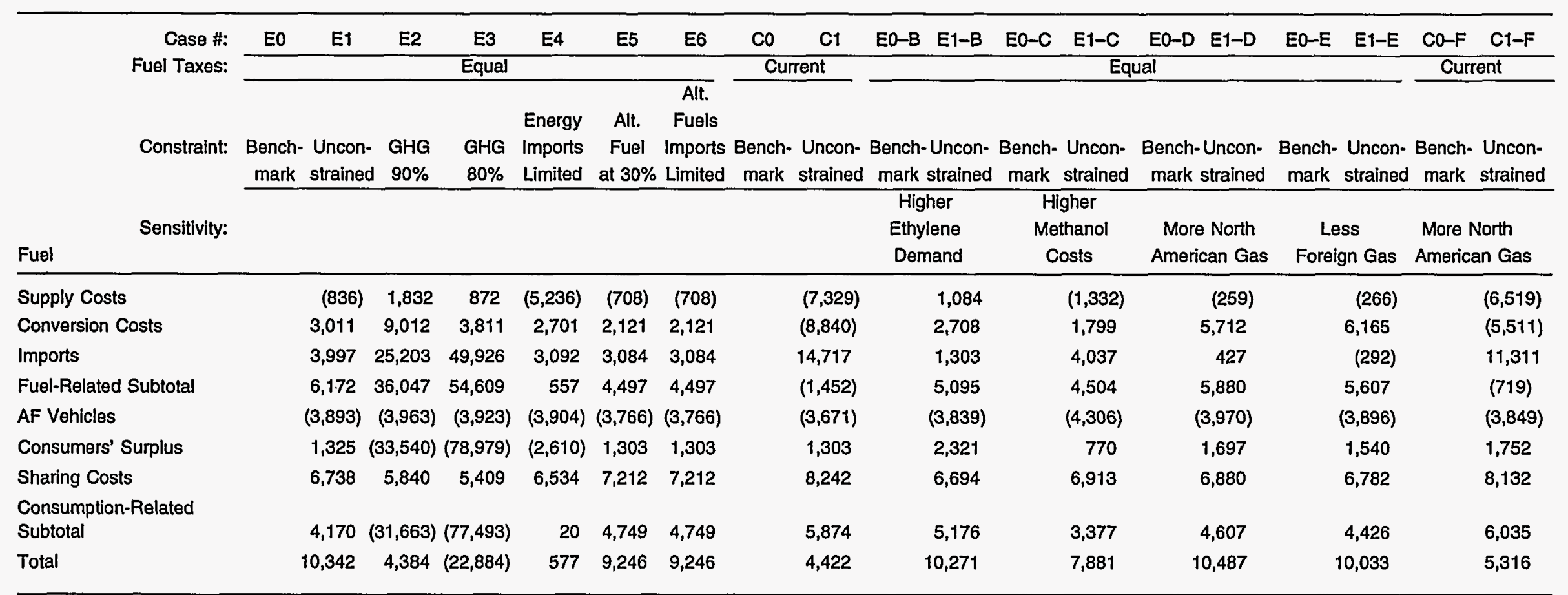


Table IV-13 - Reference Oil Price Scenario Federal and State Motor-Fuel Taxes

\begin{tabular}{|c|c|c|c|c|c|c|c|c|c|c|c|c|c|c|c|c|c|c|c|}
\hline \multirow{2}{*}{$\begin{array}{l}\text { Case \#: } \\
\text { Fuel Taxes: }\end{array}$} & E0 & E1 & E2 & E3 & E4 & E5 & E6 & $\mathrm{CO}$ & C1 & EO-B & E1-B & EO-C & $E 1-C$ & EO-D & E1-D & EO-E & $E 1-E$ & $\mathrm{CO}-\mathrm{F}$ & $C 1-F$ \\
\hline & \multicolumn{7}{|c|}{ Equal } & \multicolumn{2}{|c|}{ Current } & \multicolumn{8}{|c|}{ Equal } & \multicolumn{2}{|c|}{ Current } \\
\hline Constraint: & $\begin{array}{l}\text { Bench- } \\
\text { mark }\end{array}$ & $\begin{array}{l}\text { Uncon- } \\
\text { strained }\end{array}$ & $\begin{array}{l}\text { GHG } \\
90 \%\end{array}$ & $\begin{array}{l}\text { GHG } \\
80 \%\end{array}$ & $\begin{array}{l}\text { Energy } \\
\text { Imports } \\
\text { Limited }\end{array}$ & $\begin{array}{l}\text { Alt. } \\
\text { Fuel } \\
\text { at } 30 \%\end{array}$ & $\begin{array}{c}\text { Alt. } \\
\text { Fuels } \\
\text { Imports } \\
\text { Limited }\end{array}$ & $\begin{array}{l}\text { Bench- } \\
\text { mark }\end{array}$ & $\begin{array}{l}\text { Uncon- } \\
\text { strained }\end{array}$ & $\begin{array}{l}\text { Bench- } \\
\text { mark }\end{array}$ & $\begin{array}{l}\text {-Uncon- } \\
\text { strained }\end{array}$ & $\begin{array}{l}\text { Bench- } \\
\text { mark }\end{array}$ & $\begin{array}{l}\text { Uncon- } \\
\text { strained }\end{array}$ & $\begin{array}{l}\text { Bench- } \\
\text { mark }\end{array}$ & $\begin{array}{l}\text { Uncon- } \\
\text { strained }\end{array}$ & $\begin{array}{l}\text { Bench- } \\
\text { mark }\end{array}$ & $\begin{array}{l}\text { Uncon- } \\
\text { strained }\end{array}$ & $\begin{array}{l}\text { Bench- } \\
\text { mark }\end{array}$ & $\begin{array}{l}\text { Uncon- } \\
\text { strained }\end{array}$ \\
\hline Sensitivity: & & & & & & & & & & $\begin{array}{l}\text { High } \\
\text { Ethyl } \\
\text { Dem }\end{array}$ & $\begin{array}{l}\text { her } \\
\text { lene } \\
\text { nand }\end{array}$ & $\begin{array}{r}\mathrm{Hi} \\
\mathrm{Me} \\
\mathrm{C}\end{array}$ & $\begin{array}{l}\text { igher } \\
\text { thanol } \\
\text { osts }\end{array}$ & $\begin{array}{l}\text { More } \\
\text { Ameri }\end{array}$ & $\begin{array}{l}\theta \text { North } \\
\text { ican Gas }\end{array}$ & $\begin{array}{r}\text { Le } \\
\text { Foreig }\end{array}$ & gn Gas & $\begin{array}{l}\text { More N } \\
\text { America }\end{array}$ & $\begin{array}{l}\text { Vorth } \\
\text { an Gas }\end{array}$ \\
\hline $\begin{array}{l}\text { Total (million dollars } \\
\text { per year) }\end{array}$ & 52,859 & 53,049 & 51,629 & 50,100 & 52,866 & 52,666 & 52,666 & 53,013 & 46,304 & 52,881 & 53,053 & 52,852 & 53,067 & 52,914 & 53,122 & 52,786 & 52,968 & 53,071 & 46,300 \\
\hline $\begin{array}{l}\text { Average Rate } \\
\text { (Dollars per gallon of } \\
\text { gasoline-equivalent) }\end{array}$ & 0.328 & 0.327 & 0.327 & 0.326 & 0.327 & 0.325 & 0.325 & 0.329 & 0.285 & 0.328 & 0.327 & 0.328 & 0.327 & 0.328 & 0.327 & 0.328 & 0.327 & 0.329 & 0.285 \\
\hline $\begin{array}{l}\text { Change Relative to } \\
\text { Corresponding } \\
\text { Benchmark Case } \\
\text { (Million dollars per year) }\end{array}$ & & 190 & $(1,230)$ & $(2,759)$ & 7 & (193) & (193) & & $(7,059)$ & & 172 & & 215 & & 208 & & 182 & & $(6,771)$ \\
\hline
\end{tabular}

Nole: Includes effects of tax credit for renewables. Includes both light- and heavy-duty fuel use. 
Table IV-14 - Reference Oil Price Scenario U.S. Environmental Benefits From Alternative-Fuel Vehicles

(million dollars per year)

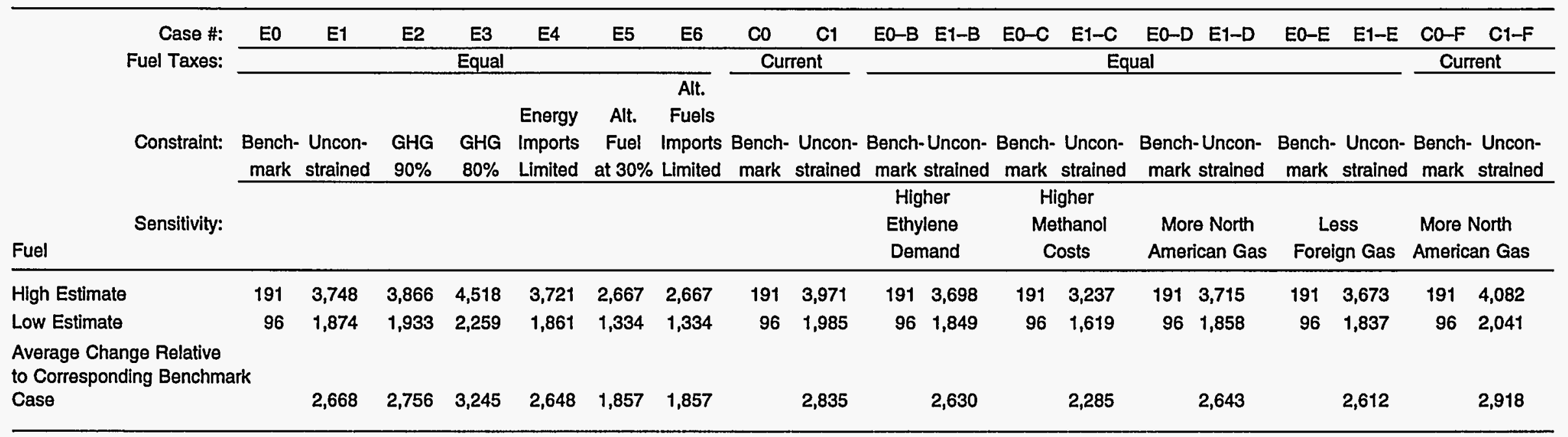


Table IV-15 - Reference Oil Price Scenario Crude Oil Production and Price

\begin{tabular}{|c|c|c|c|c|c|c|c|c|c|c|c|c|c|c|c|c|c|c|c|c|}
\hline & \multirow{2}{*}{$\begin{array}{r}\text { Case \#: } \\
\text { Fuel Taxes: }\end{array}$} & EO & E1 & E2 & E3 & E4 & E5 & E6 & $\mathrm{CO}$ & C1 & EO-B & E1-B & EO-C & $E 1-C$ & EO-D & $E 1-D$ & EO-E & E1-E & CO-F & $C 1-F$ \\
\hline & & & & & Equal & & & & \multicolumn{2}{|c|}{ Current } & \multicolumn{8}{|c|}{ Equal } & \multicolumn{2}{|c|}{ Current } \\
\hline & Constraint: & $\begin{array}{c}\text { Bench- } \\
\text { mark }\end{array}$ & $\begin{array}{l}\text { Uncon- } \\
\text { strained }\end{array}$ & $\begin{array}{l}\text { GHG } \\
90 \%\end{array}$ & $\begin{array}{l}\text { GHG } \\
80 \%\end{array}$ & $\begin{array}{l}\text { Energy } \\
\text { Imports } \\
\text { Limited }\end{array}$ & $\begin{array}{c}\text { Alt. } \\
\text { Fuel } \\
\text { at } 30 \%\end{array}$ & $\begin{array}{c}\text { Alt. } \\
\text { Fuels } \\
\text { Imports } \\
\text { Limited }\end{array}$ & $\begin{array}{c}\text { Bench- } \\
\text { mark }\end{array}$ & $\begin{array}{l}\text { Uncon- } \\
\text { strained }\end{array}$ & $\begin{array}{l}\text { Bench- } \\
\text { mark }\end{array}$ & $\begin{array}{l}\text { Uncon- } \\
\text { strained }\end{array}$ & $\begin{array}{c}\text { Bench- } \\
\text { mark }\end{array}$ & $\begin{array}{l}\text { Uncon- } \\
\text { strained }\end{array}$ & $\begin{array}{c}\text { Bench- } \\
\text { mark s }\end{array}$ & $\begin{array}{l}\text { Uncon- } \\
\text { strained }\end{array}$ & $\begin{array}{l}\text { Bench- } \\
\text { mark }\end{array}$ & $\begin{array}{l}\text { Uncon- } \\
\text { strained }\end{array}$ & $\begin{array}{l}\text { Bench- } \\
\text { mark }\end{array}$ & $\begin{array}{l}\text { Uncon- } \\
\text { strained }\end{array}$ \\
\hline Fuel & Sensitivity: & & & & & & & & & & $\begin{array}{r}\text { High } \\
\text { Ethyl } \\
\text { Dem }\end{array}$ & $\begin{array}{l}\text { her } \\
\text { lene } \\
\text { nand }\end{array}$ & $\begin{array}{r}\mathrm{HI} \\
\mathrm{Me} \\
\mathrm{C}\end{array}$ & $\begin{array}{l}\text { igher } \\
\text { thanol } \\
\text { osts }\end{array}$ & $\begin{array}{r}\text { More } \\
\text { Americ }\end{array}$ & $\begin{array}{l}\text { North } \\
\text { can Gas }\end{array}$ & $\begin{array}{r}\text { Le: } \\
\text { Foreig }\end{array}$ & gn Gas & $\begin{array}{l}\text { More N } \\
\text { America }\end{array}$ & $\begin{array}{l}\text { North } \\
\text { an Gas }\end{array}$ \\
\hline
\end{tabular}

Production (million barrels per year)

USA

Canada

Western Europe

OPEC

ROW

World Total

$\stackrel{\infty}{+}$

\begin{tabular}{|c|c|c|c|c|c|c|c|c|c|c|c|c|c|c|c|c|c|c|}
\hline 1,940 & 1,919 & 1,881 & 1,856 & 1,987 & 1,926 & 1,926 & 1,940 & 1,918 & 1,932 & 1,911 & 1,940 & 1,922 & 1,925 & 1,905 & 1,964 & 1,945 & 1,925 & 1,903 \\
\hline 615 & 608 & 596 & 589 & 630 & 611 & 611 & 615 & 608 & 613 & 606 & 615 & 609 & 611 & 604 & 623 & 617 & 611 & 604 \\
\hline 1,572 & 1,554 & 1,524 & 1,503 & 1,541 & 1,560 & 1,560 & 1,572 & 1,554 & 1,565 & 1,549 & 1,572 & 1,558 & 1,560 & 1,544 & 1,592 & 1,576 & 1,560 & 1,543 \\
\hline 14,540 & 14,412 & 14,186 & 14,038 & 14,311 & 14,456 & 14,456 & 14,540 & 14,407 & 14,494 & 14,369 & 14,540 & 14,435 & 14,452 & 14,335 & 14,687 & 14,574 & 14,451 & 14,321 \\
\hline 8,487 & 8,393 & 8,225 & 8,115 & 8,318 & 8,425 & 8,425 & 8,487 & 8,390 & 8,454 & 8,362 & 8,488 & 8,411 & 8,422 & 8,335 & 8,595 & 8,513 & 8,422 & 8,325 \\
\hline 27,154 & 26,887 & 26,412 & 26,101 & 26,788 & 26,978 & 26,978 & 27,153 & 26,877 & 27,059 & 26,797 & 27,154 & 26,936 & 26,969 & 26,723 & 27,460 & 27,225 & 26,9692 & 26,695 \\
\hline
\end{tabular}

Prices (dollars per barrel)

USA

Canada

Western Europe

OPEC

ROW

World Average

\begin{tabular}{|c|c|c|c|c|c|c|c|c|c|c|c|c|c|c|c|c|c|c|}
\hline 26.73 & 26.10 & 25.06 & 24.41 & 28.23 & 26.31 & 26.31 & 26.72 & 26.08 & 26.50 & 25.90 & 26.73 & 26.21 & 26.28 & 25.71 & 27.46 & 26.88 & 26.28 & 25.66 \\
\hline 26.11 & 25.47 & 24.45 & 23.87 & 27.59 & 25.69 & 25.69 & 26.11 & 25.44 & 25.87 & 25.28 & 26.11 & 25.57 & 25.71 & 25.12 & 26.87 & 26.27 & 25.70 & 25.07 \\
\hline 26.89 & 26.26 & 25.21 & 24.55 & 25.79 & 26.48 & 26.48 & 26.89 & 26.24 & 26.66 & 26.06 & 26.89 & 26.37 & 26.46 & 25.90 & 27.66 & 27.07 & 26.46 & 25.84 \\
\hline 25.20 & 24.57 & 23.53 & 22.88 & 24.10 & 24.78 & 24.78 & 25.20 & 24.55 & 24.97 & 24.37 & 25.20 & 24.69 & 24.77 & 24.21 & 25.94 & 25.36 & 24.76 & 24.14 \\
\hline 26.46 & 25.84 & 24.80 & 24.16 & 25.36 & 26.04 & 26.04 & 26.46 & 25.82 & 26.24 & 25.64 & 26.46 & 25.95 & 26.02 & 25.47 & 27.20 & 26.63 & 26.02 & 25.40 \\
\hline 25.82 & 25.19 & 24.15 & 23.51 & 24.98 & 25.40 & 25.40 & 25.82 & 25.17 & 25.59 & 24.99 & 25.82 & 25.31 & 25.39 & 24.83 & 26.56 & 25.99 & 25.38 & 24.76 \\
\hline
\end{tabular}


Table IV-16 - Reference Oil Price Scenario Natural Gas Production and Price (Wet Basis)

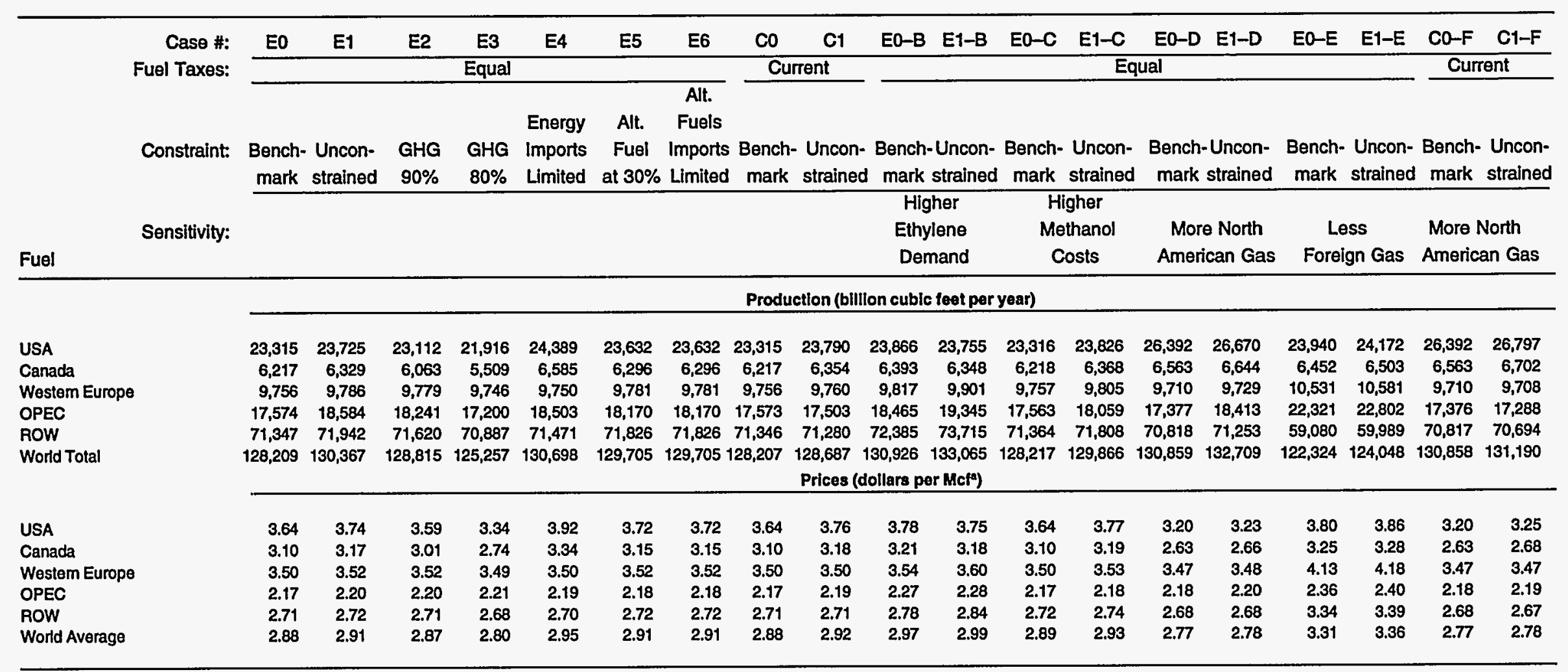

Includes value of condensate and gas plant liquids. 


\section{Table IV-17 - Reference Oil Price Scenario U.S. End-Use Prices for Natural Gas, LPG, and Fuel Oils}

\begin{tabular}{|c|c|c|c|c|c|c|c|c|c|c|c|c|c|c|c|c|c|c|c|}
\hline Case \#: & EO & E1 & E2 & E3 & E4 & E5 & E6 & $\mathrm{CO}$ & $\mathrm{Cl}$ & E0-B & $\mathrm{E} 1-\mathrm{B}$ & EO-C & $\mathrm{E} 1-\mathrm{C}$ & EO-D & E1-D & EO-E & E1-E & $\mathrm{CO}-\mathrm{F}$ & $\mathrm{C} 1-\mathrm{F}$ \\
\hline Fuel Taxes: & \multicolumn{7}{|c|}{ Equal } & \multicolumn{2}{|c|}{ Current } & \multicolumn{8}{|c|}{ Equal } & \multicolumn{2}{|c|}{ Current } \\
\hline Constraint: & $\begin{array}{c}\text { Bench- } \\
\text { mark }\end{array}$ & $\begin{array}{l}\text { Uncon- } \\
\text { strained }\end{array}$ & $\begin{array}{l}\text { GHG } \\
90 \%\end{array}$ & $\begin{array}{l}\text { GHG } \\
80 \% \\
\end{array}$ & $\begin{array}{l}\text { Energy } \\
\text { Imports } \\
\text { Limited }\end{array}$ & $\begin{array}{c}\text { Alt. } \\
\text { Fuel } \\
\text { at } 30 \%\end{array}$ & $\begin{array}{c}\text { Alt. } \\
\text { Fuels } \\
\text { Imports } \\
\text { Limited }\end{array}$ & $\begin{array}{c}\text { Bench- } \\
\text { mark }\end{array}$ & $\begin{array}{l}\text { - Uncon- } \\
\text { strained }\end{array}$ & \multicolumn{2}{|c|}{$\begin{array}{l}\text { Bench-Uncon- } \\
\text { mark strained }\end{array}$} & $\begin{array}{l}\text { Bench- } \\
\text { mark }\end{array}$ & $\begin{array}{l}\text { Uncon- } \\
\text { strained }\end{array}$ & $\begin{array}{l}\text { Bench- } \\
\text { mark }\end{array}$ & $\begin{array}{l}\text { Uncon- } \\
\text { strained }\end{array}$ & $\begin{array}{c}\text { Bench- } \\
\text { mark }\end{array}$ & $\begin{array}{l}\text { Uncon- } \\
\text { strained }\end{array}$ & $\begin{array}{c}\text { Bench- } \\
\text { mark }\end{array}$ & $\begin{array}{l}\text { Uncon- } \\
\text { strained }\end{array}$ \\
\hline Sensitivity: & & & & & & & & & & \multicolumn{2}{|c|}{$\begin{array}{l}\text { Higher } \\
\text { Ethylene } \\
\text { Demand }\end{array}$} & \multicolumn{2}{|c|}{$\begin{array}{l}\text { Higher } \\
\text { Methanol } \\
\text { Costs }\end{array}$} & \multicolumn{2}{|c|}{$\begin{array}{l}\text { More North } \\
\text { American Gas }\end{array}$} & $\begin{array}{r}\text { Le } \\
\text { Forei }\end{array}$ & igs & \multicolumn{2}{|c|}{$\begin{array}{l}\text { More North } \\
\text { American Gas }\end{array}$} \\
\hline & \multicolumn{19}{|c|}{ Price (dollars per barrel) } \\
\hline Natural Gas & 28.52 & 28.75 & 40.21 & 56.73 & 29.53 & 28.66 & 28.66 & 28.52 & 28.89 & 28.94 & 28.61 & 28.52 & 28.86 & 25.64 & 25.72 & 29.32 & 29.27 & 25.64 & 25.88 \\
\hline LPG & 37.78 & 39.47 & 49.78 & 63.94 & 41.17 & 39.20 & 39.20 & 37.78 & 39.39 & 39.56 & 39.98 & 37.78 & 39.68 & 36.99 & 39.08 & 38.71 & 40.43 & 37.00 & 38.22 \\
\hline Distillate Fuel Oil & 36.03 & 35.59 & 53.75 & 81.28 & 37.76 & 35.59 & 35.59 & 36.03 & 35.60 & 35.77 & 35.31 & 36.03 & 35.71 & 35.28 & 34.99 & 36.71 & 36.32 & 35.28 & 34.99 \\
\hline \multirow[t]{2}{*}{ Residual Fuel Oil } & 26.81 & 26.08 & 43.37 & 69.04 & 28.37 & 26.34 & 26.34 & 26.81 & 26.06 & 26.55 & 25.86 & 26.81 & 26.21 & 26.34 & 25.67 & 27.56 & 26.89 & 26.33 & 25.59 \\
\hline & \multicolumn{19}{|c|}{ Price (dollars per MMBtu) } \\
\hline Natural Gas & 4.54 & 4.57 & 6.40 & 9.02 & 4.70 & 4.56 & 4.56 & 4.54 & 4.60 & 4.60 & 4.55 & 4.54 & 4.59 & 4.08 & 4.09 & 4.66 & 4.66 & 4.08 & 4.12 \\
\hline LPG & 9.42 & 9.84 & 12.41 & 15.94 & 10.26 & 9.77 & 9.77 & 9.42 & 9.82 & 9.86 & 9.97 & 9.42 & 9.89 & 9.22 & 9.74 & 9.65 & 10.08 & 9.22 & 9.53 \\
\hline Distillate Fuel Oil & 6.25 & 6.18 & 9.33 & 14.10 & 6.55 & 6.18 & 6.18 & 6.25 & 6.18 & 6.21 & 6.13 & 6.25 & 6.20 & 6.12 & 6.07 & 6.37 & 6.30 & 6.12 & 6.07 \\
\hline Residual Fuel Oil & 4.26 & 4.15 & 6.90 & 10.98 & 4.51 & 4.19 & 4.19 & 4.26 & 4.15 & 4.22 & 4.11 & 4.26 & 4.17 & 4.19 & 4.08 & 4.38 & 4.28 & 4.19 & 4.07 \\
\hline
\end{tabular}

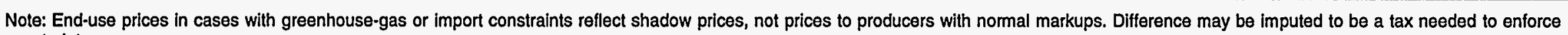
constraint. 
Table IV-18 - Reference Oil Price Scenario U.S. Natural Gas Balance (Dry Basis)

(billion cubic feet per year)

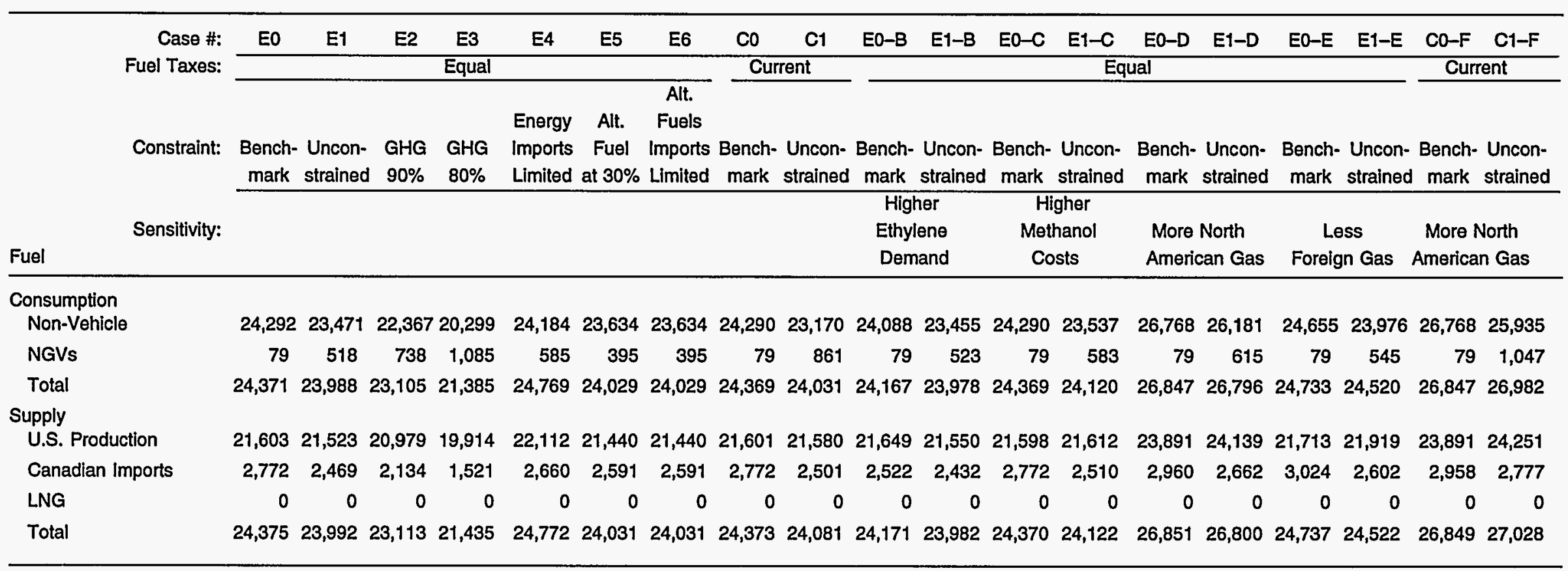

Note: Supply and consumption may not match because of rounding during unit conversions. 
Table IV-19 - Reference Oil Price Scenario U.S. LPG Balance

(million barrels per day)

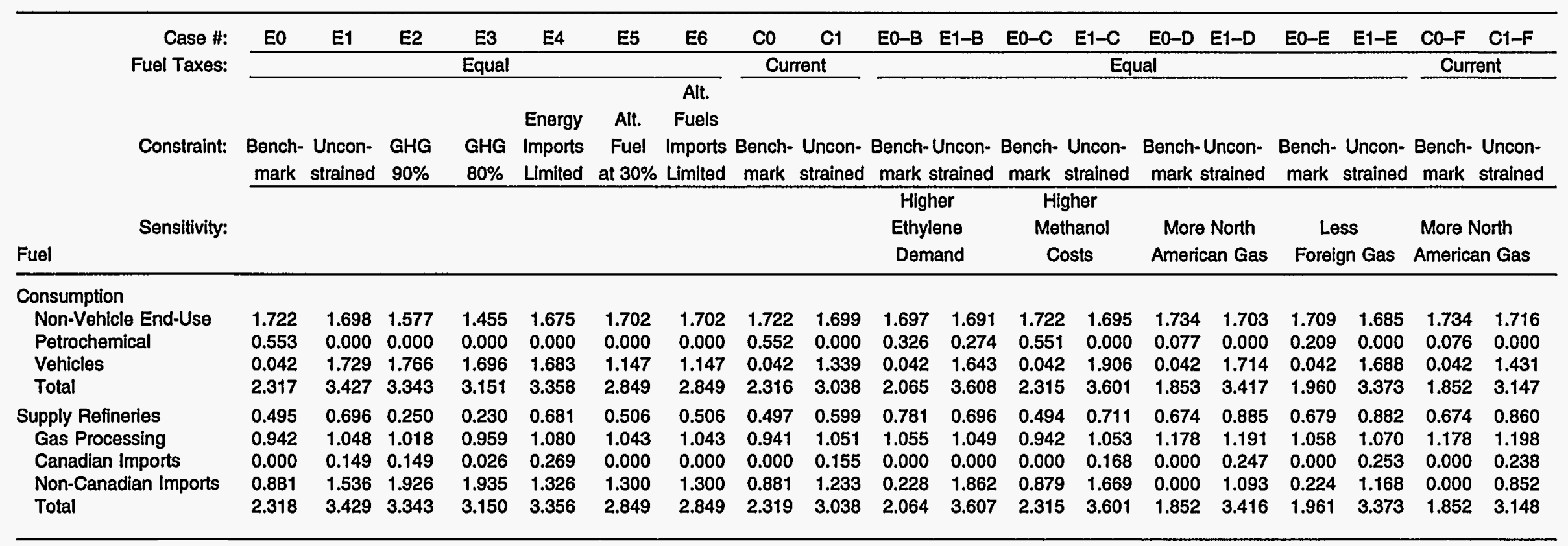

Note: Supply and consumption may not match because of rounding during unit conversions. 
Table IV-20 - Reference Oil Price Scenario U.S. Light-Duty-Vehicle Fleet in 2010

(thousand vehicles)

\begin{tabular}{|c|c|c|c|c|c|c|c|c|c|c|c|c|c|c|c|c|c|c|c|}
\hline \multirow{3}{*}{$\begin{array}{l}\text { Case \#: } \\
\text { Fuel Taxes: } \\
\text { Constraint: }\end{array}$} & EO & E1 & E2 & E3 & E4 & E5 & E6 & $\mathrm{CO}$ & C1 & EO-B & E1-B & EO-C & E1-C & EO-D & E1-D & EO-E & E1-E & $\mathrm{CO}-\mathrm{F}$ & C1-F \\
\hline & \multicolumn{7}{|c|}{ Equal } & \multicolumn{2}{|c|}{ Current } & \multicolumn{8}{|c|}{ Equal } & \multicolumn{2}{|c|}{ Current } \\
\hline & $\begin{array}{l}\text { Bench- } \\
\text { mark }\end{array}$ & $\begin{array}{l}\text { Uncon- } \\
\text { strained }\end{array}$ & $\begin{array}{l}\text { GHG } \\
90 \%\end{array}$ & $\begin{array}{l}\text { GHG } \\
80 \%\end{array}$ & $\begin{array}{l}\text { Energy } \\
\text { Imports } \\
\text { Limited }\end{array}$ & $\begin{array}{c}\text { Alt. } \\
\text { Fuel } \\
\text { at } 30 \%\end{array}$ & $\begin{array}{c}\text { Alt. } \\
\text { Fuels } \\
\text { Imports } \\
\text { Limited }\end{array}$ & $\begin{array}{c}\text { Bench- } \\
\text { mark }\end{array}$ & $\begin{array}{l}\text { - Uncon- } \\
\text { strained }\end{array}$ & $\begin{array}{l}\text { Bench- } \\
\text { mark }\end{array}$ & $\begin{array}{l}\text { Uncon- } \\
\text { strained }\end{array}$ & $\begin{array}{l}\text { Bench- } \\
\text { mark }\end{array}$ & $\begin{array}{l}\text { Uncon- } \\
\text { strained }\end{array}$ & $\begin{array}{l}\text { Bench- } \\
\text { mark }\end{array}$ & $\begin{array}{l}\text { - Uncon- } \\
\text { strained }\end{array}$ & $\begin{array}{l}\text { Bench- } \\
\text { mark }\end{array}$ & $\begin{array}{l}\text { Uncon- } \\
\text { strained }\end{array}$ & $\begin{array}{l}\text { Bench- } \\
\text { mark }\end{array}$ & $\begin{array}{l}\text { Uncon- } \\
\text { strained }\end{array}$ \\
\hline Sensitivity: & & & & & & & & & & $\begin{array}{c}\text { Higl } \\
\text { Ethyl } \\
\text { Dem }\end{array}$ & $\begin{array}{l}\text { her } \\
\text { lene } \\
\text { nand }\end{array}$ & $\begin{array}{r}\text { Hig } \\
\text { Met } \\
\text { Co }\end{array}$ & $\begin{array}{l}\text { gher } \\
\text { thanol } \\
\text { osts }\end{array}$ & $\begin{array}{l}\text { More } \\
\text { Ameri }\end{array}$ & $\begin{array}{l}\text { North } \\
\text { ican Gas }\end{array}$ & $\begin{array}{r}\text { Le } \\
\text { Foreit }\end{array}$ & igs & $\begin{array}{l}\text { More N } \\
\text { America }\end{array}$ & $\begin{array}{l}\text { North } \\
\text { an Gas }\end{array}$ \\
\hline Gasoline & 224,324 & 133,230 & 128,430 & 121,090 & 132,820 & 137,840 & 137,840 & 224,324 & 132,740 & 224,434 & 133,710 & 224,334 & 135,210 & 224,564 & 133,550 & 224,004 & 133,280 & 224,534 & 132,490 \\
\hline Alcohol Dedicated & 18 & 24,070 & 22,690 & 25,680 & 23,840 & 21,800 & 21,800 & 18 & 28,980 & 18 & 24,590 & 18 & 15,230 & 18 & 23,300 & 18 & 23,780 & 18 & 27,600 \\
\hline Alcohol Flexible-Fue! & 1,180 & 20,080 & 18,390 & 17,100 & 20,030 & 23,810 & 23,810 & 1,180 & 20,230 & 1,180 & 20,480 & 1,180 & 21,120 & 1,180 & 19,940 & 1,180 & 20,200 & 1,180 & 19,510 \\
\hline CNG Dedicated & 66 & 7,600 & 9,300 & 10,840 & 8,380 & 5,910 & 5,910 & 66 & 10,670 & 66 & 7,690 & 66 & 8,520 & 66 & 8,720 & 66 & 7,950 & 66 & 11,910 \\
\hline CNG Bifuel & 635 & 7,460 & 7,000 & 6,680 & 7,490 & 9,240 & 9,240 & 635 & 6,860 & 635 & 7,600 & 635 & 8,260 & 635 & 7,550 & 635 & 7,570 & 635 & 7,090 \\
\hline LPG Dedicated & 62 & 23,010 & 23,410 & 22,410 & 22,460 & 18,280 & 18,280 & 62 & 18,390 & 62 & 22,030 & 62 & 25,390 & 62 & 22,840 & 62 & 22,550 & 62 & 19,190 \\
\hline LPG Biluel & 635 & 13,570 & 13,770 & 13,140 & 13,230 & 11,910 & 11,910 & 635 & 11,250 & 635 & 13,000 & 635 & 14,950 & 635 & 13,460 & 635 & 13,310 & 635 & 11,680 \\
\hline Electric & 2,580 & 2,580 & 2,580 & 2,580 & 2,580 & 2,580 & 2,580 & 2,580 & 2,580 & 2,580 & 2,580 & 2,580 & 2,580 & 2,580 & 2,580 & 2,580 & 2,580 & 2,580 & 2,580 \\
\hline Total & 229,500 & 231,600 & 225,570 & 219,520 & 230,830 & 231,370 & 231,370 & 229,500 & 231,700 & 229,610 & 231,680 & 229,510 & 231,260 & 229,740 & 231,940 & 229,180 & 231,220 & 229,710 & 232,050 \\
\hline Subtotal AFVs & 5,176 & 98,370 & 97,140 & 98,430 & 98,010 & 93,530 & 93,530 & 5,176 & 98,960 & 5,176 & 97,970 & 5,176 & 96,050 & 5,176 & 98,390 & 5,176 & 97,940 & 5,176 & 99,560 \\
\hline
\end{tabular}


Table IV-21 - Low Oil Price Scenario Retail Motor-Fuel Prices

(dollars per gallon of gasoline-equivalent)

\begin{tabular}{|c|c|c|c|c|c|c|c|c|c|c|c|}
\hline \multirow{4}{*}{$\begin{array}{r}\text { Case \#: } \\
\text { Fuel Taxes: }\end{array}$} & EO & E1 & E2 & E3 & E4 & E5 & E6 & $\mathrm{CO}$ & C1 & CO-F & $\mathrm{C} 1-\mathrm{F}$ \\
\hline & & & & Equal & & & & \multicolumn{4}{|c|}{ Current } \\
\hline & $\begin{array}{l}\text { Bench- } \\
\text { Mark }\end{array}$ & $\begin{array}{l}\text { Uncon- } \\
\text { strained }\end{array}$ & $\begin{array}{l}\text { GHG } \\
90 \%\end{array}$ & $\begin{array}{l}\text { GHG } \\
80 \%\end{array}$ & $\begin{array}{l}\text { Energy } \\
\text { Imports } \\
\text { Limited }\end{array}$ & $\begin{array}{c}\text { Alt. } \\
\text { Fuel } \\
\text { at } 30 \%\end{array}$ & $\begin{array}{c}\text { Alt. } \\
\text { Fuels } \\
\text { Imports } \\
\text { Limited }\end{array}$ & $\begin{array}{l}\text { Bench- } \\
\text { Mark }\end{array}$ & $\begin{array}{l}\text { Uncon- } \\
\text { strained }\end{array}$ & $\begin{array}{c}\text { Bench- } \\
\text { Mark }\end{array}$ & $\begin{array}{l}\text { Uncon- } \\
\text { strained }\end{array}$ \\
\hline & & & & & & & & & & \multicolumn{2}{|c|}{$\begin{array}{c}\text { More North } \\
\text { American Gas }\end{array}$} \\
\hline & \multicolumn{11}{|c|}{ Absolute Price } \\
\hline Conventional Gasoline & 1.23 & 1.21 & 1.53 & 1.96 & 1.24 & 1.20 & 1.20 & 1.23 & 1.21 & 1.22 & 1.20 \\
\hline Reformulated Gasoline & 1.32 & 1.31 & 1.66 & 2.11 & 1.35 & 1.30 & 1.30 & 1.32 & 1.31 & 1.31 & 1.30 \\
\hline CNG & 1.27 & 1.26 & 1.54 & 1.88 & 1.28 & 1.27 & 1.27 & 1.14 & 1.14 & 1.10 & 1.10 \\
\hline Ethanol (E85) & 1.77 & 1.76 & 1.84 & 2.00 & 1.77 & 1.76 & 1.76 & 1.30 & 1.33 & 1.30 & 1.33 \\
\hline Methanol (M85) & 1.21 & 1.30 & 1.64 & 2.01 & 1.34 & 1.29 & 1.29 & 1.34 & 1.35 & 1.34 & 1.34 \\
\hline LPG & 1.10 & 1.17 & 1.48 & 1.85 & 1.21 & 1.16 & 1.16 & 1.17 & 1.23 & 1.12 & 1.20 \\
\hline \multirow[t]{2}{*}{ Electricity } & 0.58 & 0.58 & 1.66 & 3.10 & 0.58 & 0.58 & 0.58 & 0.58 & 0.58 & 0.57 & 0.57 \\
\hline & \multicolumn{11}{|c|}{ Difference From Corresponding Benchmark Case } \\
\hline Conventional Gasoline & & $(0.02)$ & 0.30 & 0.73 & 0.01 & $(0.03)$ & $(0.03)$ & & $(0.02)$ & & $(0.02)$ \\
\hline Reformulated Gasoline & & $(0.01)$ & 0.34 & 0.79 & 0.03 & $(0.02)$ & $(0.02)$ & & $(0.01)$ & & $(0.01)$ \\
\hline CNG & & $(0.01)$ & 0.27 & 0.61 & 0.01 & 0.00 & 0.00 & & 0.00 & & 0.00 \\
\hline Ethanol (E85) & & $(0.01)$ & 0.07 & 0.23 & 0.00 & $(0.01)$ & $(0.01)$ & & 0.03 & & 0.03 \\
\hline Methanol (M85) & & 0.09 & 0.43 & 0.80 & 0.13 & 0.08 & 0.08 & & 0.01 & & 0.00 \\
\hline LPG & & 0.07 & 0.38 & 0.75 & 0.11 & 0.06 & 0.06 & & 0.06 & & 0.08 \\
\hline Electricity & & 0.00 & 1.08 & 2.52 & 0.00 & 0.00 & 0.00 & & 0.00 & & 0.00 \\
\hline
\end{tabular}


Table IV-22 - Low Oil Price Scenario Light-Duty-Vehicle Fuel Use

(million barrels of gasoline-equivalent per day)

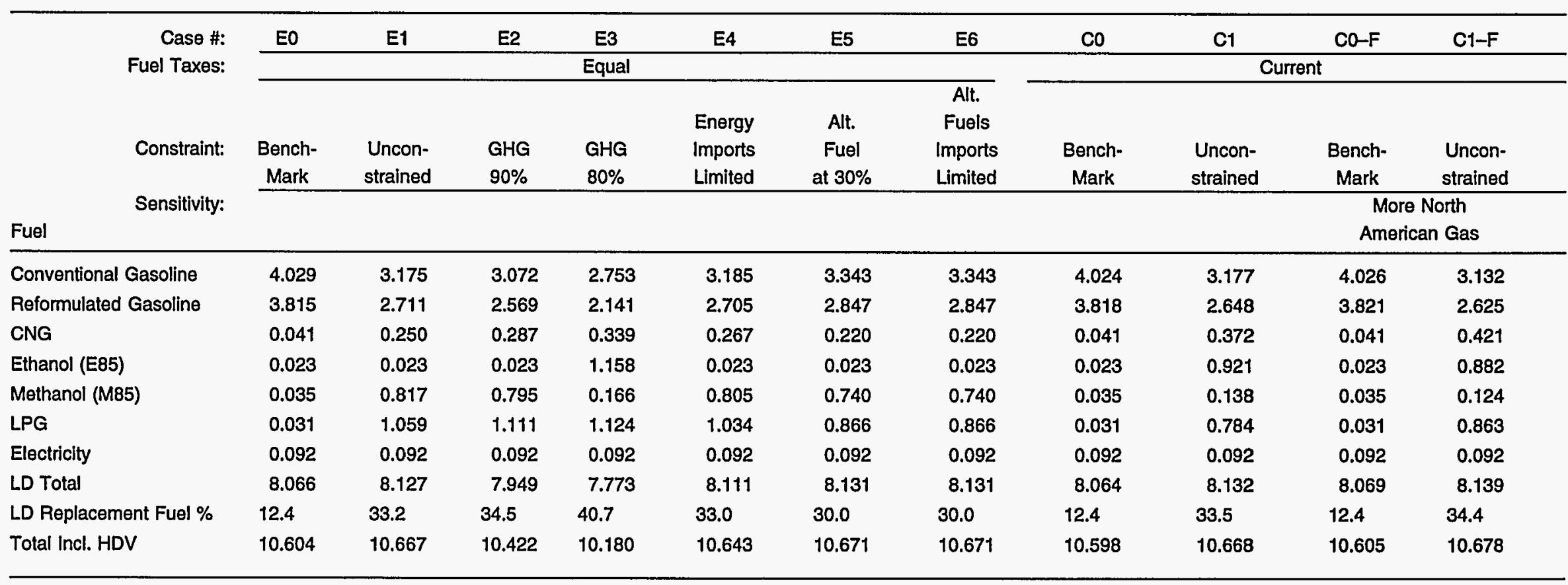

Note: "Replacement fuel" counts natural gas liquid feedstocks and oxygenates in gasoline and nongasoline portion of altemative fuels. 
Table IV-23 - Low Oil Price Scenario Imports (From Outside NAFTA)

(million barrels of crude-oil-equivalent per day)

\begin{tabular}{|c|c|c|c|c|c|c|c|c|c|c|c|c|}
\hline \multirow[b]{4}{*}{ Fuel } & Case \#: & EO & E1 & E2 & E3 & $\mathrm{E} 4$ & E5 & E6 & $\mathrm{CO}$ & C1 & $\mathrm{CO}-\mathrm{F}$ & $C 1-F$ \\
\hline & Fuel Taxes: & \multicolumn{7}{|c|}{ Equal } & \multicolumn{4}{|c|}{ Current } \\
\hline & Constraint: & $\begin{array}{l}\text { Bench- } \\
\text { Mark } \\
\end{array}$ & $\begin{array}{l}\text { Uncon- } \\
\text { strained }\end{array}$ & $\begin{array}{l}\text { GHG } \\
90 \% \\
\end{array}$ & $\begin{array}{l}\text { GHG } \\
80 \% \\
\end{array}$ & $\begin{array}{l}\text { Energy } \\
\text { Imports } \\
\text { Limited } \\
\end{array}$ & $\begin{array}{c}\text { Alt. } \\
\text { Fuel } \\
\text { at } 30 \% \\
\end{array}$ & $\begin{array}{c}\text { Alt. } \\
\text { Fuels } \\
\text { Imports } \\
\text { Limited }\end{array}$ & $\begin{array}{c}\text { Bench- } \\
\text { Mark }\end{array}$ & $\begin{array}{l}\text { Uncon- } \\
\text { strained }\end{array}$ & $\begin{array}{c}\text { Bench- } \\
\text { Mark }\end{array}$ & $\begin{array}{l}\text { Uncon- } \\
\text { strained }\end{array}$ \\
\hline & Sensitivity: & & & & & & & & & & \multicolumn{2}{|c|}{$\begin{array}{c}\text { More North } \\
\text { American Gas }\end{array}$} \\
\hline \multicolumn{13}{|c|}{ Crude and Petroleum } \\
\hline Products & & 14.57 & 13.32 & 10.38 & 8.22 & 12.33 & 13.53 & 13.53 & 14.56 & 13.34 & 13.64 & 12.36 \\
\hline Methanol & & 0.07 & 0.56 & 0.55 & 0.14 & 0.55 & 0.51 & 0.51 & 0.08 & 0.13 & 0.08 & 0.12 \\
\hline Propane & & 0.37 & 0.84 & 1.16 & 1.25 & 0.78 & 0.71 & 0.71 & 0.37 & 0.66 & 0.28 & 0.52 \\
\hline LNG & & 0.00 & 0.00 & 0.00 & 0.00 & 0.00 & 0.00 & 0.00 & 0.00 & 0.00 & 0.00 & 0.00 \\
\hline Total & & 15.01 & 14.72 & 12.08 & 9.60 & 13.66 & 14.75 & 14.75 & 15.01 & 14.13 & 14.00 & 13.00 \\
\hline
\end{tabular}


Table IV-24 - Low Oil Price Scenario Greenhouse Gas Emissions

(million short tons per day)

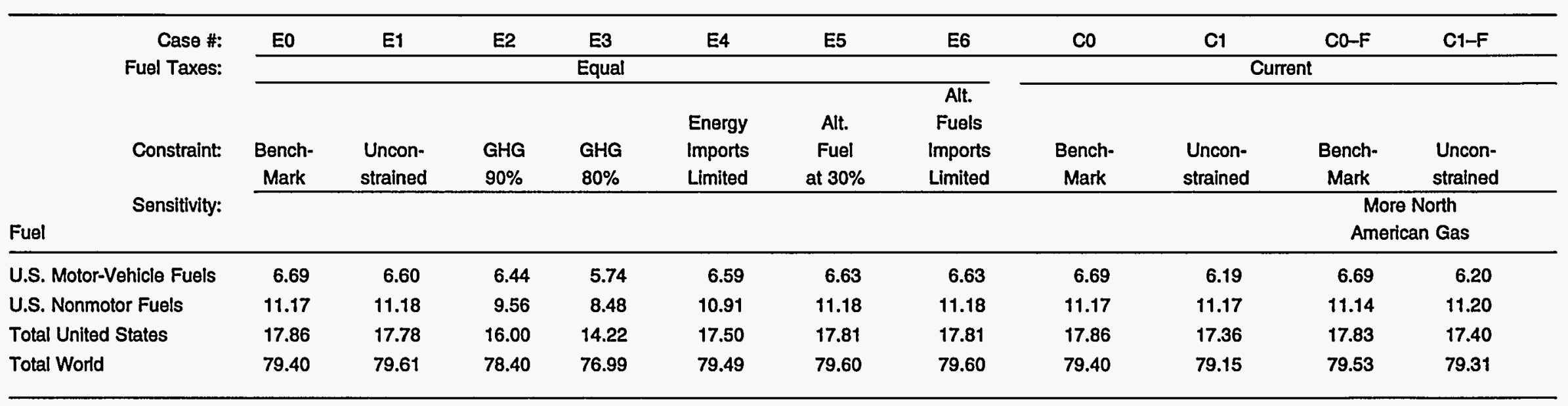

Note: Calculated only for oil and natural gas derived fuels covered in AFTM and U.S. ethanol. Excludes all coal use. 
Table IV-25 - Low Oil Price Scenario Composition of U.S. Economic Benefits and (Costs)

(million dollars per year relative to corresponding benchmark case)

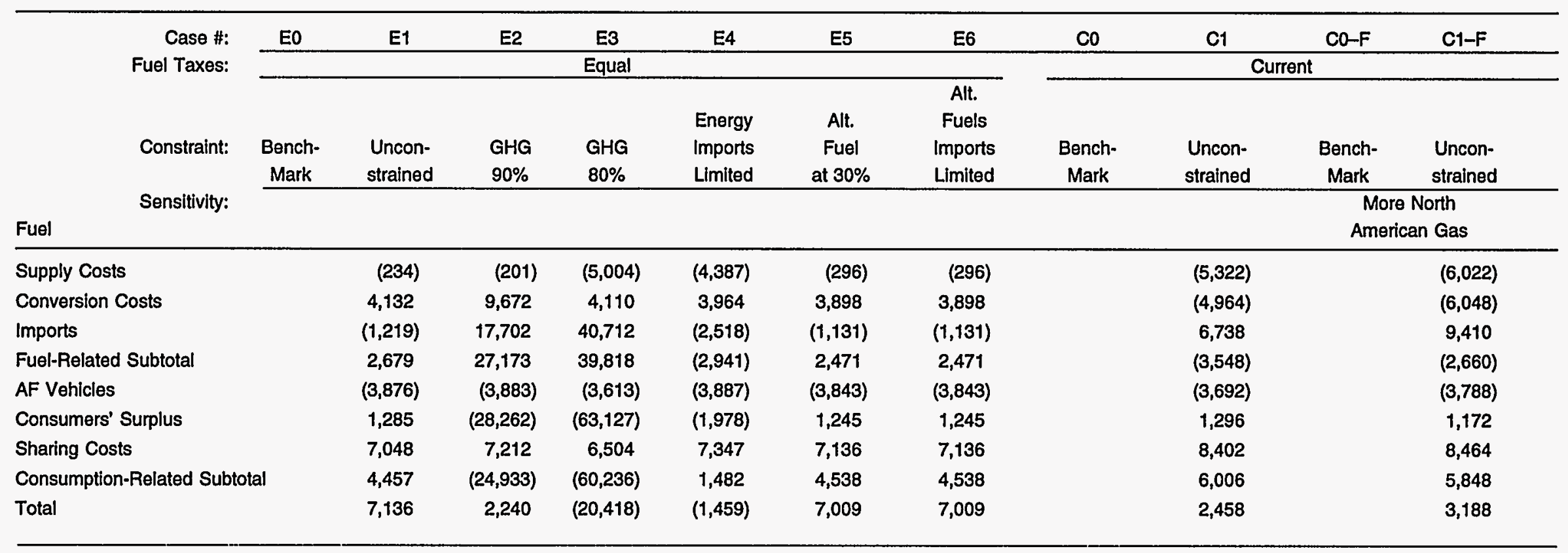


Table IV-26 - Low Oil Price Scenario Federal and State Mołor-Fuel Taxes

\begin{tabular}{|c|c|c|c|c|c|c|c|c|c|c|c|}
\hline Case \#: & E0 & E1 & E2 & E3 & E4 & E5 & E6 & $\mathrm{CO}$ & $\mathrm{C1}$ & CO-F & $C_{1}-F$ \\
\hline Fuel Taxes: & & & & Equal & & & & \multicolumn{4}{|c|}{ Current } \\
\hline Constraint: & $\begin{array}{l}\text { Bench- } \\
\text { Mark }\end{array}$ & $\begin{array}{l}\text { Uncon- } \\
\text { strained }\end{array}$ & $\begin{array}{l}\text { GHG } \\
90 \%\end{array}$ & $\begin{array}{l}\text { GHG } \\
80 \%\end{array}$ & $\begin{array}{l}\text { Energy } \\
\text { Imports } \\
\text { Limited }\end{array}$ & $\begin{array}{l}\text { Alt. } \\
\text { Fuel } \\
\text { at } 30 \%\end{array}$ & $\begin{array}{l}\text { Alt. } \\
\text { Fuels } \\
\text { Imports } \\
\text { Limited }\end{array}$ & $\begin{array}{l}\text { Bench- } \\
\text { Mark }\end{array}$ & $\begin{array}{l}\text { Uncon- } \\
\text { strained }\end{array}$ & $\begin{array}{l}\text { Bench- } \\
\text { Mark }\end{array}$ & $\begin{array}{l}\text { Uncon- } \\
\text { strained }\end{array}$ \\
\hline Sensitivity: & & & & & & & & & & \multicolumn{2}{|c|}{$\begin{array}{c}\text { More North } \\
\text { American Gas }\end{array}$} \\
\hline $\begin{array}{l}\text { Total (million dollars } \\
\text { per year) }\end{array}$ & 53,319 & 53,476 & 52,231 & 50,939 & 53,330 & 53,487 & 53,487 & 53,476 & 47,859 & 53,509 & 48,140 \\
\hline $\begin{array}{l}\text { Average Rate (dollars } \\
\text { per gallon of gasoline- } \\
\text { equivalent) }\end{array}$ & 0.328 & 0.327 & 0.327 & 0.326 & 0.327 & 0.327 & 0.327 & 0.329 & 0.293 & 0.329 & 0.294 \\
\hline $\begin{array}{l}\text { Change Relative to } \\
\text { Corresponding } \\
\text { Benchmark Case (million } \\
\text { dollars per year) }\end{array}$ & & 157 & $(1,088)$ & $(2,380)$ & 11 & 168 & 168 & & $(5,617)$ & & $(5,369)$ \\
\hline
\end{tabular}

\& Note: Includes effects of tax credit for renewables. Includes both light- and heavy-duty fuel use. 
Table IV-27 - Low Oil Price Scenario U.S. Environmental Benefits From Alternative-Fuel Vehicles (million dollars per year)

\begin{tabular}{|c|c|c|c|c|c|c|c|c|c|c|c|}
\hline Case \#: & EO & E1 & E2 & E3 & E4 & E5 & E6 & $\mathrm{CO}$ & C1 & $\mathrm{CO}-\mathrm{F}$ & $\mathrm{C} 1-\mathrm{F}$ \\
\hline Fuel Taxes: & & & & Equal & & & & \multicolumn{4}{|c|}{ Current } \\
\hline Constraint: & $\begin{array}{l}\text { Bench- } \\
\text { Mark }\end{array}$ & $\begin{array}{l}\text { Uncon- } \\
\text { strained }\end{array}$ & $\begin{array}{l}\text { GHG } \\
90 \% \\
\end{array}$ & $\begin{array}{l}\text { GHG } \\
80 \% \\
\end{array}$ & $\begin{array}{l}\text { Energy } \\
\text { Imports } \\
\text { Limited }\end{array}$ & $\begin{array}{c}\text { Alt. } \\
\text { Fuel } \\
\text { at } 30 \%\end{array}$ & $\begin{array}{l}\text { Alt. } \\
\text { Fuels } \\
\text { Imports } \\
\text { Limited }\end{array}$ & $\begin{array}{c}\text { Bench- } \\
\text { Mark }\end{array}$ & $\begin{array}{l}\text { Uncon- } \\
\text { strained }\end{array}$ & $\begin{array}{l}\text { Bench- } \\
\text { Mark }\end{array}$ & $\begin{array}{l}\text { Uncon- } \\
\text { strained }\end{array}$ \\
\hline Sensitivity: & & & & & & & & & & \multicolumn{2}{|c|}{$\begin{array}{c}\text { More North } \\
\text { American Gas }\end{array}$} \\
\hline High Estimate & 191 & 3,102 & 3,200 & 3,973 & 3,077 & 2,682 & 2,682 & 191 & 3,197 & 190 & 3,306 \\
\hline Low Estimate & 96 & 1,551 & 1,600 & 1,986 & 1,539 & 1,341 & 1,341 & 96 & 1,598 & 95 & 1,653 \\
\hline $\begin{array}{l}\text { Average Change } \\
\text { Relative to Corresponding } \\
\text { Benchmark Case }\end{array}$ & & 2,183 & 2,257 & 2,836 & 2,165 & 1,868 & 1,868 & & 2,254 & & 2,337 \\
\hline
\end{tabular}


Table IV-28 - Low Oil Price Scenario Crude Oil Production and Price

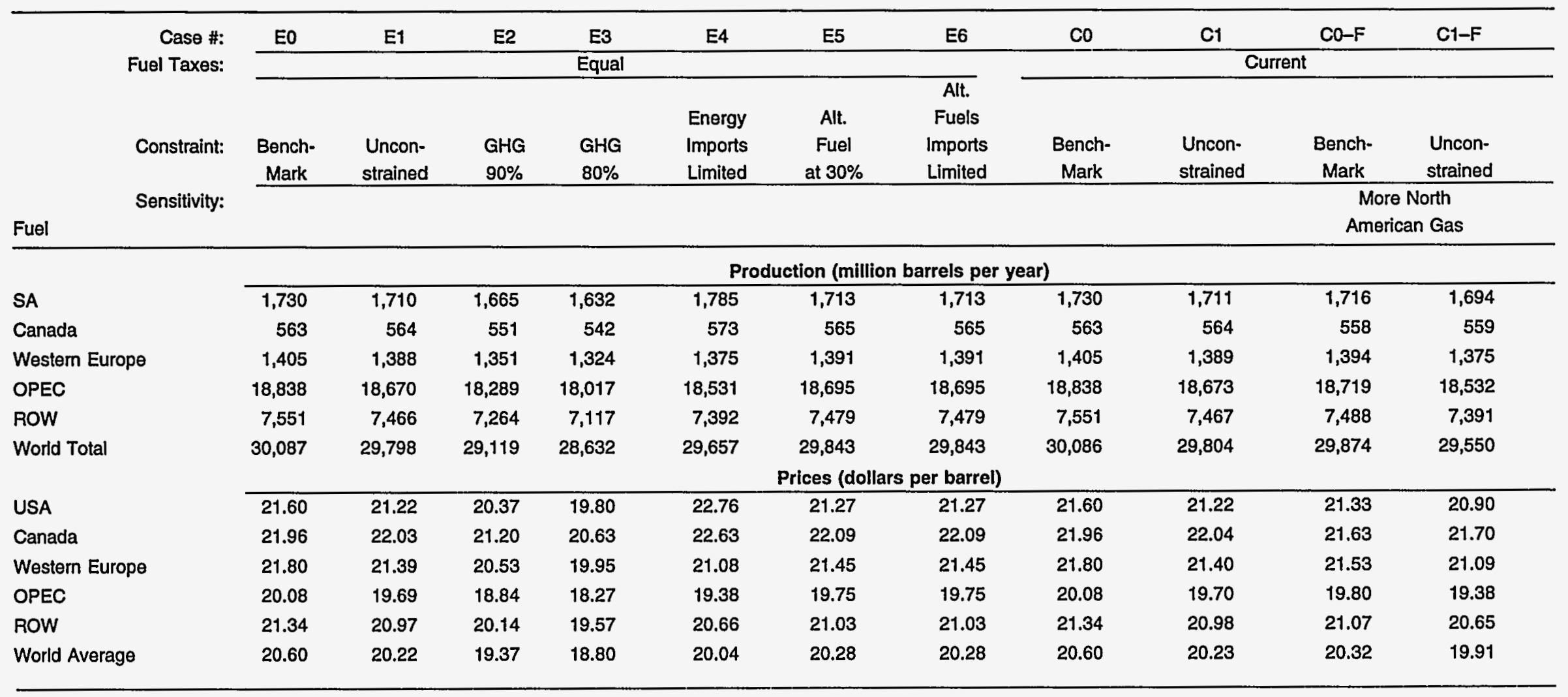


Table IV-29 - Low Oil Price Scenario Natural Gas Production and Price (Wet Basis)

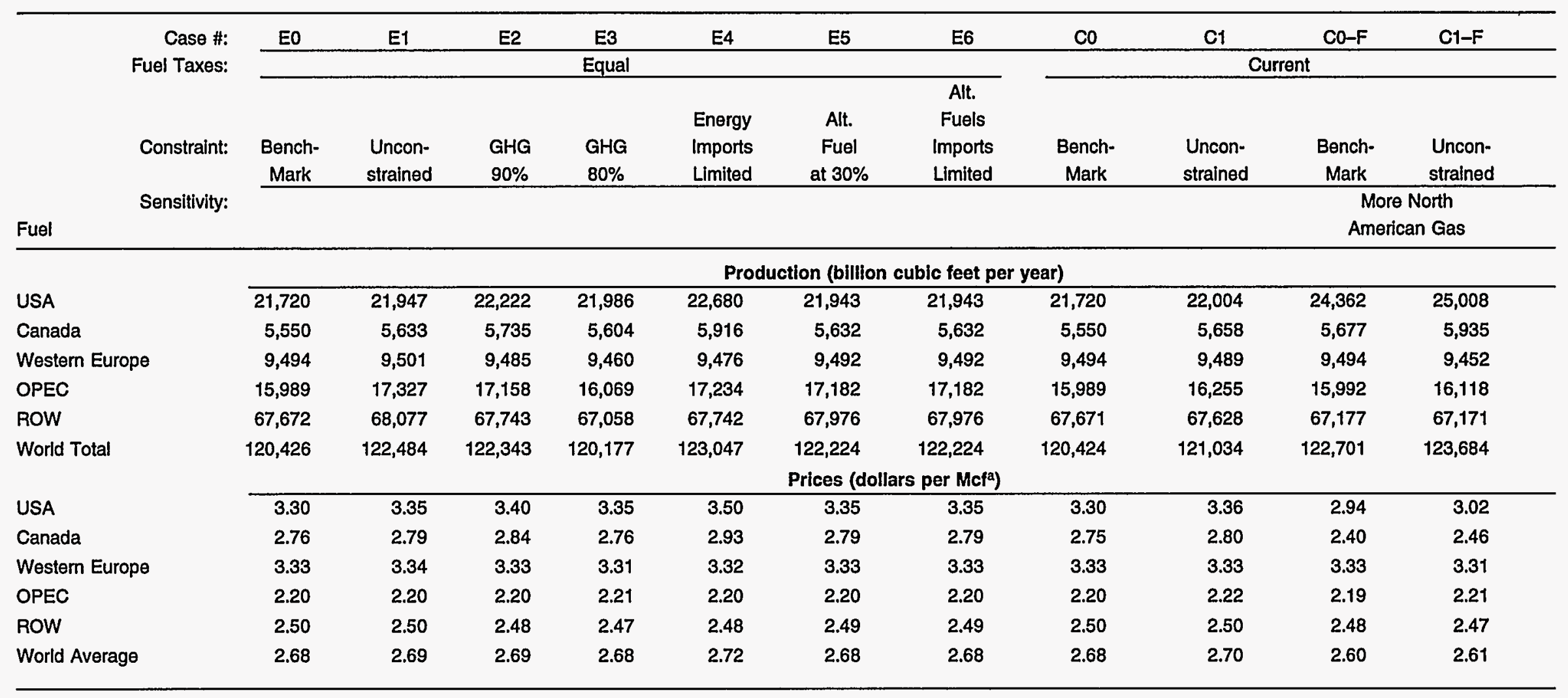

a Includes value of condensate and gas plant liquids. 
Table IV-30 - Low Oil Price Scenario U.S. End-Use Prices for Natural Gas, LPG, and Fuel Oils

\begin{tabular}{|c|c|c|c|c|c|c|c|c|c|c|c|}
\hline Case \#: & EO & E1 & E2 & E3 & E4 & E5 & E6 & Co & C1 & $\mathrm{CO}-\mathrm{F}$ & C1-F \\
\hline Fuel Taxes: & & & & Equal & & & & \multicolumn{4}{|c|}{ Current } \\
\hline Constraint: & $\begin{array}{l}\text { Bench- } \\
\text { Mark }\end{array}$ & $\begin{array}{l}\text { Uncon- } \\
\text { strained }\end{array}$ & $\begin{array}{l}\text { GHG } \\
90 \% \\
\end{array}$ & $\begin{array}{l}\text { GHG } \\
80 \% \\
\end{array}$ & $\begin{array}{l}\text { Energy } \\
\text { Imports } \\
\text { Limited }\end{array}$ & $\begin{array}{c}\text { Alt. } \\
\text { Fuel } \\
\text { at } 30 \% \\
\end{array}$ & $\begin{array}{c}\text { Alt. } \\
\text { Fuels } \\
\text { Imports } \\
\text { Limited }\end{array}$ & $\begin{array}{c}\text { Bench- } \\
\text { Mark }\end{array}$ & $\begin{array}{l}\text { Uncon- } \\
\text { strained }\end{array}$ & $\begin{array}{c}\text { Bench- } \\
\text { Mark }\end{array}$ & $\begin{array}{l}\text { Uncon- } \\
\text { strained }\end{array}$ \\
\hline \multirow[t]{2}{*}{ Sensitivity: } & & & & & & & & & & $\begin{array}{l}\text { Mo } \\
\text { Ame }\end{array}$ & $\begin{array}{l}\text { orth } \\
\text { Gas }\end{array}$ \\
\hline & \multicolumn{11}{|c|}{ Prices (dollars per barrel) } \\
\hline Natural Gas & 26.68 & 26.53 & 36.53 & 49.11 & 27.23 & 26.54 & 26.54 & 26.68 & 26.63 & 24.63 & 24.55 \\
\hline LPG & 36.43 & 38.59 & 46.79 & 56.60 & 39.79 & 38.32 & 38.32 & 36.43 & 38.30 & 34.84 & 37.30 \\
\hline Distillate Fuel Oil & 30.69 & 30.38 & 44.24 & 63.90 & 32.00 & 30.45 & 30.45 & 30.69 & 30.41 & 30.33 & 30.00 \\
\hline \multirow[t]{2}{*}{ Residual Fuel Oil } & 21.32 & 20.87 & 34.21 & 52.31 & 22.55 & 20.93 & 20.93 & 21.32 & 20.88 & 21.02 & 20.51 \\
\hline & \multicolumn{11}{|c|}{ Prices (dollars per MMBtu) } \\
\hline Natural Gas & 4.24 & 4.22 & 5.81 & 7.81 & 4.33 & 4.22 & 4.22 & 4.24 & 4.24 & 3.92 & 3.90 \\
\hline LPG & 9.08 & 9.62 & 11.67 & 14.11 & 9.92 & 9.55 & 9.55 & 9.08 & 9.55 & 8.69 & 9.30 \\
\hline Distillate Fuel Oil & 5.33 & 5.27 & 7.68 & 11.09 & 5.55 & 5.28 & 5.28 & 5.33 & 5.28 & 5.26 & 5.21 \\
\hline Residual Fuel Oil & 3.39 & 3.32 & 5.44 & 8.32 & 3.59 & 3.33 & 3.33 & 3.39 & 3.32 & 3.34 & 3.26 \\
\hline
\end{tabular}

Note: End-use prices in cases with greenhouse-gas or import constraints reflect shadow prices, not prices to producers with normal markups. Difference may be imputed to be a tax needed to enforce constraint. 
Table IV-31 - Low Oil Price Scenario U.S. Natural Gas Balance (Dry Basis)

(billion cublc feet per year)

\begin{tabular}{|c|c|c|c|c|c|c|c|c|c|c|c|}
\hline $\begin{array}{l}\text { Case \#: } \\
\text { Fuel Taxes: }\end{array}$ & EO & E1 & E2 & E3 & E4 & E5 & E6 & $\mathrm{CO}$ & C1 & $\mathrm{CO}-\mathrm{F}$ & $C 1-F$ \\
\hline & \multicolumn{7}{|c|}{ Equal } & \multicolumn{4}{|c|}{ Current } \\
\hline Constraint: & $\begin{array}{l}\text { Bench- } \\
\text { Mark }\end{array}$ & $\begin{array}{l}\text { Uncon- } \\
\text { strained }\end{array}$ & $\begin{array}{l}\text { GHG } \\
90 \%\end{array}$ & $\begin{array}{l}\text { GHG } \\
80 \%\end{array}$ & $\begin{array}{l}\text { Energy } \\
\text { Imports } \\
\text { Limited }\end{array}$ & $\begin{array}{c}\text { Alt. } \\
\text { Fuel } \\
\text { at } 30 \%\end{array}$ & $\begin{array}{c}\text { Alt. } \\
\text { Fuels } \\
\text { Imports } \\
\text { Limited }\end{array}$ & $\begin{array}{l}\text { Bench- } \\
\text { Mark }\end{array}$ & $\begin{array}{l}\text { Uncon- } \\
\text { strained }\end{array}$ & $\begin{array}{l}\text { Bench- } \\
\text { Mark }\end{array}$ & $\begin{array}{l}\text { Uncon- } \\
\text { strained }\end{array}$ \\
\hline Sensitivity: & & & & & & & & & & \multicolumn{2}{|c|}{$\begin{array}{c}\text { More North } \\
\text { American Gas }\end{array}$} \\
\hline \multicolumn{12}{|l|}{ Consumption } \\
\hline Nonvehicle & 21,679 & 21,238 & 21,548 & 21,038 & 22,144 & 21,307 & 21,307 & 21,679 & 21,064 & 24,118 & 23,728 \\
\hline NGVs & 79 & 479 & 550 & 650 & 512 & 422 & 422 & 79 & 713 & 79 & 807 \\
\hline Total & 21,757 & 21,717 & 22,098 & 21,688 & 22,656 & 21,729 & 21,729 & 21,757 & 21,777 & 24,196 & 24,535 \\
\hline \multicolumn{12}{|l|}{ Supply } \\
\hline U.S. Production & 19,742 & 19,941 & 20,187 & 19,978 & 20,593 & 19,939 & 19,939 & 19,742 & 19,994 & 22,087 & 22,663 \\
\hline Canadian Imports & 2,022 & 1,778 & 1,914 & 1,765 & 2,065 & 1,794 & 1,794 & 2,019 & 1,824 & 2,113 & 1,914 \\
\hline LNG & 0 & 0 & 0 & 0 & 0 & 0 & 0 & 0 & 0 & 0 & 0 \\
\hline Total & 21,763 & 21,720 & 22,101 & 21,743 & 22,658 & 21,734 & 21,734 & 21,761 & 21,819 & 24,200 & 24,577 \\
\hline
\end{tabular}

Note: Supply and consumption may not match because of rounding during unit conversions. 
Table IV-32 - Low Oil Price Scenario U.S. LPG Balance

(million barrels per day)

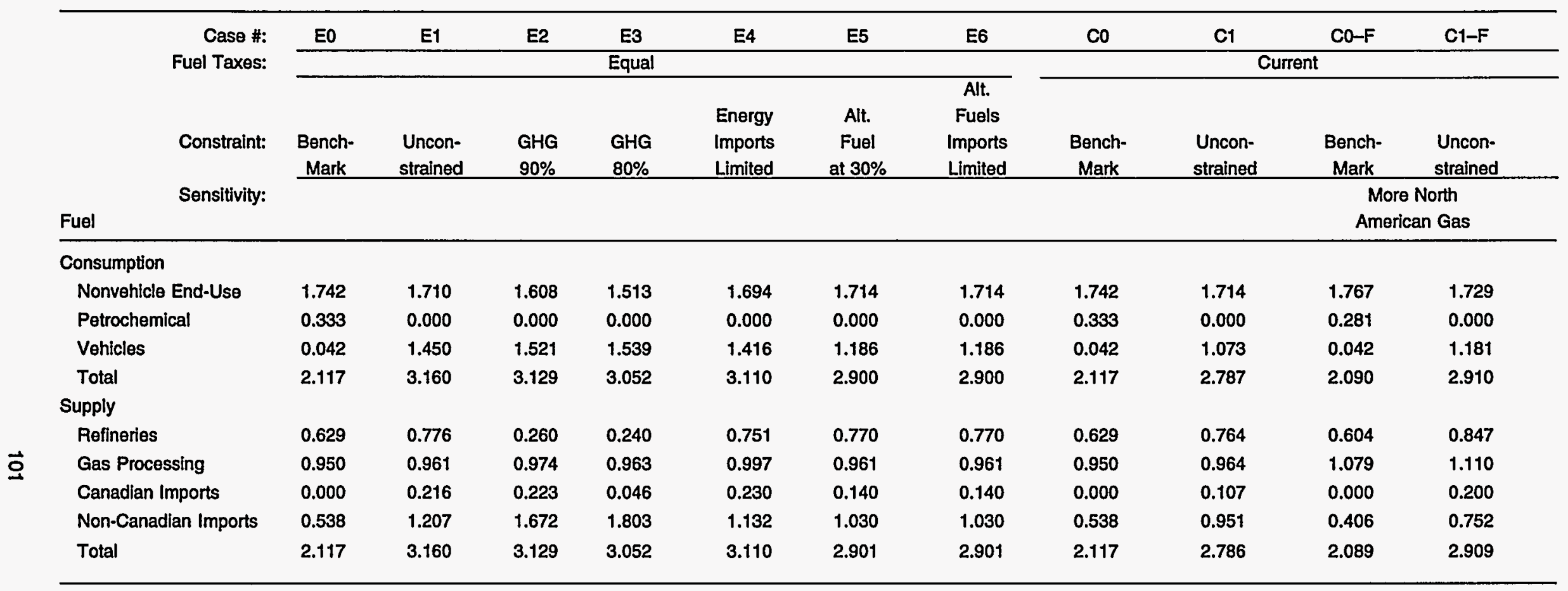

Note: Supply and consumption may not match because of rounding during unit conversions. 
Table IV-33 - Low Oil Price Scenario U.S. Light-Duty-Vehicle Fleet in 2010 (thousand vehicles)

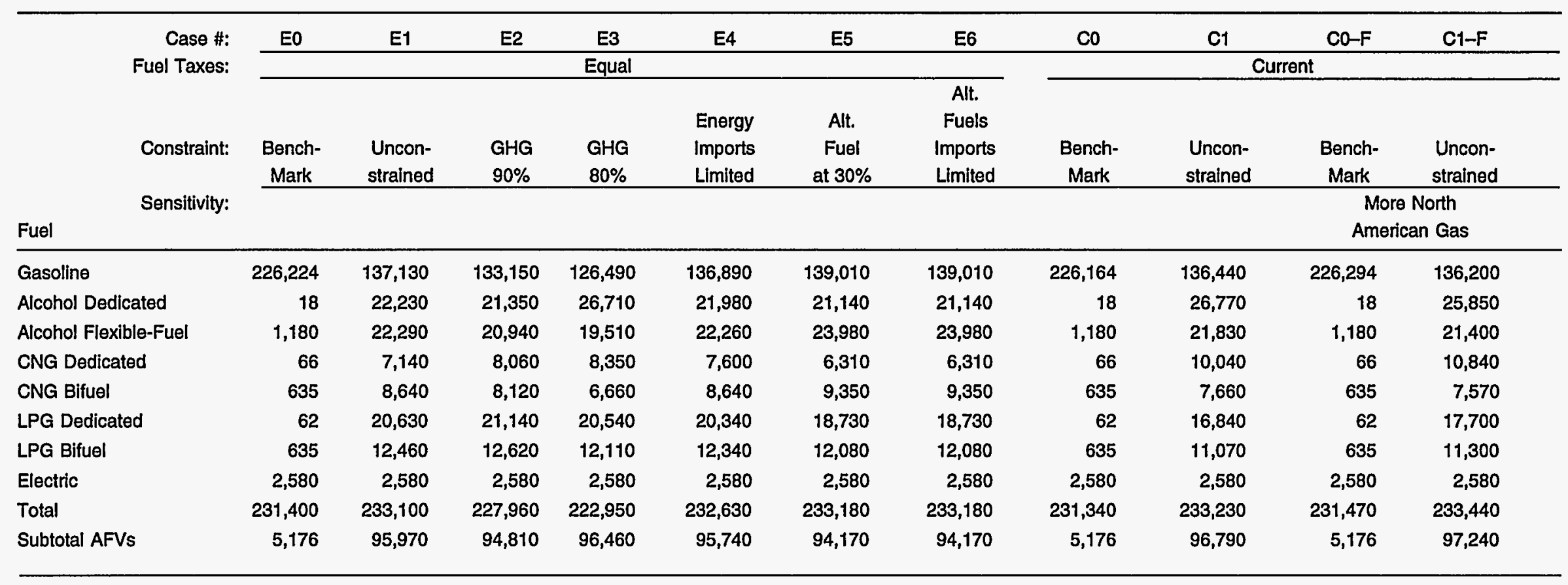




\section{REFERENCES}

Anonymous. 1993. Naphtha now clearly the world's favorite feedstock. International Butane/Propane Newsletter 17, no. 7 (April): 4.

Anonymous. 1994. International analysts focus on U.S., Asian, Latin American markets. Oil and Gas Journal 92 , no. 17:45.

EA Engineering, Science and Technology, Inc. 1993. Technical Memorandum for Task 4: ReEstimate Outlet Costs for 10K Gal./Month Volume. Prepared for the Oak Ridge National Laboratory and the U.S. Department of Energy.

Energy and Environmental Analysis, Inc. 1994. Alternative Fuel Retail Mark-Ups. Prepared for the Oak Ridge National Laboratory and the U.S. Department of Energy.

Energy Information Administration (EIA). 1993. Petroleum Supply Annual 1993 1, table 16.

EIA. 1994a. Alternatives to Traditional Transportation Fuels: An Overview, no. DOE/EIA-0585/0.

EIA. 1994b. Annual Energy Outlook 1994, no. DOE/EIA-0383(94): 28.

Gas Research Institute (GRI). 1993. GRI Baseline Projection of U.S. Energy Supply and Demand to 2010. 1993 edition. Washington, D.C.: Gas Research Institute.

Hamilton, W. 1989. Electric and Hybrid Vehicles, no. DOE/ID-I0252. Prepared for the Office of Policy, Planning, and Evaluation, U.S. Department of Energy.

International Energy Agency (IEA). 1992a. Energy Statistics and Balances of Non-OECD Countries 1989-1990. Paris: IEAJOECD.

IEA. 1992b. Oil and Gas Information 1989-1991. Paris: IEA/OECD.

IEA. 1993. Electricity Information 1992. Paris: IEA/OECD.

Poten and Partners, Inc. 1992. World Trade in Liquefied Petroleum Gases 1985-2010. New York: Poten and Partners, Inc.

Rhodes, A.K. 1994. World ethylene capacity tops 71 million $\mathrm{mt} / \mathrm{y}$; recovery on horizon. Oil and Gas Journal 92, no. 17 (April): 35.

Singh, M.K. 1993. Personal communication to Barry McNutt, Office of Policy, U.S. Department of Energy.

Singh, M., and M.A. Delucchi. 1994. Estimates of Greenhouse Gas Emissions From Alternative Transportation Fuels and Industrial Fuels. Draft memo prepared in support of the AFTM study. Included in this report as Appendix D.

United Nations. 1992. 1990 Energy Statistics Yearbook. New York: United Nations.

U.S. Department of Energy. 1989. Assessment of Costs and Benefits of Flexible and Alternative Fuel Use in the U.S. Transportation Sector, Technical Report 3: Methanol Production and Transportation Costs, no. DOE/PE-0093. 
U.S. Department of Energy. 1991. Second Interim Report of the Interagency Commission on Alternative Motor Fuels.

U.S. Department of Energy. 1992. Assessment of Costs and Benefits of Flexible and Alternative Fuel Use in the U.S. Transportation Sector, Technical Report Ten: Analysis of Alternative-Fuel Fleet Requirements, no. DOE/PE-0103-P.

U.S. Department of Energy. 1992. Final Report of the Interagency Commission on Alternative Motor Fuels, no. DOE/EP-0002P.

U.S. Department of Energy. 1993. Assessment of Costs and Benefits of Flexible and Alternative Fuel Use in the U.S. Transportation Sector, Technical Report Nine: Development Costs of Undeveloped Nonassociated Gas Reserves in Selected Countries, no. DOE/EP-003P.

Zanetti, R. 1993. The Ethylene Barometer. Chemical Engineering 100, no. 1 (January): 5. 


\section{APPENDIX A. FUELS AND CONVERSION PROCESSES USED IN THE ALTERNATIVE FUELS TRADE MODEL}

This appendix presents tables depicting all the fuels and conversion processes used in the Alternative Fuels Trade Model (AFTM).

\section{Table A-1 - Fuels Included in the Alternative Fuels Trade Model}

\section{Primary Resources}

Natural Gas and Associated Liquids (a primary resource)

Light Crude Oil (a primary resource), Composite Blend of Light/Sweet Crudes

Heavy Crude Oil (a primary resource), Composite Blend of Heavy/Sour Crudes

Ethanol Feedstock C (a primary resource), Nonoil/Gas Inputs to Grain Ethanol Production

Ethanol Feedstock B (a primary resource), Nonoil/Gas Inputs to Biomass (wood) Ethanol Production

Intermediate Products or Non-Motor-Fuel Final Products

Light Petroleum Products (an aggregate refinery output, defined as 50 percent motor gasoline, 20 percent

kerosene and jet fuel and 30 percent distillate oil)

Distillate Fuel

Residual Fuel Oil (a refinery output)

Boiler Fuel (substitutable between residual fuel oil and natural gas)

Natural Gas (primarily methane; use in residential, commercial, industrial sectors)

LPG (use in residential, commercial, industrial sectors)

Ethylene (primary petrochemical product)

Liquefied Natural Gas (LNG, for ocean transport of remote natural gas)

Ethanol, Wholesale (for subsequent blending into transport fuels) From Corn or Cellulosic Biomass

Methanol, Wholesale (for subsequent processing into transport fuels)

Motor Fuels

Conventional Gasoline (single grade)

Reformulated Gasoline (single grade)

85 percent Ethanol and 15 percent Gasoline, or 85 percent Ethanol and 15 percent Reformulated Gasoline (E85)

85 percent Methanol and 15 percent Gasoline, or 85 percent Methanol and 15 percent Reformulated Gasoline (M85)

Alcohol/Gasoline (motor fuel, for dedicated methanol vehicle use)

Alcohol/RFG (fuel for alcohol FFVs, substitutable between E85, M85, and reformulated gasoline)

Compressed Natural Gas (CNG)

CNG/Gasoline (motor fuel for flexible-fuel CNG vehicles, substitutable between CNG and gasoline)

Liquefied Petroleum Gas (LPG)

Electricity for Use by Electric Vehicles

Note: In some cases these fuel names are also prefixed by " $W$ " to discriminate between wholesale/plantgate and retail. 
Table A-2 - Conversion Processes in the Alternative Fuels Trade Model

Processes Producing Intermediate and Nontransportation Fuels

21 Submodes for Low Complexity Refineries, Simple Refining Modes With Highest Proportion of Heavy Products

30 Submodes for Middle Complexity Refineries

39 Submodes for Complex Refineries, With Higher Costs and Higher Light-Product Fractions

Natural Gas Liquefaction at the Point of Origin (LNG-source)

LNG Regasification at the Destination (LNG-destination)

Methanol Produced From Natural Gas

Ethanol From Grain (corn) Feedstock

Ethanol From Cellulosic Biomass

3 Submodes for Cryogenic Gas Processing

3 Submodes for Refrigeration Gas Processing

3 Submodes for Dehydration Only Gas Processing

Ethane Distribution for Petrochemical Market

LPG Distribution for Petrochemical/Industrial Markets

Naphtha/Gas Oil Distribution for Petrochemical Market

3 Modes for Ethylene Manufacturing

Accounting Processes To Accommodate Simpler Fuel Demands in Non-U.S. Regions

Accounting Process Merging Unexported Gasoline With Light-Product Stream in Non-U.S. Regions

Accounting Process Merging Unexported Reformulated Gasoline With Light-Product Stream

in Non-U.S. Regions

Accounting Process Merging Unexported Distillate With Light-Product Stream in Non-U.S. Regions

Processes Generating Retail Motor Fuels

Production of Motor Gasoline Oxygenated With ETBE, With Retail Markup

Production of Motor Gasoline Oxygenated With MTBE, With Retail Markup

M85 Production From Methanol and 15 Percent Gasoline, With Retail Markup

E85 Production From Ethanol and 15 Percent Gasoline, With Retail Markup

Gasohol Production From Gasoline and 10 Percent Ethanol by Volume, With Retail Markup

Vehicle Electricity Generation Accounting for Residual Fuel Oil and Gas Use

Wellhead Natural Gas to Retail CNG Markup

Refinery Gate to Retail Gasoline Markup

Refinery Gate to Retail Reformulated Gasoline Markup

Plantgate to Retail LPG Markup

Wellhead to Retail (citygate) Natural Gas Markup 
Processes Generating Inputs for Substitutable (Composite) Fuel Demands

Substitutable Natural Gas Use for Boiler Fuel

Substitutable Residual Fuel Oil Use for Boiler Fuel

Substitutable Gasoline Use for Alcohol-Gasoline FFVs

Substitutable E85 Use for Alcohol-Gasoline FFVs

Substitutable M85 Use for Alcohol-Gasoline FFVs

Substitutable Reformulated-Gasoline Use for Alcohol-Gasoline FFVs in RFG Regions

Substitutable E85 Use for Alcohol-Gasoline FFVs in RFG Regions

Substitutable M85 Use for Alcohol-Gasoline FFVs in RFG Regions

Substitutable Gasoline Use for CNG-Gasoline FFVs

Substitutable CNG Use for CNG-Gasoline FFVs

Substitutable Reformulated-Gasoline Use for CNG-Gasoline FFVs in RFG Areas

Substitutable Gasoline Use for CNG-Gasoline FFVs in RFG Areas 


\section{Table A-3 - Conversion Factors Used in the Alternative Fuels Trade Model: Słandard Physical Unit Assumptions}

\begin{tabular}{|c|c|c|c|c|}
\hline 1 & Barrel & $=$ & 42 & U.S. Gallons \\
\hline 1 & Metric Ton & $=$ & 2,205 & Pounds \\
\hline 1 & Metric Ton LNG & $=$ & 52.1 & MMBtu Natural Gas \\
\hline 1 & Mcf WETGAS & $=$ & 1,306 & MMBtu Hydrocarbons, Including Condensate \\
\hline 1 & Mcf LEANGAS & $=$ & 1,148 & MMBtu Hydrocarbons, Including Condensate \\
\hline 1 & Mcf DRYGAS & $=$ & 1,088 & MMBtu Hydrocarbons, Including Condensate \\
\hline 1 & Cubic Foot Methane & $=$ & 1,009 & Btu (gross) \\
\hline 1 & Cubic Foot Ethane & $=$ & 1,769 & Btu (gross) \\
\hline 1 & Cubic Foot Propane & $=$ & 2,517 & Btu (gross) \\
\hline 1 & Cubic Foot Butane & $=$ & 3,262 & Btu (gross) \\
\hline 1 & Cubic Foot LPG & $=$ & 2,815 & Btu (gross) \\
\hline 1 & Cubic Foot Pentane + & $=$ & 4,000 & Btu (gross) \\
\hline 1 & Bbl Condensate & $=$ & 5.67 & MMBtu \\
\hline 1 & Gallon Ethane & $=$ & 37.5 & Cubic Foot Ethane \\
\hline 1 & Gallon Propane & $=$ & 36.4 & Cubic Foot Propane \\
\hline 1 & Gallon Butane & $=$ & 31.0 & Cubic Foot Butane \\
\hline 1 & Gallon Pentane + & $=$ & 26.0 & Cubic Foot Pentanet \\
\hline 1 & Gallon Ethane & $=$ & 2.97 & Pound Ethane \\
\hline 1 & Gallon LPG & $=$ & 4.51 & Pound LPG \\
\hline 1 & Gallon Naphtha & $=$ & 6.47 & Pound Naphtha \\
\hline 1 & Gallon Ethylene & $=$ & 2.97 & Pound Ethylene \\
\hline 1 & Metric Ton Ethylene & $=$ & 17.67 & Bbl Ethylene \\
\hline 1 & Bbl Heavy Crude & $=$ & 5.860 & MMBtu \\
\hline 1 & Bbl Light Crude & $=$ & 5.670 & MMBtu \\
\hline 1 & Bbl Residual Fuel Oil & $=$ & 6.287 & MMBtu \\
\hline 1 & "Bbl" Natural Gas & $=$ & 6.287 & MMBtu \\
\hline 1 & "Bbl" Boiler Fuel & $=$ & 6.287 & MMBtu \\
\hline 1 & Bbl Distillate & $=$ & 5.763 & MMBtu \\
\hline 1 & $\mathrm{Bb} / \mathrm{LPG}$ & $=$ & 4.011 & MMBtu \\
\hline 1 & Bbl Light Product & $=$ & 5.508 & MMBtu \\
\hline 1 & Bbl Ethanol & $=$ & 3.536 & MMBtu \\
\hline 1 & Bbl Methanol & $=$ & 2.626 & MMBtu \\
\hline 1 & Bbl Ethane & $=$ & 2.785 & MMBtu \\
\hline 1 & Bbl Naphtha & $=$ & 5.250 & MMBtu \\
\hline 1 & Bbl Gasoline & $=$ & 5.253 & MMBtu \\
\hline 1 & BGE & $=$ & 5.253 & MMBtu \\
\hline 1 & "Bbl" CNG & $=$ & 1 & BGE \\
\hline 1 & Bbl M85 & $=$ & 1 & BGE \\
\hline 1 & $\mathrm{Bbl}$ E85 & $=$ & 1 & BGE \\
\hline
\end{tabular}


Table A-4 - Conversion Factors Used in the Alternative Fuels Trade Model: Processing Conversion Assumptions for Motor-Vehicle Fuels

\begin{tabular}{|c|c|c|}
\hline Input & & Output \\
\hline 1 & BGSE & 895 Miles Traveled in a Light-Duty Vehicle \\
\hline 1 & BGE & $5.253 \mathrm{MMBtu}$ \\
\hline 1 & Bbl Gasoline & $1 \mathrm{BGE}$ \\
\hline 1.011 & Bbl Reformulated gasoline & $1 \mathrm{BGE}$ \\
\hline 1.310 & $\mathrm{Bb} / \mathrm{LPG}$ & $1 \mathrm{BGE}$ \\
\hline 5.253 & MMBtu Natural gas & 1 "Bbl" CNG (= BGE) \\
\hline 0.104 & Bbl Ethanol & $1 \mathrm{Bbl} \mathrm{GASOH}(=\mathrm{BGE})$ \\
\hline 0.930 & Bbl Gasoline & \\
\hline 1.478 & Bbl Methanol & $1 \mathrm{Bbl} \mathrm{M85}$ (= BGE) \\
\hline 0.261 & Bbl Gasoline & \\
\hline 1.177 & Bbl Ethanol & $1 \mathrm{Bb}$ E85 (= BGE) \\
\hline 0.208 & Bbl Gasoline & \\
\hline 1 & Bbl/BGE Gasoline & 1 BGSE \\
\hline 1 & BGE Reformulated gasoline & 1 BGSE \\
\hline 1 & BGE LPG (use in dedicated vehicle) & 1 BGSE \\
\hline \multirow[t]{2}{*}{1.3696} & BGE LPG (use in bifuel & \\
\hline & vehicle) & 1 BGSE \\
\hline 1 & BGE CNG (use in dedicated vehicle) & 1 BGSE \\
\hline 1.03 & BGE CNG (use in bifuel vehicle) & 1 BGSE \\
\hline 0.99 & Bbl M85 (use in flex-fuel vehicle) & 1 BGSE \\
\hline 0.99 & Bbl E85 (use in flex-fuel vehicle) & 1 BGSE \\
\hline 0.95 & Bbl M85 (use in alcohol vehicle) & 1 BGSE \\
\hline 0.95 & Bbl E85 (use in alcohol vehicle) & 1 BGSE \\
\hline 1.224 & MMBtu Electricity & 1 BGSE \\
\hline
\end{tabular}




\section{Table A-5 - Conversion Factors Used in the Alternative Fuels Trade Model: Processing Conversion Assumptions for Non-Motor-Vehicle Fuels}

Intermediate Fuel Conversions

Input Output

1.10 MMBtu Natural Gas

0.09 MMBtu Natural Gas

6.287 MMBlu Dry Hydrocarbon Gas

$1.049 \mathrm{Bbl}$ Gasoline/Reformulated-Gasoline

$0.956 \mathrm{Bbl}$ Distillate

MMBtu LNG

1 Gallon Methanol

1 "Bbl" Natural Gas

$1 \mathrm{Bbl}$ Light Product

Ethylene Manufacturing

$1 \mathrm{Bbl}$ Light Product

\begin{tabular}{lcccc} 
& \multicolumn{4}{c}{ Output (pounds) } \\
\cline { 2 - 5 } Input & Ethylene & Olefins & Aromatics & Fuel Oil/Other \\
\hline 1.25 Pounds Ethane & 1.00 & 0.063 & 0.026 & 0.068 \\
2.50 Pounds LPG & 1.00 & 0.500 & 0.050 & 0.764 \\
4.35 Pounds Naphtha & 1.00 & 1.217 & 0.957 & 0.852
\end{tabular}

Raw Gas Processing

Rrocess $\quad$ Raw Gas $\quad$ Outputs (percent recovery)

\begin{tabular}{|c|c|c|c|c|c|c|c|}
\hline Process & Input & Methane & Ethane & Propane & Butane & Pentanes+ & Condensate \\
\hline Cryogenic Processing & $1.000 \mathrm{Mol}$ & 94 & 90 & 100 & 100 & 100 & 100 \\
\hline Refrigeration Processing & $1.000 \mathrm{Mol}$ & 96 & 40 & 65 & 85 & 100 & 100 \\
\hline $\begin{array}{l}\text { No Liquids Extraction } \\
\text { Processing }\end{array}$ & $1.000 \mathrm{Mol}$ & 98 & 0 & 0 & 0 & 0 & 100 \\
\hline
\end{tabular}

Cryogenic Processing Outputs (Btu)

\begin{tabular}{|c|c|c|c|c|c|c|c|c|c|c|}
\hline \multirow[b]{3}{*}{ Input } & \\
\hline & \multicolumn{4}{|c|}{ Hydrocarbon Gases } & \multirow[b]{2}{*}{ Fuel Use } & \multicolumn{5}{|c|}{ Natural Gas Liquids } \\
\hline & Methane & Ethane & Propane & Butane & & Ethane & Propane & Butane & Pentanest & Condensate \\
\hline \multirow[t]{3}{*}{$\begin{array}{l}1 \text { Cu. Ft. Wet Gas } \\
1 \text { Cu. Ft. Lean Gas } \\
1 \text { Cu. Ft. Dry Gas }\end{array}$} & $\begin{array}{l}976 \\
969 \\
956\end{array}$ & $\begin{array}{c}10 \\
4 \\
3\end{array}$ & $\begin{array}{l}0 \\
0 \\
0\end{array}$ & $\begin{array}{l}0 \\
0 \\
0\end{array}$ & $\begin{array}{l}62 \\
62 \\
61\end{array}$ & $\begin{array}{l}88 \\
40 \\
24\end{array}$ & $\begin{array}{l}49 \\
22 \\
11\end{array}$ & $\begin{array}{c}18 \\
8 \\
7\end{array}$ & $\begin{array}{c}18 \\
8 \\
3\end{array}$ & $\begin{array}{l}85 \\
40 \\
23\end{array}$ \\
\hline & \multicolumn{10}{|c|}{ Refrigeration Processing Outputs (Btu) } \\
\hline & \multicolumn{4}{|c|}{ Hydrocarbon Gases } & & \multicolumn{5}{|c|}{ Natural Gas Liquids } \\
\hline Input & Methane & Ethane & Propane & Butane & Fuel Use & Ethane & Propane & Butane & Pentanest & Condensate \\
\hline \multirow[t]{3}{*}{$\begin{array}{l}1 \text { Cu. Ft. Wet Gas } \\
1 \text { Cu. Ft. Lean Gas } \\
1 \text { Cu. Ft. Dry Gas }\end{array}$} & $\begin{array}{l}996 \\
989 \\
977\end{array}$ & $\begin{array}{l}59 \\
27 \\
16\end{array}$ & $\begin{array}{c}17 \\
8 \\
4\end{array}$ & $\begin{array}{l}3 \\
1 \\
1\end{array}$ & $\begin{array}{l}42 \\
41 \\
41\end{array}$ & $\begin{array}{l}39 \\
18 \\
11\end{array}$ & $\begin{array}{c}32 \\
14 \\
7\end{array}$ & $\begin{array}{c}16 \\
7 \\
6\end{array}$ & $\begin{array}{c}18 \\
8 \\
3\end{array}$ & $\begin{array}{l}85 \\
40 \\
23\end{array}$ \\
\hline & \multicolumn{10}{|c|}{ No Liquids Extraction Processing Outputs (Btu) } \\
\hline & \multicolumn{4}{|c|}{ Hydrocarbon Gases } & & \multicolumn{5}{|c|}{ Natural Gas Liquids } \\
\hline Input & Methane & Ethane & Propane & Butane & Fuel Use & Ethane & Propane & Butane & Pentanest & Condensate \\
\hline $\begin{array}{l}1 \text { Cu. Ft. Wet Gas } \\
1 \text { Cu. Ft. Lean Gas } \\
1 \text { Cu. Ft. Dry Gas }\end{array}$ & $\begin{array}{c}1015 \\
1008 \\
995\end{array}$ & $\begin{array}{l}98 \\
44 \\
27\end{array}$ & $\begin{array}{l}49 \\
22 \\
11\end{array}$ & $\begin{array}{l}37 \\
17 \\
15 \\
\end{array}$ & $\begin{array}{l}23 \\
23 \\
22 \\
\end{array}$ & $\begin{array}{l}0 \\
0 \\
0\end{array}$ & $\begin{array}{l}0 \\
0 \\
0\end{array}$ & $\begin{array}{l}0 \\
0 \\
0\end{array}$ & $\begin{array}{l}0 \\
0 \\
0\end{array}$ & $\begin{array}{l}85 \\
40 \\
23\end{array}$ \\
\hline
\end{tabular}




\section{APPENDIX B. OPEC OIL SUPPLY CURVES}

The cases presented in this report were based on two oil price scenarios that differ only in terms of the anticipated market behavior of OPEC. In the Reference Oil Price Scenario, it is expected that a substantial number of the OPEC members (the "OPEC core") will operate as an imperfect (von Stakelberg) monopoly that will limit production to the point where net revenues (gross revenues minus costs) are highest. The remaining, non-core members of OPEC, as well as all non-OPEC countries, are assumed to operate competitively - that is, they will produce at levels where marginal costs equal marginal revenues. In the Low Oil Price Scenario, it is assumed that no OPEC core exists and that all countries in the world act competitively.

\section{LONG-RUN MARGINAL COSTS OF OPEC PRODUCTION}

The process of creating the oil supply curves begins with the creation of a marginal-cost
OPEC supply curve for the year 2010. This curve, shown as Figure B-1, was constructed under the assumption that the marginal capital cost of supplying the 44 million barrels per day (MMBD) of oil called for in the Energy Information Administration (EIA) Annual Energy Outlook 1994 reference case would be $\$ 10,000$ per barrel per day (BD) of capacity. This compares with estimates published by an OPEC official showing that currently planned capacity expansions for the mid- to late-1990s are in the range of $\$ 6,600$ (in the Persian Gulf region) to $\$ 9,200$ (outside the gulf region) per gross BD expansion (Saudi 1994; Smail and Miremadi 1993). Using the financial assumptions shown in Table B-1, this $\$ 10,000$-per-BD capital cost translates into a required selling price of $\$ 13.75$ per barrel. (This defines the price on the curve in Figure $\mathrm{B}-1$ at 44 MMBD.) The financial assumptions are similar to those used in the AFTM for evaluating the price required to

Figure B-1 - OPEC Marginal Cosł Oil Curve: 2010

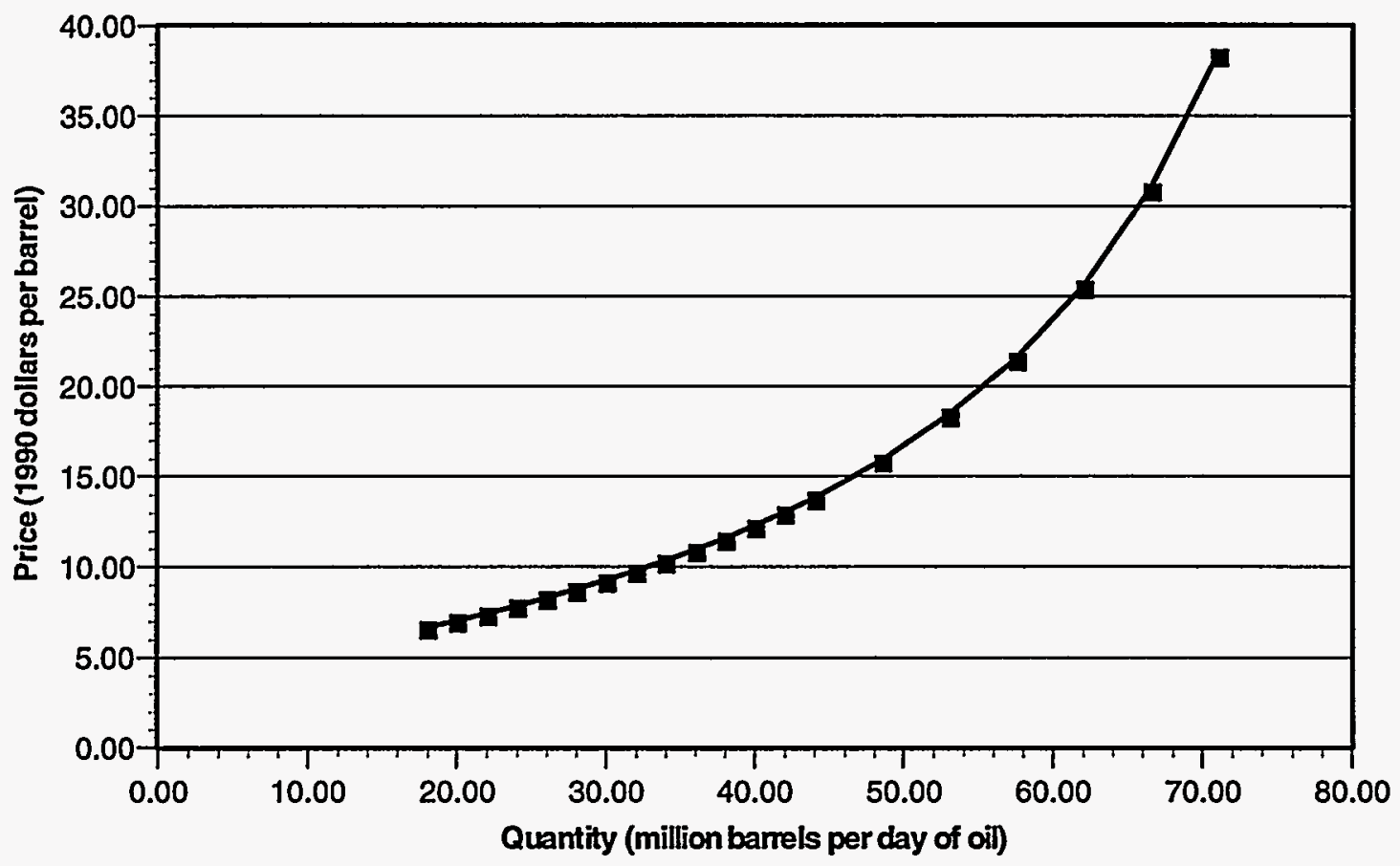


Table B-1 - Discounted Cash Flow Analysis of Average OPEC Oil
Development Costs for 1 Barrel per Day of Oil Production Capacity

\begin{tabular}{|c|c|c|c|c|}
\hline \multicolumn{2}{|c|}{$\begin{array}{l}\text { Capital Cost }(\$ / B D) \\
\text { Variable Cost }(\$ / b b l) \\
\text { Real Discount Rate } \\
\end{array}$} & \multicolumn{2}{|l|}{$\begin{array}{c}\$ 10,000 \\
\$ 2.00 \\
9.5 \% \\
\end{array}$} & \multirow[b]{2}{*}{$\begin{array}{c}\text { Cumulative } \\
\text { Revenue } \\
\text { at Min. Price } \\
\text { Less Cost (\$) }\end{array}$} \\
\hline Year & Cost (\$) & $\begin{array}{l}\text { Annual } \\
\text { Production } \\
\text { (barrels) }\end{array}$ & $\begin{array}{c}\text { Revenue } \\
\text { at Min. Price (\$) }\end{array}$ & \\
\hline 1 & $(10,000)$ & 0.0 & 0 & $(10,000)$ \\
\hline 2 & $(730)$ & 365.0 & 5,020 & $(5,710)$ \\
\hline 3 & $(730)$ & 365.0 & 5,020 & $(1,420)$ \\
\hline 4 & (730) & 365.0 & 5,020 & 2,870 \\
\hline 5 & (657) & 328.5 & 4,518 & 6,732 \\
\hline 6 & (591) & 295.7 & 4,066 & 10,207 \\
\hline 7 & (532) & 266.1 & 3,660 & 13,334 \\
\hline 8 & (479) & 239.5 & 3,294 & 16,149 \\
\hline 9 & (431) & 215.5 & 2,964 & 18,682 \\
\hline 10 & (388) & 194.0 & 2,668 & 20,962 \\
\hline 11 & (349) & 174.6 & 2,401 & 23,014 \\
\hline 12 & (314) & 157.1 & 2,161 & 24,861 \\
\hline 13 & (283) & 141.4 & 1,945 & 26,523 \\
\hline 14 & (255) & 127.3 & 1,750 & 28,019 \\
\hline 15 & (229) & 114.5 & 1,575 & 29,365 \\
\hline Sum & $(16,698)$ & $3,349.1$ & 46,064 & \\
\hline NPV & $(12,878)$ & $1,872.6$ & 25,755 & \\
\hline
\end{tabular}

Resource Cost per Barrel

$\$ 6.88$

Minimum Government Take

$50 \%$

Minimum Selling Price

$\$ 13.75$

Sensitivity of Minimum Selling Price

to Discount Rate and Government Take (\$/bbl)

\begin{tabular}{lccr}
\hline Discount & \multicolumn{3}{c}{ Government Take } \\
\cline { 2 - 4 } Rate (\%) & $40 \%$ & $50 \%$ & $60 \%$ \\
\hline 5.5 & 10.07 & 12.08 & 15.10 \\
7.5 & 10.75 & 12.90 & 16.13 \\
9.5 & 11.46 & 13.75 & 17.19 \\
11.5 & 12.19 & 14.63 & 18.28 \\
13.5 & 12.93 & 15.52 & 19.40
\end{tabular}

Sensitivity of Minimum Selling

Price to Investment Cost

(9.5\% ROR, $50 \%$ gov. take)

\begin{tabular}{rc}
\hline$\$ / \mathrm{BD}$ & Min. Price $(\$ / \mathrm{bbl})$ \\
\hline 19,000 & 22.53 \\
16,000 & 19.61 \\
13,000 & 16.68 \\
10,000 & 13.75 \\
7,000 & 10.83 \\
4,000 & 7.90
\end{tabular}


develop remote natural gas deposits. These assumptions are as follows:

- A real discount rate of 9.5 percent

- A 15-year life for economic evaluation

- A government take for taxes, royalties, and so forth that is equivalent to roughly 50 percent of gross revenue.

The bottom portion of Table B-1 shows how the required selling price of oil changes with differing financial and cost assumptions. For example, a 2-percentage-point reduction in the real discount rate would reduce the required selling price from $\$ 13.75$ to $\$ 12.90$ per barrel. An increase in the government take to 60 percent of gross revenue would raise the required selling price to $\$ 17.19$ per barrel.

\section{LOW OIL PRICE SCENARIO}

In the Low Oil Price Scenario, the curve depicting OPEC's marginal cost for oil

(Figure B-1) is used to represent OPEC's annual production in the AFTM. The only change made to the curve is the conversion from the total of crude oil, lease condensate, and gas plant liquids (the accounting convention in EIA's Annual Energy Outlook) to the crude-oilonly basis needed in the AFTM.

\section{Reference Oil Price Scenario}

In the Reference Oil Price Scenario, two oil price curves are used in the AFTM. The noncore curve representing the competitive part of OPEC is a certain fraction of the OPEC marginal cost curve. That is, it is the curve shown in Figure $\mathrm{B}-1$ with the $\mathrm{X}$-axis multiplied by a fraction representing the portion of the potential OPEC capacity in countries that are not acting monopolistically. This fraction must be such that the resulting world oil price approximates the price in the Annual Energy Outlook 1994 reference scenario- $\$ 25.83$ per barrel in 1990 dollars. To achieve this result, 72 percent of the potential OPEC capacity must be assumed to exist in the OPEC core, which will act monopolistically; the remaining 28 percent of potential capacity represents the non-core, competitive portion of OPEC.
The calculations behind this finding are shown in Table B-2. The first column in the table is the assumed average world oil price ranging from $\$ 19.50$ to $\$ 28.00$ per barrel. The second column is an estimate of world demand for petroleum liquids (crude, condensate, and gas plant liquids) at each assumed world oil price level. These demands were estimated by running the AFTM with various constrained levels of oil production to force the oil price to move to different points along the price range. The resulting demand levels for liquids were then smoothed using a continuous function.

The third and fourth columns represent competitive oil supplies for the non-OPEC regions in the AFTM and for the non-core portion of OPEC. The non-core OPEC curve is simply the marginal cost curve shown in Figure B-1 multiplied by the fraction of potential OPEC capacity assumed to be competitive-in this case, 28 percent. Key data for the monopolistic part of OPEC are shown in the fifth through tenth columns and are defined as follows:

- Residual demand for core OPEC oil is the world liquids demand less what can be produced from non-OPEC and non-core OPEC countries.

- Marginal cost is the price point on the OPEC core's marginal cost curve (Figure B-1 with the $X$-axis multiplied by 72 percent) at which the residual demand is produced.

- Gross revenues is the world oil price times the residual demand for OPEC core oil.

- Total cost is the area under the marginal cost curve up to the point at which the residual demand is produced. That is, it is the total cost of producing at the level of residual demand. The marginal cost curve assumes the existence of a political constraint that forces one-half of the gross revenues from any marginal project to go to the government. Therefore, one-half of the total costs is revenue paid to the government.

- Net revenue is gross revenue less total costs.

- Marginal revenue is the change in net revenue going down from one row to the 
Table B-2 - Solve for Monopolistic Percent of OPEC (Based on 1994 AEO Oil Price, etc.)

\begin{tabular}{|c|c|c|c|c|c|c|c|c|c|c|c|c|c|c|c|c|}
\hline \multirow{2}{*}{$\begin{array}{l}\text { World } \\
\text { Oil } \\
\text { Price } \\
(\$ / b b l)\end{array}$} & \multirow[b]{2}{*}{$\begin{array}{l}\text { World } \\
\text { Demand } \\
\text { (MMBD) }\end{array}$} & \multicolumn{2}{|c|}{$\begin{array}{l}\text { Competitive } \\
\text { Supplies } \\
\text { (MMBD) }\end{array}$} & \multicolumn{6}{|c|}{$\begin{array}{c}\text { OPEC Monopolistic Group } \\
\end{array}$} & \multicolumn{4}{|c|}{ OPEC Competitive Group } & \multirow{2}{*}{$\begin{array}{c}\text { Total } \\
\text { OPEC } \\
\text { Market } \\
\text { Share } \\
(\%)\end{array}$} & \multirow{2}{*}{$\begin{array}{l}\text { Monopoly } \\
\text { Share } \\
\text { of OPEC } \\
\text { Production } \\
(\%)\end{array}$} & \multirow{2}{*}{$\begin{array}{c}\text { Total } \\
\text { OPEC } \\
\text { Net } \\
\text { Revenue } \\
(\mathrm{MM} \$ / \mathrm{yr})\end{array}$} \\
\hline & & $\begin{array}{l}\text { Non- } \\
\text { OPEC } \\
\text { Supply }\end{array}$ & $\begin{array}{l}\text { OPEC } \\
\text { Supply }\end{array}$ & $\begin{array}{l}\text { Residual } \\
\text { Demand } \\
\text { (MMBD) }\end{array}$ & $\begin{array}{c}\text { Marginal } \\
\text { Costs } \\
(\$ / \mathrm{bbl})\end{array}$ & $\begin{array}{c}\text { Gross } \\
\text { Revenue } \\
\text { (MM\$/yr) }\end{array}$ & $\begin{array}{c}\text { Total } \\
\text { Costs } \\
(\mathrm{MM} \$ / \mathrm{yr})\end{array}$ & $\begin{array}{c}\text { Net } \\
\text { Revenue } \\
\text { (MM\$/yr) }\end{array}$ & $\begin{array}{l}\text { Marginal } \\
\text { Revenue } \\
\text { (MM\$/yr) }\end{array}$ & $\begin{array}{c}\text { Marginal } \\
\text { Costs } \\
\text { (\$/bbl) }\end{array}$ & $\begin{array}{c}\text { Gross } \\
\text { Revenue } \\
\text { (MM } \$ / y r)\end{array}$ & $\begin{array}{c}\text { Cost } \\
(\mathrm{MM} \$ / \mathrm{yr})\end{array}$ & $\begin{array}{c}\text { Net } \\
\text { Revenue } \\
(\mathrm{MM} \$ / \mathrm{yr})\end{array}$ & & & \\
\hline 28.00 & 69.41 & 28.34 & 18.15 & 22.91 & 9.69 & 234,159 & 57,248 & 176,911 & & 28.00 & 185,483 & 89,383 & 96,099 & 59.2 & 55.8 & 273,011 \\
\hline 27.00 & 70.40 & 27.89 & 17.90 & 24.60 & 10.35 & 242,471 & 63,641 & 178,830 & 1,918 & 27.00 & 176,437 & 86,872 & 89,565 & 60.4 & 57.9 & 268,395 \\
\hline 26.75 & 70.65 & 27.77 & 17.84 & 25.04 & 10.53 & 244,460 & 65,308 & 179,152 & 322 & 26.75 & 174,181 & 86,244 & 87,937 & 60.7 & 58.4 & 267,089 \\
\hline 26.50 & 70.90 & 27.65 & 17.77 & 25.48 & 10.71 & 246,431 & 67,029 & 179,402 & 250 & 26.50 & 171,928 & 85,613 & 86,315 & 61.0 & 58.9 & 65,717 \\
\hline 26.25 & 71.16 & 27.53 & 17.71 & 25.92 & 10.91 & 248,385 & 68,806 & 179,578 & 176 & 6.25 & 169,677 & 84,979 & 84,699 & 61.3 & .4 & 64,277 \\
\hline 26.00 & 71.42 & 27.40 & 17.64 & 26.38 & 11.10 & 250,320 & 70,643 & 179,677 & 99 & 6.00 & 167,429 & 84,340 & 83,089 & 61.6 & 99.9 & 262,766 \\
\hline 25.75 & 71.68 & 27.27 & 17.58 & 26.83 & 11.31 & 252,205 & 72,528 & 179,677 & $(0)$ & 5.75 & 165,184 & 83,699 & 81,485 & 62.0 & 30.4 & 261,162 \\
\hline 25.50 & 71.95 & 27.14 & 17.51 & 27.30 & 11.52 & 254,071 & 74,477 & 179,594 & (83) & 25.50 & 162,941 & 83,053 & 79,888 & 62.3 & 60.9 & 259,482 \\
\hline 25.25 & 72.21 & 27.01 & 17.44 & 27.77 & 11.74 & 255,918 & 76,494 & 179,424 & (170) & 25.25 & 160,701 & 82,404 & 78,297 & 62.6 & 61.4 & 257,721 \\
\hline 25.00 & 72.49 & 26.87 & 17.37 & 28.25 & 11.97 & 257,746 & 78,583 & 179,163 & (260) & 25.00 & 158,464 & 81,752 & 76,712 & 62.9 & 1.9 & 55,876 \\
\hline 24.75 & 72.76 & 26.73 & 17.29 & .73 & 12.21 & 259,555 & 80,746 & 178,808 & 55) & 4.75 & 156,229 & 81,095 & 75,134 & 3.3 & & 53,942 \\
\hline 24.50 & 73.04 & 26.59 & 17.22 & .22 & 12.46 & 261,343 & 82,989 & 178,355 & 54) & 4.50 & 153,998 & 80,435 & 73,563 & 3.6 & 9 & 51,917 \\
\hline 24.25 & 73.32 & 26.45 & 17.15 & 73 & 12.72 & 263,111 & 85,314 & 177,797 & (557) & 4.25 & 151,770 & 772 & 71,998 & 3.9 & & 49,795 \\
\hline 24.00 & 73.61 & 26.30 & 17.07 & 30.24 & 12.99 & 264,859 & 87,728 & 177,131 & (666) & 4.00 & 149,544 & 104 & 70,440 & 64.3 & 9 & 247,572 \\
\hline 23.75 & 73.90 & 26.15 & 16.99 & 30.75 & 13.27 & 266,586 & 90,234 & 176,352 & (779) & 3.75 & 147,322 & 78,433 & 68,889 & 64.6 & t.4 & 245,242 \\
\hline 23.50 & 74.20 & 26.00 & 16.92 & 31.28 & 13.56 & 268,292 & 92,838 & 175,453 & (899) & 23.50 & 145,103 & 77,757 & 67,346 & 65.0 & 64.9 & 242,799 \\
\hline 23.25 & 74.50 & 25.85 & 16.84 & 81 & 13.87 & 269,976 & 95,547 & 174,429 & $1,024)$ & 23.25 & 142,887 & 77,078 & 65,809 & 65.3 & 65.4 & 240,239 \\
\hline 23.00 & 74.80 & 25.69 & 16.76 & 32.36 & 14.20 & 271,638 & 98,365 & 173,273 & $(1,156)$ & 23.00 & 140,675 & 76,395 & 64,280 & 65.7 & 65.9 & 237,554 \\
\hline 22.75 & 75.11 & 25.53 & 16.68 & 32.91 & 14.54 & 273,278 & 101,300 & 171,978 & $(1,295)$ & 2.75 & 138,466 & 75,708 & 62,759 & 66.0 & 66.4 & 234,737 \\
\hline 22.50 & 75.42 & 25.36 & 16.59 & 33.47 & 14.90 & 274,895 & 104,358 & 170,537 & $(1,442)$ & 2.50 & 136,261 & 75,017 & 61,245 & 66.4 & 66.9 & 231,781 \\
\hline 22.25 & 75.74 & 25.19 & 16.51 & 34.05 & 15.27 & 276,489 & 107,549 & 168,940 & $(1,597)$ & 2.25 & 134,060 & 74,321 & 59,738 & 66.7 & 67.3 & 228,678 \\
\hline 22.00 & 76.07 & 25.02 & 16.42 & 34.63 & 15.67 & 278,059 & 110,880 & 167,179 & $(1,761)$ & 22.00 & 131,862 & 73,622 & 58,240 & 67.1 & 67.8 & 225,419 \\
\hline 21.50 & 76.72 & 24.66 & 16.24 & 35.82 & 16.52 & 281,087 & 118,063 & 163,023 & $(4,156)$ & 21.50 & 127,478 & 72,203 & 55,275 & 67.9 & 68.8 & 218,299 \\
\hline 1.00 & 77.40 & 24.29 & 16.06 & & 17.48 & 284,014 & 125,941 & 158,072 & $(4,951)$ & 1.00 & 123,111 & 70,766 & 52,344 & 68.6 & 69.8 & 210,416 \\
\hline 20.50 & 78.10 & 23.90 & 15.87 & 38.33 & 18.56 & 286,836 & 134,619 & 152,217 & $(5,855)$ & 20.50 & 118,760 & 69,313 & 49,448 & 69.4 & 70.7 & 201,665 \\
\hline 20.00 & 78.83 & 23.49 & 15.68 & 39.66 & 19.79 & 289,551 & 144,226 & 145,325 & $(6,892)$ & 20.00 & 114,428 & 67,841 & 46,587 & 70.2 & 71.7 & 191,912 \\
\hline 19.50 & 79.57 & 23.06 & 15.47 & 41.05 & 21.19 & 292,152 & 154,919 & 137,233 & $(8,092)$ & 19.50 & 110,114 & 66,351 & 43,763 & 71.0 & 72.6 & 180,996 \\
\hline
\end{tabular}

Notes: This analysis is based on Annual Energy Outlook convention wherein crude oil, condensate, and NGL volumes are combined. AFTM has different conventions.

Changes in world oil demand estimated from AFTM runs counting demand for crude and condensate.

"Total costs" approximates area under marginal cost curve, which has embedded in it 50 percent government take of gross revenues. 
next-that is, as OPEC core production goes up one step.

For the case shown in Table B-2, the OPEC core maximizes net revenue (marginal net revenue is zero) when it produces 26.38 MMBD. At that point, world demand is $71.42 \mathrm{MMBD}$ and the world oil price is $\$ 26.00$ per barrel. Total OPEC production, including 17.64 MMBD from the non-core countries, is 44.02 MMBD.

These results are similar to the prices and volumes shown in EIA's reference scenario in the Annual Energy Outlook 1994. The similarity of results was achieved by solving for the fraction of OPEC potential capacity that would be under monopoly control and the fraction that would be competitive. Figure B-2 shows what world oil prices would be in 2010 if different fractions of OPEC were to act monopolistically. Given this study's various assumptions for supply and demand, EIA's \$26.00 Reference Oil Price scenario is consistent with the assumption that 71.8 percent of OPEC acts monopolistically. If 50 percent of potential
OPEC capacity were to act competitively, world oil prices would fall to approximately $\$ 22.00$ per barrel (see Table B-3).

The production level of 17.64 MMBD at $\$ 26.00$ represents one point on the AFTM OPEC core supply curve under the Reference Oil Price Scenario. Additional points on the curve are found by recalculating the data in Table B-2 under different assumptions for world oil demand. For example, if 2 MMBD of world demand were to be eliminated through slower economic growth, energy conservation, or an alternative-fuels program, the world oil price would be approximately $\$ 25.00$ per barrel, and the OPEC core would produce 26.22 MMBD (Table B-4). This is a second point on the OPEC core monopolistic supply curve. This process was repeated for additional subtractions from or additions to demand, and the points were smoothed into the AFTM curve as shown in Figure B-2. Although the AFTM curve is defined on a crude-only basis, the tables follow the EIA conventions of aggregating supplies and demands for crude oil, condensate, and gas plant liquids.

\section{Figure B-2 - Oil Price Versus Participation in OPEC Monopoly}

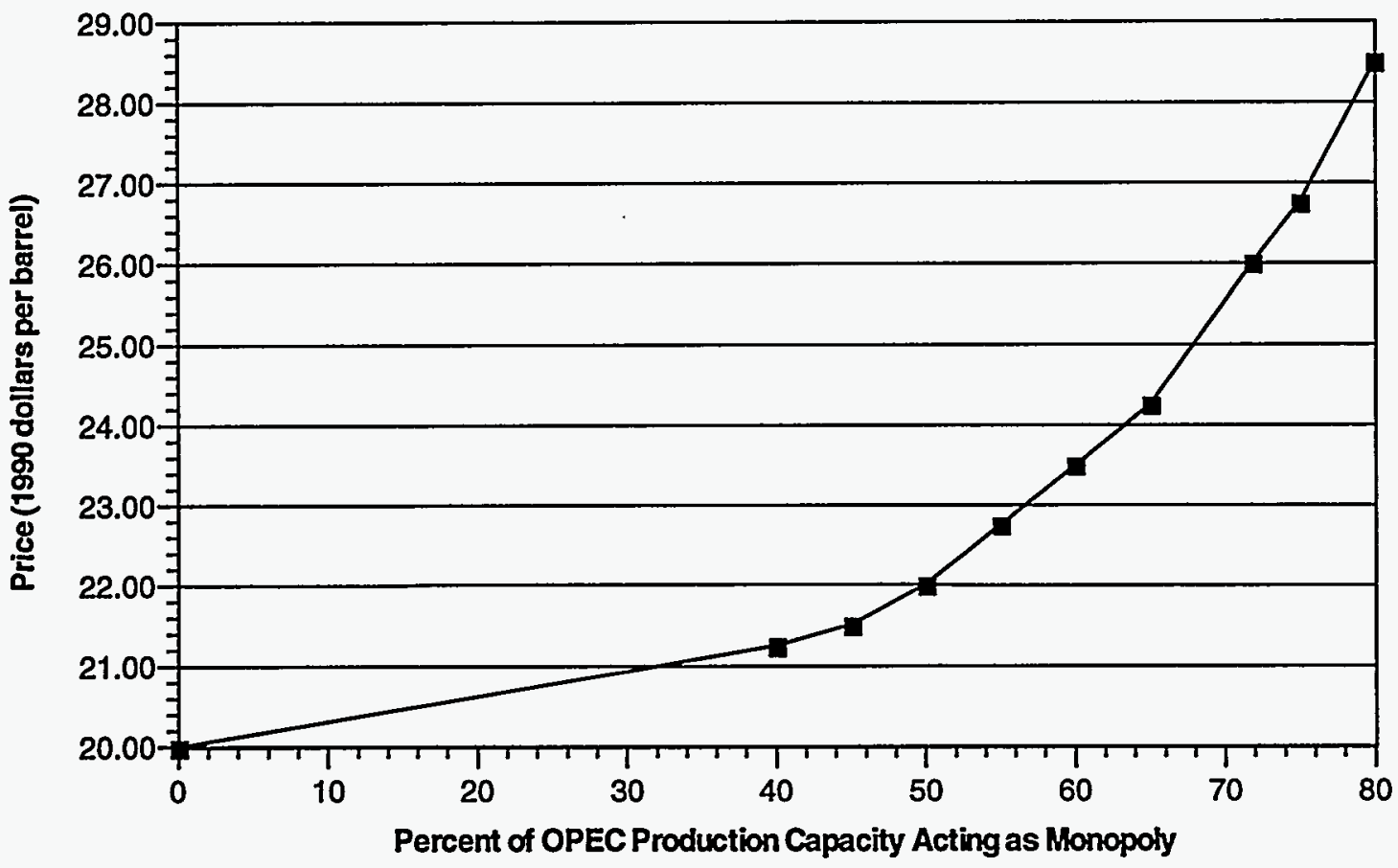


Table B-3 - Assume Monopolistic Fraction of OPEC Is $\mathbf{5 0}$ Percent of Potential Capacity

\begin{tabular}{|c|c|c|c|c|c|c|c|c|c|c|c|c|c|c|c|c|}
\hline \multirow{2}{*}{$\begin{array}{l}\text { World } \\
\text { Oil } \\
\text { Price } \\
\text { (\$/bbl) }\end{array}$} & \multirow{2}{*}{$\begin{array}{l}\text { World } \\
\text { Demand } \\
\text { (MMBD) }\end{array}$} & \multicolumn{2}{|c|}{$\begin{array}{l}\text { Competitive } \\
\text { Supplies } \\
\text { (MMBD) }\end{array}$} & \multicolumn{6}{|c|}{ OPEC Monopolistic Group } & \multicolumn{4}{|c|}{ OPEC Competitive Group } & \multirow{2}{*}{$\begin{array}{c}\text { Total } \\
\text { OPEC } \\
\text { Market } \\
\text { Share } \\
(\%)\end{array}$} & \multirow{2}{*}{$\begin{array}{c}\text { Monopoly } \\
\text { Share } \\
\text { of OPEC } \\
\text { Production } \\
(\%)\end{array}$} & \multirow{2}{*}{$\begin{array}{c}\text { Total } \\
\text { OPEC } \\
\text { Net } \\
\text { Revenue } \\
\text { (MM\$/yr) }\end{array}$} \\
\hline & & $\begin{array}{l}\text { Non- } \\
\text { OPEC } \\
\text { Supply }\end{array}$ & $\begin{array}{l}\text { OPEC } \\
\text { Supply }\end{array}$ & $\begin{array}{l}\text { Residual } \\
\text { Demand } \\
\text { (MMBD) }\end{array}$ & $\begin{array}{c}\text { Marginal } \\
\text { Costs } \\
(\$ / b b l)\end{array}$ & $\begin{array}{c}\text { Gross } \\
\text { Revenue } \\
\text { (MM\$/yr) }\end{array}$ & $\begin{array}{c}\text { Total } \\
\text { Costs } \\
\text { (MM } \$ / y r)\end{array}$ & $\begin{array}{c}\text { Net } \\
\text { Revenue } \\
(\mathrm{MM} \$ / \mathrm{yr})\end{array}$ & $\begin{array}{l}\text { Marginal } \\
\text { Revenue } \\
\text { (MM } \$ / y r)\end{array}$ & $\begin{array}{c}\text { Marginal } \\
\text { Costs } \\
\text { (\$/bbl) }\end{array}$ & $\begin{array}{c}\text { Gross } \\
\text { Revenue } \\
\text { (MM\$/yr) }\end{array}$ & $\begin{array}{c}\text { Cost } \\
(\mathrm{MM} \$ / \mathrm{yr})\end{array}$ & $\begin{array}{c}\text { Net } \\
\text { Revenue } \\
\text { (MM } \$ \text { /yr) }\end{array}$ & & & \\
\hline 28.00 & 69.41 & 28.34 & 32.16 & 8.90 & 6.58 & 90,924 & 17,186 & 73,738 & & 28.00 & 328,718 & 158,408 & 170,310 & 59.2 & 21.7 & 244,048 \\
\hline 27.00 & 70.40 & 27.89 & 31.73 & 10.78 & 7.29 & 106,222 & 22,196 & 84,026 & 10,288 & 27.00 & 312,687 & 153,957 & 158,729 & 60.4 & 25.4 & 242,755 \\
\hline 26.75 & 70.65 & 27.77 & 31.62 & 11.26 & 7.49 & 109,952 & 23,515 & 86,437 & 2,411 & 26.75 & 308,689 & 152,845 & 155,844 & 60.7 & 26.3 & 242,281 \\
\hline 26.50 & 70.90 & 27.65 & 31.50 & 11.75 & 7.69 & 113,663 & 24,891 & 88,773 & 2,336 & 26.50 & 304,696 & 151,726 & 152,970 & 61.0 & 27.2 & 241,742 \\
\hline 26.25 & 71.16 & 27.53 & 31.38 & 12.25 & 7.90 & 117,355 & 26,325 & 91,030 & 2,258 & 26.25 & 300,707 & 150,601 & 150,106 & 61.3 & 28.1 & 241,136 \\
\hline 26.00 & 71.42 & 27.40 & 31.27 & 12.75 & 8.12 & 121,027 & 27,821 & 93,206 & 2,176 & 26.00 & 296,723 & 149,470 & 147,253 & 61.6 & 29.0 & 240,459 \\
\hline 25.75 & 71.68 & 27.27 & 31.15 & 13.26 & 8.35 & 124,645 & 29,372 & 95,273 & 2,068 & 25.75 & 292,744 & 148,333 & 144,411 & 62.0 & 29.9 & 239,684 \\
\hline 25.50 & 71.95 & 27.14 & 31.03 & 13.78 & 8.59 & 128,243 & 30,992 & 97,252 & 1,978 & 25.50 & 288,769 & 147,189 & 141,580 & 62.3 & 30.8 & 238,831 \\
\hline 25.25 & 72.21 & 27.01 & 30.90 & 14.30 & 8.84 & 131,820 & 32,685 & 99,136 & 1,884 & 25.25 & 284,799 & 146,039 & 138,760 & 62.6 & 31.6 & 237,895 \\
\hline 25.00 & 72.49 & 26.87 & 30.78 & 14.84 & 9.11 & 135,376 & 34,455 & 100,921 & 1,785 & 25.00 & 280,834 & 144,883 & 135,951 & 62.9 & 32.5 & 236,872 \\
\hline 24.75 & 72.76 & 26.73 & 30.65 & 15.38 & 9.38 & 138,910 & 36,308 & 102,602 & 1,681 & 24.75 & 276,874 & 143,720 & 133,155 & 63.3 & 33.4 & 235,756 \\
\hline 24.50 & 73.04 & 26.59 & 30.52 & 15.93 & 9.67 & 142,421 & 38,249 & 104,173 & 1,571 & 24.50 & 272,920 & 142,550 & 130,370 & 63.6 & 34.3 & 234,542 \\
\hline 24.25 & 73.32 & 26.45 & 30.39 & 16.48 & 9.98 & 145,910 & 40,283 & 105,628 & 1,455 & 24.25 & 268,970 & 141,374 & 127,597 & 63.9 & 35.2 & 233,225 \\
\hline 24.00 & 73.61 & 26.30 & 30.25 & 17.05 & 10.30 & 149,377 & 42,417 & 106,960 & 1,332 & 24.00 & 265,027 & 140,190 & 124,836 & 64.3 & 36.0 & 231,796 \\
\hline 23.75 & 73.90 & 26.15 & 30.12 & 17.63 & 10.64 & 152,820 & 44,657 & 108,163 & 1,203 & 23.75 & 261,088 & 139,001 & 122,088 & 64.6 & 36.9 & 230,251 \\
\hline 23.50 & 74.20 & 26.00 & 29.98 & 18.21 & 11.01 & 156,239 & 47,012 & 109,227 & 1,065 & 23.50 & 257,156 & 137,804 & 119,352 & 65.0 & 37.8 & 228,579 \\
\hline 23.25 & 74.50 & 25.85 & 29.84 & 18.81 & 11.39 & 159,634 & 49,489 & 110,145 & 918 & 23.25 & 253,229 & 136,600 & 116,629 & 65.3 & 38.7 & 226,775 \\
\hline 23.00 & 74.80 & 25.69 & 29.70 & 19.42 & 11.79 & 163,005 & 52,097 & 110,908 & 762 & 23.00 & 249,309 & 135,389 & 113,919 & 65.7 & 39.5 & 224,827 \\
\hline 22.75 & 75.11 & 25.53 & 29.55 & 20.03 & 12.22 & 166,350 & 54,846 & 111,504 & 596 & 22.75 & 245,394 & 134,172 & 111,223 & 66.0 & 40.4 & 222,726 \\
\hline 22.50 & 75.42 & 25.36 & 29.40 & 20.66 & 12.68 & 169,670 & 57,748 & 111,922 & 418 & 22.50 & 241,486 & 132,947 & 108,540 & 66.4 & 41.3 & 220,461 \\
\hline 22.25 & 75.74 & 25.19 & 29.25 & 21.30 & 13.17 & 172,964 & 60,815 & 112,149 & 228 & 22.25 & 237,585 & 131,715 & 105,870 & 66.7 & 42.1 & 218,020 \\
\hline 22.00 & 76.07 & 25.02 & 29.10 & 21.95 & 13.70 & 176,232 & 64,059 & 112,173 & 23 & 22.00 & 233,690 & 130,475 & 103,215 & 67.1 & 43.0 & 215,387 \\
\hline 21.50 & 76.72 & 24.66 & 28.79 & 23.27 & 14.86 & 182,644 & 71,259 & 111,385 & $(787)$ & 21.50 & 225,921 & 127,960 & 97,961 & 67.9 & 44.7 & 209,346 \\
\hline 21.00 & 77.40 & 24.29 & 28.46 & 24.65 & 16.21 & 188,944 & 79,400 & 109,544 & $(1,842)$ & 21.00 & 218,180 & 125,414 & 92,766 & 68.6 & 46.4 & 202,309 \\
\hline 20.50 & 78.10 & 23.90 & 28.13 & 26.08 & 17.80 & 195,126 & 88,673 & 106,453 & $(3,091)$ & 20.50 & 210,470 & 122,838 & 87,632 & 69.4 & 48.1 & 194,085 \\
\hline 20.00 & 78.83 & 23.49 & 27.78 & 27.56 & 19.69 & 201,186 & 99,327 & 101,859 & $(4,593)$ & 20.00 & 202,792 & 120,230 & 82,563 & 70.2 & 49.8 & 184,422 \\
\hline 19.50 & 79.57 & 23.06 & 27.42 & 29.10 & 22.00 & 207,119 & 111,692 & 95,426 & $(6,433)$ & 19.50 & 195,148 & 117,589 & 77,559 & 71.0 & 51.5 & 172,985 \\
\hline
\end{tabular}

Notes: This analysis is based on Annual Energy Outlook convention wherein crude oil, condensate, and NGL volumes are combined. AFTM has different conventions.

Changes in world oil demand estimated from AFTM runs counting demand for crude and condensate.

"Total costs" approximates area under marginal cost curve, which has embedded in it 50 percent government take of gross revenues. 
Table B-4 - World Oil Demand Reduced 2 MMBOPD (Based on 1994 AEO Oil Price, etc.)

\begin{tabular}{|c|c|c|c|c|c|c|c|c|c|c|c|c|c|c|c|c|}
\hline \multirow{2}{*}{$\begin{array}{l}\text { World } \\
\text { Oil } \\
\text { Price } \\
\text { (\$/bbl) }\end{array}$} & \multirow{2}{*}{$\begin{array}{l}\text { World } \\
\text { Demand } \\
\text { (MMBD) }\end{array}$} & \multicolumn{2}{|c|}{$\begin{array}{l}\text { Competitive } \\
\text { Supplies } \\
\text { (MMBD) } \\
\end{array}$} & \multicolumn{6}{|c|}{$\begin{array}{c}\text { OPEC Monopolistic Group } \\
\end{array}$} & \multicolumn{4}{|c|}{ OPEC Competitive Group } & \multirow{2}{*}{$\begin{array}{c}\text { Total } \\
\text { OPEC } \\
\text { Market } \\
\text { Share } \\
(\%)\end{array}$} & \multirow{2}{*}{$\begin{array}{c}\text { Monopoly } \\
\text { Share } \\
\text { of OPEC } \\
\text { Production } \\
(\%)\end{array}$} & \multirow{2}{*}{$\begin{array}{c}\text { Total } \\
\text { OPEC } \\
\text { Net } \\
\text { Revenue } \\
\text { (MM\$/yr) }\end{array}$} \\
\hline & & $\begin{array}{l}\text { Non- } \\
\text { OPEC } \\
\text { Supply }\end{array}$ & $\begin{array}{l}\text { OPEC } \\
\text { Supply }\end{array}$ & $\begin{array}{l}\text { Residual } \\
\text { Demand } \\
\text { (MMBD) }\end{array}$ & $\begin{array}{l}\text { Marginal } \\
\text { Costs } \\
\text { (\$/bbl) }\end{array}$ & $\begin{array}{c}\text { Gross } \\
\text { Revenue } \\
\text { (MM\$/yr) }\end{array}$ & $\begin{array}{c}\text { Total } \\
\text { Costs } \\
\text { (MM\$ } \$ \text { yr) }\end{array}$ & $\begin{array}{c}\text { Net } \\
\text { Revenue } \\
\text { (MM } \$ / y r)\end{array}$ & $\begin{array}{l}\text { Marginal } \\
\text { Revenue } \\
\text { (MM\$/yr) }\end{array}$ & $\begin{array}{c}\text { Marginal } \\
\text { Costs } \\
\text { (\$/bbl) }\end{array}$ & $\begin{array}{c}\text { Gross } \\
\text { Revenue } \\
\text { (MM\$ } \$ / y r)\end{array}$ & $\begin{array}{c}\text { Cost } \\
\text { (MM\$/yr) }\end{array}$ & $\begin{array}{c}\text { Net } \\
\text { Revenue } \\
\text { (MM\$/yr) }\end{array}$ & & & \\
\hline 28.00 & 67.46 & 28.34 & 18.15 & 20.97 & 8.99 & 214,296 & 49,711 & 164,584 & & 28.00 & 185,483 & 89,383 & 96,099 & 58.0 & 53.6 & 260,684 \\
\hline 27.00 & 68.43 & 27.89 & 17.90 & 22.63 & 9.59 & 223,044 & 55,535 & 167,509 & 2,924 & 27.00 & 176,437 & 86,872 & 89,565 & 59.2 & 55.8 & 257,074 \\
\hline 26.75 & 68.67 & 27.77 & 17.84 & 23.08 & 9.75 & 225,143 & 57,052 & 168,091 & 582 & 26.75 & 174,181 & 36,244 & 87,937 & 59.6 & & 256,028 \\
\hline 26.50 & 68.92 & 27.65 & 17.77 & 23.49 & 9.91 & 227,226 & 58,618 & 168,608 & 517 & 26.50 & 171,928 & 85,613 & 86,315 & 59.9 & & 254,923 \\
\hline 26.25 & 69.17 & 27.53 & 17.71 & 23.93 & 10.08 & 229,292 & 60,235 & 169,057 & 449 & 26.25 & 169,677 & 84,979 & 84,699 & 60.2 & 57.5 & 253,756 \\
\hline 26.00 & 69.42 & 27.40 & 17.64 & 24.38 & 10.26 & 231,340 & 61,906 & 169,435 & 378 & 26.00 & 167,429 & 84,340 & 83,089 & 60.5 & 8.0 & 252,524 \\
\hline 25.75 & 69.67 & 27.27 & 17.58 & 24.83 & 10.44 & 233,339 & 63,618 & 169,721 & 286 & 25.75 & 165,184 & 83,699 & 81,485 & 60.9 & 8.6 & 251,206 \\
\hline 25.50 & 69.93 & 27.14 & 17.51 & 28 & 10.63 & 235,319 & 65,389 & 169,931 & 210 & 25.50 & 162,941 & 83,053 & 79,888 & 61.2 & 9.1 & 249,819 \\
\hline 25.25 & 70.19 & 7.01 & 17.44 & & 10.83 & 237 & 67 & 170,062 & 131 & 25.25 & 701 & 404 & 78,297 & 61.5 & 6 & 248,358 \\
\hline 25.00 & 7 & 26.87 & 17.37 & & 11.03 & 239,224 & 69,114 & 170,110 & 49 & 25.00 & 158,464 & 1,752 & 76,712 & 61.9 & 2 & 246,822 \\
\hline 24.75 & 70.72 & 26.73 & 17.29 & 26.69 & 11.25 & 241,148 & 71,075 & 170,073 & -37 & 24.75 & 156,229 & 1,095 & 75,134 & 62.2 & .7 & 245,207 \\
\hline 24.50 & 70.99 & 26.59 & 17.22 & 27.18 & 11.47 & 243,052 & 73,106 & 169,946 & -127 & 24.50 & 153,998 & 80,435 & 73,563 & 62.5 & & 243,509 \\
\hline 24.25 & 71.27 & 26.45 & 17.15 & 27.67 & 11.70 & 244,937 & 75,211 & 169,726 & -220 & 24.25 & 151,770 & 79,772 & 71,998 & 62.9 & 1.7 & 241,724 \\
\hline 24.00 & 71.55 & 26.30 & 17.07 & 28.17 & 11.93 & 246,802 & 77,394 & 169,408 & -318 & 24.00 & 149,544 & 79,104 & 70,440 & 63.2 & 3 & 239,848 \\
\hline 23.75 & 71.83 & 26.15 & 16.99 & 28.68 & 12.18 & 248,646 & 79,659 & 168,987 & -421 & 23.75 & 147,322 & 78,433 & 68,889 & 63.6 & .8 & 237,876 \\
\hline 23.50 & 72.12 & 26.00 & 16.92 & 9.20 & 12.44 & 250,470 & 82,011 & 168,459 & -528 & 23.50 & 145,103 & 77,757 & 67,346 & 63.9 & 3 & 235,805 \\
\hline 23.25 & 72.41 & 25.85 & 16.84 & 9.73 & 12.72 & 252,272 & 84,454 & 167,818 & -641 & 23.25 & 142,888 & 77,078 & 65,809 & 64.3 & 3.8 & 233,627 \\
\hline 23.00 & & 25.69 & 16.76 & .26 & 13.00 & 254,053 & 86,994 & 167,059 & -759 & 23.00 & 140,675 & 76,395 & 64,280 & 64.7 & 84.4 & 231,339 \\
\hline 22.75 & 73.01 & 25.53 & 16.68 & .81 & 13.30 & 255,812 & 89,637 & 166,175 & -884 & 22.75 & 138,467 & 75,708 & 62,759 & 65.0 & 34.9 & 228,934 \\
\hline 22.50 & 73.31 & 25.36 & 16.59 & 31.36 & 13.61 & 257,549 & 92,388 & 165,161 & $-1,014$ & 22.50 & 136,261 & 75,017 & 61,245 & 65.4 & 5.4 & 226,405 \\
\hline 22.25 & 73.62 & 25.19 & 16.51 & 31.92 & 13.94 & 259,263 & 95,255 & 164,008 & $-1,153$ & 22.25 & 134,060 & 74,321 & 59,738 & 65.8 & 55.9 & 223,747 \\
\hline 22.00 & 73.94 & 25.02 & 16.42 & 32.50 & 14.28 & 260,954 & 98,244 & 162,710 & $-1,298$ & 22.00 & 131,862 & 73,622 & 58,240 & 66.2 & 36.4 & 220,950 \\
\hline 21.50 & 74.57 & 24.66 & 16.24 & 33.67 & 15.02 & 264,226 & 104,675 & 159,551 & $-3,159$ & 21.50 & 127,478 & 72,203 & 55,275 & 66.9 & 67.5 & 214,826 \\
\hline 21.00 & 75.23 & 24.29 & 16.06 & 34.89 & 15.85 & 267,400 & 111,708 & 155,692 & $-3,859$ & 21.00 & 123,111 & 70,766 & 52,344 & 67.7 & 68.5 & 208,036 \\
\hline 20.50 & 75.91 & 23.90 & 15.87 & 36.15 & 16.77 & 270,471 & 119,429 & 151,042 & $-4,650$ & 20.50 & 118,760 & 69,313 & 49,448 & 68.5 & 69.5 & 200,490 \\
\hline 20.00 & 76.62 & 23.49 & 15.68 & 37.46 & 17.81 & 273,437 & 127,945 & 145,492 & $-5,550$ & 20.00 & 114,428 & 67,841 & 46,587 & 69.3 & 70.5 & 192,079 \\
\hline 19.50 & 77.35 & 23.06 & 15.47 & 38.82 & 18.99 & 276,292 & 137,384 & 138,908 & $-6,584$ & 19.50 & 110,114 & 66,351 & 43,763 & 70.2 & 71.5 & 182,671 \\
\hline
\end{tabular}

Notes: This analysis is based on Annual Energy Outlook convention wherein crude oil, condensate, and NGL volumes are combined. AFTM has different conventions.

Changes in world oil demand estimated from AFTM runs counting demand for crude and condensate.

"Total costs" approximates area under marginal cost curve, which has embedded in it 50 percent government take of gross revenues. 


\section{REFERENCES}

Smail, I.A.H., and Miremadi. 1993. Middle East due even greater role in worldwide oil supply. Oil and Gas Journal (June): 61.

Saudi, Abdullah A., 1994. Developments in the Oil Industry and the Changing Role of Arab Banks.

Presentation to Middle East Petroleum and Gas Conference (January). 


\section{APPENDIX C. ALTERNATIVE FUELS \\ AND VEHICLES CHOICE MODEL}

\section{CONTEXT}

This appendix describes the theory and implementation of the Alternative Fuels and Vehicles Choice (AFVC) model, designed for use with the Department of Energy's Alternative Fuels Trade Model (AFTM). Development of the AFVC model is part of the ongoing Assessment of the Costs and Benefits of Flexible and Alternative Fuel Use in the U.S. Transportation Sector (DOE 1988). Information and analytical tools developed in the course of the assessment are being applied to answer questions posed by Section 502(b) of the Energy Policy Act of 1992 (EPACT) concerning the technical and economic feasibility for alternative fuels to replace petroleum fuels, reduce greenhouse gas emissions, and displace U. S. energy imports. The act sets goals of 10 percent replacement by the year 2000 and 30 percent by 2010 . The key analytical tool for this assessment is the AFTM, a static equilibrium computer model of world supply and demand for liquid fuels (Manne 1989; Leiby 1993). The AFTM represents world supply and demand for liquid fuels by means of an optimization model comprising resource supply, conversion into liquid fuel products, transportation and distribution, and demand for fuels (Leiby 1993). A unique feature of the AFTM is the inclusion of the choices of alternative-fuel vehicles (AFVs) and alternative fuels in solving for a world energy market equilibrium. It accomplishes this by incorporating a multinomial logit (MNL) model into the AFTM's objective function (Leiby and Greene 1993). This appendix sets forth the methodology of the AFVC model and explains how the parameters of the model are developed and converted into an appropriate format for use in the AFTM.

The philosophy underlying the AFVC model is to maintain a direct and explicit linkage between assumptions about fuels, vehicles, and consumer behavior, and the resulting model coefficients. The model's parameters do not emerge from a "black box," but are instead derived from assumptions about vehicles and consumer behavior that must be stated explicitly. To forecast the demand for new commodities such as alternative fuels and vehicles, a number of important assumptions must be made about (1) what attributes influence the choices of fuels and vehicles, (2) how consumers will value the differences among fuels and vehicles, and (3) how sensitive choices will be to fuel prices. Fuel prices are the only variables in the AFTM affecting fuel and vehicle choices. 1 Calibration of the AFVC model begins by stipulating the characteristics of vehicles and fuels that are expected to be important in consumers' decisionmaking. Next, each important attribute of the vehicles and fuels is quantified. Typical (average) values (dollars per unit) for each characteristic are then used to obtain a value in dollars for each attribute. These values can be directly translated into coefficients of the MNL choice model, once the price elasticities of fuel and vehicle choices are specified.

The steps required to calibrate the AFVC model are illustrated in Figure $\mathrm{C}-1$. Boxes indicate where critical assumptions are introduced. The calibration method relies on existing studies of consumer choices of conventional and alternative fuels, analyses of surveys of consumer preferences for alternative fuels, existing technology assessments for alternative-fuel vehicles, and assumptions about key factors such as the discount rate and value of time. By deriving parameters from specific assumptions about consumer behavior and vehicle attributes, the method requires a clear statement of the suppositions on which the model's predictions are based. Uncertainty about many important aspects of the future markets for

\footnotetext{
${ }^{1}$ Because the value of at least one attribute is a function of fuel prices, the method does not allow a fully simultaneous determination of fuel prices and fuel and vehicle choices. This shortcoming can be overcome by iteratively solving the AFTM and recomputing parameter values.
} 


\section{Figure C-1 - Alternative Fuels and Vehicles Choice Model Flowchart of Calibration Process}

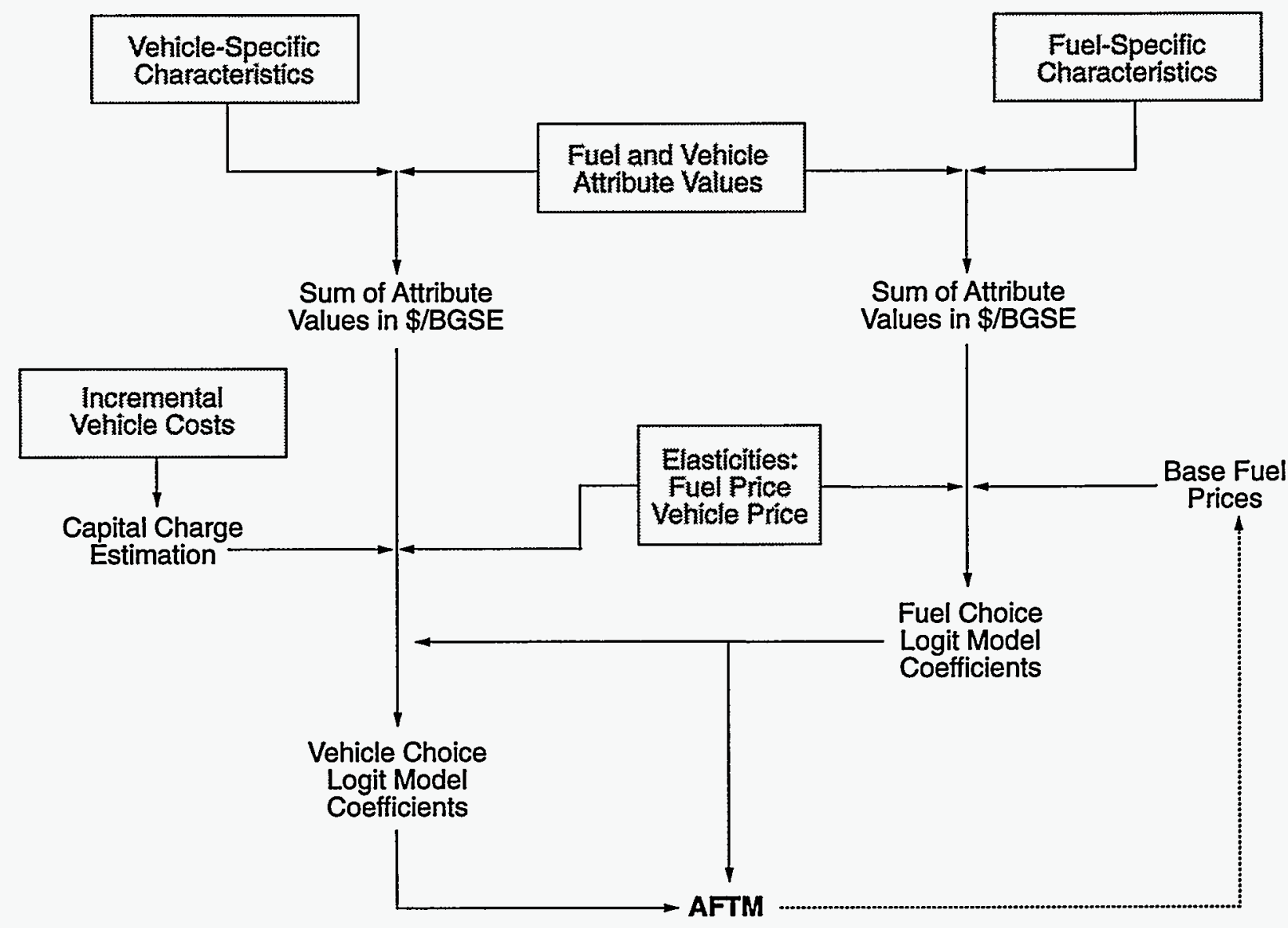

alternative fuels and vehicles makes it important both to be clear about what assumptions have been made and to be able to change assumptions and repeat the analysis. The AFVC methodology maintains a clear record of assumptions so that their effects on predicted outcomes can be understood.

Modeling demand for novel products for which there is no history of market experience is always tricky. Existing studies of consumer demand for alternative fuels offer a reasonable consensus about which fuel characteristics are important but permit only a limited quantification of consumers' willingness to pay for fuel attributes. In addition, some key characteristics of future alternative-fuel vehicles are only approximately known at this time. For some alternative fuels, positive and negative characteristics of the fuel may offset each other to a substantial degree, leaving market share to be determined by price and intangible or unpredictable factors, such as consumer perceptions of fuel "quality" or individual willingness to pay for fuels with social rather than private benefits. The price responsiveness of fuel and vehicle demand in the context of a well-developed alternative-fuels market is also not definitively known. Existing econometric studies of conventional-fuel-type choice, indicate very high price elasticities $(-10$ to -40$)$ of demand in a variety of contexts. The price elasticity of vehicle-type choice is also likely to be quite high for most vehicle types. To the extent that alternative fuels are perceived to be nearly equivalent to gasoline, vehicle and fuel choice is likely to be highly sensitive to very small price or quality differences. 
What is required is a modeling method that recognizes the existence of uncertainties, permits what is known to be used in a rigorous manner, and requires all critical assumptions to be made explicitly. The AFVC model accomplishes these goals by starting with a theoretically rigorous model structure and calculating all of its parameters from data or explicitly stated assumptions. The AFTM incorporates the AFVC model into its objective function in order to predict the market shares that maximize social welfare (Leiby and Greene 1993).

The process of calibration begins with the specification of key assumptions about consumer behavior and fuel and vehicle attributes (Figure C-1). These are entered in a spreadsheet that uses them to calculate fuel attribute values in 1990 dollars per barrel of gasoline equivalent. Dollar values of fuel attributes are first used to estimate coefficients for the fuelchoice decisions for multifuel vehicles, which are then subsumed, or nested, in the vehiclechoice model.

Based on assumptions about vehicle use, depreciation rates, fuel economy, length of ownership, and discount rates, which are also entered in the spreadsheet, price differences among vehicles are converted to price differences per barrel of gasoline equivalent. Price slope coefficients are then calculated from three items of data supplied by the user: (1) a price elasticity at (2) a given market share and (3) initial vehicle price. ${ }^{2}$ The price slope is then used to transform the dollar values of attributes into alternative-specific constants for the logit model. As a result, the coefficients of the MNL choice model in the AFTM depend directly and entirely on the assumptions made about vehicle characteristics and related factors.

Because the AFTM is a static equilibrium model, solutions represent long-run adjustments of supply and demand to prices. The AFTM does not attempt to represent the dynamic process of new vehicle purchases and the aging and retirement of vehicle stock. Simi-

\footnotetext{
2 Price slope here refers to the coefficient of price in the consumer's indirect utility function as distinguished from the derivative of market share with respect to fuel price.
}

larly, the expansion of AFV manufacturing capability and alternative-fuel processing and distribution networks is not represented. The stock of AFVs and the choice of fuel by flexible-fuel vehicles (FFVs) and dual-fuel or bifuel vehicles (DFVs) are determined at the same time and are, by assumption, in longrun accord with fuel prices. It is therefore desirable that the choice of vehicle reflect the consumer's evaluation of the fuels the AFVs can use and that this evaluation be consistent with the modeling of fuel choices. This is accomplished by an explicit linking of the fuel and vehicle choice logit models. Fuel attribute values from the fuel-choice logit model enter into the vehicle-choice model in a way that reflects their expected value to the vehicle purchaser. This linkage between the fuel- and vehicle-type choice models ensures consistent parameter values for the two models. It does not, of course, remove the inherent limitations of static equilibrium models. The AFTM assumes that there has been sufficient time for products to be developed and sold and to penetrate the fleet and for manufacturing and fuel supply capacity to be expanded. It also assumes that prices have been stable long enough to allow the market to reach a stable equilibrium. Clearly, world energy markets are anything but static, so model solutions are probably best interpreted as directions in which markets are likely to move; and even then, they must be interpreted cautiously.

It is assumed that a long-run market equilibrium has one enormously important implication for the AFVC model. The model treats all alternative fuels and vehicle technologies equally. More specifically, it assumes that every alternative fuel is widely available (like gasoline) and that every AFV technology is available for every make and model of vehicle consumers may desire. This assumption is unrealistic for dynamically evolving real world markets. Even in a long-run equilibrium market, it is likely that economies of scale would limit the availability of the less popular AFV technologies and alternative fuels. Thus, the AFVC methodology may also overstate the market shares of less popular fuel and vehicle types. Modeling the crucially important dynamics of alternativefuels markets is a subject for future research. 
SPECIFICATION OF A VEHICLE AND FUEL CHOICE MODEL

Alternative fuels and alternative-fuel vehicles are unfamiliar commodities to the vast majority of consumers. Despite three decades of efforts, predicting demand for novel commodities remains on the frontier of economic analysis. Predicting the demand for alternatives to conventional vehicles is inherently tricky because direct historical experience from which to draw inferences about future behavior is lacking. Researchers have developed two approaches for coping with inadequate historical data on consumer demand for new commodities, such as alternative fuels and AFVs. One approach is to develop synthetic data by means of surveys that pose hypothetical questions about purchases of vehicles and fuels to potential consumers (for example, Golob et al. 1992). Such surveys produce information about consumers' "stated preferences," which may or may not match the "revealed preferences" they express by their actual purchase decisions. The alternative is to draw inferences, based on revealed preferences expressed in analogous but different situations, about how consumers value the attributes of similar goods. Analogous situations might include, for example, choices among different grades, brands, and service levels for gasoline, choice of gasoline or diesel engines for automobiles and light trucks, and choices among different types of automobiles. Both methods have important shortcomings and, indeed, there is no generally accepted method for predicting the demand for new commodities. ${ }^{3}$ While each has advantages and disadvantages, the latter approach was chosen here for the reasons given below.

A real danger in stated preference surveys is that respondents will provide biased answers not representative of their actual behavior.

\footnotetext{
${ }^{3}$ The numbers of relevant attributes and correlations among them as well as difficulties in defining and measuring attributes often make it difficult to infer reliable attribute values from past choices. Inferences from surveys based on hypothetical choices are usually ambiguous because of likely differences between what respondents say they will do (stated preferences) as opposed to what they actually will do (revealed preferences).
}

Respondents have a tendency to tell an interviewer what they think he or she wants to hear, or what they believe is the socially correct response. AFVs are often perceived to be environmentally "clean" vehicles that would help relieve the country of its dependence on imported petroleum. Both of these are public rather than private benefits, creating exactly the kinds of conditions that tend to produce biased responses in stated preference surveys. Furthermore, when a survey deals with novel commodities, respondents often have great difficulty evaluating technologies with which they have no first-hand experience. They may not fully appreciate the implications of certain vehicle or fuel characteristics, and they may also introduce assumptions and biases not presented to them in the survey. Once choice models have been estimated using the survey data, there is no way to sort out these potential biases.

Drawing analogies from actual behavior in similar situations also has deficiencies. Situations are never exactly analogous, and it is not possible to control for all the dissimilar factors. In addition, existing studies do not cover all of the differences between alternative- and conventional-fuel vehicles. A good example of this might be the recharging of batterypowered electric vehicles. The gaps must be filled in by assumption. This is viewed as an advantage rather than a disadvantage because the assumptions on which the analysis is based are explicit, rather than hidden. It is a useful property for the purposes of policy analysis to have conclusions that can be directly related to assumptions. It also facilitates testing the sensitivity of results to the assumptions that have been made.

\section{Hedonic Demand and Random Utility}

Predicting demand for new commodities is one of the most difficult problems in economics. Without the benefit of historical data from which to infer patterns of consumer behavior, it is difficult to formulate a credible quantitative model of demand. The theory of hedonic demand was developed to address this situation indirectly by postulating that consumers' utility depends on the attributes of goods rather than the good, per se (for example, Lancaster 1966). Thus, if the value of attributes could be 
determined, demand for novel goods might be inferred from the values of their attributes. When predicting consumers' choice among a set of discrete options, the hedonic demand premise led to the development of random utility theory. Random utility theory extends the hedonic demand concept by postulating that in addition to the value attached to observed attributes, there is a portion of the utility of a good that can be considered random (McFadden 1974). Let $U_{\text {in }}$ stand for a quantitative measure of the utility, or satisfaction, consumer $n$ derives from good $i$, let $V\left(x_{i k}\right)$ represent the function that assigns a quantitative value to the observable attributes $\left(x_{k}\right)$ of good $i$, and let $\varepsilon_{i n}$ be the random component for good $i$ and consumer $n$.

$$
\mathrm{U}_{i n}=V\left(\mathrm{x}_{i k}\right)+\varepsilon_{i n} .
$$

An important implication of this equation is that no alternative has a strictly higher utility than any other. Rather it has a greater expected utility, $V\left(x_{i k}\right)$, or a greater probability of having a higher utility.

The random utility component represents a multitude of factors left out of the measured utility function $V$. Econometricians have explained its role as follows:

We start with the assumption that consumers are rational in the sense that they make choices that maximize their perceived utility subject to constraints on expenditures. However, there are many errors in this maximization, because of imperfectperception and optimization, as well as the inability of the analyst to measure exactly all of the relevant variables. (Maddala 1992, p. 59)

Maddala has further described the random component as a factor "that captures unobserved variations in tastes and in the attributes of alternatives and errors in the perception and optimization by the consumer." (Maddala 1992, p. 60)

That consumers make errors in perception and optimization implies that even they may not know at the time they make their choices how satisfied they will be with them. Thus, the buyer of a new car is not entirely certain at the time of purchase how satisfied he or she will be with it-a very plausible assumption.

In the MNL model, there is a direct relationship between the sensitivity of choices to price and the relative importance of the random component in the choice decision. The proof of this, which can be found in the accompanying box, also squares with intuition. The more certain we are of the value of our options, the more the decision will turn on price. Put another way, the more similar the choices are, given the factors accounted for in the function $V$, the more price sensitive the choice will be. In economic terms, this is another way of saying the choices are close substitutes (conditional on $V)$. The practical result of this special relationship for the MNL model is that when price elasticities are specified so also are the random error components.

The essence of the AFVC approach is the following. First, an explicit and rigorous model of the alternative-fuel vehicle choice process is specified. Next the factors to be considered in the choice process are enumerated. Fuels and vehicles are then described by specific values for each factor. Drawing on the existing literature on vehicle and fuel choice and travel behavior, values are developed for each relevant factor, including prices. Parameters of the vehicle choice model are then computed directly from these data and assumptions. The result is a choice model whose parameters can be directly traced to vehicle and fuel characteristics and to assumptions about consumers' valuation of them.

\section{Theory and Mathematical Form of the AFVC Model}

It seems natural to consider the alternativefuel-choice decision as composed of two sequential steps: choice of vehicle and choice of fuel for that vehicle. In real life, this is the temporal order in which the decisions would be made. However, in the context of a long-run static equilibrium model such as the AFTM model, the choices are made simultaneously. In other words, market shares are determined simultaneously for the elementary choices consisting of a vehicle and fuel combination (for example, "flexible-fuel vehicle (FFV) using 


\section{Derivation of Multinomial Logit Model}

We wish to show that if the utility of option $i$ is defined as $U_{i}=V_{i}+\varepsilon_{i}=V\left(X_{i}\right)+\varepsilon_{i}$ where $X_{i}$ is a vector of known attributes and $\varepsilon_{i}$ is a random error term having the type 1 extreme value distribution (Johnson and Kotz 1970) with cumulative density function,"

$$
F\left(\varepsilon_{i}<\varepsilon\right)=\exp \left(-e^{-\beta \varepsilon}\right)
$$

and probability density function,

$$
f\left(\varepsilon_{l}\right)=\beta \exp \left(-\beta \varepsilon_{i}-e^{-\beta \varepsilon_{i}}\right)
$$

then the probability that $\mathrm{U}_{i}=\max \left(\mathrm{U}_{1}, \mathrm{U}_{2}, \mathrm{U}_{3}, \ldots, \mathrm{U}_{M}\right)$, that is, that has the $i^{\text {th }}$ choice has the highest utility of all $M$ possible choices, given the vectors $\mathrm{X}_{j}(j=1, M)$, is given by

$$
\operatorname{prob}\left(\mathbf{U}_{i}=\max \left(\mathbf{U}_{j}\right), \forall j\right)=\frac{e^{\beta \mathbf{V}_{i}}}{\sum_{j=i}^{M} e^{\beta \mathbf{V}_{j}}}
$$

The condition $U_{i}=\max \left(U_{1}, U_{2}, U_{3}, \ldots, U_{M}\right)$ implies

$$
\varepsilon_{j}<\varepsilon_{i}+\mathbf{V}_{i}-\mathbf{V}_{j}, \forall j \neq i
$$

and the probability of this is given by

$$
\operatorname{prob}\left(\varepsilon_{j}<\varepsilon_{i}+\mathbf{v}_{i}-\mathbf{v}_{j}\right)=\int_{-\infty}^{\infty} \prod_{j \neq i} F\left(\varepsilon_{i}+\mathbf{v}_{j}-\mathbf{v}_{j}\right) \times f\left(\varepsilon_{i}\right) d \varepsilon_{j}
$$

Substituting the appropriate cumulative and probability density functions, this becomes

$$
\operatorname{prob}\left(\mathbf{U}_{i}=\max \right)=\int_{-\infty}^{\infty} \prod_{j \neq i} \exp \left(-e^{-\beta\left(\varepsilon_{i}+\mathbf{v}_{i}-\mathbf{v}_{j}\right)}\right) \times \beta \exp \left(-\beta \varepsilon_{i}-e^{-\beta \varepsilon_{i}}\right) d \varepsilon_{i}
$$

'This exposition follows that of Maddala (1992, 60-61). 
Carrying out the multiplication within the product symbol we get

$$
\operatorname{prob}\left(\mathbf{U}_{i}=\max \right)=\int_{-\infty}^{\infty} \exp \left(-e^{-\beta \varepsilon_{i}} \sum_{j \neq i} e^{-\beta \mathbf{V}_{i}+\beta \mathbf{V}_{j}}\right) \times \beta \exp \left(-\beta \varepsilon_{i}-e^{-\beta \varepsilon_{i}}\right) d \varepsilon_{i}
$$

Rearranging terms gives

$$
\operatorname{prob}\left(\mathbf{U}_{i}=\max \right)=\int_{-\infty}^{\infty} \beta \exp \left(-\beta \varepsilon_{i}-e^{-\beta \varepsilon_{i}}\left(1+\sum_{j \neq i} e^{-\beta V_{i}+\beta V_{i}}\right)\right) d \varepsilon_{i}
$$

If we make the substitution

$$
\lambda_{i}=\log \left(1+\sum_{j \neq i} \frac{e^{\beta V_{j}}}{e^{\beta V_{i}}}\right)=\log \left(\sum_{j=1}^{M} \frac{e^{\beta V_{j}}}{e^{\beta V_{i}}}\right)
$$

we get a much simplified integral, which can be further simplified by making the additional substitution $\varepsilon_{\mathrm{i}}^{*}=\varepsilon_{\mathrm{i}}-\lambda_{\mathrm{i}}$ and noting that the integral of a probability density function is equal to 1 . This derivation is extremely important because it shows that the coefficient of the function $V(X)$ is precisely the scale parameter of the random error's probability density function. Note that this is true regardless of the units in which $\mathbf{V}_{\boldsymbol{i}}$ is expressed because these are taken into account by the units in which $\beta$ is expressed. Therefore, if we choose $V_{i}$ to be a generalized cost function, enumerated in dollars, the coefficient of price in $v_{i}$ equals $\beta$. This result is useful because it allows us to precisely specify the logsum term in the nested logit model, based on knowledge of the price coefficients of the choice subsets (nests).

$$
\begin{gathered}
\operatorname{prob}\left(\mathbf{U}_{i}=\max \right)=\int_{-\infty}^{\infty} \beta \exp \left(-\beta \varepsilon_{i}-e^{-\beta\left(\varepsilon_{i}-\lambda_{i}\right)}\right) d \varepsilon_{i}, \\
\exp \left(-\lambda_{l}\right) \int_{-\infty}^{\infty} \beta \exp \left(-\beta \varepsilon_{i}^{*}-e^{-\beta \varepsilon_{i}^{*}}\right) d \varepsilon_{i}^{*}=\exp \left(-\lambda_{i}\right)=\frac{e^{\beta V_{i}}}{\sum_{j=1}^{M} e^{\beta V_{j}}} .
\end{gathered}
$$


gasoline," "natural gas bifuel (NGBiF) using compressed natural gas (CNG)," and so forth (see Figure C-2). The temporal sequencing is not relevant. However, for reasons other than the timing of decisionmaking, it will prove useful and appropriate to structure the fuels and vehicles choice model in a way that distinguishes between vehicle and fuel choices.

It also seems obvious that the fuels a vehicle can use and their characteristics should influence the choice among vehicle types. The model structure proposed here explicitly embeds, or nests, the fuel-choice decision for a multifuel vehicle within the vehicle-choice decision. Factors affecting fuel choice thus directly influence vehicle choice, and the parameters of the vehicle-choice model are composed in part of the parameters of the fuel-choice model. In this section, the structure of the choice model is described, the MNL model and the concept of generalized cost used here to compute coefficients for the model are then introduced, and it is shown how the choice structure gives rise to a generalization of the MNL model termed the nested MNL model.
There is an extensive literature on the subject of models of "qualitative responses"

(McFadden 1974; Amemiya 1985; Maddala 1992) in which individuals choose one option from a set of discrete alternatives. These models have been widely used in transportation to represent choices among destinations for trips and modes of transport (for example, BenAkiva and Lerman 1987) and to represent consumers' decisionmaking in choosing an automobile (for example, Train 1986). The most widely used type of qualitative choice model is the MNL, which combines relative mathematical simplicity, enormous flexibility, and ease of estimation, with a rigorous derivation based on economic theory.

Most often, the MNL model is used to represent the choices of individual (or disaggregate) decisionmaking units such as households or persons. Its use in representing macroeconomic behavior has traditionally been thought to give rise to problems of aggregation bias unless appropriate simulation methods are used (for example, Train 1986, ch. 6). However, the model can also be interpreted as

Figure C-2 - Nested Structure of Alternative-Fuel and Vehicle Choice Decisions

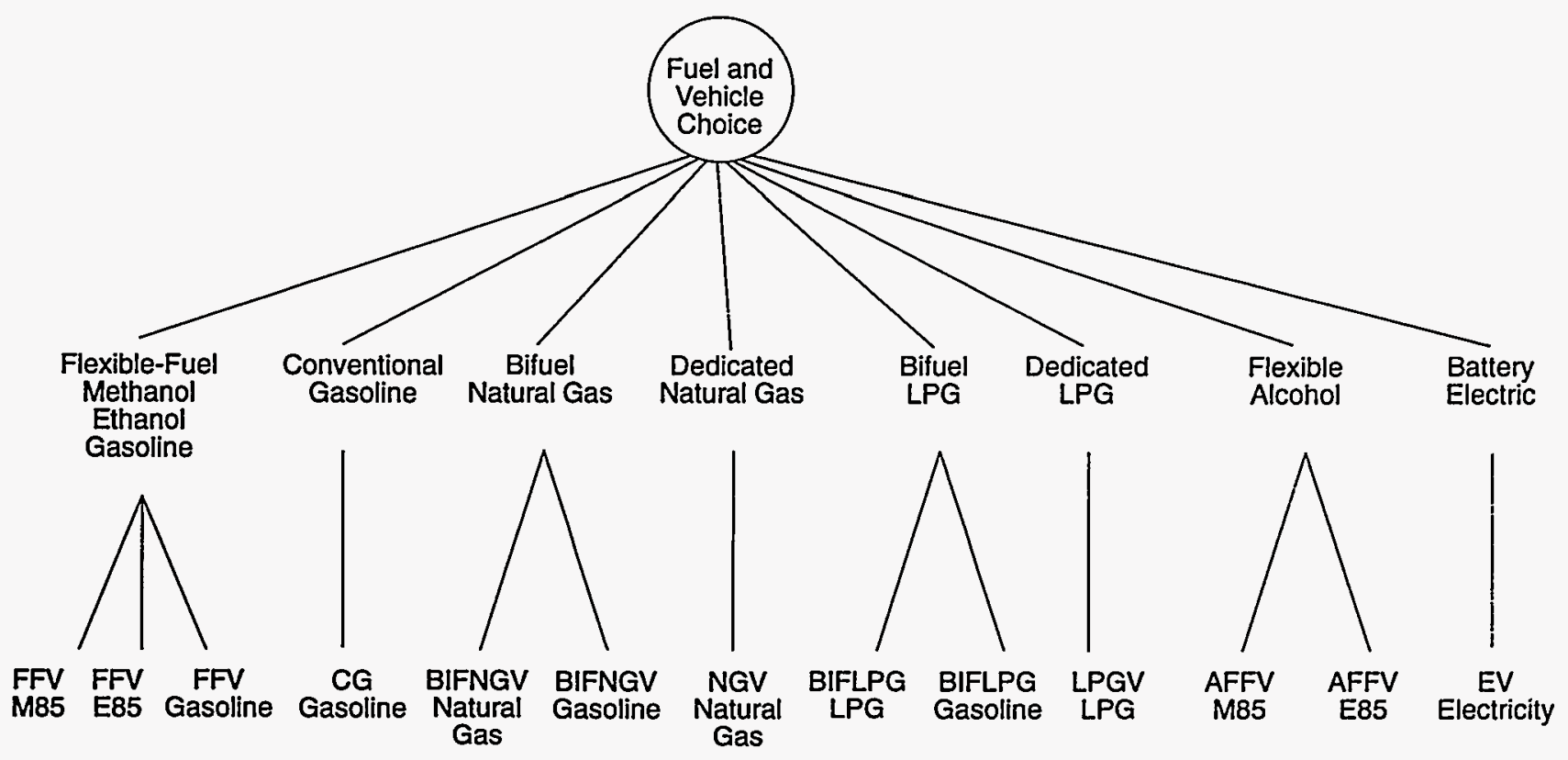


representing the average behavior of a group of consumers. Recently, Anderson, De Palma, and Thisse (1988) have shown how a macroeconomic version of the MNL model can be derived based on a "representative consumer" or a population with diverse tastes.

The MNL is construed in this report to be a representation of the general or typical behavior of a population, allowing a random error term to represent general deficiencies in the model, including variations across individuals. It is assumed that the goodness or utility of an alternative can be represented by a function,

$$
\mathbf{u}_{i}=V\left(\mathbf{X}_{l}\right)+\varepsilon_{i}
$$

in which the $X_{i}$ 's are observable variables describing option $i, V$ is a linear utility function, and the $\varepsilon$ represents, in Madalla's words, "a residual that captures unobserved variations in tastes and in the attributes of alternatives and errors in the perception and optimization by the consumer" (Madalla 1992, p. 60). If the error terms are independently and identically distributed and follow a type I extreme value distribution with probability density

$$
f\left(\varepsilon_{i}\right)=\beta \exp \left(-\beta \varepsilon_{i}-\exp \left(-\beta \varepsilon_{i}\right)\right),
$$

then it can be shown (for example, see the proof in Maddala 1992, pp. 60-61, which is summarized on pages 6-7 of this appendix) that the probability of option $i$ being chosen by any given consumer is given by the multinomial logit function of its utility, $V\left(\mathbf{X}_{i}\right)=\beta C\left(\mathbf{X}_{i}\right) \cdot{ }^{4}$

$$
\mathbf{s}_{i}=\frac{\exp \left(\beta \mathbf{C}_{i}\right)}{\sum_{j=1}^{n} \exp \left(\beta \mathrm{C}_{j}\right)} .
$$

It was decided to represent utility as a constant, $\beta$, times a "generalized cost" function $\mathrm{C}_{i}=C\left(\mathrm{X}_{i}\right)$, in order to show the relationship between the price sensitivity of choice probabilities, or market shares, and the

\footnotetext{
4 Throughout this exposition, probability and market share are used interchangeably and are represented by the letter $s$.
}

parameter of the extreme value distribution function. The linear utility function can be written as a sum of other variables times their coefficients $\left(a_{k}\right.$ 's) plus $\beta c_{i}$, where $c_{i}$ is the cost or price of the $i^{\text {th }}$ option.

$$
\begin{aligned}
V_{l} & =\beta c_{i}+\sum_{k=1}^{K} a_{i k} x_{i k} \\
& =\beta\left(c_{i}+\sum_{k=1}^{K} \frac{a_{i k} x_{i k}}{\beta}\right)=\beta c_{i} .
\end{aligned}
$$

Thus, $\beta$ is both the price slope of the utility function and the scale parameter of the random error term. This has the following useful interpretation. The more price sensitive the choice among options is, the smaller the variance of the random utility component, that is, the more completely the observed variables reflect the important factors in consumers' decisionmaking. This is an intuitively satisfying property. If, with the exception of the observed variables, the choices are extremely similar, they should be very close substitutes, and therefore, choices among them should be very price elastic. This property will be helpful when it comes time to specify parameters for the MNL model, and will also be used to explain why a nested logit structure may be the most appropriate structure to represent vehicle and fuel choice.

The price elasticity of choice in the MNL model depends on $\beta, c_{p}$ and $s_{p}$ the market share.

$$
\begin{aligned}
\eta_{i, c_{i}} & =\frac{\partial s_{i}}{\partial c_{i}} \frac{c_{i}}{s_{i}}=\beta c_{i}\left(1-s_{i}\right) \\
& \Rightarrow \beta=\frac{\eta_{i, c_{i}}}{c_{i}\left(1-s_{i}\right)} .
\end{aligned}
$$

Equation (C-6) implies that elasticities will be very high at low market shares and decrease as shares approach market dominance. Equation (C-6) also provides a means of estimating the cost parameter $\beta$ if the elasticity at a particular market share and price is known.

It seems reasonable to assert that the choice among fuels for a given type of AFV will be 
more price sensitive than the choice of vehicle type. Interpreting this in terms of the parameter $\beta$, one would say that the variation in unobserved attributes is less for choice of fuel than for choice of vehicle. This seems a very plausible assertion because the fuels are to be used in the same vehicle, making all vehiclespecific attributes constant. There is ample evidence, for instance, that price elasticities of choice of car type are in the range of -1 to -5 , while the elasticities of choice of type of gasoline have been estimated to be -20 or higher at typical market shares. Whenever $\beta$ parameters differ for definable subsets of the full choice set, a special type of multinomial logit model, called the nested multinomial logit model (NMNL) provides a more accurate representation of the decision process. Suppose the elementary choice set (all vehicle fuel combinations) is divided into subsets, such that a subset contains the elementary choices corresponding to a particular type of alternative-fuel vehicle. For example, "FFV using gasoline," "FFV using M85 (a mixture of 85 percent methanol and 15 percent gasoline)," and "FFV using E85 (a mixture of 85 percent ethanol and 15 percent gasoline)" would be in one subset, ${ }^{5}$ while "bifuel natural gas vehicle (BiFNGV) using compressed natural gas" and "BiFNGV using gasoline" would be in another. This choice structure is illustrated in Figure $\mathrm{C}-1$. The probability of choice of fuel type $j$ used in vehicle type $i, s_{i j}$, can always be expressed as the product of the (conditional) probability of choice of fuel type $j$, given vehicle type $i$ has been chosen, times the (marginal) probability of choice of vehicle type $i$.

$$
s_{i j}=s_{j l i} \times S_{i}
$$

It is assumed that the choice of fuel within a subset is multinomial logit, with generalized cost $c_{i j}$ and price slope $\mu_{i}$ (price sensitivity is constant within a subset but may vary across subsets). The conditional probability of choice of fuel type $j$, given vehicle type $i$, is then

\footnotetext{
${ }^{5} \mathrm{M} 85$ is a blend of 15 percent gasoline and 85 percent methanol. E85 is similarly a 15 -percent/85-percent blend of gasoline and ethanol.
}

$$
S_{j l i}=\frac{e^{\mu_{i} c_{i j}}}{\sum_{k=1}^{n} e^{\mu_{i} c_{i k}}}
$$

The probability of choice of vehicle type $i$ depends on its generalized cost $\mathbf{c}_{i}$ and the cost slope for vehicle type choice, which will be represented by $\beta$. Recall that $\beta$ is also the scale parameter of the distribution of random influences (unobserved factors, differences in tastes, imperfect information, and so forth) for the vehicle-type choice decision. The generalized cost for vehicle type $i$ is composed of factors that do not vary over fuel types, and of the average generalized cost of the fuels that vehicle type $i$ can use. If it were not for the random error term, the average generalized cost would be the weighted average of the generalized costs, $\mathrm{c}_{i j}$, of the fuel options in subset $i$, the weights being the fuels' market shares. But if it were not for the random error term, only the fuel with the lowest generalized cost would be chosen by utility maximizing consumers, and so the average generalized cost would be that of the lowest cost fuel. Because it is assumed that there are random components to the generalized cost, the average cost is given by

$$
\overline{c_{i}}=\frac{1}{\mu_{i}} \ln \sum_{j=1}^{n_{i}} e^{\mu_{i} c_{i j}}+k .
$$

(Williams 1977) where the $k$ can be omitted because it has no effect on the choice probabilities (Fisk and Boyce 1984). The generalized cost of vehicle type $i$ is the sum of the vehicle specific costs (designated $\mathbf{u}_{j}$ ) and the average cost of the choice of fuel type. ${ }^{6}$ The probability of choice of vehicle type $i$ is then

\footnotetext{
6 It is imperative that these costs be expressed in the same units. If vehicle costs are in terms of initial capital costs, fuel costs must be expressed in terms of costs capitalized over the vehicle's lifetime to present value. Likewise, if fuel costs are to be expressed in dollars per unit (for example, per barrel) then vehicle costs must be expressed in dollars per unit of fuel consumption.
} 


$$
s_{I}=\frac{e^{\beta\left(u_{i}+\overline{c_{i}}\right)}}{\sum_{k=1}^{M} e^{\beta\left(u_{k}+\overline{c_{k}}\right)}},
$$

where $M$ is the number of vehicle types. The coefficient of the logsum term is the ratio $\beta / \mu_{i}$, the price coefficient of the vehicle-choice decision divided by the price coefficient of the fuelchoice decision (the prices must be in the same units). This ratio will always lie between 0 and 1 if the nesting has been properly structured. If the ratio equals 1 , then there is no nesting structure, as shown below. This property of the NMNL logit model has an interesting economic interpretation, namely that choices within a nested subset must be closer substitutes (their market shares must be more sensitive to price) than choices at the higher level. Put another way, the random factor in the choice decision must be smaller within a nest than at a higher level in the choice structure. In the AFVC model, this implies that for the vehicle-choice decision, the unobserved error component must be larger (the price elasticity must be smaller) than for the fuelchoice decision.

The product of equations $(C-8)$ and $(C-10)$ comprises a NMNL model for the joint probability of vehicle- and fuel-type choice $\left(s_{i j}\right)$. If we assume that $\mu_{i}=\beta$ for all $i$, then the nested model collapses to a simple multinomial logit model. By substituting equation (C-9) in equation (C-10), substituting $\beta$ for $\mu_{j}$, and multiplying equations $(\mathrm{C}-8)$ and $(\mathrm{C}-10)$ together (because $s_{j j}=s_{j i} \times s_{i}$ ), and simplifying one obtains the following,

$$
s_{i j}=\frac{e^{\beta\left(u_{i}+c_{i j}\right)}}{\sum_{k=1}^{M} e^{\beta\left(u_{k}+c_{i j}\right)}} .
$$

This equation is a simple MNL model. The fact that generalized cost has been separated into vehicle-specific and fuel-specific components is a result of the choice of notation. Thus, it is the differences in price sensitivity $\left(\beta \neq \mu_{i}\right)$, or equivalently, the differences in the relative importance of the error component, that creates the nested structure. Because research on vehicle and fuel choice, as well as intuition, strongly suggest that the elasticity of fuel choice for a multifuel vehicle will be more price sensitive than the choice of vehicle, the NMNL structure is preferred over the simple MNL model.

\section{Factors in the Fuel Choice Decision}

The first step in constructing the AFVC model is to identify the characteristics consumers will consider in choosing vehicles and fuels. This section describes factors that are believed likely to influence consumers' choices of alternative fuels and vehicles. The discussion draws heavily from the extant literature. The next section of this appendix explains how factors are quantified and translated in NMNL model parameters.

Some factors that are important today should not be included in the AFVC model because they pertain to the transition to alternative fuels and would disappear in a mature market. As long as there are few AFVs on the road, the low level of demand for alternative fuels will not support an extensive network of refueling stations. The difficulty in finding an alternative fuel or the extra distance that must be traveled to obtain it will discourage demand for alternative fuels. In the early stages of fuel and vehicle introduction, there may also be unforeseen reliability or performance problems that can have a drastic effect on consumers' acceptance of alternative-fuel vehicles and alternative fuels. Experience in the United States with diesel automobiles illustrates the importance of "startup" problems with vehicle technology (Kurani and Sperling 1988). But the U.S. diesel car experience also illustrates that such problems can be overcome, and shows the ultimate importance of a fuel-cost advantage to the market success of alternative fuels (Greene 1986). Because the AFTM is a longrun static equilibrium model, it assumes that all of these "startup" problems have been solved. It also assumes that fuel is readily available to those who wish to buy it. Ignoring fuel availability costs, however, will cause the market 
shares of fuels with a small share of the market to be overstated.

Surveys of motorists have determined that at a minimum, the factors listed in Table $\mathrm{C}-1$ are important to the decision to choose an alternative fuel (for example, Golob et al. 1992). Some characteristics are associated with vehicle technologies and do not depend on which fuel is being used. Others are fuel-specific and occur only when the fuel is used. Thus, a multifuel vehicle will have different characteristics depending on which fuel is being used.

The factors included in the AFTM AFVC model are highlighted in boldface (Table $\mathrm{C}-1$ ). The remaining factors and the manner in which they are treated in the AFVC model are discussed below.

Fuel Availability is consistently rated a major concern by prospective alternative-fuel buyers (Golob et al. 1992; Kurani 1992). In practice, however, fuel availability rarely turns out to be a problem for those actually using alternativefuel vehicles, even if only 10 to 20 percent of the stations offer the fuel (Sperling and Kurani 1987; Kurani 1993; Greene 1989). Because it is likely that perhaps 10 percent of the stations would offer an alternative fuel that accounts for only 1 to 2 percent of total gallonage, availability is likely to be a problem during only the early stages of fuel introduction, or only if fuel sales are very small. In either case, when using a long-run equilibrium model, it seems reasonable to assume that fuel availability is not a problem, but caution should be used in interpreting the model's predictions. ${ }^{7}$ For a fuel with a large equilibrium market share (for example, greater than 10 percent), fuel availability is a transitory problem and, therefore, not appropriate for a market equilibrium model. For fuels with a very small market share (say less than 2 percent), fuel availability is likely to be a suf-

\footnotetext{
${ }^{7}$ An alternative option would be to incorporate a simultaneous relationship into the AFTM so that the cost of fuel availability would be high if fuel sales were very small but would decrease rapidly at market shares over 2 percent, or so. The approach used in this analysis assumes that fuel availability is not a problem, but recognizes that if the AFTM predicts market shares of less than 2 percent for alternative fuels, the true market share is probably much lower.
}

ficiently serious problem to relegate the fuel to niche markets. Thus, fuel availability is likely to be a crucial factor only for fuels with predicted shares in single digits.

Refueling difficulty may be of two kinds: increased time required for refueling and increased difficulty or complexity of the refueling task. Because alcohol fuels are liquids and will be handled exactly like gasoline, the complexity of the refueling task will be the same for ethanol and methanol as for conventional gasoline. Liquefied petroleum gas (LPG) is also handled as a liquid under modest pressure and as such has about two-thirds the energy density as gasoline, so that refueling should be only slightly more complex than for gasoline or alcohol. CNG refueling, however, must be done at pressures of approximately 3,000 psi. Even "fast-fill" CNG refueling is likely to take a few minutes longer than refueling with liquid fuels. Battery-electrics are a special case. Although "fast recharge" tech-

\section{Table C-1 - Fuel and Vehicle Choices}

\section{Fuel Characteristics}

Cost
Fuel Availability
Refueling Difficulty
Range (frequency)
Refueling Time and Convenience
Fuel Quality
Performance (acceleration or power)
Effect on Vehicle Reliability and Maintenance
Health and Safety
Aesthetics
Social Benefits
Emissions
Oil Dependence

Vehicle Characteristics

Cost

Reliability and Maintenance

Performance (acceleration or power)

Health and Safety

Capacity (to carry people and cargo)

Value of Multifuel Option

Combined Effects of Fuel Characteristics 
nologies exist and may be improved in the future, slow charge over a period of 6 hours is assumed to be the norm. But battery recharging will not fully occupy the motorist's time the way refueling does. Thus, although the time required is much longer, it should not be valued at the same rate, because it does not require the motorist's full attention.

Range, or refueling frequency, is a function of the energy density of the alternative fuel relative to gasoline, the capacity of the storage device, and the relative efficiency of the vehicle when using the alternative fuel. Alternative fuels vary considerably in their energy densities per unit volume (Table $\mathrm{C}-2$ ). Though available evidence is not conclusive, it appears that fuel-flexible and bifuel vehicles achieve roughly equal fuel economy on a gallon of gasoline-equivalent energy basis (McNutt 1993). Alcohol-flexible vehicles not designed to use gasoline may achieve up to 10 percent better mpg (Interagency Commission on Alternative Motor Fuels 1991, p. 22). The far greater energy efficiency of electric drives, helps to mitigate the very low energy density of even advanced batteries.

Given a fuel tank of equal size, the lower energy densities of M85 and E85, for example, imply that FFVs using them will require refueling about 127 percent or 59 percent more often, respectively. This is disadvantageous because it demands more of the consumer's time. Assuming a total of 6 minutes' time for each refueling, valuing time at $\$ 10$ per hour, ${ }^{8}$ and assuming that an average of two-thirds of a tank is purchased per refueling, the average refueling cost of $\$ 0.09$ per gallon of gasoline. ${ }^{9}$ By this same reasoning, the extra refueling required for M85 and E85 adds an additional $\$ 0.09$ and $\$ 0.04$ to the cost per gasoline equivalent gallon of these fuels. These assumptions appear reasonable and are comparable to (though slightly lower than) what can

\footnotetext{
${ }^{8}$ Ten dollars per hour (1990 dollars) is a reasonable estimate of the average value travelers attach to their time (Chui and MacFarland 1986). We are not aware of specific estimates of the value of time spent refueling conventional vehicles.

${ }^{9}$ The assumption of 6 minutes is intended to represent the instation refueling time, not including travel time to and from the station.
}

\section{Table C-2 - Relative Energy Density (Btu/gallon)}

\begin{tabular}{lc}
\hline Fuel & $\begin{array}{c}\text { Energy Content } \\
\text { (lower heating value) }\end{array}$ \\
\hline Unleaded Gasoline & 115,400 \\
Methanol & 56,560 \\
Ethanol & 75,670 \\
M85 & 65,386 \\
E85 & 81,999 \\
CNG (3,000 psi) & 24,700 \\
LPG (propane) & 83,765 \\
Battery Electric & $2,000^{\text {a }}$ \\
\hline
\end{tabular}

a Assumes a sodium/sulfur battery with a volumetric energy density of $0.15 \mathrm{kWh} / \mathrm{iter}$.

be inferred from the responses to a recent survey about alternative-fuel vehicles conducted for the California Energy Commission (Golob et al. 1992). Battery-electric vehicles are so different from liquid- or gaseous-fueled vehicles that it is difficult to compare them on a consistent basis. Even an electric vehicle (EV) with an advanced battery (a battery not available today) would require almost 60 gallons of volume to store the equivalent of $1 \mathrm{gal}-$ lon of gasoline. Despite the fact that an EV is likely to be more than twice as efficient as a conventional vehicle, 60 gallons of batteries would permit an effective range of less than 100 miles for an advanced EV. Moreover, refueling would require approximately 6 hours. Clearly the refueling time of an EV cannot be valued at the same rate as that of a liquid- or gaseous-fueled vehicle, yet it still has value, and vehicle owners would undoubtedly be willing to pay something to reduce it.

Fuel-Quality issues could be significant, yet there is little basis at this time for assigning fuel-quality values to different fuels. Four varieties of potential fuel-quality issues have been raised, but because of inadequate information on consumers' perceptions of the qualities of alternative fuels, no attempt is made to estimate values for them. The four fuel-quality issues are as follows:

- Reliability of operation 
- Maintenance costs

- Health and safety (for example, toxicity, flammability)

- Aesthetics (for example, smell, appearance)

For most fuel-quality issues, there is insufficient evidence on which to base even a crude estimate of consumer perception. It is known that consumers will pay for premium and midgrade gasoline, despite the fact that their engines do not require the higher octane of premium. Higher octane, "premium grade" gasolines may in some cases contain more additives (for example, to clean fuel injectors) than regular grade fuel, although there is considerable controversy over whether motorists are paying for perceived rather than real differences in fuel quality (Dougher, Hofmann, and Hogarty 1990). Based on an econometric analysis of consumers' choices among leaded regular, leaded premium, unleaded regular, and unleaded premium, Greene (1989) estimated the average willingness to pay for higher octane fuel at 1 to 2 cents per octane number per gallon. This would imply a 5- to 10-cent per gallon willingness to pay for premium versus regular grade gasoline. To the extent that consumers are buying other premium qualities besides octane, these are included in the 1- to 2-cents per octane number per gallon estimate. Although there is some evidence that consumers will pay more for fuels they believe to have higher quality, there is presently very little basis for evaluating the value to consumers of the perceived quality of each alternative fuel.

It is assumed that all alternative-fuel vehicles will be equally reliable and equally safe. Although there may well be some differences, it does not appear that reliability, maintenance, or safety and health effects will pose any particular problems for the alternative fuels considered. It is likely that consumers will perceive different aesthetic values for alcohols, gaseous fuels, and electricity, but no known studies can provide a basis for estimating monetary values for such aesthetic characteristics. It has been claimed that maintenance may be lower for EVs (Delucchi, Wang, and Sperling 1989), but battery replacement costs will probably elimi- nate this potential advantage, depending on the state of battery technology.

Vehicle performance characteristics that are related to fuel and engine type consist of driveability and acceleration capability (Bechtold 1993). Driveability refers to ease of starting and a relatively smooth and linear response to the accelerator pedal. AFV fuel systems are already rapidly approaching the smooth and predictable response of conventional gasoline systems, and there is no reason to believe that AFV driveability will not be equal to gasoline vehicles between the year 2000 and 2010.

Acceleration capability will vary because of changes in fuel properties (for example, octane number) and in vehicle weight. The net effect of either type of change can be expressed as an effective change in the ratio of horsepower to weight. Octane ratings of 99 or 100 , together with a higher latent heat of vaporization should give flexible-fuel vehicles higher power when running on alcohols. ${ }^{10} \mathrm{Dy}$ namometer tests have shown a 6-percent gain in horsepower for engines optimized for gasoline, but running on M85 or E85 (Bechtold 1993). Gaseous bifuel vehicles will have reduced acceleration. Bifuel natural gas vehicles (NGV) and liquefied petroleum gas vehicles (LPGV) deliver fuel to the engine in a gaseous rather than a liquid state. The fuel thus displaces air that would otherwise have been drawn into the cylinder, effectively decreasing the engine's displacement. This volumetric efficiency loss is estimated to be 10 percent for bifuel NGVs and 5 percent for bifuel LPGVs (Bechtold 1993). Battery-electric and bifuel gaseous energy systems add significantly to the weight of the vehicle. Bechtold (1993) has estimated weight increases of 3 to 4 percent for LPG cars and light trucks, and 4 to 6 percent for NGVs. The extra weight of batteries is likely to cause EVs to weigh 25-30 percent more than a comparable conventional vehicle.

\footnotetext{
${ }^{10}$ Higher latent heat of vaporization results in a greater absorption of heat from the air in the intake charge when fuel is injected into a cylinder. This produces greater cooling of the gases in the cylinder, reducing the work required to compress the charge, thereby increasing the engine's output.
} 
On the other hand, the electric motor can easily be sized to provide equal if not superior acceleration at equal or lower cost (batteries not included). The combined effects are summarized later under "Refueling Costs." For the purpose of modeling the vehicle- and fuelchoice decision, it is important to recognize that the weight changes affect vehicle performance regardless of which fuel is used, while the volumetric efficiency, latent heat of vaporization, and octane effects are specific to the fuel being used.

The extra storage tanks of bifuel vehicles and the additional volume likely to be required in electric vehicles for battery storage will also likely necessitate compromises in vehicle design. ${ }^{11}$ Modern vehicle designs are carefully optimized to use space efficiently, so that the additional space requirements of gaseous fuel storage are certain to require reduction in carrying capacity. It is assumed that cargo space rather than passenger space will be sacrificed, and that all of the additional fuel storage volume will translate into lost cargo capacity.

A major reason for promoting alternative fuels is that they will produce social benefits in the form of reduced pollutant emissions and improved energy security. Revealed-preference studies of motor-fuel purchasing generally indicate that typical consumers will not individually and voluntarily pay to generate these social benefits. However, in several statedpreference surveys, consumers say they are willing to pay on the order of 2 to 5 cents per gallon more for fuels with much lower emissions than conventional gasoline (Golob et al. 1992). In a recent survey of car owners in New York and California (Setiawan, Hungerford, and Sperling 1990), roughly 50 percent of respondents stated that they would pay $\$ 0.10$ or more for fuels that "produced less air pollution" than gasoline. The consumers were not told in what context they would pay, however (for example, involuntary tax or voluntary pur-

\footnotetext{
11 Delucchi, Wang, and Sperling (1989) argue that space savings due to the absence of an exhaust system and pollution control equipment, in conjunction with the smaller size of an electric drivetrain, will totally compensate for the greater volume required for energy storage.
}

chase). The base case assumes no individual willingness to pay for social benefits. ${ }^{12}$ This assumption can be easily changed, however, to explore other possibilities.

\section{Strategy for Calibrating the AFVC Model}

The following section describes how the vehicle and fuel characteristics under consideration are transformed into coefficients of the AFVC model. Only the general methodology is described here. Following are the key steps in the calibration process:

- Specify the characteristics of alternative fuels and vehicles.

- Specify the value per unit for each characteristic.

- Estimate a "generalized cost" as a sum of the dollar value of AFV characteristics, plus initial costs (all in dollars-per-barrel gasoline equivalent).

- Specify the sensitivity of the fuel- and vehicle-choice decisions to prices.

- Transform the values of characteristics and elasticities into MNL model coefficients. ${ }^{13}$

All costs are converted to units of 1990 dollars per barrel of gasoline-equivalent, present value. The costs and values of fuel-specific variables are most naturally expressed in terms of dollars per gallon of gasolineequivalent. Most vehicle-specific variables, on the other hand, will be in terms of dollars per vehicle, initial cost. The AFTM requires the logit model to determine the shares as a function of dollars per barrel of gasoline-equivalent. It is therefore necessary to transform both vehicle-specific and fuel-specific costs into

\footnotetext{
12 This is not meant to imply no collective willingness to pay. For example, motorists may be more willing to pay for "cleaner fuels" if everyone pays, and thus might support a price subsidy for clean fuels, although they would not pay more at the pump on their own initiative if there were no guarantee that others would pay their share. ${ }^{13}$ This last step is optional because the transformation may be done easily within the AFTM itself.
} 
dollars per barrel of gasoline-equivalent. This is done by multiplying initial costs by an annual capital charge rate and dividing by the average annual fuel consumption of a conventional gasoline vehicle in barrels of gasoline, and multiplying costs per gallon of gasolineequivalent by 42 (gal/bbl). The result is a generalized cost, in dollars per barrel of gasoline-equivalent, for each fuel (in the case of fuel choice) or each vehicle type (in the case of vehicle-type choice).

To derive the MNL model coefficients the AFTM requires, the sensitivity of fuel choice to price must be specified. This is done by assuming price elasticities for the fuel- and vehicle-choice decisions, based on judgment informed by previous studies of fuel and vehicle-type choice. A model to predict future choices among commodities that are not yet readily available cannot be calibrated to data on actual choices. As a result, it is not possible to ensure that the values chosen will be correct in the sense that they can be shown to be consistent with the real world. Thus, it is prudent to test the sensitivity of the model's predictions to key assumptions. An analysis of the sensitivity of vehicle- and fuel-share predictions to assumptions about price elasticities and attribute values appears later in this appendix.

\section{SPECIFICATION AND VALUATION OF FUEL AND VEHICLE CHARACTERISTICS}

The previous section described the characteristics that distinguish among alternative fuels, and it presented the theory and mathematical form of the NMNL choice model. This section details the final steps required to complete the AFVC model: selection of numerical values for the characteristics of alternative fuels and vehicles, conversion of those characteristics into dollar values (generalized costs), and translation of generalized costs into coefficients of the NMNL model. The following section then explains how these processes have been implemented as a computer spreadsheet program.

In this section, the relevant characteristics of alternative-fuel vehicles are specified and evaluated in terms of dollars per barrel of gasoline-equivalent energy services. With the exception of battery-electric vehicles, vehicle characteristics were taken from studies by Bechtold (1993a, 1993b) for the U. S. Department of Energy. Characteristics associated with the consumption of fuel are taken up first, followed by capital charges associated with the purchase of a given type of AFV. In the section on capital costs, the conversion of capital costs into a capital charge per unit of gasolineequivalent energy service is explained.

\section{Characteristics Associated With Fuel Use}

Characteristics accounted for as flows include refueling frequency, refueling convenience, fuel-specific performance changes, and the fuel option value for multifuel vehicles. Values were not estimated for fuel availability, perceived fuel quality, and social benefits.

\section{Refueling Costs}

The cost of greater refueling frequency consequent to decreased onboard energy storage capability is assumed to be the value of the additional time required. The relative increase in refueling $(R)$ is computed by dividing the energy content of gasoline $\left(E_{g}\right)$ by the energy content of the alternative fuel $\left(E_{j}\right)$ times 1 plus its efficiency gain or loss $\left(e_{j}\right)$. This is then multiplied by the ratio of gasoline tank size $\left(Q_{g}\right)$ to alternative-fuel tank size $\left(Q_{j}\right)$, in physical units.

$$
R=\frac{E_{g}}{E_{j}\left(1+e_{j}\right)}\left(\frac{Q_{g}}{Q_{j}}\right) \text {. }
$$

Estimated percent increases in refueling frequency $((R-1) \times 100)$ and supporting data are shown in tables below. To obtain the cost increase in terms of dollars per gallon, it is necessary to multiply the increase in relative refueling minus $1(R-1)$, times the average refueling time for that fuel $\left(T_{j}\right)$, times the assumed value of time $\left(V_{j}\right)$, and divide this number by the assumed fuel purchase quantity $\left(Q_{i} \times r\right)$, where $r$ is the typical fraction of the tank that is replaced during refueling. This gives additional cost in dollars per unit of alternative fuel (usually per volumetric gallon). This is converted to dollars per gallon of gasoline- 
equivalent energy by multiplying by $E_{g}\left(E_{j}(1+\right.$ e) $)^{-1}$.

$$
C_{R}=\frac{(R-1) T_{j} V_{I}}{Q_{j} r}
$$

Refueling convenience is represented as an increase in refueling time per event. This is computed as the difference between the alternative-fuel refueling cost per gasolineequivalent gallon, minus the gasoline refueling cost per gallons delivered.

$$
C_{D}=\frac{T_{J} V_{I}}{Q_{j} r}-\frac{T_{g} V_{g}}{Q_{g} r}
$$

The sum of these equations gives the total difference in refueling costs for a gasolineequivalent gallon of the alternative fuel in comparison to gasoline.

Available evidence suggests that the fuel economy of flexible and bifuel vehicles will be nearly identical to that of conventional gasoline vehicles. A 1-percent fuel economy gain is assumed for fuel-flexible methanol and ethanol vehicles using alcohol versus their fuel economy using gasoline (McNutt 1993). Bifuel CNG and LPG vehicles using gasoline are assumed to achieve equal fuel economy, except for the weight penalty attributable to their extra fuel storage tanks. For CNG vehicles, this increase will be in the range of 4 to 5 percent, and for LPG vehicles, 3 to 4 percent, for fuel economy losses of about 3 percent and 2 percent, respectively (Bechtold 1993a, Table $\mathrm{C}-8$; it is assumed that a 1-percent increase in weight reduces mpg by 0.7 percent). Dedicated gaseous-fueled vehicles are assumed to achieve the same mpg as a conventional gasoline vehicle. The alcohol-flexible vehicle (M85 or E85) is assumed to achieve a 5-percent fuel economy advantage (McNutt 1993). Electric vehicles should be about three times as energy efficient as conventional gasoline vehicles, when energy use is measured in kWh from the electrical outlet and the extra weight of the battery system is taken into ac- count. ${ }^{14}$ The assumptions and calculations underlying this estimate are shown in Table C-3. The energy storage requirements, battery requirements, gross vehicle weight, and realized energy efficiency, shown in Table C-3 (bold numbers) have been computed iteratively based on desired range, power train efficiency, battery characteristics, and typical depth of discharge. Assumptions about electric vehicles differ somewhat from those about internal combustion engine (ICE) vehicles. ICE vehicles are assumed to achieve $21.3 \mathrm{mpg}$ on the road, which includes a shortfall of 30 percent from Federal test cycle fuel economy. It is assumed that EVs will have regenerative braking, will have no idling losses, and will not travel at the same highway speeds. Their onroad correction has been therefore adjusted to only 10 percent. As a result, if a conventional vehicle achieves $21.3 \mathrm{mpg}$ in actual use, a comparable EV will attain the equivalent of 27.4 in terms of miles per gallon of gasoline-equivalent energy. However, the EV does much better because of its inherently more efficient (5.5 times) powertrain. Miles per kWh are computed by multiplying $27.4 \mathrm{mpg}$ by 5.5 , then multiplying by the ratio of Btu per $\mathrm{kWh}$ to Btu per gallon and finally correcting for the efficiency loss an EV suffers because of the additional weight of its batteries. Because this loss is not known until the weight of batteries relative to the weight of the vehicle is known, miles per kWh must be computed iteratively.

The calculations in Table $\mathrm{C}-3$ proceed as follows. First, energy storage required to achieve the desired 100 mile operating range is computed. Second, the weight of batteries required for the necessary energy storage is computed, and vehicle weight is revised. Third, energy efficiency is adjusted because of the increase in weight, requiring a recalculation of energy storage and battery requirements. Calculations are made iteratively until convergence is reached. Finally, the cost of the required batteries is computed.

\footnotetext{
14 Considering the overall efficiency of primary energy conversion to electricity at the outlet of $\mathbf{3 0}$ percent, battery-electric vehicles are close to conventional gasoline vehicles in terms of primary energy efficiency.
} 


\section{Table C-3 - Estimation of Characteristics of Baftery-Electric Vehicles}

Desired Range
Efficiency (mi/kWh)
Depth of Discharge
Charger Efficiency
Battery Efficiency
Relative Powertrain Efficiency
Battery Energy Density (Wh/kg)
Volumetric Energy Density (Wh/)
Net Energy Storage Required (kWh)
Gross Energy Storage Req. (kWh)
Energy Storage Required (kg)
Energy Storage Required (l)
Initial Vehicle Weight
EV Weight Reduction (minus battery) (\%)
EV Gross Weight (incl. battery)
Additional Structural Support (lb/lb)
EV Gross Weight (incl. battery)
Net Increase in Weight (\%)
Net Efficiency Loss Due to Weight (\%)
Estimated OEM Battery Cost ( $\$ / \mathrm{kWh})$
Estimated OEM to Retail Markup (\%)
Estimated Battery Cost (\$)
Cost Difference of EV (minus battery) (\$)
Net Cost Difference of EV (\$)
Estimated Recharging Time (hrs)

100

3.99

0.75

0.90

0.75

5.50

80.0

150.0

33.4 (1.0 gals gasoline)

49.5

417.7 (919.0 lbs)

222.8 (58.9 gals)

$\underset{10.0}{1,609}(3,539 \mathrm{lbs})$

1,866

0.07

$1,883 \quad(4,104 \mathrm{lbs})$

17.1

10.5

110

50

5,514

(500)

5,014
In-Use

Factor

$\begin{array}{ccc}\text { EV MPG } & \text { Btu/kWh } & \text { Gasoline } \\ 27.4 & 3,412 & \text { MPG } \\ \text { MPGEG } & \text { Btu/Gal } & 21.31 \\ \text { From Outlet } & 115,400 & \text { In-Use } \\ \text { 91.1 } & & \text { Factor } \\ \text { Rel. Eff. } & & \text { Gasoline } \\ 428 \% & & 70 \%\end{array}$

EV $90 \%$

Note: "Net Efficiency Loss Due to Weight" is computed assuming an elasticity of energy efficiency with respect to weight of -0.7 . Once convergence has been achieved with respect to weight and efficiency, the cost of batteries is computed. Here the assumption is $\$ 110$ per kilowatthour production cost and a 50-percent retail markup; $\$ 500$ is subtracted from this estimate to account for the othenwise lower cost of an EV without batteries.

Sources: Delucchi, Wang, and Sperling, 1989; Automotive Engineering, 1992.

"Efficiency" in Table C-3 is the product of mpg, the "Relative Powertrain Efficiency" of the EV, 1 minus the "Net Efficiency Loss Due to Weight" times the ratio of Btu per kWh to Btu per gallon of gasoline. Here the lower heating value of gasoline is used for comparability to the energy available for useful work in a kWh of electricity. The "Energy Required" equals the "Desired Range" divided by the "Depth of Discharge" (the nominal or maximum range) divided by "Efficiency." The volume and weight of energy storage is computed by dividing "Energy Required" by the appropriate "Energy Density." Because an EV without batteries is lighter than a conventional vehicle by about 10 percent, the average vehicle weight is first adjusted downward before the weight of batteries is added. The weight of additional structural support for the batteries is then added to give total gross EV weight.

The relative efficiency factor to be entered in the AFVC model "Refueling" spreadsheet (see "Calculation of Value of Range and Refueling Time" in the next section) is the mpg in energy-equivalent gasoline-gallons energy from the electrical outlet, divided by the gasoline $\mathrm{mpg}$, not the EV mpg $(91.1 / 21.3=4.28$ or 428 percent). The relevant energy storage value for the AFVC "Refueling" spreadsheet is the "Gross" rather than the "Net" energy storage requirement (49.5 kWh). The "Gross value 
accounts for charger and battery efficiency losses and thus represents energy required from the outlet rather than from the battery.

The lower energy densities of alternative fuels and the need for dual-fuel storage systems in bifuel vehicles result in reduced operating ranges for some alternative fuels and thus increased frequencies of refueling. With the exception of EVs, all energy storage capacities for AFVs are given in terms of gallons of gasoline-equivalent energy (Table C-4). Conventional gasoline vehicles (CGVs), BiFNGVs, and BiFLPGVs are all assumed to be equipped with 15.4 volumetric gallon fuel tanks. FFVs are assumed to have 18 volume gallon tanks, enabling them to store 10.2 GEG of M85 and 12.8 GEG of E85. Bifuel CNG vehicles are assumed to have only 5.2 GEG of CNG storage capacity, while BiFLPGVs will be able to store 14.5 GEG because of the relatively high energy density of LPG stored in liquid form.

Refueling times are derived from those presented in Bechtold (1993a), except that it is not assumed that owners of bifuel vehicles will always refuel both storage systems simultaneously. Bechtold (1993) assumes that bifuel operators will use up their gaseous fuel, switch to gasoline, and refuel after using 25 percent of their gasoline storage. This places a strong constraint on the relative shares of natural gas and gasoline consumed by these vehicles, which is contrary to the economic theory of fuel choice underlying the AFVC model. Instead, it is assumed that either fuel will be used independently, and that simultaneous refueling will not be possible. It is assumed, however, that essentially all of the alternative fuel will be used by bifuel vehicles before refueling and that little or no reserve will be maintained. Bechtold (1993a) assumes that all other vehicles will maintain a 90-mile reserve-approximately one-fourth tank-and that assumption is made here, except for electric vehicles, which are assumed to have a practical range of 100 miles when recharging at 25 percent of full battery charge.

The above assumptions are used to compute the time cost of refueling, assuming time spent refueling is valued at $\$ 10$ per hour for all vehicles except EVs, for which it is valued at $\$ 1.00$ per hour. The value of time for EV refueling is highly uncertain. Clearly, time spent recharging by slow recharge methods that require on the order of 6 hours for a complete

\section{Table C-4 - Alternative-Fuel Vehicle Onboard Fuel Storage Capacities and Refueling Times}

\begin{tabular}{lcc}
\hline Vehicle and Fuel Type & Tank Size (GEG) & Refueling Time (min) \\
\hline Conventional Gasoline & 15.4 & 6 \\
FFV & & \\
Gasoline & 18.0 & 6.5 \\
M85 & 10.2 & 6.5 \\
E85 & 12.8 & 6.5 \\
Bifuel NGV & & \\
Gasoline & 15.4 & 6.0 \\
CNG & 5.2 & 7.0 \\
Bifuel LPG & 15.4 & 6.0 \\
Gasoline & 14.6 & 6.5 \\
LPG & 10.4 & 8 \\
Dedicated CNG & 15.4 & 6.5 \\
Dedicated LPG & & \\
Alcohol-Flexible Vehicle & 10.2 & 6.5 \\
$\quad$ M85 & 12.8 & 6.5 \\
E85 & & \\
\hline
\end{tabular}


recharge is qualitatively different from the few minutes spent refueling a conventional vehicle. One is a sizable block of time that allows other activities (sleeping, working) to take place simultaneously while the other demands nearly full attention for its brief duration. Past studies have viewed this battery-EV characteristic as a limitation on the vehicle's capabilities, rather than a cost for time (for example, Charles River Assoc., Inc. 1981; Beggs and Cardell 1980; Train 1980). Nonetheless, the long recharging times assumed here definitely impose a nontrivial cost, and the values assumed appear to be plausible though very uncertain.

\section{Fuel Option Value for Multifuel Vehicles}

In a static equilibrium model such as the AFTM, there is only one price for each fuel. Thus, a fuel is unambiguously cheaper, equal in price, or more expensive than another. In reality, fuel prices fluctuate over time, so that a fuel that is on average more expensive may occasionally be cheaper. FFV owners have an option to select whichever fuel is cheapest at any time. This gives FFVs a cost advantage over single-fuel vehicles that is not reflected in any other variable in the vehicle-choice model. Whether or not such an option value should be included in a static equilibrium model is an open question. At the very least, it requires a reinterpretation of the static equilibrium framework. Perhaps the most straightforward method is to interpret the prices of an AFTM forecast as expected values of prices that are actually random variables. ${ }^{15}$

Under this assumption, the fuel price for a single-fuel vehicle is adequately captured by its expected value, but the fuel price for a flexible-fuel vehicle is not, because the owner has an option to select the cheaper fuel at any given time.

Consider a set of $T$ pairs of fuel prices (indexed $t$ ) for the conventional and an alternative fuel $\left\{p_{c t}, p_{a t}\right\}$. If this set is divided into two parts-a subset $C$ which contains all the pairs for which the conventional fuel is cheaper$\left(p_{c t}<p_{a t}\right)$, and a subset $A$, defined by $p_{a t}<$ $p_{c t}$ the average prices for the fuels are

$p_{c}=\frac{1}{T} \sum_{t=1}^{T} p_{c t}, \quad p_{a}=\frac{1}{T} \sum_{t=1}^{T} p_{a t}$.

If it is assumed that pairs were generated in such a way that each pair is equally likely to occur (that is, the pairs are random), ${ }^{16}$ the relative frequency (or probability density) associated with each pair is $1 / T$.

The option value of the flexible-fuel combination $[c, a]$ is defined as

$$
\begin{aligned}
\Delta= & \frac{1}{2}\left(\sum_{c} \frac{1}{T}\left(p_{a t}-p_{c t}\right)\right. \\
& \left.+\sum_{A} \frac{1}{T}\left(p_{c t}-p_{a t}\right) \pm\left(p_{c}-p_{a}\right)\right),
\end{aligned}
$$

where the \pm indicates that the difference in means $\left(p_{c}-p_{a}\right)$ will be subtracted if $p_{a}>p_{c}$ and added otherwise. The average price equations (3.4) are substituted into equation (3.5), separating the summation over $T$ into two parts corresponding to the sets $C$ and $A$.

$$
\begin{aligned}
\Delta= & \frac{1}{2 T}\left(\sum_{c}\left(p_{a t}-p_{c t}\right)+\sum_{A}\left(p_{c t}-p_{a t}\right)\right. \\
& \left. \pm\left[\sum_{c}\left(p_{c t}-p_{a t}\right)+\sum_{A}\left(p_{c t}-p_{a t}\right)\right]\right) .
\end{aligned}
$$

Combining and canceling terms gives the average price advantage of being able to buy the cheapest fuel in comparison to a single-fuel vehicle using the cheaper of the two fuels. Assuming that $p_{a}>p_{c}$, then the term should be subtracted in square brackets. The two

\footnotetext{
${ }^{16}$ Another notion is that the pairs represent a time series of prices.
}

15 This interpretation further requires that decisionmakers be risk neutral to avoid having to consider the distributions of variables in computing an equilibrium solution. 
terms involving summation over $A$ will cancel so that the option value is

$$
\Delta=\frac{1}{T} \sum_{C}\left(p_{a t}-p_{c t}\right)
$$

An interesting result that follows from the above is that the average price reduction available with a flexible-fuel vehicle versus a singlefuel vehicle that uses the fuel with the lowest average price is exactly equal to the average price reduction attainable with a flexible-fuel vehicle versus a single-fuel vehicle that uses the fuel with the highest price minus the average price advantage of the fuel with the lower average price. Thus, in comparison to a singlefuel vehicle using the low price fuel, the option value of the flexible-fuel vehicle is $\Delta$. In comparison to the single-fuel vehicle using the higher priced fuel, the multifuel vehicle's option value is $\Delta+\left(p_{c}-p_{a}\right)$. The difference in average prices is taken into account in the NMNL choice model, which is a function of average prices. The utility of a single-fuel vehicle using the higher priced fuel is computed using that higher price and, thus, reflects its greater average cost. For the FFVs, both prices are used in computing the logsum value, but the prices are assumed to be constant. The NMNL model treats the average prices as if they were constant prices (that is, as if there were a static equilibrium). Using the assumptions stated above, the option value term, $\Delta$, accounts for the fact that prices are not constant.

Estimation of the fuel option value for flexiblefuel and bifuel vehicles is based on fuel prices estimated by the AFTM, together with assumed price distributions based on an analysis of historical price series. For each multifuel vehicle, fuel prices are assumed to follow a bivariate normal probability distribution. ${ }^{17}$ The bivariate normal distribution is specified by the

\footnotetext{
17 A trivariate normal distribution of gasoline, ethanol, and methanol prices would be most appropriate for FFVs. Because this greatly complicates the spreadsheet implementation, and because the option value for ethanol versus gasoline or methanol is approximately zero, we use a bivariate distribution based on methanol and gasoline prices to compute the option value for FFVs.
}

mean prices of the two fuels $\left(\mu_{g}, \mu_{\mathrm{a}}\right)$, their standard deviations $\left(\sigma_{g}, \sigma_{a}\right)$, and the correlation of their prices $(\rho)$. The integral over the region where $p_{a}<p_{g}$ of the product of the price difference $\left(p_{g}-p_{a}\right)$ and the bivariate normal density function $\left(f\left(\mu_{g}, \mu_{a}, \sigma_{g}, \sigma_{a}, \rho\right)\right)$ gives the expected advantage of being able to buy the alternative fuel whenever it is cheaper. Similarly, integrating the product of $\left(f\left(\mu_{g}, \mu_{a}, \sigma_{g}, \sigma_{a}\right.\right.$, $\rho)$ ) and $p_{a}-p_{g}$ whenever gasoline is cheaper, gives the expected advantage of the option to buy gasoline when it is cheaper. Subtracting the expected price difference between the two fuels from the sum of the two integrals gives the advantage of having the option to buy cheaper fuel as prices vary, over using the fuel with the lowest average price all the time. This difference is defined as the option value of the FFV.

$$
\begin{aligned}
\Delta= & \frac{1}{2}\left(\int_{p_{a}=0}^{p_{c}} F\left(p_{c}-p_{a}\right) \partial p_{c} \partial p_{a} \quad(\mathrm{C}-19)\right. \\
& \left.+\int_{p_{c}=0}^{p_{a}} F\left(p_{a}-p_{c}\right) \partial p_{a} \partial p_{c}-\left|p_{c}-p_{a}\right|\right),
\end{aligned}
$$

where $F=f\left(\mu_{c}, \mu_{a}, \sigma_{c}, \sigma_{a}, \rho\right)$.

The option value is computed by numerical integration of a specified density function. Predicted prices are used as the mean price parameters of $f$. Values of $\rho$ and $\sigma$ have been chosen based on an analysis of annual fuel prices from 1978 to 1992 (Figure C-3). For liquid fuels, representative values of the parameters appear to be $\rho=0.9$ or higher, and $\sigma_{a}$ and $\sigma_{g}$ equal to 25 to 30 percent of the mean (Table C-5). Gaseous fuels (propane, commercial natural gas, and residential natural gas) are highly correlated with each other $(\rho \approx$ $0.9)$ but much less strongly correlated with the prices of liquid fuels ( $\rho$ values range from 0.22 to 0.66 ). In addition, the variation in prices of gaseous fuels has been lower, standard deviations being on the order of 15 percent of the mean. No doubt this is partly attributable to historical regulation of the natural gas market. Strictly on the basis of these historical data, one would choose $\sigma \approx 0.3$ and $\rho \approx 0.95$ for 
Figure C-3 - Fuel Prices 1978-1992
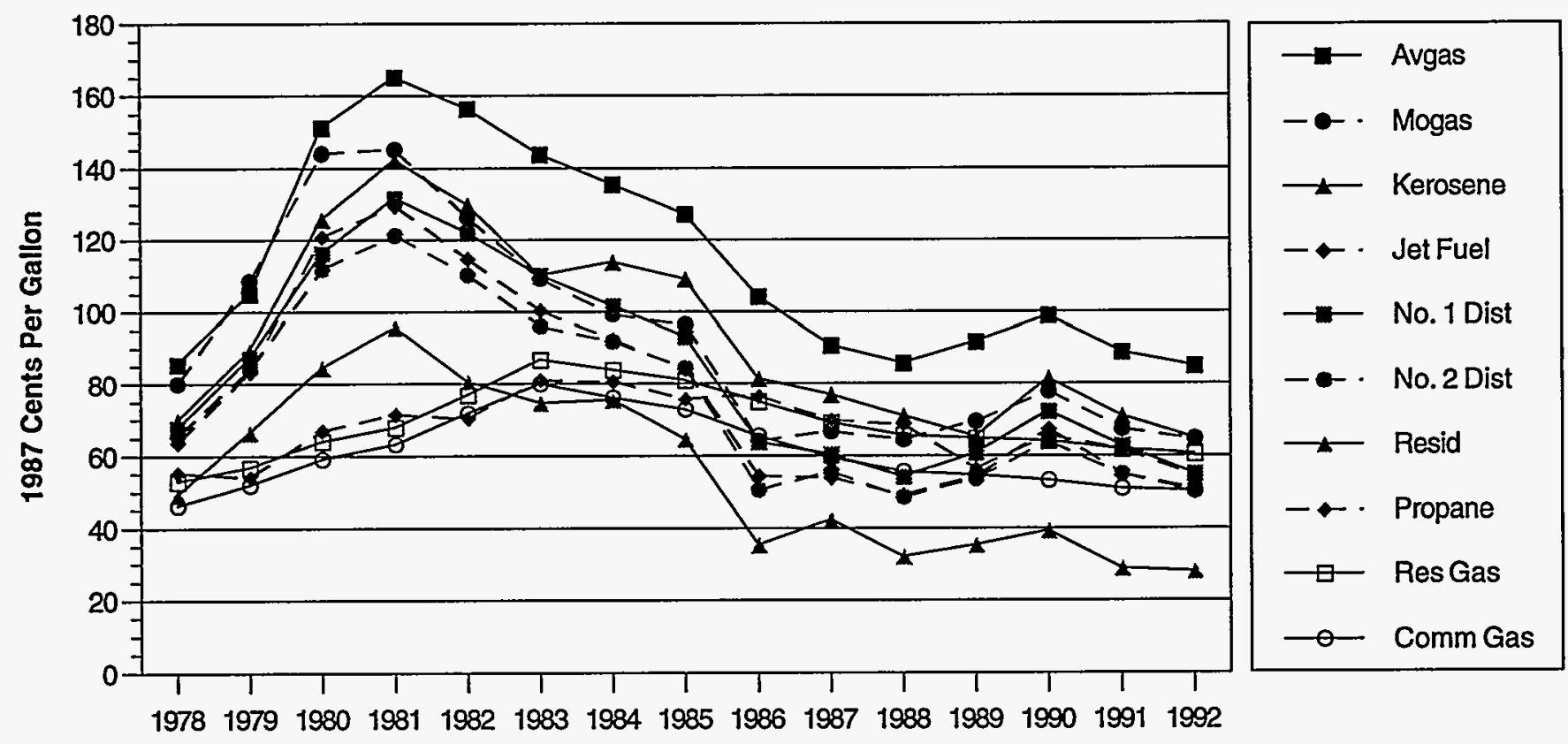

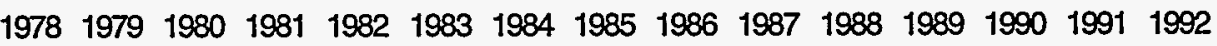

Table C-5 - Variation and Correlation Among Fuel Prices, 1978-1992

\begin{tabular}{|c|c|c|c|c|c|c|c|c|c|}
\hline $\begin{array}{l}\text { Aviation } \\
\text { Gasoline }\end{array}$ & $\begin{array}{c}\text { Motor } \\
\text { Gasoline }\end{array}$ & Kerosene & $\begin{array}{l}\text { Jet } \\
\text { Fuel }\end{array}$ & $\begin{array}{c}\text { No. } 1 \\
\text { Distillate }\end{array}$ & $\begin{array}{c}\text { No. } 2 \\
\text { Distillate }\end{array}$ & Oil & Propane & $\begin{array}{c}\text { Residential } \\
\text { Nat. Gas }\end{array}$ & $\begin{array}{c}\text { Commercial } \\
\text { Nat. Gas }\end{array}$ \\
\hline \multicolumn{10}{|c|}{ Mean } \\
\hline 114.4 & 92.5 & 93.5 & 78.5 & 84.0 & 76.4 & 55.6 & 67.5 & 5.51 & 4.87 \\
\hline \multicolumn{10}{|c|}{ Standard Deviation (Coefficient of Variation) } \\
\hline $\begin{array}{l}29.1 \\
(25 \%)\end{array}$ & $\begin{array}{c}29.0 \\
(31 \%)\end{array}$ & $\begin{array}{c}26.0 \\
(28 \%)\end{array}$ & $\begin{array}{c}27.7 \\
(35 \%)\end{array}$ & $\begin{array}{c}26.6 \\
(32 \%)\end{array}$ & $\begin{array}{c}25.3 \\
(33 \%)\end{array}$ & $\begin{array}{c}23.0 \\
(41 \%)\end{array}$ & $\begin{array}{c}9.2 \\
(14 \%)\end{array}$ & $\begin{array}{c}0.80 \\
(14 \%)\end{array}$ & $\begin{array}{c}0.83 \\
(17 \%)\end{array}$ \\
\hline
\end{tabular}

\section{Correlation Coefficients}

\begin{tabular}{|c|c|c|c|c|c|c|c|c|c|}
\hline $\begin{array}{l}\text { Aviation } \\
\text { Gasoline }\end{array}$ & 0.92 & 0.99 & 0.96 & 0.98 & 0.95 & 0.93 & 0.58 & 0.57 & 0.71 \\
\hline Motor Gasoline & & 0.93 & 0.99 & 0.96 & 0.98 & 0.96 & 0.26 & 0.22 & 0.41 \\
\hline Kerosene & & & 0.97 & 0.98 & 0.96 & 0.95 & 0.57 & 0.52 & 0.67 \\
\hline Jet Fuel & & & & 0.99 & 0.99 & 0.97 & 0.39 & 0.35 & 0.53 \\
\hline No. 1 Distillate & & & & & 0.99 & 0.97 & 0.47 & 0.45 & 0.62 \\
\hline No. 2 Distillate & & & & & & 0.98 & 0.37 & 0.36 & 0.58 \\
\hline $\begin{array}{l}\text { Residual Fuel } \\
\text { Oil }\end{array}$ & & & & & & & 0.43 & 0.40 & 0.58 \\
\hline Propane & & & & & & & & 0.91 & 0.90 \\
\hline $\begin{array}{l}\text { Residential } \\
\text { Natural Gas }\end{array}$ & & & & & & & & & 0.97 \\
\hline
\end{tabular}


liquid fuels, and $\sigma \approx 0.15$ and $\rho \approx 0.5$ for gaseous fuels. However, there is reason to expect that correlations among prices would be more similar to those of liquid fuels given a substantial transportation fuel market for gaseous fuels. It is also possible that gaseous fuel prices could become more volatile in the future in the absence of price regulation.

In general, the closer the mean prices, the larger the standard deviations; and the smaller the correlation between their prices, the larger the option value will be. Example options values and key assumptions are presented in Table C-6.

Strictly speaking, option values should be determined simultaneously with the overall market equilibrium for fuels. Option values tend to be small relative to mean prices, however, so that changing the option values will have little effect on the world equilibrium energy prices. This suggests that if prices from an initial run excluding option prices are used to compute the option prices and then the new AFVC model coefficients are substituted into the AFTM and it is rerun, further iteration will not be necessary. Initial experimentation has borne this out: changes in world fuel prices on a second iteration have been $\$ 0.01$ per barrel or smaller.

\section{Capitalized Values}

Certain alternative-fuel characteristics are inherently capital charges. The incremental cost of AFV technology is the most obvious ex- ample. Other characteristics are most readily evaluated as capital costs (or values) because of the nature of the information available on the value consumers attach to them. Changes in performance and the cost of cargo capacity converted to fuel storage fall into this category. Despite the fact that performance is experienced over time as the vehicle (and fuel) are used, most information comes from studies of motor-vehicle demand and is expressed in terms of dollars per vehicle, initial price equivalent. All capital costs must be converted into dollars per barrel of gasoline-equivalent energy service in order to be consistent with the AFTM methodology. How this is done using the concept of a capital charge rate is explained below. Next, incremental costs of AFVs are discussed, followed by performance changes and the effects of fuel storage on cargo capacity.

To obtain an annual charge per barrel of gasoline-equivalent energy service, the annual charge is divided by annual fuel consumption. Average annual fuel consumption equals overall miles driven divided by fleet average miles per gallon. The average household vehicle traveled 10,600 miles per year in 1991, according to the latest Department of Energy survey (DOE/EIA 1993, Table 5). Annual motor vehicle usage has remained in the vicinity of 10,000 miles per year for at least two decades (Davis and Strang 1993, Table 4-18). Projections to 2010, however, call for vehicle stock to grow at a slower rate than vehicle use, resulting in increased annual miles per vehicle by 2010. The U.S. Department of

\section{Table C-6 - Estimated Option Values for Pairs of Alternative Fuels and Gasoline}

(Prices in 1990 dollars per barrel of gasoline-equivalent)

\begin{tabular}{lcccc}
\hline & $\begin{array}{c}\text { Expected } \\
\text { Fuel }\end{array}$ & $\begin{array}{c}\text { Expected Price } \\
\text { Difference Versus } \\
\text { Gasoline }(\$)\end{array}$ & \multicolumn{2}{c}{ Net Expected Value of Multifuel Option } \\
\cline { 5 - 5 } & Price $(\$)$ & -4.18 & $(\$ /$ gal $)$ & $(\$ / \mathrm{bbl})$ \\
\hline M85 & 48.04 & 20.30 & 0.018 & 0.76 \\
E85 & 72.52 & 12.66 & 0.001 & 0.04 \\
CNG & 64.88 & -3.07 & 0.003 & 0.13 \\
LPG & 49.15 & 0.026 & 1.09 \\
\hline
\end{tabular}

Note: Assumes a correlation of 0.9 and coefficient of variation of 0.25 for each fuel. 
Energy (DOE/EIA 1993b, Table A-14) projected light-duty vehicle annual miles of 11,383 and average fuel economy of $21.3 \mathrm{mpg}$ for the year 2010 giving an average annual fuel consumption of 12.7 barrels of gasoline..$^{18}$ The same capital charge rate and annual barrels of gasoline are used for every fuel type regardless of the actual level of annual energy use required by that particular technology to produce the same number of vehicle-miles. That is, the capital charge is therefore a charge per unit of energy service (vehicle-miles), rather than per unit of energy use.

\section{Estimation of Capital Costs per Barrel of Gasoline-Equivalent}

Characteristics of the elementary choices (the fuel and vehicle combinations illustrated in Figure $\mathrm{C}-1$ ) can be divided into two types: those associated with the use of a particular fuel that are experienced by the consumer only when that fuel is used and those associated with a vehicle that are experienced whenever the vehicle is used, regardless of which fuel powers it. Because the prices that drive choices in the AFTM model are the prices of fuels expressed in dollars per barrel of gasoline-energy-equivalents (BGE), both fuel and vehicle characteristics must be valued in terms of dollars per BGE. For characteristics that can be naturally expressed in terms of dollars per gallon (or dollars per energy unit) this can be done by simply multiplying by 42 . Characteristics that are more naturally expressed as capital costs (for example, incremental vehicle cost) must be converted into dollars per barrel. This is done using a levelized cost method to compute a capital charge rate per barrel of gasoline-equivalent energy service.

Assume that a vehicle purchaser expects to own a vehicle for a period of $Y=4$ years, at which time he will resell. Let the cost of the vehicle be $C$, the depreciation rate for automobiles be $\delta \approx 0.15$ ( 15 percent per year), and

\footnotetext{
${ }^{18}$ Any of these assumptions can be varied in the spreadsheet implementation of this methodology, described below.
}

the real interest (or discount) rate be $i=0.07$ (7 percent).

The cost of the investment to the purchaser is the initial capital cost minus the present value of the resale price. The annual cost, $C_{o}$, is given by

$$
\int_{0}^{Y} C_{0} \exp (-i t) d t=C-C \exp (-(i+\delta) \gamma) \text {. }
$$

Solving this for the capital charge rate $R=\left(C_{0} / C\right)$ yields

$$
\frac{C_{0}}{C}=i \frac{(1-\exp (-(i+\delta) Y))}{(1-\exp (-i Y))}
$$

which, when plugging in the above assumptions for $i, \delta$, and $Y$, gives an annual capital charge rate of 16.8 percent. It is assumed that all incremental capital costs (hedonic or financial) of AFVs can be converted to equivalent annual charges in this way.

\section{Incremental Costs of AFVs}

FFVs and DFVs require additional fuel metering or fuel storage equipment, and may demand more costly materials. Gaseous-fueled vehicles, in particular, require more expensive, space-consuming fuel tanks, capable of storing fuels at 3,000 pounds per square inch (psi), or greater. Battery-electric vehicles may cost less to manufacture, batteries not included, but the additional cost of batteries is likely to make their initial cost considerably higher than CGVs. Because AFVs are not in full-scale production, there remains considerable uncertainty about their eventual cost differences. Several studies suggest that the incremental costs based on Bechtold (1993a) shown in Table $\mathrm{C}-7$ provide a reasonable range (Wang, Sperling, and Olmstead 1993; Interagency Commission on Alternative Fuels 1990). In some cases, Bechtold (1993a) provides a clear high and low cost estimate. Where he does not, a high cost that is 33-percent higher 


\section{Table C-7 - Incremental Initial Cost Estimates for AFVs (1990 dollars)}

\begin{tabular}{lcc}
\hline Vehicle Type & $\begin{array}{c}\text { High } \\
\text { Estimate }\end{array}$ & $\begin{array}{c}\text { Low } \\
\text { Estimate }\end{array}$ \\
\hline FFV & 300 & 100 \\
CNG DFV & 1,111 & 817 \\
LPG DFV a & 861 & 625 \\
CNG Dedicated & 600 & 451 \\
LPG Dedicated & 225 & 171 \\
Alcohol FV & 100 & 0 \\
Battery EV & 6,692 & 5,019 \\
\hline
\end{tabular}

a Bechtold (1993a) does not provide a cost estimate for original equipment manufacture (OEM) LPG vehicles. The estimate shown here is obtained by dividing Bechtold's estimated labor costs by two and using his material costs as given.

than his single cost estimate is assumed. For AFVs $\$ 100$ is assumed as a high-estimate cost increment.

\section{Value of Performance Changes}

Performance advantages are specified in terms of an increase in horsepower per pound.
Greene and Liu (1988) surveyed more than a dozen models of vehicle-type choice and found a wide range of values for acceleration performance. They chose a typical value of $\$ 55$ per cid per $1,000 \mathrm{lbs} .$, which they equated to $\$ 110$ per hp per $1,000 \mathrm{lbs}$. (1985 dollars).

For a typical 1985 vehicle with approximately $35 \mathrm{hp}$ per $1,000 \mathrm{lbs}$. (Murrell et al. 1993) this equals $\$ 385$ per 10 percent increase in performance (just over $\$ 450$ in 1990 dollars). In a stated-preference survey of motorists in New York and California, Sperling, Hungerford, and Kurani (1990) found that about 50 percent expressed willingness to pay $\$ 0.10$ per gallon, or more, for a 10 percent increase in power. For a typical car, this equates to $\$ 250$ to $\$ 300$ in purchase price. Because light-duty-vehicle performance has been steadily increasing over time and because a decreasing marginal willingness to pay for performance increases is assumed, a value of $\$ 25$ per 1 percent increase in performance was chosen to value the performance differences of AFVs (Table C-8).

Sperling et al. claimed that use of methanol in an FFV would give approximately a 10-percent increase in power; but this assumes that the FFV has been optimized for methanol, and will therefore run very poorly on conventional gasoline. Perhaps FFVs will be designed to run somewhat better on alcohol than gasoline,

\section{Table C-8 - Power-to-Weight Changes for Alternative-Fuel Vehicles}

\begin{tabular}{lcccc}
\hline Vehicle & Fuel & $\begin{array}{c}\text { Change in Vehicle } \\
\text { Weight (percent) }\end{array}$ & $\begin{array}{c}\text { Change in } \\
\text { HP (percent) }\end{array}$ & $\begin{array}{c}\text { Change in HPNt } \\
\text { Ratio (percent) }\end{array}$ \\
\hline Conventional & Gasoline & 0.00 & 0.00 & 0.00 \\
FFV & Gasoline & 0.00 & 0.00 & 0.00 \\
FFV & M85 & 0.00 & 3.00 & 3.00 \\
FFV & E85 & 0.00 & 3.00 & 3.00 \\
CNG Bifuel & Gasoline & 4.70 & 0.00 & -4.49 \\
CNG Bifuel & CNG & 4.70 & 10.00 & -14.04 \\
LPG Bifuel & Gasoline & 3.70 & 0.00 & -3.57 \\
LPG Bifuel & LPG & 3.70 & -5.00 & -8.39 \\
CNG Dedicated & CNG & 6.50 & 0.00 & -6.10 \\
LPG Dedicated & LPG & 2.00 & 0.00 & -1.96 \\
AFV & M85 & 0.00 & 10.00 & 10.00 \\
AFV & E85 & 0.00 & 10.00 & 10.00 \\
Electric & Battery EV & 0.00 & 0.00 & 0.00 \\
\end{tabular}


but it is doubtful that anywhere near full advantage can be taken of the roughly 5 to 6 extra octane points. Similarly, natural gas has an octane rating of 120 . Dual-fuel vehicles (DFVs) that must also run well on gasoline could not take advantage of even a small fraction of CNG's additional octane rating without some sort of variable displacement design. To date, no known natural gas vehicles (NGVs) derive any performance advantage from natural gas' high octane number. Thus, no octane advantage is assumed for CNG DFVs.

For CNG BiFNGVs there is also a volumetric displacement penalty, because of the fact that as a gas, CNG displaces air in the cylinder effectively reducing the size of the charge. Because natural gas requires an air/fuel ratio of about 10 to 1 for stoichiometry, the effective volumetric reduction is about 10 percent (Interagency Commission on Alternative Fuels 1990). ${ }^{19}$ It is assumed that the 10-percent displacement penalty equates to a 10-percent performance penalty (Bechtold 1993a).

\footnotetext{
${ }^{19}$ The volumetric performance loss of CNG dual-fuel vehicles is the result of optimizing the engines to run on gasoline. Innovative design, perhaps using variable displacement design, could mitigate the performance loss. Such designs have not been used to date, however.
}

\section{Value of Cargo Capacity}

The lower energy densities of gaseous fuels and electricity storage in batteries will require that significantly more space be devoted to energy storage for these types of alternativefuel vehicles. In addition, bifuel vehicles will require more space for their second fuel system. The shape and size of CNG storage tanks virtually require that they be stored in cargo space. Although innovative solutions to CNG storage may be developed, it is assumed that cargo space will be reduced. For bifuel CNG vehicles, it is assumed that all of the additional CNG storage volume will translate into reduced cargo volume. For dedicated $\mathrm{CNG}$ vehicles, the volume of a conventional gasoline tank is subtracted from the CNG tank volume to estimate the net loss of cargo space. Delucchi et al. (1989) have argued that battery-electric vehicles can be designed to accommodate batteries with no loss of passenger or cargo volume from the reduced size of powertrain components. The size of a gasoline tank is subtracted from the estimated required battery volume, then the remainder is divided in half to allow for the powertrain advantage of an EV (Table C-9).

The value of cargo capacity is difficult to pinpoint. Few studies have attempted to estimate

\section{Table C-9 - Loss of Cargo Capacity to Energy Storage}

\begin{tabular}{lcccc}
\hline Vehicle & Fuel & $\begin{array}{c}\text { Total Fuel } \\
\text { Storage } \\
\text { Space (gallons) }\end{array}$ & $\begin{array}{c}\text { Increase } \\
\text { Relative to } \\
\text { Gasoline (gallons) }\end{array}$ & $\begin{array}{c}\text { Relative to } \\
\text { Gasoline (cu. ft.) }\end{array}$ \\
\hline Conventional & Gasoline & 15.8 & 0.00 & 0.00 \\
FFV & Gasoline & 18.5 & 2.7 & 0.4 \\
FFV & M85 & 18.5 & 2.7 & 0.4 \\
FFV & E85 & 18.5 & 2.7 & 0.4 \\
CNG Bifuel & Gasoline & 51.8 & 36.0 & 4.9 \\
CNG Bifuel & CNG & 51.8 & 36.0 & 4.9 \\
LPG Bifuel & Gasoline & 37.0 & 21.2 & 2.9 \\
LPG Bifuel & LPG & 37.0 & 21.2 & 2.9 \\
CNG Dedicated & CNG & 49.9 & 34.1 & 4.6 \\
LPG Dedicated & LPG & 21.2 & 5.4 & 0.7 \\
AFV & M85 & 18.5 & 2.7 & 0.4 \\
AFV & E85 & 18.5 & 2.7 & 0.4 \\
Electric & Battery EV & 38.7 & 22.9 & 3.1 \\
\hline
\end{tabular}


it, and those that have, have produced inconsistent results. For example, one recent study found that increasing trunk space actually reduced the likelihood of vehicle purchase for U.S.- and European-manufacture vehicles and had no effect on the desirability of Japanese vehicles, results the authors termed "anomalies" (McCarthy and Tay 1989). In an earlier study, Manski and Sherman (1980) estimated that the value of 1 additional cubic foot of luggage space was worth between $\$ 44$ and $\$ 238$ (1976 dollars), depending on the income and education levels of buyers. Train and Lohrer (1982) estimated marginal values per cubic foot of luggage space of from $\$ 118$ to $\$ 365$ (1978 dollars), with higher values for larger, higher income households. However, luggage space appeared as a significant variable only in their model for households owning one vehicle. In their multivehicle household analysis, luggage space was not a factor. The positive values appear to be high relative to estimates of consumer willingness to pay for passenger volume. In a survey of 10 studies and 14 models, Greene and Liu (1988) found a range of typical estimates of from $\$ 26$ to $\$ 156$ (1984 dollars) per cubic foot of interior volume. In light of the facts that only three studies provide estimates of the value of cargo volume, that those that do present estimates are not consistent, ${ }^{20}$ and that cargo space should probably be valued at less than passenger space, a value of $\$ 25$ per cubic foot was chosen as an estimate of the marginal value of cargo space lost to fuel storage.

20 Inconsistent parameter estimates across econometrically estimated vehicle choice models often present a problem. These estimates appear to result from a combination of factors, including the complexity of the vehicle-choice decision and the large number of potential variables, the strong correlations among variables associated with vehicle size and luxury features, and the difficulty of formulating a model that takes into account all factors that are relevant to the diverse population of car buyers.

\section{Calculation of MNL Model Coefficients}

Six AFV attributes are included in computing AFV-specific constants for the MNL model:21

- Initial vehicle cost

- Cost of increased refueling due to range limitations

- Cost of increased refueling time

- Value of performance increases or decreases

- Value of the FFV fuel option

- Value of cargo capacity lost to fuel storage

Seven vehicle types are considered as alternatives to the conventional gas vehicle:

- FFV (using M85, E85, or conventional gasoline)

- CNG bifuel natural gas vehicle (BiFNGV)

- LPG bifuel liquefied petroleum gases (BiFLPG)

- CNG dedicated (NGV)

- LPG dedicated (LPGV)

- Alcohol-flexible (using M85 or E85) (AFFV)

- EV

\section{Parameter Estimation}

Given the monetary values assigned to vehicle attributes parameters of the NMNL, vehicleand fuel-choice equations can be calculated by specifying fuel price slope coefficients for the

\footnotetext{
${ }^{21}$ An additional option that could be included in the future is estimated maintenance and repair costs. These are likely to differ across alternatives, especially between electric and internal combustion engine vehicles.
} 
vehicle-and fuel-choice models. The fuel price slope is estimated by specifying an assumed own price elasticity of demand at a specific market share and initial average vehicle price. It is convenient to use $\mathbf{5 0}$ percent as the initial market share, although any share percentage could be used. Initial elasticity estimates can be based on previous empirical studies of fuel and vehicle-type choice. Given the price slopes, the alternative-fuel intercept terms can be computed by multiplying the sum of fuel attribute values in dollars per barrel by the price slope. The price slope is the coefficient that translates dollars per barrel into the utility measure of the MNL model, $\mathbf{U}_{i}$. Its units must therefore be "utils" per dollar. Multiplying the dollar value of nonvariable attributes by the price slope similarly transforms dollars into the MNL constant term (in utils).

In the multinomial logit model, the elasticity $\left(\beta_{j}\right)$ of market share $\left(s_{j}\right)$ for choice $i=1,2$ with respect to price $(p)$ is

$$
\beta_{i}=b p_{i}\left(1-s_{i}\right) \text {. }
$$

By rearranging, the MNL price slope parameter $b$ can be computed.

$$
b=\frac{\beta_{i}}{p_{i}\left(1-s_{i}\right)} .
$$

Thus, if an arbitrary market share (for example, 50 percent) and base price (for example, $\$ 55$ per bbl) are known or assumed, it is possible to compute $b$ directly from equation (3.11). Given a value for $b$, the MNL model constants, $A_{i}$, can be calculated as the product of $b$ and the sum of option is attribute values $\left(\Sigma_{k} C_{k}\right)$

$$
\mathbf{A}_{i}=b \sum_{k=1}^{n} C_{i k}
$$

Two recent studies of motor-gasoline demand both indicate that the price elasticity of demand for similar motor fuels is very large. In a study of choice among premium leaded, regular leaded, premium unleaded, and regular unleaded gasolines, Greene (1989) estimated price elasticities at 50 percent market share of -15 to -20 , for the years 1982 to 1985 . Using a different data set and estimation method,
Phillips and Schutte (1988) estimated own price elasticities (at the mean values for their sample) for demand for full versus self-service gasoline of -35 to -40 . This evidence suggests that if FFV owners perceive gasoline and alternatives to be much like different grades or service levels of gasoline, demand will be very price elastic. Much lower elasticities of alternative-fuel choice were obtained by Golob et al. (1992) and Bunch et al. (1993) using the California Energy Commission's (CEC) recent stated-preference survey. Using an estimated fuel cost per mile of 8 cents per mile (the average of the choices described to respondents) the elasticity of fuel choice for a multifuel vehicle would be about -3 . This is three times as large as the elasticity of vehicle choice (about -1 at 50 percent share and average price) obtained in the same survey. Thus, the CEC stated-preference survey results tend to confirm the belief that fuel choice is much more elastic than vehicle choice, which is consistent with the nested choice structure used here. The stated preference elasticities, however, are much smaller than those found in revealed preference studies of gasoline grade choice. Two reasons for this difference may be the fact that gasoline grades are more similar than alternative fuels for multifuel vehicles, and that the hypothetical stated choice situation gives greater importance to unobserved attributes. The more dissimilar the fuels are, the lower the own price elasticity should be. Thus, the choice between gasoline and compressed natural gas should be less price elastic than the choice between premium and regular grade gasoline. The derivation of the logit model in Appendix A shows that the variance of the random error term representing unobserved attributes in the MNL model is inversely related to the price elasticity. In a hypothetical choice, stated-preference survey, more is left to the respondent's imagination and so the importance of unobserved attributes is very likely to be exaggerated relative to a real-world choice situation in which the options are familiar.

Numerous studies have estimated the price sensitivity of vehicle-type choice decisions. In nearly all, however, the choice is among passenger cars or light-duty vehicles of all types, large and small, luxury and economy. The AFVC model assumes that consumers are 
choosing among vehicles that are virtually identical, except for characteristics related to alternative fuels. Perhaps the best analogy for this situation comes from a study of the choice of diesel versus gasoline powerplants for specific makes and models of passenger cars over the period 1979 to 1983 (Greene 1986). Estimated price slopes ranged from -0.00029 (for Mercedes) to -0.00205 (Buick). The average price of a passenger car in 1983 was $\$ 10,640$ (1993 dollars ; MVMA 1989, p. 40). Assuming a car price of $\$ 10,000$, a price slope of -0.002 gives an elasticity of -10 . A price slope of -0.0003 and price of $\$ 30,000$ implies an elasticity of -4 at a 50-percent share. These price elasticity estimates are considerably higher than those for choices across all types of vehicles. A survey of a dozen such models chose -0.00056 as a typical price slope, which given a $\$ 10,000$ vehicle price and a 50-percent share results in a price elasticity of -2.8 . The pioneering estimation of a MNL model of vehicle-type choice by Lave and Train (1979) produced a typical price slope of -0.00066 , implying a price elasticity of -3 at 50 percent market share.

The price elasticity of fuel-type choice for multifuel vehicles should be lower than that for choice of grade of gasoline $(-40$ to -20$)$ but two to three times higher than for choice of alternative-fuel vehicle. The price elasticity of AFV choice should be similar to that found by Greene (1986) for diesel engine choice (about -5 to -10$)$, and higher than that in studies that consider choices across all vehicle types (about -3). Based on the available empirical studies, a range of elasticities of -20 to -10 for fuel choice and -5 to -10 for vehicle choice appears to be reasonable, although higher elasticities might be justifiable.

For each multifuel vehicle type (i), a fuel price elasticity $\left(\beta_{j}\right)$ at a specified market share $\left(s_{i}=\right.$ 50 percent) is assumed. Given an initial gasoline price, the fuel price slope $\left(b_{j}\right)$ is computed using the price of gasoline, $\beta_{i}$ and $s_{i}$

$$
b_{l}=\frac{\beta_{l}}{P_{l}\left(1-s_{l}\right)}
$$

In the absence of information to the contrary, the same elasticity is assumed for all multifuel vehicle types although this assumption can be easily changed. The values of nonprice fuelspecific attributes $\left(V_{i j}\right)$ are then summed to obtain an overall hedonic value per gallon of gasoline equivalent. This is converted to barrels by multiplying by 42 . The hedonic value in dollars is converted to a fuel-specific logit coefficient, $A_{i j}$, by multiplying by the respective fuel price slope, $b_{i}$.

\section{Estimation of Inclusive Values for Multifuel and Single-Fuel Vehicles}

In a random utility model such as the NMNL, an option does not have a fixed value but rather a probability distribution of values. As a result, the value of a nested set of options cannot be described simply by the average of the values of its components or even by the value of its most desirable option. ${ }^{22}$ Instead, the ability to choose the highest value option from among those in the nested set gives the set a higher expected value than that of any single choice in the set. The expected cost of a nested choice set is given by equation (C-9), above.

The inclusive value, or expected generalized cost of a nest is passed directly to the respective vehicle-choice equation, where it is added to the generalized cost of the vehicle-specific characteristics and multiplied by the vehicle price coefficient, $\beta$, to yield the generalized cost for the vehicle type (i). For single-fuel vehicles the inclusive value term collapses to the generalized cost of the fuel-specific characteristics for that vehicle type, $c_{i j}=c_{i}$

$$
\begin{aligned}
& c_{i}=\beta\left(u_{i}+\overline{c_{j}}\right) \\
& c_{i}=\beta\left(u_{i}+c_{j j}\right)
\end{aligned}
$$

Vehicle shares may then be computed.

\footnotetext{
22 In the case in which the generalized cost coefficient is very large, the value of the nested choice set will approach the expected value of the single option with the greatest expected value.
} 


\section{IMPLEMENTATION OF THE ALTERNATIVE FUEL AND VEHICLE CHOICE MODEL AS A SPREADSHEET}

The Alternative Fuel and Vehicle Choice (AFVC) model has been implemented in the form of a computer model using the Microsoft Excel spreadsheet software. Seven spreadsheets combined as an Excel Workbook compose the model. The individual worksheets are as follows:

- AFTM and AFVC Scenario

- Calculation of Value of Range and Refueling Time

- Calculation of Performance Values

- Calculation of Value of Lost Cargo Space

- Calculation of Fuel Choice Option Values

- Calculation of AFVC Model Parameters for AFTM

- Macro Spreadsheet to Control Printing and Recalculation

This section describes each spreadsheet and its operation. The sole function of the Macro spreadsheet (7) is to print each of the other six thereby documenting a particular model run. Details of this spreadsheet will therefore not be described here.

\section{AFTM Fuel- and Vehicle-Choice Scenario}

The "Scenario" spreadsheet contains the key assumptions used in the other spreadsheets to value AFV attributes and calculate logit coefficients. Five categories of data are included:

- AFV characteristics

- Vehicle economics

- Vehicle attribute (hedonic) values

- Fuel prices

- Choice elasticity assumptions
The Scenario spreadsheet serves as a convenient, single table in which to enter all the critical numerical assumptions for the AFVC model (Table C-10).

Eight characteristics must be entered for each AFV:

- Relative efficiency (per gallon of gasolineenergy-equivalent)

- Change in vehicle weight (versus CV)

- Change in horsepower

- Fuel storage volume

- Quantity of fuel stored (in customary units, not used)

- Refueling time

- Fuel search time (not used)

- Additional vehicle cost

Relative efficiency is specified as a percent of conventional gasoline vehicle and assumes that efficiency for all vehicle types has been measured on the basis of energy equivalent to 1 gallon of gasoline. Change in weight is the percent increase or decrease versus a conventional vehicle, and change in horsepower is similarly measured. Storage space must be given in gallons and must represent the total volume required by the fuel storage system, which is slightly greater than the volume of fuel stored. Storage in units is the quantity of fuel stored, given in customary units: gallons for liquids, standard cubic feet (SCF) for gases, and kilowatthours (kWh) for electricity. Refueling time is given in minutes and represents only the time spent refueling, not the time spent traveling to or searching for a refueling station. Again, it is assumed that multifuel vehicles must be refueled one fuel at a time. Search time has been included for possible future use but does not enter into any current AFTM scenarios. Additional vehicle cost is the incremental purchase cost of the AFV to the consumer. Note that changes in weight, storage space, and additional cost are vehicle-, 


\section{Table C-10 - AfTM Fuel and Vehicle Choice Scenario}

\begin{tabular}{lr}
\hline Fuel Prices (\$/BGE) & \\
Gasoline & 55.02 \\
Reformulated Gasoline & 58.80 \\
M85 & 55.86 \\
E85 & 75.18 \\
CNG & 55.02 \\
LPG & 49.56 \\
Electric & 107.93 \\
Hedonlc Values (\$) & \\
Value of Cubic Foot of Cargo Space \\
Value of 1\% Change in HPMt. Ratio \\
Value of Hour to Refuel (nonelectric) \\
Value of Hour to Refuel Electric Vehicles \\
Elastlcity Speciflcations (\%) \\
Vehlcle: Base Share \\
Vehicle: Elasticity
\end{tabular}

Fuel: Base Share (\%)

Fuel: Elasticity

$\begin{array}{lc}\text { Vehicle Economics } & \\ \text { Annual Miles } & 11,383 \\ \text { Average MPG } & 21.30 \\ \text { Discount Rate (\%) } & 7.0 \\ \text { Depreciation Rate (\%) } & 15.0 \\ \text { Years of Ownership } & 4 \\ \text { Capital Recovery Factor } & 0.168 \\ \text { Base Vehicle Price (\$) } & 16,700\end{array}$

$\begin{array}{rrrr}25.00 & & & \\ 25.00 & & & \\ 10.00 & & & \\ 1.00 & & & \\ & & & \\ 50 & & & \\ -10.00 & - & \text { LPG } & \text { Alcohol } \\ \text { Flex-Fuel } & \text { CNG } & \text { Bifuel } & \text { Ded. } \\ \text { Vehicle } & \text { Bifuel } & 50 \\ 50 & 50 & 50 & -20.00 \\ -20.00 & -20.00 & -20.00 & -200\end{array}$

\begin{tabular}{|c|c|c|c|c|c|c|c|c|c|}
\hline Vehicle & Fuel & $\begin{array}{l}\text { LHV } \\
\text { Relative } \\
\text { Energy } \\
\text { Efficiency } \\
\text { (percent) }\end{array}$ & $\begin{array}{c}\text { Change } \\
\text { in Vehicle } \\
\text { Weight } \\
\text { (percent) }\end{array}$ & $\begin{array}{l}\text { Change } \\
\text { in } \mathrm{HP} \\
\text { (percent) }\end{array}$ & $\begin{array}{l}\text { Storage } \\
\text { Space } \\
\text { (gallons) }\end{array}$ & $\begin{array}{c}\text { Storage } \\
\text { in Units } \\
\text { (gal, scf, } \\
\text { kWh) }\end{array}$ & $\begin{array}{c}\text { Refueling } \\
\text { Time } \\
\text { (minutes) }\end{array}$ & $\begin{array}{c}\text { Search } \\
\text { Time } \\
\text { (minutes) }\end{array}$ & $\begin{array}{l}\text { Additional } \\
\text { Vehicle } \\
\text { Cost } \\
\text { (\$l } \\
\text { Vehicle) }\end{array}$ \\
\hline Conventional & Gasoline & 100.0 & 0.00 & 0.00 & 15.8 & 15.4 & 6.0 & 0.0 & 0 \\
\hline Flex-Fuel Vehicle & Gasoline & 100.0 & 0.00 & 0.00 & 18.5 & 18.0 & 6.5 & 0.0 & 100 \\
\hline Flex-Fuel Vehicle & M85 & 101.0 & & 3.00 & & 18.0 & 6.5 & 0.0 & \\
\hline Flex-Fuel Vehicle & E85 & 101.0 & & 3.00 & & 18.0 & 6.5 & 0.0 & \\
\hline CNG Bifuel & Gasoline & 97.0 & 4.70 & 0.00 & 51.8 & 15.4 & 6.0 & 0.0 & 817 \\
\hline CNG Bifuel & CNG & 97.0 & & -10.00 & & 650.0 & 7.0 & 0.0 & \\
\hline LPG Bifuel & Gasoline & 98.0 & 3.70 & 0.00 & 37.0 & 15.4 & 6.0 & 0.0 & 625 \\
\hline LPG Bifuel & LPG & 98.0 & & -5.00 & & 20.0 & 6.5 & 0.0 & \\
\hline CNG Dedicated & CNG & 100.0 & 6.50 & 0.00 & 49.9 & $1,300.0$ & 8.0 & 0.0 & 451 \\
\hline LPG Dedicated & LPG & 100.0 & 2.00 & 0.00 & 21.2 & 20.0 & 6.5 & 0.0 & 171 \\
\hline Alcohol Dedicated & M85 & 105.0 & 0.00 & 10.00 & 18.5 & 18.0 & 6.5 & 0.0 & 0 \\
\hline Alcohol Dedicated & E85 & 105.0 & & 10.00 & & 18.0 & 6.5 & 0.0 & \\
\hline Electric & Battery EV & 428.0 & 0.00 & 0.00 & 38.7 & 49.5 & 360.0 & 0.0 & 5,014 \\
\hline
\end{tabular}

but not fuel-specific. All other variables are vehicle- and fuel-specific.

Vehicle economic factors include average annual miles per vehicle, average miles per galIon, and average sales price of a new gasoline vehicle. Three additional variables must be supplied to compute the capital recovery factor: the annual real discount rate, the annual capital depreciation rate for light duty vehicles, and the estimated term of ownership for new car buyers, in years.

Hedonic values, dollar values per unit of vehicle characteristic or per time, must also be specified in the Scenario spreadsheet. The two hedonic parameters required are the value of 1 cubic foot of cargo space and the value of a 
1-percent change in the ratio of horsepower to vehicle weight, a measure of performance.

Two values of time must be entered, one for refueling all but EVs, the other for the time required to recharge EVs.

Price elasticities must be provided for the vehicle- and fuel-choice equations. Elasticities are unitless, representing the ratio of relative (percent) change in market share corresponding to a relative (percent) change in price. As noted above in the theoretical discussion of the AFVC model, the elasticity of fuel-type choice must be greater in absolute value than that of vehicle-type choice. In addition to a base price and elasticity, the market share at which the elasticity applies is required.

Finally, price estimates per barrel of gasolineequivalent must be supplied for each fuel.

These prices are used in the estimation of the value of the fuel-choice option for multifuel vehicles. They should therefore be as close as practical to the final AFTM equilibrium prices for the scenario in question. This should require only one iteration to achieve reasonable convergence (producing a set of AFVC coefficients, entering them in the AFTM, running it and reentering the resulting prices in the AFVC spreadsheet).

\section{Calculation of Value of Range and Refueling Time}

This spreadsheet estimates the cost of additional time spent refueling alternative-fuel vehicles. The total change in refueling time comprises two components: more frequent refueling (range) and greater time required per refueling. The two are computed in terms of dollars per barrel of gasoline-equivalent and added to produce the range and refueling time cost.

The "Refueling" spreadsheet carries forward average annual miles traveled and average miles per gallon from the Scenario spreadsheet. In addition, it brings forward fuel storage capacity, in customary units; relative fuel efficiency; station time per refueling event; and the value of time spent refueling. The energy content of a customary unit of fuel must be specified by the user in this spreadsheet (Table C-11).

The first step is calculation of the range per refill for each fuel type. This is by definition either the range on a full tank, minus a 90-mile reserve for liquid fuels; 95 percent of the full range for bifuel gaseous fuels; or 75 percent of the maximum range for battery-electric vehicles. First, storage in customary units is converted to storage in million Btu by multiplying tank size, $Q_{i}$, by energy content $B_{i}$. Relative efficiency, $R_{i}$, which is the ratio of AFV mpg of gasoline-equivalent energy to $\mathrm{CV} \mathrm{mpg}$, is multiplied by the ratio of AFV to CV energy storage capacity, and the product is multiplied by CV range to obtain the range for a "full tank," $M_{i}$.

$$
M_{i}=\frac{B_{i} Q_{i}}{B_{g} Q_{g}} R_{i} M_{g}=\frac{B_{i} Q_{i}}{B_{g} Q_{g}} \frac{(M P G)_{i}}{(M P G)_{g}} M_{g}
$$

Range per refill $\left(M_{i}\right)$ is simply $M_{i}-90$ for liquid fuels, $0.95 M_{i}$ for gaseous bifuel vehicles, and $0.75 M_{i}$ for EVs.

The cost per barrel of gasoline-equivalent energy is computed as follows. Average annual miles, $A$, is divided by range per refill to obtain the average number of refills per year. This is multiplied by the estimated station time (converted to hours) required per refill (plus the search time which is assumed to be zero in all cases), times the average value of time, $W$, to obtain the total annual time cost of refueling, $T_{i}$.

$$
T_{i}=\frac{A}{m_{i}}\left(\frac{T_{l}}{60}\right) W
$$

The annual refueling time cost is $T_{j}$, divided by the annual fuel consumption in barrels of gasoline to obtain refueling time cost per barrel of gasoline energy service equivalent. The incremental refueling cost per barrel is simply the alternative-fuel refueling cost per barrel minus the gasoline refueling cost. 
Table C-11 - Calculation of Value of Range and Refueling Time

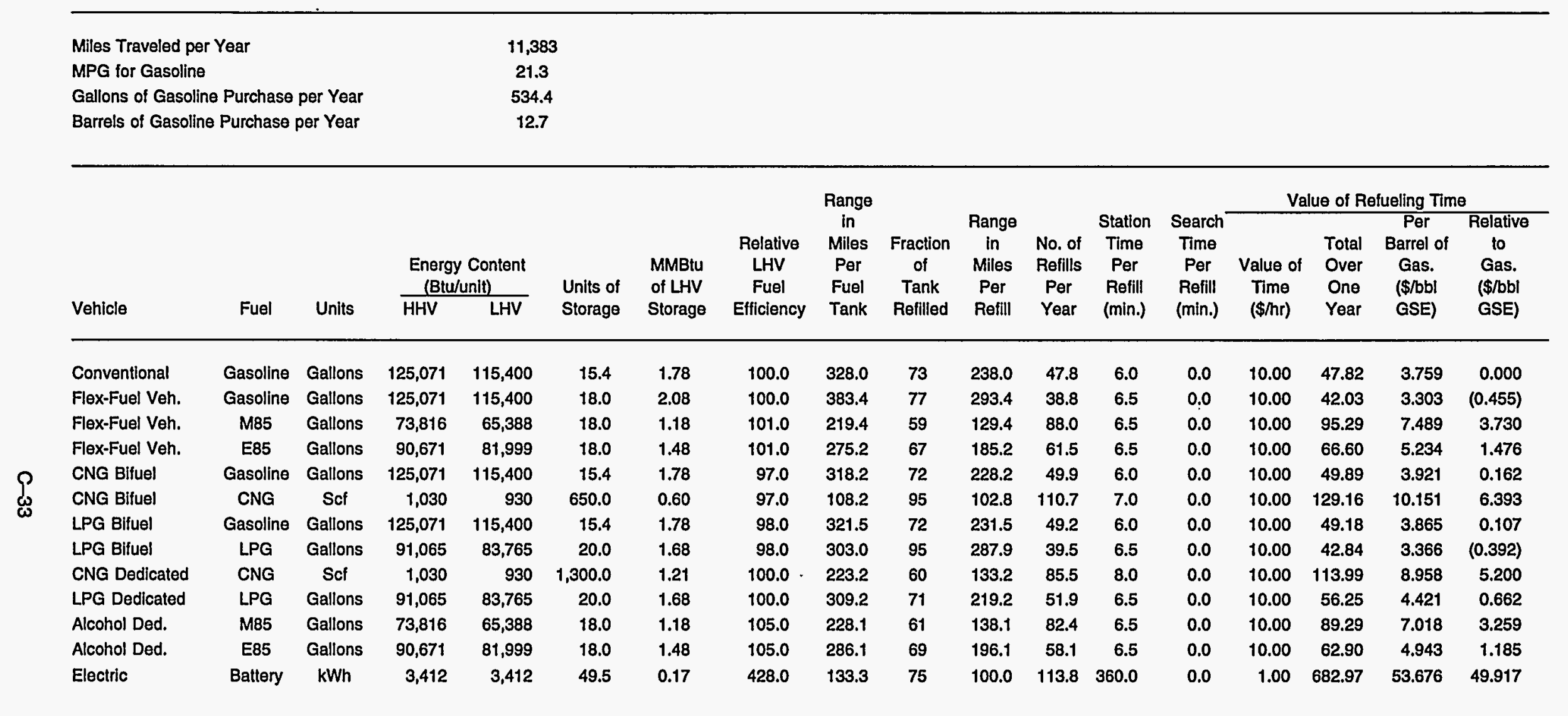

Notes: Refills assumed to take place with 90 mlles of fuel remaining, except for bifuel CNG, bifuel LPG, and electric. Neat methanol has 2.626 MMBtu per barrel or 62,534 Btu per gallon higher heating value. Lower healing value (LHV) is 65,386 Btu/gallon. 


$$
\Delta t_{i}=\frac{t_{i}-t_{g}}{G} .
$$

\section{Calculation of Lost Cargo Space Value}

In general, alternative-fuel vehicles will require more volume for energy storage than a conventional gasoline-powered vehicle. In this spreadsheet, assumptions about the onboard storage requirements of AFVs are translated into an equivalent loss of cargo space, and the lost cargo space is translated into a dollar charge per barrel of gasoline-equivalent energy service.

Four data are passed from the Scenario spreadsheet to the "Cargo" spreadsheet (Table C-12):
- The average dollar value of 1 cubic foot of cargo space $(C)$

- The annual capital recovery factor $(R)$

- The average annual gasoline consumption (G)

- Fuel storage volumes, in gallons $\left(V_{i}\right)$

The value of cargo space lost to fuel storage is computed as follows. First the fuel storage volume required for gasoline is subtracted from the alternative-fuel storage volume $V_{i}$ to obtain an estimate of gallons of cargo space lost. ${ }^{23}$ Gallons are converted to cubic feet by dividing

23 In general, the total volume required for a fuel storage system will be somewhat greater than the volume of fuel stored.

\section{Table C-12 - Calculation of Value of Lost Cargo Space}

$\begin{array}{lc}\text { Value of Cubic Foot of Cargo Space (\$) } & 25.00 \\ \text { Annual Capital Recovery Factor } & 0.168 \\ \text { Gasoline Gallons per Year } & 534\end{array}$

\begin{tabular}{|c|c|c|c|c|c|c|c|}
\hline \multirow[b]{2}{*}{ Vehicle } & \multirow[b]{2}{*}{ Fuel } & \multicolumn{3}{|c|}{ Fuel Storage Space } & \multicolumn{3}{|c|}{ Cost (Benefit) of Change } \\
\hline & & In Gallons & $\begin{array}{l}\text { Relative to } \\
\text { Gasoline } \\
\text { in Gallons }\end{array}$ & $\begin{array}{c}\text { Relative } \\
\text { to Gasoline } \\
\text { in Cu. Ft. }\end{array}$ & $\begin{array}{c}\text { Value of } \\
\text { a New } \\
\text { Vehicle (\$) }\end{array}$ & (\$/gal. GSE) & (\$/BGSE) \\
\hline Conventional & Gasoline & 15.8 & 0.0 & 0.0 & 0 & 0.000 & 0.000 \\
\hline FFV & Gasoline & 18.5 & 2.7 & 0.4 & 9 & 0.003 & 0.120 \\
\hline FFV & M85 & 18.5 & 2.7 & 0.4 & 9 & 0.003 & 0.120 \\
\hline FFV & E85 & 18.5 & 2.7 & 0.4 & 9 & 0.003 & 0.120 \\
\hline CNG Bifuel & Gasoline & 51.8 & 36.0 & 4.9 & 122 & 0.038 & 1.603 \\
\hline CNG Bifuel & CNG & 51.8 & 36.0 & 4.9 & 122 & 0.038 & 1.603 \\
\hline LPG Bifuel & Gasoline & 37.0 & 21.2 & 2.9 & 72 & 0.022 & 0.944 \\
\hline LPG Bifuel & LPG & 37.0 & 21.2 & 2.9 & 72 & 0.022 & 0.944 \\
\hline CNG Dedicated & CNG & 49.9 & 34.1 & 4.6 & 115 & 0.036 & 1.519 \\
\hline LPG Dedicated & LPG & 21.2 & 5.4 & 0.7 & 18 & 0.006 & 0.240 \\
\hline AFV & M85 & 18.5 & 2.7 & 0.4 & 9 & 0.003 & 0.120 \\
\hline AFV & E85 & 18.5 & 2.7 & 0.4 & 9 & 0.003 & 0.120 \\
\hline Electric & Battery EV & 38.7 & 22.9 & 3.1 & 77 & 0.024 & 1.020 \\
\hline
\end{tabular}

Note: Each gallon represents 7.4 cubic feet of space. 
by 7.4. Cubic feet of cargo space lost is multiplied by the assumed dollar value per cubic foot, $C$, to obtain the present value (or vehicle price-equivalent value) of lost cargo space.

This is converted to a capital charge per barrel by multiplying by the capital charge rate, dividing by the average annual fuel consumption in gallons, and multiplying by the number of gallons per barrel (42). The complete equation for the value of lost cargo space per barrel of gasoline-equivalent energy service is

$$
P_{\text {cargo }}=\frac{42 C R}{G}\left(\frac{V_{i}-V_{a}}{7.4}\right) \text {. }
$$

\section{Calculation of Performance Value}

In this spreadsheet, changes in performance (expressed as percent changes in the ratio of horsepower to weight) are translated into dollar charges per barrel of gasoline-equivalent energy service. Although some causes of performance changes, such as the additional weight of storage tanks on a bifuel vehicle, are inherent to the vehicle regardless of the fuel used, all performance changes are treated as fuel-specific. It is a characteristic of the nested MNL model that costs that are common to all the fuels that an AFV can use will not affect the choice of fuel for that vehicle type but will affect the decision to choose that vehicle type. This can be seen from the definition of average general cost, $c_{i}$, in equation (C-9) above. If we assume that a component, $K_{i}$, of the costs of fuels for vehicle type $i$ is common to the vehicle and does not vary over fuel type $(j)$, the average generalized fuel cost can be written as

$$
\begin{aligned}
\overline{c_{l}} & =\frac{1}{\mu_{i}} \ln \sum_{j=i}^{N_{l}} \exp \left(\mu_{i} C_{l}+\mu_{i} K_{i}\right) \\
& =\frac{1}{\mu_{i}} \ln \exp \left(\mu_{i} K_{i}\right) \sum_{j=i}^{N_{i}} \exp \left(\mu_{i} C_{i j}\right) \\
& =K_{i}+\frac{1}{\mu_{i}} \ln \sum_{j=i} \exp \left(\mu_{i} C_{i j}\right) .
\end{aligned}
$$

Thus the common cost component, $K_{i}$, carries through to the vehicle-choice equation but will "cancel out" of the fuel-choice equation. Thus, all performance costs can be treated as if they were fuel costs without affecting the AFVC model at all.

The "Performance" spreadsheet obtains several data from the Scenario spreadsheet

(Table C-13):

- The value of a 1-percent change in horsepower (HP) per weight

- The annual capital recovery factor

- The average annual gasoline service equivalent consumption, in gallons

- The percent change in vehicle weight

- The percent change in horsepower by vehicle and fuel type

The percent change in HP per weight, $\Delta h$, is computed from the percent change in $\mathrm{HP}, \Delta H$, and weight, $\Delta W$, as follows:

$$
\Delta h_{i}=\frac{1+\Delta H_{i}}{1+\Delta W_{i}}-1 .
$$

Note that the variables are actually fractional rather than percent changes although they are displayed in the spreadsheet in percent format.

The values of the $\Delta h_{i}$ are computed by multiplying times the value of a 1-percent change in horsepower per weight and again times 100 . This gives the value in vehicle purchase price equivalent dollars. This is divided by average annual consumption, in gallons, and multiplied by 42 to derive the cost per barrel of gasolineequivalent energy service.

\section{Alternative-Fuels Option Value Calculation}

This spreadsheet estimates the expected value of the option an AFV owner has of buying the cheapest fuel as fuel prices fluctuate over time. It is this spreadsheet that requires a set of prices for all fuels that is reasonably close to the final solution set produced by a 
Value of Cubic Foot of Cargo Space (\$) Annual Capital Recovery Factor Gasoline Gallons per Year
25.00

0.168

534

\begin{tabular}{|c|c|c|c|c|c|c|c|}
\hline \multirow[b]{2}{*}{ Vehicle } & \multirow[b]{2}{*}{ Fuel } & \multirow[b]{2}{*}{$\begin{array}{c}\text { Change } \\
\text { in Vehicle } \\
\text { Weight }\end{array}$} & \multirow[b]{2}{*}{$\begin{array}{c}\text { Change } \\
\text { in } \mathrm{HP}\end{array}$} & \multirow[b]{2}{*}{$\begin{array}{c}\text { Change } \\
\text { in HPNWt } \\
\text { Ratio }\end{array}$} & \multicolumn{3}{|c|}{ Cost (Benefit) of Change } \\
\hline & & & & & $\begin{array}{c}\text { Value of } \\
\text { a New } \\
\text { Vehicle (\$) }\end{array}$ & (\$/gal. GSE) & (\$/BGSE) \\
\hline Conventional & Gasoline & 0.00 & 0.00 & 0.00 & 0 & 0.000 & 0.000 \\
\hline FFV & Gasoline & 0.00 & 0.00 & 0.00 & 0 & 0.000 & 0.000 \\
\hline FFV & M85 & 0.00 & 3.00 & 3.00 & (75) & $(0.024)$ & $(0.989)$ \\
\hline FFV & E85 & 0.00 & 3.00 & 3.00 & (75) & $(0.024)$ & $(0.989)$ \\
\hline CNG Bifuel & Gasoline & 4.70 & 0.00 & -4.49 & 112 & 0.035 & 1.479 \\
\hline CNG Bifuel & CNG & 4.70 & -10.00 & -14.04 & 351 & 0.110 & 4.627 \\
\hline LPG Bifuel & Gasoline & 3.70 & 0.00 & -3.57 & 89 & 0.028 & 1.176 \\
\hline LPG Bifuel & LPG & 3.70 & -5.00 & -8.39 & 210 & 0.066 & 2.765 \\
\hline CNG Dedicated & CNG & 6.50 & 0.00 & -6.10 & 153 & 0.048 & 2.011 \\
\hline LPG Dedicated & LPG & 2.00 & 0.00 & -1.96 & 49 & 0.015 & 0.646 \\
\hline AFV & M85 & 0.00 & 10.00 & 10.00 & $(250)$ & $(0.078)$ & (3.296) \\
\hline AFV & E85 & 0.00 & 10.00 & 10.00 & $(250)$ & $(0.078)$ & (3.296) \\
\hline Electric & Battery EV & 0.00 & 0.00 & 0.00 & 0 & 0.000 & 0.000 \\
\hline
\end{tabular}

Note: Each gallon represents 7.4 cubic feet of space.

given AFTM scenario. The "Option" spreadsheet uses the prices per barrel of gasolineequivalent energy service entered in the Scenario spreadsheet. It also checks the "Shares" spreadsheet to see if the type of conventional gasoline assumed is reformulated, or not. Finally, the user is required to enter the parameters of a bivariate normal distribution of prices for two hypothetical fuels:

- Mean fuel prices for the two fuels (values entered do not affect the calculation of option values).

- Standard deviations of fuel prices as a fraction of the respective mean (these do matter).
- The correlation coefficient for fuel prices (this also matters).

Using the bivariate normal distribution parameters the spreadsheet completes three tables:

- Bivariate normal probability densities

- The table of expected savings on fuel 1

- The table of expected savings on fuel 2

The expected savings in the two tables are summed, added to the difference of mean prices, and the total is divided by two to obtain the option value [according to equation (C-8) above]. Because this value is in gallons, it is multiplied by 42 to give the per barrel value. 
A "what-if" table is used to compute option values for each relevant pair of fuels. The actual per barrel prices form the margins of the table and are correspondingly used as the mean prices for computing option values. This is why the mean prices initially entered do not matter, they are simply placeholders for the actual fuel price pairs. Unless the prices used in the "what-if" table are reasonably close to the final AFTM equilibrium prices, the estimated option values will not be accurate. Experience shows, however, that a single iteration is sufficient to achieve pennies per barrel accuracy because option values do not greatly influence market equilibrium prices. Thus, one may run a new AFTM scenario with MNL coefficients computed without option values or with option values computed with a previous scenario's prices, obtain a new set of market prices, substitute these into the AFVC Scenario spreadsheet, recompute MNL coefficients and then complete the final AFTM run with the second generation coefficients. No further iteration is likely to be necessary to achieve price convergence of 1 to 2 cents per barrel.

\section{Vehicle- and Fuel-Choice Market Shares Calculation}

This final spreadsheet in the workbook calculates the AFVC choice model parameters and produces preliminary estimates of market shares (Tables $\mathrm{C}-14$ and $\mathrm{C}-15$ ). Only the model coefficients are passed to the AFTM; the shares estimates are computed for the purpose of checking for errors and for sensitivity analyses of key parameters. The only new item of data entered in the "Shares" spreadsheet is a designation of whether reformulated or conventional gasoline is the default fuel.

First the generalized cost coefficients $\left(\beta, \mu_{i}\right)$ are computed using information contained in the Scenario spreadsheet. The vehicle choice coefficient is calculated by dividing the price elasticity by the product of the base price and 1 minus the corresponding market share. Base price is expressed in dollars per barrel of gasoline-equivalent energy service and comprises vehicle purchase cost, fuel cost, and hedonic costs. The elasticity must therefore be the market share elasticity of generalized cost rather than the elasticity of vehicle purchase cost. The generalized cost elasticity will always be greater (in absolute value) than the purchase price elasticity in proportion to the ratio of generalized cost to vehicle price. Here, generalized cost exceeds vehicle purchase price by about 25 percent. Thus if the vehicle price elasticity were -8 , the generalized cost elasticity would be about -10 . The generalized cost coefficient for fuel shares $\left(\mu_{i}\right)$ is directly computed by dividing the specified elasticity by the gasoline service equivalent fuel price times 1 minus the corresponding market share. In this version of the spreadsheet only a single, common $\mu$ is computed, although it is not necessary in theory that $\mu_{i}=\mu$ for all $i$ multifuel vehicle types. A single $\mu$ is used here because of the lack of information about how elasticity may vary by type of AFV.

The remainder of the spreadsheet consists of two tables. In the larger table, fuel prices and hedonic values from the other spreadsheets are displayed and used to compute MNL model intercept terms for fuels and vehicles and preliminary market shares for fuels and vehicles. In the second table, fuel prices and hedonic values are displayed in terms of cents per mile. These are computed by dividing the hedonic costs in dollars per barrel of gasolineequivalent energy service by the average miles per barrel of gasoline. These data are provided solely as a more intuitive measure for checking the dollars per barrel estimates.

Calculation of MNL model constants and market shares begins by converting fuel prices in dollars per barrel of gasoline-equivalent energy to dollars per barrel of gasoline-equivalent energy service by dividing by relative fuel efficiency (this adjusted price is needed only for computing preliminary market shares). Next hedonic values for refueling time, performance, cargo space, and multifuel option value are extracted from their respective spreadsheets and summed to give total hedonic costs. Additional vehicle purchase cost is extracted from the Scenario spreadsheet and converted from capital cost to a charge per barrel of gasolineequivalent energy service in the usual way. These two are summed to give total nonfuel price costs. The sum is converted to a MNL fuel choice model constant by dividing by the relevant AFV generalized cost coefficient. 
Table C-14 - AFTM Vehicle- and Fuel-Choice Market Shares-Conventional Gasoline

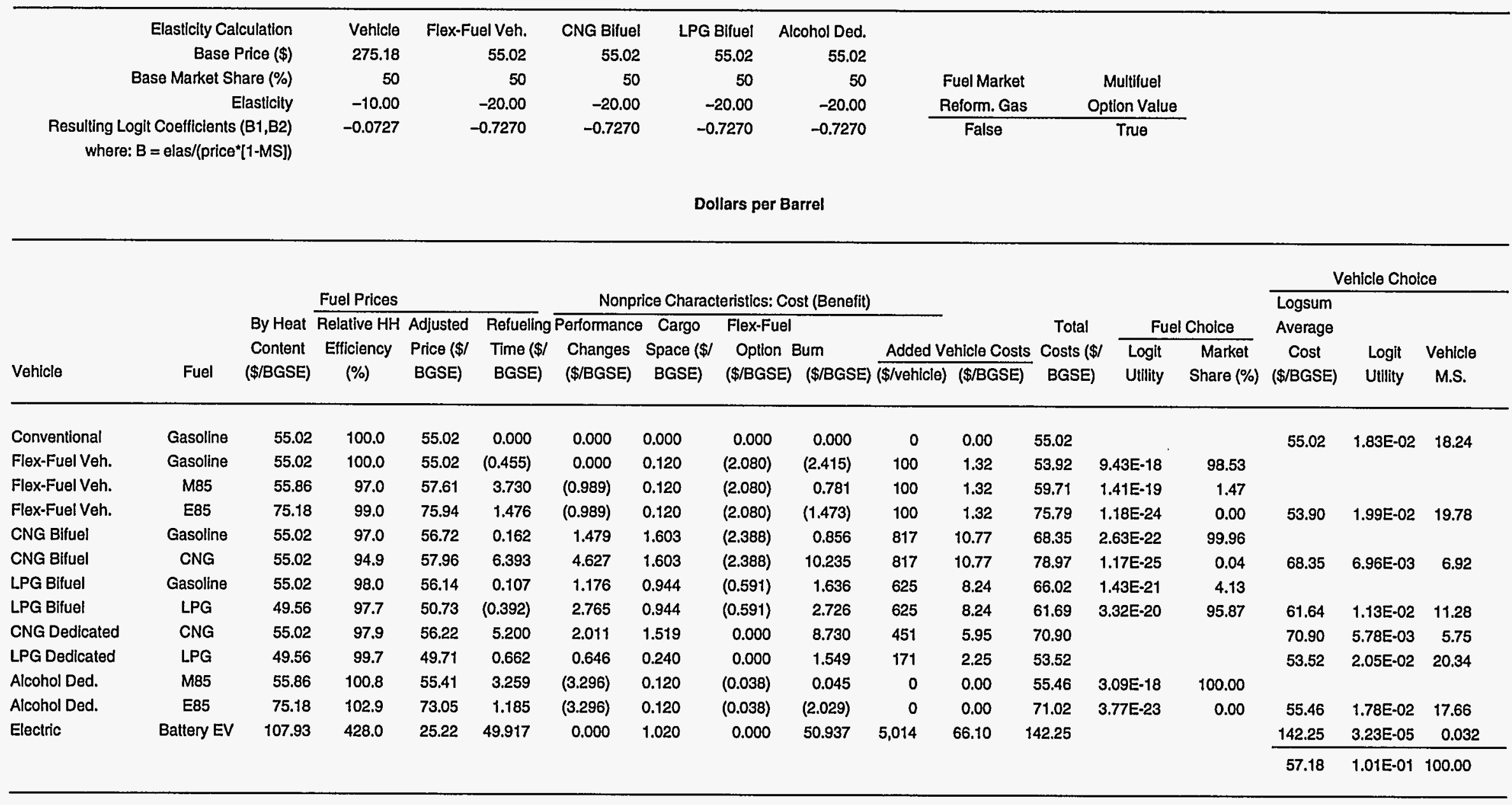


Table C-14 - AFTM Vehicle- and Fuel-Choice Market Shares-Conventional Gasoline (continued)

Cents per Mile

\begin{tabular}{|c|c|c|c|c|c|c|c|c|c|c|c|c|c|}
\hline \multirow[b]{4}{*}{ Vehicle } & \multirow[b]{4}{*}{ Fuel } & \multirow{4}{*}{$\begin{array}{l}\text { By Heat } \\
\text { Content } \\
\text { (\$IBGE) }\end{array}$} & \multicolumn{2}{|l|}{ Fuel Prices } & \multicolumn{5}{|c|}{ Nonprice Characteristics: Cost (Benefit) } & & & \multirow{4}{*}{$\begin{array}{c}\text { Total } \\
\text { Costs } \\
\text { (d/mile) }\end{array}$} & \multirow{4}{*}{$\begin{array}{c}\text { Average } \\
\text { Cost } \\
\text { (c/mile) }\end{array}$} \\
\hline & & & \multirow{3}{*}{$\begin{array}{c}\text { Relative HH } \\
\text { Efficiency } \\
(\%)\end{array}$} & \multirow{3}{*}{$\begin{array}{l}\text { Adjusted } \\
\text { Price } \\
\text { (c/mile) }\end{array}$} & \multicolumn{2}{|c|}{ Refueling Performance } & \multirow{3}{*}{$\begin{array}{l}\text { Cargo } \\
\text { Space } \\
\text { ( } / \text { /mile) }\end{array}$} & \multirow{3}{*}{$\begin{array}{c}\text { Flex Fuel } \\
\text { Option } \\
\text { (\&/mile) }\end{array}$} & \multirow{3}{*}{$\begin{array}{c}\text { Bum } \\
\text { ( } / \text { mile) }\end{array}$} & \multirow{2}{*}{\multicolumn{2}{|c|}{ Vehicie Costs }} & & \\
\hline & & & & & Time & Changes & & & & & & & \\
\hline & & & & & (\$/mile) & $(\& / m i l \theta)$ & & & & (\$lvehicle) & (c/mile) & & \\
\hline Conventional & Gasoline & 55.02 & 100.0 & 6.15 & 0.00 & 0.00 & 0.00 & 0.00 & 0.00 & 0 & 0.00 & 6.15 & 6.15 \\
\hline Flex-Fuel Veh. & Gasoline & 55.02 & 100.0 & 6.15 & .0 .05 & 0.00 & 0.01 & -0.23 & -0.27 & 100 & 0.15 & 6.03 & \\
\hline Flex-Fuel Veh. & M85 & 55.86 & 97.0 & 6.44 & 0.42 & -0.11 & 0.01 & -0.23 & 0.09 & 100 & 0.15 & 6.67 & \\
\hline Flex-Fuel Veh. & E85 & 75.18 & 99.0 & 8.49 & 0.16 & -0.11 & 0.01 & -0.23 & -0.16 & 100 & 0.15 & 8.47 & 6.03 \\
\hline CNG Blfuel & Gasoline & 55.02 & 97.0 & 6.34 & 0.02 & 0.17 & 0.18 & -0.27 & 0.10 & 817 & 1.20 & 7.64 & \\
\hline CNG Bifuel & CNG & 55.02 & 94.9 & 6.48 & 0.71 & 0.52 & 0.18 & -0.27 & 1.14 & 817 & 1.20 & 8.83 & 7.64 \\
\hline LPG Bifuel & Gasoline & 55.02 & 98.0 & 6.28 & 0.01 & 0.13 & 0.11 & -0.07 & 0.18 & 625 & 0.92 & 7.38 & \\
\hline LPG Bifuel & LPG & 49.56 & 97.7 & 5.67 & -0.04 & 0.31 & 0.11 & -0.07 & 0.30 & 625 & 0.92 & 6.90 & 6.89 \\
\hline CNG Dedicated & CNG & 55.02 & 97.9 & 6.28 & 0.58 & 0.22 & 0.17 & 0.00 & 0.98 & 451 & 0.66 & 7.93 & 7.93 \\
\hline LPG Dedicated & LPG & 49.56 & 99.7 & 5.56 & 0.07 & 0.07 & 0.03 & 0.00 & 0.17 & 171 & 0.25 & 5.98 & 5.98 \\
\hline Alcohol Ded. & M85 & 55.86 & 100.8 & 6.19 & 0.36 & -0.37 & 0.01 & 0.00 & 0.01 & 0 & 0.00 & 6.20 & \\
\hline Alcohol Ded. & E85 & 75.18 & 102.9 & 8.17 & 0.13 & -0.37 & 0.01 & 0.00 & -0.23 & 0 & 0.00 & 7.94 & 6.20 \\
\hline Electric & Battery EV & 107.93 & 428.0 & 2.82 & 5.58 & 0.00 & 0.11 & 0.00 & 5.69 & 5,014 & 7.39 & 15.90 & 15.90 \\
\hline & & & & & & & & & & & & & 6.39 \\
\hline
\end{tabular}


Table C-15 - AFTM Vehicle- and Fuel-Choice Market Shares-Reformulated Gasoline

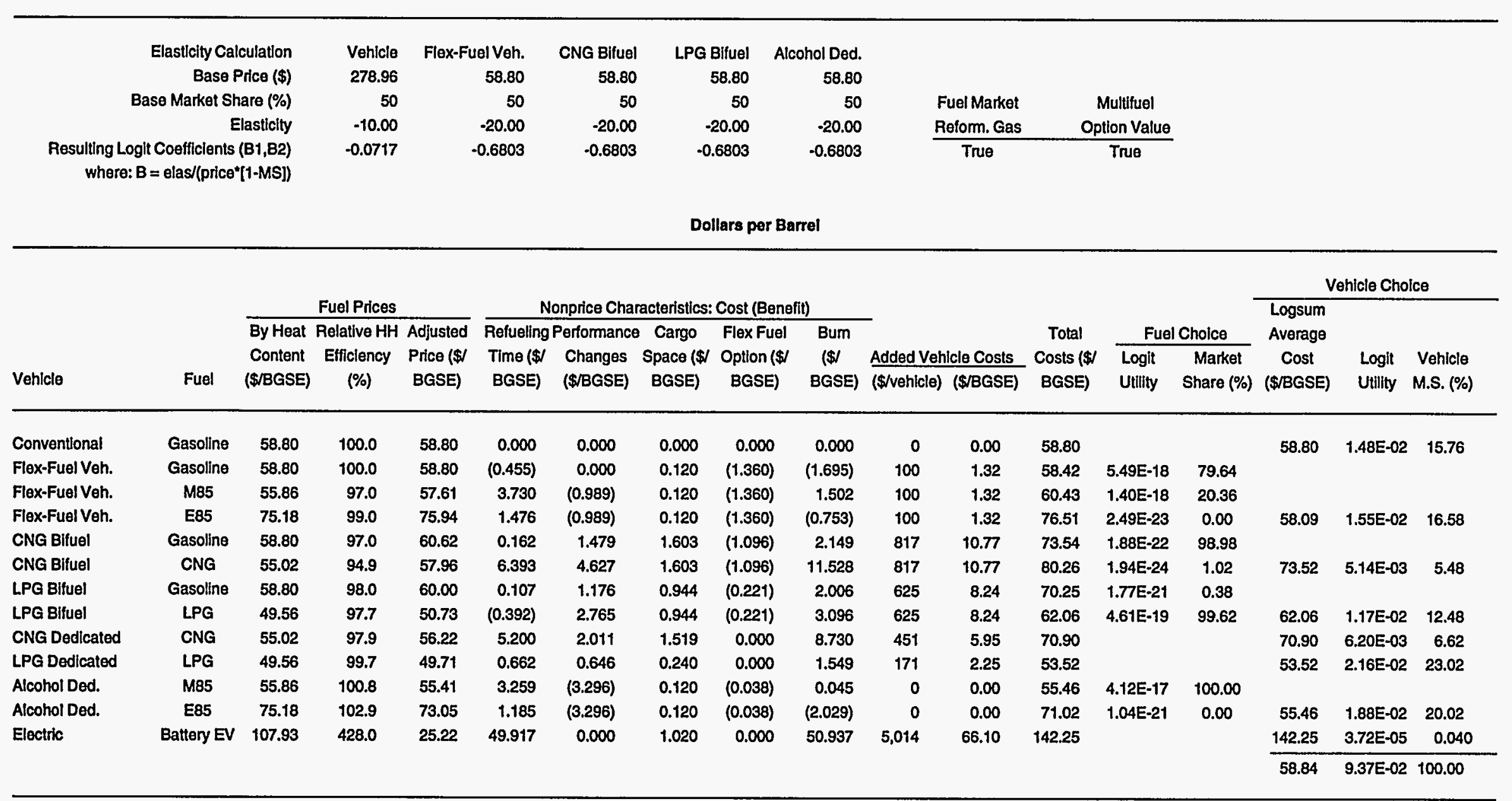


Table C-15 - AFTM Vehicle- and Fuel-Choice Market Shares-Reformulated Gasoline (continued)

Conts per Mile

\begin{tabular}{|c|c|c|c|c|c|c|c|c|c|c|c|c|c|}
\hline \multirow[b]{3}{*}{ Vehicle } & \multirow[b]{3}{*}{ Fuel } & \multicolumn{3}{|c|}{ Fuel Prices } & \multicolumn{5}{|c|}{ Nonprice Characteristics: Cost (Benefit) } & & & \multirow{3}{*}{$\begin{array}{l}\text { Total } \\
\text { Costs } \\
\text { (\&/mile) }\end{array}$} & \multirow{3}{*}{$\begin{array}{c}\text { Average } \\
\text { Cost } \\
\text { (@/mile) }\end{array}$} \\
\hline & & \multirow{2}{*}{$\begin{array}{l}\text { By Heat } \\
\text { Content } \\
\text { (\$BGE) }\end{array}$} & \multirow{2}{*}{$\begin{array}{c}\text { Relative HH } \\
\text { Efficiency } \\
(\%)\end{array}$} & \multirow{2}{*}{$\begin{array}{l}\text { Adjusted } \\
\text { Price } \\
\text { (ब/mile) }\end{array}$} & \multicolumn{2}{|c|}{ Refueling Performance } & \multirow{2}{*}{$\begin{array}{l}\text { Cargo } \\
\text { Space } \\
\text { (c/mile) }\end{array}$} & \multirow{2}{*}{$\begin{array}{c}\text { Flex-Fuel } \\
\text { Option } \\
\text { (\&/mile) }\end{array}$} & \multirow{2}{*}{$\begin{array}{l}\text { Bum } \\
\text { (\&/mile) }\end{array}$} & \multicolumn{2}{|c|}{ Vehicle Costs } & & \\
\hline & & & & & (\&/mile) & (\&/mile) & & & & (\$lvehicle) & (c/mile) & & \\
\hline Conventional & Gasoline & 58.80 & 100.0 & 6.57 & 0.00 & 0.00 & 0.00 & 0.00 & 0.00 & 0 & 0.00 & 6.57 & 6.57 \\
\hline Flex-Fuel Veh. & Gasoline & 58.80 & 100.0 & 6.57 & -0.05 & 0.00 & 0.01 & -0.15 & -0.19 & 100 & 0.15 & 6.53 & \\
\hline Flex-Fuel Veh. & M85 & 55.86 & 97.0 & 6.44 & 0.42 & -0.11 & 0.01 & -0.15 & 0.17 & 100 & 0.15 & 6.75 & \\
\hline Flex-Fuel Veh. & E85 & 75.18 & 99.0 & 8.49 & 0.16 & -0.11 & 0.01 & -0.15 & -0.08 & 100 & 0.15 & 8.55 & 6.49 \\
\hline CNG Blfuel & Gasoline & 58.80 & 97.0 & 6.78 & 0.02 & 0.17 & 0.18 & -0.12 & 0.24 & 817 & 1.20 & 8.22 & \\
\hline CNG Blfuel & CNG & 55.02 & 94.9 & 6.48 & 0.71 & 0.52 & 0.18 & -0.12 & 1.29 & 817 & 1.20 & 8.97 & 8.22 \\
\hline LPG Bifuel & Gasoline & 58.80 & 98.0 & 6.71 & 0.01 & 0.13 & 0.11 & -0.02 & 0.22 & 625 & 0.92 & 7.85 & \\
\hline LPG Bifuel & LPG & 49.56 & 97.7 & 5.67 & -0.04 & 0.31 & 0.11 & -0.02 & 0.35 & 625 & 0.92 & 6.94 & 6.94 \\
\hline CNG Dedicated & CNG & 55.02 & 97.9 & 6.28 & 0.58 & 0.22 & 0.17 & 0.00 & 0.98 & 451 & 0.66 & 7.93 & 7.93 \\
\hline LPG Dedicated & LPG & 49.56 & 99.7 & 5.56 & 0.07 & 0.07 & 0.03 & 0.00 & 0.17 & 171 & 0.25 & 5.98 & 5.98 \\
\hline Alcohol Ded. & M85 & 55.86 & 100.8 & 6.19 & 0.36 & -0.37 & 0.01 & 0.00 & 0.01 & 0 & 0.00 & 6.20 & \\
\hline Alcohol Ded. & E85 & 75.18 & 102.9 & 8.17 & 0.13 & -0.37 & 0.01 & 0.00 & -0.23 & 0 & 0.00 & 7.94 & 6.20 \\
\hline Electric & Battery EV & 107.93 & 428.0 & 2.82 & 5.58 & 0.00 & 0.11 & 0.00 & 5.69 & 5,014 & 7.39 & 15.90 & 15.90 \\
\hline & & & & & & & & & & & & & 6.58 \\
\hline
\end{tabular}


Note that because all vehicle-specific attributes as well as fuel- and vehicle-specific attributes have been included in the fuel- and vehiclespecific constants, there is no need for vehiclespecific constant terms. As shown in the section dealing with performance value, vehiclespecific constants will simply be passed through as costs from the fuel-choice equation to the respective vehicle-choice equation.

The computation of preliminary market shares continues with the calculation of total generalized cost as the sum of fuel and nonfuel costs. For multifuel vehicles this value is converted to utility by multiplying by the respective generalized cost coefficient, and then it is exponentiated.

$$
\exp \left(U_{i j}\right)=\exp \left(\mu_{i} C_{i j}\right)
$$

Market shares for fuel types are then directly computed by the logit equation

$$
s_{i j}=\frac{\exp \left(U_{i j}\right)}{\sum_{j} \exp \left(U_{i j}\right)} .
$$

Vehicle-type utilities are computed for dedicated AFVs by multiplying their total generalized cost times the vehicle choice generalized cost coefficient, $\beta$. For multifuel AFVs, utilities are computed by multiplying the generalized cost coefficient times the logarithm of the sum of the exponentiated utilities of their respective fuel types (the "logsum" term).

$$
\mathbf{U}_{i}=\beta \frac{1}{\mu_{i}} \ln \left(\sum_{j=1}^{N_{i}} \exp \left(\mu_{i} C_{i j}\right)\right) \text {. }
$$

Given all the $\mathbf{U}_{\boldsymbol{i}}$ for dedicated and multifuel AFVs, vehicle-type shares are computed by the logit equation

$$
\mathbf{s}_{i}=\frac{\exp \left(\mathbf{U}_{i}\right)}{\sum_{i} \exp \left(\mathbf{U}_{i}\right)} \text {. }
$$

\section{SENSITIVITY OF AFVC MODEL TO KEY PARAMETERS}

The strategy used in developing the AFVC model has been to construct a theoretical framework for integrating data and assumptions about alternative-fuel vehicles and consumers' valuation of their attributes. One advantage of this approach is that it is amenable to sensitivity analysis. This section explores the sensitivity of the AFVC model's predictions to assumptions about model parameters: elasticities of vehicle- and fuelchoices to generalized cost, and values attached to vehicle attributes and time spent refueling. This report does not explore the sensitivity of model predictions to vehicle characteristics. A common set of fuel prices representative of AFTM projections is assumed throughout, although sensitivity to fuel prices is also illustrated. In addition, a common set of assumptions about vehicle economics (use, mpg, cost, and so forth) is also used (Table C-16). In nearly all comparisons below, alternative fuels are compared to gasoline rather than reformulated gasoline. A comparison at the reformulated gasoline price is included to illustrate the price sensitivity of vehicle and market shares.

The key findings of this sensitivity analysis are that market shares of vehicles and fuels are reasonably stable given even large variations in assumptions about model parameters; that lower elasticities of choice with respect to generalized cost produce a more even distribution of vehicle- and fuel-type shares; the general pattern of market shares is not greatly affected by large variations in hedonic values; and market shares depend strongly on fuel prices. These results suggest that model parameters would have to be radically different from those assumed in the base case to significantly alter the AFTM scenarios.

In the AFVC model, elasticity determines the sensitivity of market shares to generalized costs. As pointed out above in the theoretical discussion of the NMNL model, sensitivity to cost is equivalent to the relative importance of unobserved attributes in the choice decision. Increasing the price elasticity makes market shares more sensitive to the costs of all factors, price and nonprice (hedonic). Thus, ve- 
Table C-16 - Fuel Price and Vehicle Economics

\begin{tabular}{lc|lc}
\hline Fuel Prices (\$/BGE) & & Vehicle Economics \\
\hline Gasoline & 55.02 & Annual Miles & 11,383 \\
Reformulated Gasoline & 58.80 & Average MPG & 21.30 \\
M85 & 55.86 & Discount Rate (\%) & 7 \\
E85 & 75.18 & Depreciation Rate (\%) & 15 \\
CNG & 55.02 & Years of First Ownership & 4 \\
LPG & 49.56 & Capital Recovery Factor & 0.168 \\
Electric & 107.93 & Base Vehicle Price (\$) & 16,700 \\
\hline
\end{tabular}

hicle and fuels with a generalized cost advantage will get even larger market shares and those at a disadvantage will lose market share. Conversely, using lower price elasticities magnifies the importance of unobserved attributes, tending to distribute demand more equally across vehicle and fuel types.

The base case and alternative High and Low elasticity assumptions are shown in Table C-17. All elasticity assumptions are made for a market share of 50 percent for ease of comparison. The base case assumes an elasticity of vehicle type choice of -10 , and fuel type choice elasticities twice as great, -20 . Because the full cost of a vehicle per barrel of gasoline-equivalent energy service is about five times the cost of the fuel, the generalized cost parameter of the vehicle choice equation will be roughly one-fifth as large at equal elasticities and one tenth as great at the elasticity values of the base case. The High and Low elasticity cases not only assume different elasticity values, but vary the fuel-type choice elasticities in a plausible way. The High vehicle choice elasticity is 2.5 times the base case, the Low is 30 percent of the base case value. In both the High and Low cases, the fuel choice elasticity for bifuel CNG vehicles is half of the value for FFVs, that of bifuel LPG vehicles is three-fourths the FFV number, and the elasticity for alcohol-flexible vehicles is 1.5 times the FFV value.

The effects of the three different elasticity assumptions on vehicle-type shares are illustrated in Figure $\mathrm{C}-4$. In the base case, alcohol-fueled vehicles (alcohol FVs), LPG dedicated vehicles, and FFVs have nearly equal market shares at just over 19 percent. Conventional gasoline vehicles are close behind at just over 17 percent, followed by LPG bifuel (11 percent), CNG dedicated and bifuel at about 6 percent each, and battery-electric vehicles at 0.03 of a percent. Increasing the generalized cost elasticities boosts the alcohol FV and FFV shares to 27 percent each or a combined total of about 55 percent. Dedicated LPG and conventional gasoline vehicles also gain slightly to about 22 percent and 19 percent, respectively. All remaining vehicle types account for under 5 percent of the total light-

\section{Table C-17 - Alternative Elasticity Assumptions for Vehicle and Fuel Choices}

\begin{tabular}{lccccc}
\hline Elasticity & & & & & \\
Assumption & Vehicle Choice & FFV & Bifuel CNG & Bifuel LPG & Alcohol FV \\
\hline Base & -10 & -20 & -20 & -20 & -20 \\
High & -25 & -50 & -25 & -37.5 & -75 \\
Low & -3 & -10 & -5 & -7.5 & -15 \\
\hline
\end{tabular}




\section{Figure C-4 - Sensitivity of Vehicle-Type Market Shares to Elasticity Assumptions}

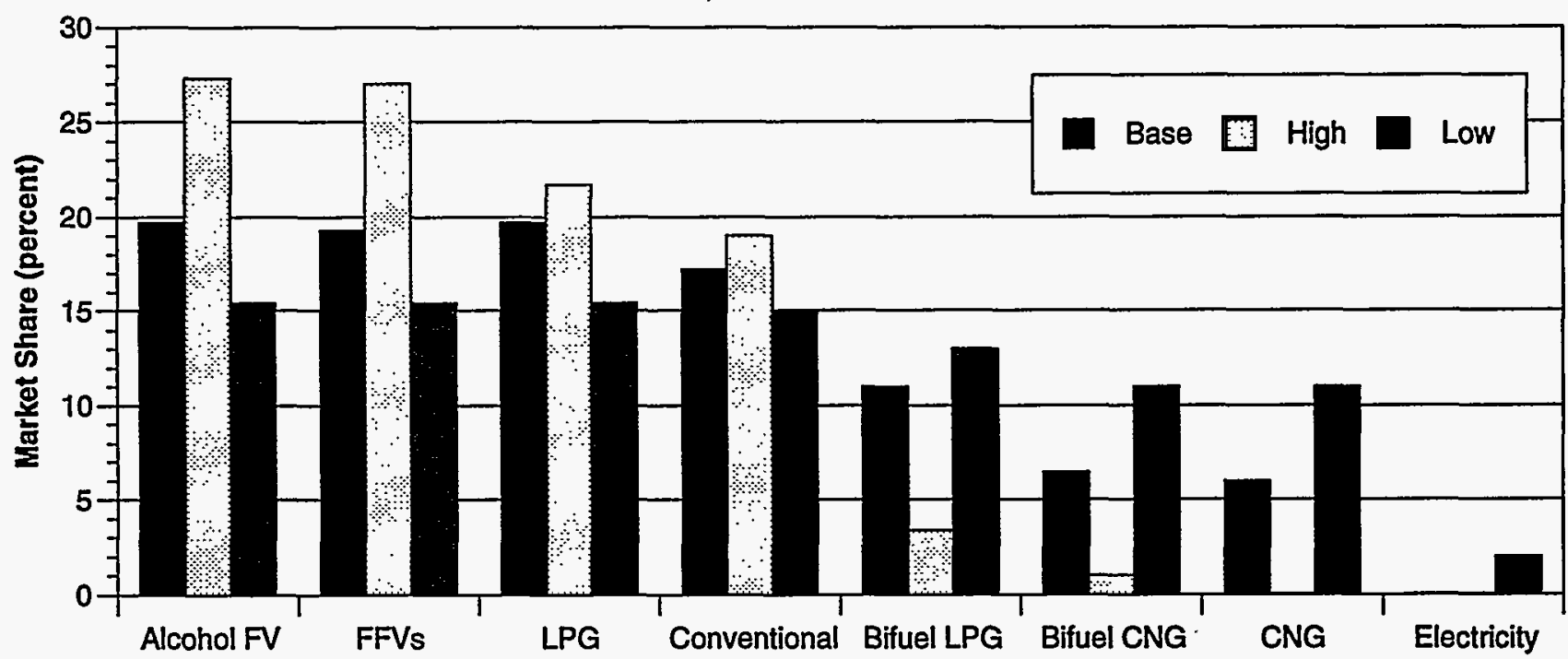

duty vehicle market. Note that M85 is only slightly more expensive than gasoline, according to price assumptions. At essentially equal price, M85 is an attractive fuel AFVC, and vehicles that can use it are also attractive to consumers. FFVs cost little more than conventional vehicles and alcohol-fueled vehicles cost no more, according to assumptions. With slightly improved performance and fuel economy counterbalancing slightly increased refueling costs, it should not be surprising that alcohol-capable vehicles garner a large share of the market. The relative success of dedicated LPG vehicles may seem surprising in light of the relatively small market share captured by other gaseous-fueled vehicles. According to our assumptions, however, dedicated LPG vehicle cost only about $\$ 200$ more than conventional gasoline vehicles, are closest to gasoline vehicles in range, and have equivalent performance and nearly equal fuel economy. On the plus side, LPG costs about 10 percent less than gasoline. It is also interesting to note that while most of the discussion about alternative-fuel vehicles focuses on other fuels, LPG vehicles comprise 90 percent of the alternative-fuel vehicles in use in the United States today (EIA 1994, Tables 3 and 4).

Lowering price elasticities tends to distribute sales more evenly across vehicle types. FFVs, alcohol-fueled vehicles, dedicated LPG, and conventional gasoline vehicles all get 15 percent market shares. This is closely followed by bifuel LPG (13 percent), bifuel CNG (11 percent) and dedicated CNG (11 percent). Only battery-electrics get a significantly smaller share (2 percent). The tendency toward equal shares as elasticity decreases is a property of the multinomial logit model. Low elasticity implies reduced importance of generalized cost versus unobserved attributes. Because unobserved attributes are assumed to be equal across vehicle types, increasing their importance leads to a more equal distribution of market shares.

The alternative elasticity assumptions have a more pronounced effect on the market shares of fuels (Figure C-5). Fuel shares were computed by multiplying fuel shares for multifuel vehicles by the vehicle-type market share and adding up across vehicle types for each fuel type. Thus, the M85 share includes methanol fuel purchased for FFVs and alcohol-fueled vehicles. No attempt was made to attribute the gasoline component of alcohol fuels to gasoline, so that the actual amount of gasoline burned will be understated. In the base case, gasoline accounts for 42 percent of the fuel market, followed by LPG (30 percent) and M85 (22 percent). The reason for gasoline's larger share of the fuel market is that FFVs use gaso- 
Figure C-5 - Sensitivity of Fuel-Type Market Shares to Elasticity Assumptions

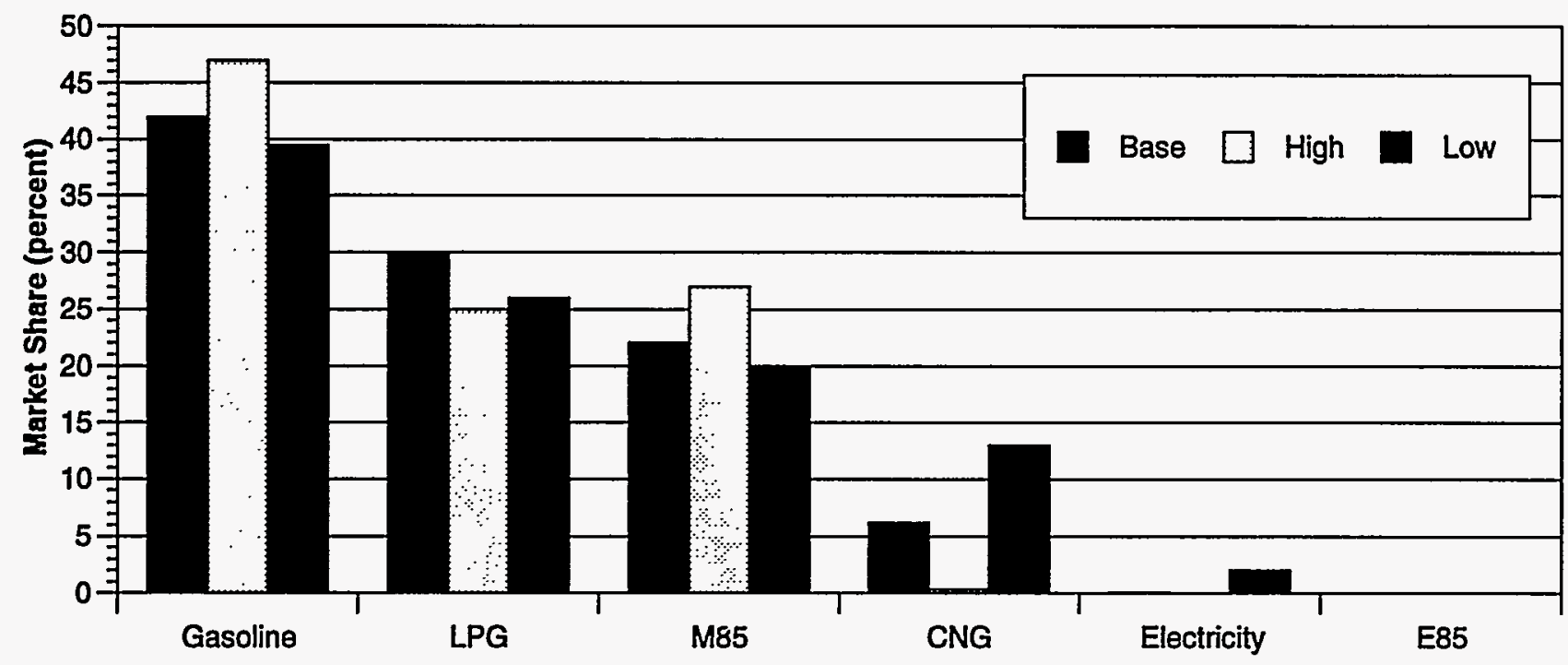

line nearly 90 percent of the time, and CNG bifuel vehicles use it almost all of the time. Although alcohol-fueled vehicles comprise 20 percent of the market, E85 is essentially ignored because of its high price under the assumptions used here. Greater price sensitivity increases gasoline's market share to 47 percent.

M85 also gains but only because alcoholfueled vehicles gain market share. At the higher price elasticity, FFVs choose gasoline all of the time. At lower price elasticities fuel shares tend to be more evenly distributed. Gasoline is still dominant at nearly 40 percent of the market, followed by LPG (26 percent), M85 (20 percent) and CNG (13 percent). Electricity gets the same share as its vehicle market share (2 percent) and even E85 shows up with a nonzero market share (0.01 percent).

Fuel-type market shares are sensitive to fuel price, as can be seen by comparing fuel shares in conventional gasoline versus reformulated gasoline (RFG) regions. Under the price assumptions used here, RFG costs $\$ 3.78$ more per barrel, or $\$ 0.09$ per gallon. Under the base elasticity assumptions, this 9-cent-per-gallon price increase costs gasoline 15 percentage points in market share

(Figure C-6). Gasoline's loss of market share is almost entirely divided between M85 which gains 11 points and LPG, which gains just under 4 percentage points. CNG picks up less than 1 point and electricity and E85 remain unchanged.

The effect of eliminating the option value for multifuel vehicles is also illustrated in Figure $\mathrm{C}-6$. The option value describes the expected benefit to the owner of a multifuel vehicle of being able to buy the least expensive fuel as fuel prices fluctuate. In a static equilibrium model, fuel prices are constant, but in reality they fluctuate and the option value is an attempt to capture the effect on demand for multifuel vehicles. As Figure C-6 illustrates, however, the effect is minimal. Only the market share of gasoline changes by more than 1 percentage point. The effect on vehicle-type market shares (not shown) is also minor, the largest effect being a gain of 2 percent by FFVs.

Finally, the sensitivity of market shares to assumptions about the value of vehicle attributes (hedonic values) was explored. High and Low cases were constructed using the attribute values and time values shown in Table C-18. The High case doubles the value of cargo space, triples the value of performance, increases the value of time spent refueling electric vehicles by a factor of five and doubles the value of time spent refueling other vehicle 


\section{Figure C-6 - Fuel-Type Market Shares Reformulated Gasoline and Option Value}

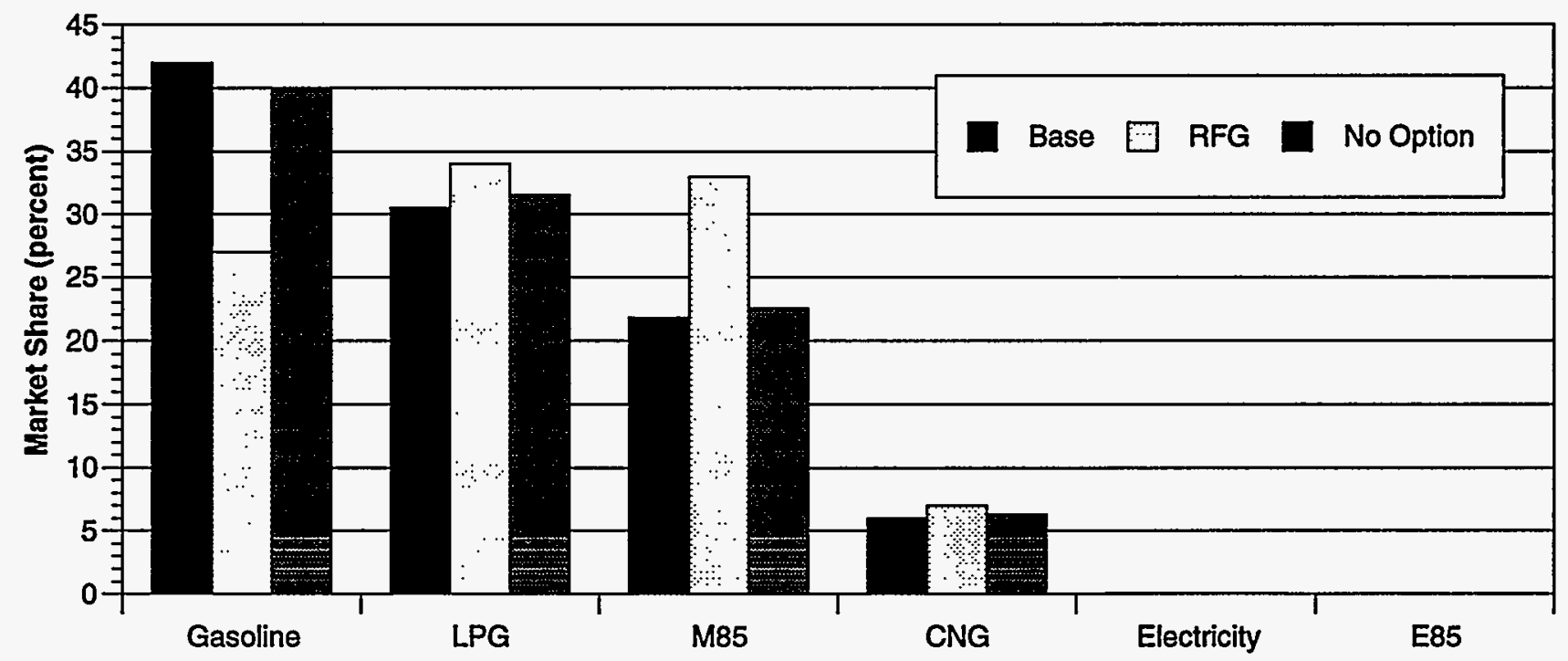

Table C-18 - Alternate Values for Vehicle Aftributes and Refueling Time
(dollars)

\begin{tabular}{lccc}
\hline Factor & Base & High & Low \\
\hline Value of Cubic Foot of Cargo Space & 25.00 & 50.00 & 12.50 \\
Value of 1\% Change in HPW Weight Ratio & 25.00 & 75.00 & 12.50 \\
Value of 1 Hour Refueling & 10.00 & 20.00 & 5.00 \\
Value of 1 Hour Refueling Battery Electric & 1.00 & 5.00 & 0.50 \\
\hline
\end{tabular}

types. The Low case cuts all the base values in half.

The principal effect of increasing the hedonic values of attributes is to shift sales toward alcohol-vehicles, particularly the alcoholflexible vehicle which moves up to 27 percent from 20 percent (Figure $\mathrm{C}-7$ ). The chief reason is its improved performance. Conventional gasoline vehicles also gain slightly. In general, gaseous-fueled vehicles lose because their performance tends to be lower and because of the loss of cargo space to bulkier fuel storage tanks. Cutting hedonic values in half, on the other hand, has relatively small impacts across the board. Alcohol-fueled vehicles, FFVs, and conventional gasoline vehicles each lose about 1 point, dedicated LPG vehicles remain the same and the other three types of gaseousfueled vehicles gain about 1 point. Relatively speaking, the biggest winner is the EV whose share increases from 0.03 percent to 0.19 percent. Apparently the base hedonic value levels, together with the assumed vehicle attributes, make characteristics relatively less important in determining vehicle market shares than purchase prices and fuel prices.

This sensitivity analysis has explored the effects of alternative assumptions about AFVC model parameters in a relatively wide range about the base values. Although the predicted market shares for vehicles and fuels are sensitive to changing parameter values, none of the changes tested here altered the basic structure of market demand for alternative fuels and 
Figure C-7 - Sensitivity of Vehicle-Type Market Shares to Hedonic Values

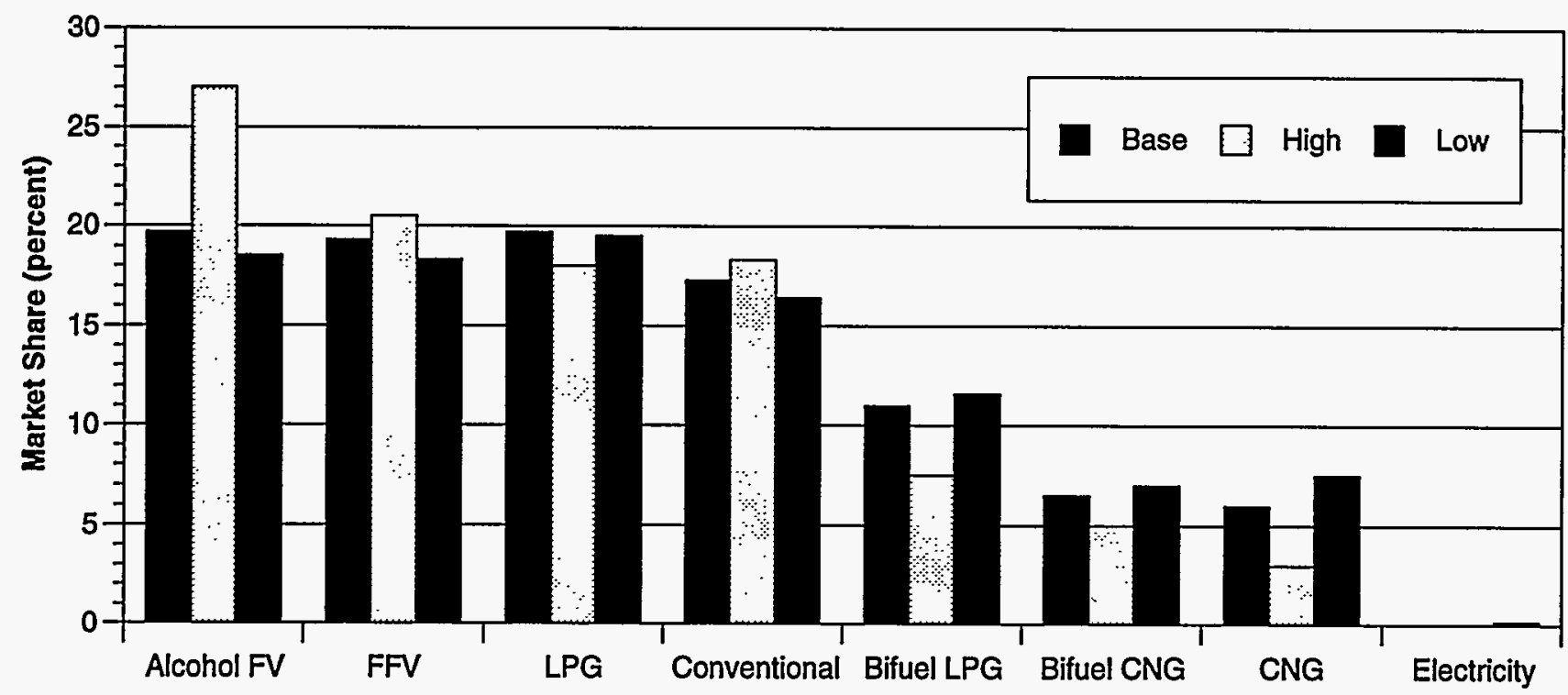

vehicles. That structure is primarily determined by fuel prices together with assumptions about initial vehicle costs and objective vehicle attributes. Increasing elasticities of vehicle and fuel demand did tend to shift demand toward the more successful fuels: alcohol, gasoline, and LPG. Reducing elasticities tends to distribute demand more evenly across all vehicle and fuel options. Increasing the value of performance favors the high-performing alcoholfueled vehicles, and increasing the value of time favors all liquid-fueled vehicles and LPG (which is stored on board in liquid phase). Market shares are sensitive to price, which means that AFVs do substantially better against RFG than conventional gasoline. Although the results of this sensitivity analysis suggest a certain degree of robustness in the AFVC model predictions, ultimately those predictions are entirely dependent on the reasonableness of assumed vehicle characteristics and fuel prices.

\section{REFERENCES}

Amemiya, T. 1985. Advanced Econometrics. Cambridge, Massachusetts: Harvard University Press.

Anderson, S. P., A. De Palma, and J. F. Thisse. 1988. A representative consumer theory of the logit model. International Economic Review 29, no. 3 (August): 461-466.

Bechtold, R. L. 1993a. AFV Differential Costs. Technical memorandum. EA Engineering, Science, and Technology, Inc. (September).

Bechtold, R. L. 1993b. Light Duty Vehicle Queueing Analysis for Alternative-fuel/Gasoline and Conventional Gasoline Refueling Stations. EA Engineering, Science, and Technology, Inc.

Bechtold, R. 1993c. CNG Vehicle Loss of Trunk Volume. Personal communication to D. Greene of Oak Ridge National Laboratory from EA Engineering, Science, and Technology, Inc. 
Beggs, S. D., and N. S. Cardell. 1980. Choice of smallest car by multi-vehicle households and the demand for electric vehicles. Transportation Research A 14A, no. 5-6: 389-404.

Ben-Akiva, M., and S. R. Lerman. 1987. Discrete Choice Analysis: Theory and Applications to Travel Demand. Cambridge, Massachusetts: MIT Press.

Bunch, D. S., M. Bradley, T. F. Golob, R. Kitamura, and G. P. Occhiuzzo. 1993. Demand for cleanfuel vehicles in California: a discrete-choice state preference pilot project. Transportation Research A 27A, no. 3: 237-254.

Charles River Associates, Inc. 1981. The Demand for Electric Automobiles. Project 1145-1 Final Report to Electric Power Research Institute, no. EPRI EA 2072.

Chui, M. K., and W. F. McFarland. 1986. The Value of Travel Time: New Estimates Developed Using a Speed Choice Model. Texas Transportation Institute, The Texas A \& M University System, no. TTI:2-8-84-396-2F (May).

Davis, S. C., and S. G. Strang. 1993. Transportation Energy Data Book: 13, Center for Transportation Analysis, Oak Ridge National Laboratory, no. ORNL-6743.

Delucchi, M. A., Q. Wang, and D. Sperling. 1989. Electric vehicles: performance, life-cycle costs, emissions, and recharging requirements. Transportation Research A 23-A, no. 3 (May): 255-278.

Dougher, R. S., L. A. Hofmann, and T. F. Hogarty. 1990. Analysis of Factors Influencing the Consumption of Premium Motor Gasolines. American Petroleum Institute, Res. Study \#052.

Energy Information Administration (EIA). 1993. Household Vehicles Energy Consumption 1991, no. DOE/EIA-0464(91).

EIA. 1993. Annual Energy Outlook 1993, no. DOE/EIA-0383(93).

EIA. 1994. Alternatives to Traditional Transportation Fuels: An Overview, no. DOE/EIA-0585/O.

Energy and Environmental Analysis, Inc. 1987. Fuel Purchasing Patterns and Vehicle Use Trends From the NPD Research Gasoline Diary Data Base: October 1983-September 1984 Data Display.

Fisk, C. S., and D. Boyce. 1984. A modified composite cost measure for probabilistic choice modeling. Environment and Planning A 16: 241-248.

Golob, T. F., R. Kitamura, D. S. Bunch, M. Bradley, and J. Golob. 1992. Clean Vehicles/Fuels Stated Preference Pilot Study: Final Report. Demand Forecasting Office, California Energy Commission.

Greene, D. L. 1986. The market share of diesel cars in the USA, 1979-83. Energy Economics 8, no. 1 (January): 13-21.

Greene, D. L., and J. T. Liu. 1988. Automotive fuel economy and consumers' surplus. Transportation Research A 22A, no. 3: 203-218.

Greene, D. L. 1989. Motor fuel choice: an econometric analysis. Transportation Research A 23A, no. 3: 243-253. 
Greene, D. L. 1989. Fuel Choice for Dual-Fuel Vehicles: An Analysis of the Canadian Natural Gas Vehicles Survey, no. SAE 892067. In Gaseous Fuels: Technology, Performance, and Emissions, Society of Automotive Engineers.

Johnson, N. L., and S. Kotz. 1970. Continuous Univariate Distributions Volume 1. Boston: Houghton Mifflin \& Company.

Kurani, K. 1993. Fuel Availability, Dual Fuel Vehicles and Learning in New Zealand. Paper presented at the 72nd Annual Meeting of the Transportation Research Board, Washington, DC (January).

Kurani, K. S., and D. Sperling. 1988. Rise and Fall of Diesel Cars: A Consumer Choice Analysis. Transportation Research Record 1175, Transportation Research Board.

Lancaster, K. J. 1966. A new approach to consumer theory. Journal of Political Economy 74, no. 2 (April): 132-157.

Lave, C. A., and K. Train. 1979. A disaggregate model of autotype choice. Transportation Research 13A: 1-9.

Leiby, P. N. 1993. A Methodology for Assessing the Market Benefits of Alternative Motor Fuels. Oak Ridge National Laboratory, no. ORNL-6771.

Leiby, P. N., and D. L. Greene. 1993. Including Sharing Functions in an Optimization Framework: The Multinomial Logit Case. Draft memorandum. Oak Ridge National Laboratory.

Maddala, G. S. 1992. Limited-Dependent and Qualitative Variables in Econometrics, Cambridge: Cambridge University Press.

Manne, A. 1989. Alternative-Fuels Trade Model. Memorandum to the U. S. Department of Energy, Office of Energy Demand Policy, from Alan Manne, Stanford University.

Manski, C. F., and L. Sherman. 1980. An empirical analysis of household choice among motor vehicles. Transportation Research A 14A, nos. 5-6: 349-366.

McCarthy, P. S., and R. Tay. 1989. Consumer valuation of new car attributes: an econometric analysis of the demand for domestic and Japanese/Western European imports. Transportation Research $23 \mathrm{~A}$, no. 5 .

McFadden, D. 1974. Conditional logit analysis of qualitative choice behavior. In Frontiers in Econometrics. P. Zarembka, ed. New York: Academic Press.

McNutt, B. 1993. Memorandum entitled, Alternative-Fuel Vehicle Fuel Economy Estimates. U.S. Department of Energy, Office of Energy Demand Policy (August).

Murrell, J. D. 1980. Passenger Car Fuel Economy: EPA and Road. U.S. Environmental Protection Agency (EPA), Motor Vehicle Emission Lab. no. EPA 460/3-80-010.

Murrell, J. D., K. H. Hellman, and R. M. Heavenrich. 1993. Technical Report: Light-Duty Automotive Technology and Fuel Economy Trends Through 1993. EPA, Emission Control Technology Division, no. EPA/AATDG/93-01.

Phillips, O. R., and D. P. Schutte. 1988. Identifying profitable self-service markets: a test in gasoline retailing. Applied Economics 20: 263-272. 
Setiawan, W., D. Hungerford, and D. Sperling. 1990. Premium Gasoline and Methanol: A Consumer Choice Analysis. Mimeo, Transportation Research Group, University of California at Davis (June).

Society of Automotive Engineers. 1992. Battery and electric vehicle update. Automotive Engineering 100, no. 9 (September): 17-25.

Sperling, D., and K. S. Kurani. 1987. Refueling and the Vehicle Purchase Decision: The Diesel Car Case. Society of Automotive Engineers. no. SAE 870644.

Sperling, D., D. Hungerford, and K. Kurani. 1990. Consumer Demand for Methanol. In Methanol as an Alternative-fuel Choice: An Assessment, W. L. Kohl, ed. School of Advanced International Studies, The Johns Hopkins University.

Train, K. 1980. The potential market for non-gasoline-powered automobiles. Transportation Research A 14A, no. 5-6: 405-414.

Train, K., and M. Lohrer. 1982. Vehicle Ownership and Usage: An Integrated System of Disaggregate Demand Models. Report prepared for the California Energy Commission by Cambridge Systematics, Inc.

Train, K. 1986. Qualitative Choice Analysis. Cambridge, Massachusetts: MIT Press.

U.S. Department of Energy. 1988. Assessment of Costs and Benefits of Flexible and Alternative Fuel Use in the U.S. Transportation Sector, Technical Report 1: Study Objectives and Methodologies, no. DOE/PE-0086.

U.S. Department of Energy. 1990. First Interim Report of the Interagency Commission on Alternative Motor Fuels.

U.S. Department of Energy. 1991. Second Interim Report of the Interagency Commission on Alternative Motor Fuels.

U.S. House of Representatives. Energy Policy Act of 1992, Conference Report 102-1018 to Accompany H. R. 776. Washington, DC: U.S. Government Printing Office.

Wang, Q., D. Sperling, J. Olmstead. 1993. Emission Control Cost-Effectiveness of Alternative-Fuel Vehicles. Institute of Transportation Studies, University of California, Davis.

Williams, H.C.W.L. 1974. On the formation of travel demand models and the evaluation of user benefit. Environment and Planning A 9: 285-344. 


\section{APPENDIX D. ESTIMATES OF GREENHOUSE GAS EMISSIONS FROM ALTERNATIVE TRANSPORTATION FUELS AND INDUSTRIAL FUELS}

\section{INTRODUCTION}

Under Section 502(b) of the Energy Policy Act of 1992 (EPACT), the Department of Energy is required to determine the greenhouse-gas (GHG) emissions implications of increasing the use of replacement fuels, including an estimate of the maximum feasible reduction in such emissions from replacement fuels. The Department is conducting the alternative-fuels feasibility study to address this and other issues. For this study, Argonne National Laboratory (ANL) is responsible for developing the GHG emissions coefficients that apply to various alternative transportation fuels being evaluated in the study. These coefficients are to be used as inputs to the Alternative Fuels Trade Model (AFTM), which in turn will be used to generate total GHG emissions for various scenarios of alternative-fuel use. ANL developed coefficients for replacement fuels and for industrial fuels and delivered the final coefficients in March 1994. This appendix briefly documents the derivation of these coefficients.

\section{GHG EMISSIONS MODEL}

The model used to develop the GHG coefficients was that developed by Mark $A$. Delucchi (Delucchi 1991; Delucchi 1993a; Delucchi 1993b). For each alternative transportation fuel, this model accounts for GHG emissions from vehicle operation, vehicle manufacture, fuel production and distribution, and feedstock recovery and transport (the transportation fuel cycle). The type and amount of energy used at each stage of the fuel cycle is accounted for, as is the type and amount of GHG emissions at each stage.

Delucchi developed a base-case analysis of the GHG emissions of alternative transportation fuels as well as various scenario analy- ses. The base-case estimates presented in his report Emissions of Greenhouse Gases from the Use of Transportation Fuels and Electricity served as the starting point for the analysis in this study (Delucchi 1991; Delucchi 1993a). Delucchi's base case for vehicles compares projected fuel-cycle emissions from alternativefuel vehicles (AFVs) with those from gasoline light-duty vehicles (LDVs) and diesel heavyduty vehicles (HDVs) in the year 2000. All alternatives, except the electric vehicle (EV), are compared with the gasoline vehicle under a condition that represents combined cityhighway driving, assumed to be 30 miles per gallon (mpg). The comparison of the EV with the gasoline vehicle assumes city driving only (24.5 mpg), because EVs will usually not be used for long highway trips. The base-case diesel HDVs get $6 \mathrm{mpg}$. In general, Delucchi assumes that alternative-fuel LDVs are more efficient than gasoline LDVs and that alternative-fuel HDVs are less efficient than diesel HDVs.

For the alternative-fuels feasibility study, Delucchi reviewed and revised his original model. The revisions that he made are described in the annex to this appendix (Delucchi $1993 \mathrm{~b})$. The key revision, according to Delucchi, is his revision of the "Global Warming Potentials" (GWPs) of greenhouse gases. GWPs convert mass emissions of non-carbon dioxide $\left(\mathrm{CO}_{2}\right)$ gases to the mass amount of $\mathrm{CO}_{2}$ with a given GWP over an assumed period of time. In his revision, Delucchi considered recent analyses by the Intergovernmental Panel on Climate Change (IPCC) and Martin and Michaelis (Martin and Michaelis 1992; IPCC 1992). Table D-1 presents the GWPs used for the base case in Delucchi's original analysis and the revised estimates used in this analysis. Delucchi states that this revision results in a greater change from his original analysis of fuel cycle $\mathrm{CO}_{2}$-equivalent emissions than does any other revision made for this alternative-fuels feasibility study. 


\section{Table D-1 - Global Warming Potential of Non- $\mathrm{CO}_{2}$ Greenhouse Gases (100-Year Time Horizon)}

\begin{tabular}{llllrrr}
\hline Source & $\mathrm{CH}_{4}$ & $\mathrm{~N}_{2} \mathrm{O}$ & $\mathrm{CO}$ & $\mathrm{NMHC}$ & $\mathrm{NO}_{2}$ & \multicolumn{2}{c}{ CFC-12 } \\
\hline Delucchi (1991 and 1993a) & 20 & 290 & 3 & 11 & 40 & 7,300 \\
Delucchi (1993b) & 21 & 270 & 2 & 5 & 4 & Not used \\
\hline
\end{tabular}

\section{REVISIONS TO INPUT ASSUMPTIONS FOR ALTERNATIVE TRANSPORTATION FUELS}

The alternative-fuels feasibility study used Delucchi's revised base case, but made several revisions to his assumptions. First, he uses a fuel economy of $30 \mathrm{mpg}$ for LDVs operating on conventional gasoline. This analysis uses the on-road fuel economy of cars and light-duty trucks (LDTs) projected for 2010 by the Energy Information Administration's Annual Energy Outlook 1994 (EIA 1994). This latter fuel-economy estimate is $21.3 \mathrm{mpg}$.

Second, Delucchi's base case assumes that AFVs are more efficient than gasoline vehicles. This analysis assumes no efficiency improvement with AFVs, except EVs. This analysis uses Delucchi's characterization of EVs as described in the model and the revisions in the annex to this appendix (Delucchi 1991; Delucchi 1993a; Delucchi 1993b). However, because that characterization is tied to the characterization of gasoline LDVs, including their fuel economy, and because this analysis has changed the LDV fuel-economy assumption, the EV fuel-cycle emissions generated in this analysis differ from Delucchi's estimates.

Finally, this analysis assumes that the conventional vehicles will all be operating on RFG using sufficient MTBE to achieve 2.1 percent oxygen content. Although a variety of oxygenates will be used in RFG, the $\mathrm{CO}_{2}$-equivalent emissions of the various RFGs are similar; therefore, this analysis uses one for comparison with alternative fuels (Singh 1994).
GHG EMISSIONS COEFFICIENTS FOR ALTERNATIVE TRANSPORTATION FUELS

Tables D-2 and D-3 present the final coefficients derived for the alternative-fuels feasibility study. The AFVs are all assumed to operate 100 percent of the time on alternative fuels. The alcohol fuels are assumed to be 100 percent alcohol (that is, M100 or E100). Subsequent analysis conducted as part of the alternative-fuels feasibility study will revise these assumptions to combine the coefficients for gasoline and methanol or ethanol to generate estimates for M85 and E85 fuels.

Table D-4 presents these same coefficients but in more complete detail. The results in Table D-4 can be compared directly with Delucchi's revised base case, which is shown in Table D-5. Because hydrogen vehicles are not included in the alternative fuels feasibility study, these estimates were not revised.

\section{INDUSTRIAL FUELS}

Table D-6 presents the estimates contained in Delucchi's model for $\mathrm{CO}_{2}$-equivalent emissions of industrial fuels. This analysis made no revisions to these estimates beyond the revisions reported in the annex. 


\section{Table D-2 - Greenhouse Gas Emissions for Light-Duty Vehicles (fuel-cycle $\mathrm{CO}_{2}$-equivalent emissions)}

\begin{tabular}{|c|c|c|c|c|c|c|}
\hline & RFG & Methanol & Ethanol & Natural Gas & LPG & EVs \\
\hline Grams per Mile & 629 & 668 & 776 & 515 & 521 & 499 \\
\hline $\begin{array}{l}\text { Grams per Gallon of } \\
\text { Gasoline-Equivalent }\end{array}$ & 13,404 & 14,233 & 16,531 & 10,968 & 11,101 & 13,614 \\
\hline $\begin{array}{l}\text { Fuel Economy (mpg of } \\
\text { gasoline-equivalent) }\end{array}$ & 21.3 & 21.3 & 21.3 & 21.3 & 21.3 & 27.3 \\
\hline
\end{tabular}

Notes:

1. Excludes CFCs.

2. Btu assumptions (higher heating values): $\mathrm{RFG}=123,700 \mathrm{Btu} / \mathrm{gal}$; methanol $=64,500 \mathrm{Btu} / \mathrm{gal}$; ethanol $=84,600 \mathrm{Btu} / \mathrm{gal}$; natural gas $=1,031.5 \mathrm{Btu} / \mathrm{scf} ; \mathrm{LPG}=92,000 \mathrm{Btu} / \mathrm{gal}$; electricity $=10,400 \mathrm{Btu} / \mathrm{kWh}$.

\section{Table D-3 - Greenhouse Gas Emissions for Heavy-Duty Vehicles (fuel-cycle $\mathrm{CO}_{2}$-equivalent emissions)}

\begin{tabular}{|c|c|c|c|c|c|}
\hline & Diesel & Methanol & Ethanol & Natural Gas & LPG \\
\hline Grams per Mile & 2,268 & 2,537 & 2,968 & 1,898 & 1,948 \\
\hline $\begin{array}{l}\text { Grams per Gallon of } \\
\text { Diesel-Equivalent }\end{array}$ & 13,606 & 15,223 & 17,805 & 11,387 & 11,685 \\
\hline $\begin{array}{l}\text { Fuel Economy (mpg of } \\
\text { diesel-equivalent) }\end{array}$ & 6.0 & 6.0 & 6.0 & 6.0 & 6.0 \\
\hline
\end{tabular}

Notes:

1. Excludes CFCs.

2. Btu assumptions (higher heating values): Diesel $=138,700 \mathrm{Btu} / \mathrm{gal}$; methanol $=64,500 \mathrm{Btu} / \mathrm{gal} ;$ ethanol $=84,600 \mathrm{Btu} /$ gal; natural gas = 1,031.5 Btu/scf; LPG = 92,000 Btu/gal. 

Table D-4 - Final Estimates of Greenhouse Gas Emissions, by Fuel and Słage
(fuel-cycle $\mathrm{CO}_{2}$-equivalent emissions in grams per mile)

\begin{tabular}{|c|c|c|c|c|c|c|c|c|c|c|c|}
\hline Source & Gasoline & Diesel & $\begin{array}{l}\text { MeOH/ } \\
\text { LD }\end{array}$ & $\begin{array}{c}\mathrm{MeOH} / \\
\mathrm{H}\end{array}$ & $\begin{array}{l}\text { NG/ } \\
\text { LD }\end{array}$ & $\begin{array}{l}N G / \\
H D\end{array}$ & EVs & $\begin{array}{c}\mathrm{EtOH} / \\
\text { LD }\end{array}$ & $\begin{array}{c}\text { EtOH/ } \\
\text { HD }\end{array}$ & $\begin{array}{l}\text { LPG/ } \\
\text { LD }\end{array}$ & $\begin{array}{l}\text { LPG/ } \\
\text { HD }\end{array}$ \\
\hline $\begin{array}{l}\text { Vehicle Operation } \\
\text { With Wood Fuels }\end{array}$ & $\stackrel{425.8}{-}$ & $\stackrel{1,736.3}{-}$ & $\begin{array}{r}392.9 \\
21.1\end{array}$ & $\begin{array}{r}1,539.2 \\
63.6\end{array}$ & $\begin{array}{r}348.3 \\
36.9\end{array}$ & $\begin{array}{r}1,349.5 \\
110.1\end{array}$ & $\stackrel{0.0}{-}$ & $\begin{array}{l}21.9 \\
21.9\end{array}$ & $\begin{array}{l}64.2 \\
64.2\end{array}$ & $\stackrel{396.4}{-}$ & $\stackrel{1,554.7}{\longrightarrow}$ \\
\hline \multicolumn{12}{|c|}{ Fuel Production and Distribution } \\
\hline $\begin{array}{l}\text { Compress/Liquefy } \\
\text { With Wood Fuels }\end{array}$ & $\stackrel{0.0}{-}$ & $\stackrel{0.0}{-}$ & $\begin{array}{l}0.0 \\
0.0\end{array}$ & $\begin{array}{l}0.0 \\
0.0\end{array}$ & $\begin{array}{l}29.4 \\
25.4\end{array}$ & $\begin{array}{l}117.1 \\
101.2\end{array}$ & $\stackrel{0.0}{-}$ & $\begin{array}{l}0.0 \\
0.0\end{array}$ & $\begin{array}{l}0.0 \\
0.0\end{array}$ & $\underline{0.0}$ & $\underline{0.0}$ \\
\hline $\begin{array}{l}\text { Fuel Distribution } \\
\text { With Wood Fuels }\end{array}$ & $\underline{8.0}$ & 31.1 & $\begin{array}{l}40.1 \\
25.7\end{array}$ & $\begin{array}{l}159.4 \\
102.3\end{array}$ & $\begin{array}{r}15.1 \\
3.2\end{array}$ & $\begin{array}{l}60.0 \\
12.6\end{array}$ & $\stackrel{4.9}{-}$ & $\begin{array}{l}27.1 \\
19.5\end{array}$ & $\begin{array}{r}107.7 \\
77.8\end{array}$ & $\stackrel{9.4}{-}$ & 37.4 \\
\hline $\begin{array}{l}\text { Fuel Production } \\
\text { With Wood Fuels }\end{array}$ & 88.9 & $\stackrel{143.6}{-}$ & $\begin{array}{r}105.0 \\
43.6\end{array}$ & $\begin{array}{l}417.8 \\
173.7\end{array}$ & $\begin{array}{r}8.3 \\
31.4\end{array}$ & $\begin{array}{r}33.0 \\
124.9\end{array}$ & $\stackrel{386.2}{-}$ & $\begin{array}{r}382.0 \\
-106.0\end{array}$ & $\begin{array}{l}1,520.0 \\
-422.0\end{array}$ & 16.1 & 64.1 \\
\hline $\begin{array}{l}\text { Feedstock Trans. } \\
\text { With Wood Fuels }\end{array}$ & $\underline{11.6}$ & $\begin{array}{l}56.4 \\
-\end{array}$ & $\begin{array}{r}9.0 \\
13.4\end{array}$ & $\begin{array}{l}35.9 \\
53.3\end{array}$ & $\begin{array}{r}0.0 \\
12.0\end{array}$ & $\begin{array}{r}0.0 \\
47.7\end{array}$ & $\stackrel{5.8}{-}$ & $\begin{array}{l}23.2 \\
19.7\end{array}$ & $\begin{array}{l}92.4 \\
78.2\end{array}$ & $\underline{3.6}$ & 14.2 \\
\hline $\begin{array}{l}\text { Feedstock and Fertilize } \\
\text { With Wood Fuels }\end{array}$ & $\underline{13.6}$ & $\underline{65.8}$ & $\begin{array}{l}26.3 \\
38.0\end{array}$ & $\begin{array}{l}104.7 \\
151.1\end{array}$ & $\begin{array}{r}9.7 \\
34.0\end{array}$ & $\begin{array}{r}38.6 \\
135.3\end{array}$ & $\stackrel{7.7}{-}$ & $\begin{array}{r}249.8 \\
40.6\end{array}$ & $\begin{array}{l}994.1 \\
221.9\end{array}$ & $\underline{10.4}$ & $\stackrel{41.4}{-}$ \\
\hline $\begin{array}{l}\mathrm{CH}_{4} \text { Leaks and Flares } \\
\text { With Wood Fuels }\end{array}$ & $\stackrel{9.3}{-}$ & $\underline{45.3}$ & $\begin{array}{r}22.9 \\
0.0\end{array}$ & $\begin{array}{r}91.0 \\
0.0\end{array}$ & $\begin{array}{r}22.9 \\
2.4\end{array}$ & $\begin{array}{r}91.0 \\
9.6\end{array}$ & 16.3 & $\begin{array}{l}0.0 \\
0.0\end{array}$ & $\begin{array}{l}0.0 \\
0.0\end{array}$ & 11.4 & $\underline{45.3}$ \\
\hline $\begin{array}{l}\text { Subtotal } \\
\text { With Wood Fuels }\end{array}$ & 131.4 & $\stackrel{342.2}{-}$ & $\begin{array}{l}203.3 \\
120.7\end{array}$ & $\begin{array}{l}808.8 \\
480.4\end{array}$ & $\begin{array}{r}85.4 \\
106.4\end{array}$ & $\begin{array}{l}339.7 \\
431.2\end{array}$ & $\begin{array}{r}421.0 \\
0.0\end{array}$ & $\begin{array}{l}682.1 \\
-26.2\end{array}$ & $\begin{array}{r}2,714.2 \\
-44.1\end{array}$ & $\begin{array}{r}50.8 \\
0.0\end{array}$ & $\begin{array}{r}202.3 \\
0.0\end{array}$ \\
\hline \multicolumn{12}{|l|}{ Vehicle Manufacture } \\
\hline Assembly & 16.6 & 47.2 & 16.6 & 47.2 & 17.6 & 49.3 & 16.7 & 16.6 & 47.2 & 17.1 & 47.5 \\
\hline Materials & 55.5 & 142.0 & 55.5 & 142.0 & 63.6 & 159.4 & 61.5 & 55.5 & 142.0 & 56.8 & 142.9 \\
\hline Subtotal & 72.1 & 189.1 & 72.1 & 189.1 & 81.2 & 208.7 & 78.2 & 72.1 & 189.1 & 73.9 & 190.4 \\
\hline $\begin{array}{l}\text { Total } \\
\text { With Wood Fuels }\end{array}$ & $\frac{629.3}{-}$ & $\stackrel{2,267.6}{-}$ & $\begin{array}{l}668.2 \\
213.9\end{array}$ & $\begin{array}{r}2,537.1 \\
733.1\end{array}$ & $\begin{array}{l}514.9 \\
226.5\end{array}$ & $\begin{array}{r}1,897.9 \\
750.0\end{array}$ & $\stackrel{499.2}{-}$ & $\begin{array}{r}776.1 \\
67.8\end{array}$ & $\begin{array}{r}2,967.5 \\
209.2\end{array}$ & $\stackrel{521.2}{-}$ & $\underline{1,947.5}$ \\
\hline Btu/Mile & $5,809.0$ & $23,115.0$ & $5,809.0$ & $23,115.0$ & $5,809.0$ & $23,115.0$ & $4,537.0$ & $5,809.0$ & $23,115.0$ & $5,809.0$ & $23,115.0$ \\
\hline $\begin{array}{l}\text { Fuel Economy } \\
\text { (gasoline- or } \\
\text { diesel-equivalent) }\end{array}$ & 21.3 & 6.0 & 21.3 & 6.0 & 21.3 & 6.0 & 27.3 & 21.3 & 6.0 & 21.3 & 6.0 \\
\hline $\begin{array}{l}\text { Grams per Gallon } \\
\text { (gasoline or diesel- } \\
\text { equivalent) }\end{array}$ & $13,404.5$ & $13,605.8$ & $14,233.0$ & $15,222.6$ & $10,967.5$ & $11,387.2$ & $13,613.9$ & $16,530.6$ & $17,805.2$ & $11,101.1$ & $11,684.8$ \\
\hline With Wood Fuels & - & - & $4,556.3$ & $4,398.8$ & $4,823.4$ & $4,499.8$ & - & $1,444.4$ & $1,255.0$ & - & - \\
\hline
\end{tabular}

Notes:

1. Excludes CFCs.

2. "With wood fuels" refers to wood as a feedstock.

3. The first ethanol scenario is ethanol from com.

4. $\mathrm{HD}=$ heavy-duty application (diesel); LD = light-duty application (gasoline).

5. Gasoline, methanol, and ethanol refer to mixtures.

6. Gasoline production emissions include emissions from EtOH and $\mathrm{MeOH}$ manufacture for ETBE and MTBE.

7. Btu assumptions: $\mathrm{RFG}=123,700 \mathrm{Btu} / \mathrm{gal}$; diesel = 138,700; $\mathrm{MeOH}=64,500 \mathrm{Btu} / \mathrm{gal} \mathrm{MeOH} ; \mathrm{EtOH}=84,600 \mathrm{Btu} / \mathrm{gal}$ EtOH; LPG = 92,000 Btu/gal LPG; natural gas $=1,031.5 \mathrm{Btu} / \mathrm{scf}$; electricity $=10,400 \mathrm{Btu} / \mathrm{kWh}$. 
Table D-5 - Delucchi's Revised Base-Case Estimates of Greenhouse Gas Emissions, by Fuel and Stage

(fuel-cycle $\mathrm{CO}_{2}$-equivalent emissions in grams per mile)

\begin{tabular}{|c|c|c|c|c|c|c|c|c|c|c|c|c|c|}
\hline Source & Gasoline & Diesel & $\begin{array}{c}\mathrm{MeOH} / \\
\mathrm{L}\end{array}$ & $\begin{array}{c}\mathrm{MeOH} / \\
\mathrm{H}\end{array}$ & $\begin{array}{l}\text { NG/ } \\
\text { LD }\end{array}$ & $\begin{array}{l}N G / \\
H D\end{array}$ & EVs & $\begin{array}{l}\mathrm{H} 2 / \\
\mathrm{LD}\end{array}$ & $\begin{array}{l}\mathrm{H} 2 \mathrm{~J} \\
\mathrm{HD}\end{array}$ & $\begin{array}{c}\text { EtoHI } \\
\mathrm{L}\end{array}$ & $\begin{array}{c}\text { EtOH/ } \\
\mathrm{H}\end{array}$ & $\begin{array}{l}\text { LPG/ } \\
\text { LD }\end{array}$ & $\begin{array}{l}\text { LPGI } \\
\text { HD }\end{array}$ \\
\hline $\begin{array}{l}\text { Vehicles } \\
\text { With Wood Fuels }\end{array}$ & $\begin{array}{c}311.9 \\
-\end{array}$ & $\begin{array}{c}1,736.3 \\
-\end{array}$ & $\begin{array}{r}253.4 \\
21.1\end{array}$ & $\begin{array}{r}1,585.0 \\
63.8\end{array}$ & $\begin{array}{r}246.6 \\
36.9\end{array}$ & $\begin{array}{r}1,594.2 \\
110.1\end{array}$ & $\frac{0.0}{-}$ & $\stackrel{5.5}{-}$ & $\begin{array}{l}52.9 \\
-\end{array}$ & $\begin{array}{l}21.9 \\
21.9\end{array}$ & $\begin{array}{l}64.3 \\
64.3\end{array}$ & $\begin{array}{c}268.6 \\
-\end{array}$ & $\begin{array}{c}1,820.2 \\
-\end{array}$ \\
\hline $\begin{array}{l}\text { Compress/Liquefy } \\
\text { With Wood Fuels }\end{array}$ & $\underline{0.0}$ & $\begin{array}{l}0.0 \\
-\end{array}$ & $\begin{array}{l}0.0 \\
0.0\end{array}$ & $\begin{array}{l}0.0 \\
0.0\end{array}$ & $\begin{array}{l}19.8 \\
17.1\end{array}$ & $\begin{array}{l}140.2 \\
121.1\end{array}$ & $\underline{0.0}$ & 31.3 & $\begin{array}{c}192.3 \\
-\end{array}$ & $\begin{array}{l}0.0 \\
0.0\end{array}$ & $\begin{array}{l}0.0 \\
0.0\end{array}$ & $\underline{0.0}$ & $\underline{0.0}$ \\
\hline $\begin{array}{l}\text { Fuel Distribution } \\
\text { With Wood Fuels }\end{array}$ & $\stackrel{5.8}{-}^{-}$ & 31.1 & $\begin{array}{l}25.0 \\
16.0\end{array}$ & $\begin{array}{l}164.3 \\
105.5\end{array}$ & $\begin{array}{r}10.1 \\
2.1\end{array}$ & $\begin{array}{l}71.8 \\
15.1\end{array}$ & $\underline{3.7}$ & $\underline{0.4}$ & $\underline{2.5}$ & $\begin{array}{l}17.0 \\
12.3\end{array}$ & $\begin{array}{r}114.6 \\
82.7\end{array}$ & $\frac{6.2}{-}$ & $\frac{44.2}{-}$ \\
\hline $\begin{array}{l}\text { Fuel Production } \\
\text { With Wood Fuels }\end{array}$ & $\underline{63.8}$ & $\stackrel{143.6}{-}$ & $\begin{array}{l}65.5 \\
27.2\end{array}$ & $\begin{array}{l}430.7 \\
179.1\end{array}$ & $\begin{array}{r}5.6 \\
21.1\end{array}$ & $\begin{array}{r}39.5 \\
149.5\end{array}$ & $\stackrel{287.0}{-}$ & $\frac{66.2}{-}$ & $\begin{array}{c}406.6 \\
-\end{array}$ & $\begin{array}{l}240.5 \\
-66.8\end{array}$ & $\begin{array}{l}1,617.1 \\
-448.9\end{array}$ & $\frac{10.6}{-}$ & 75.5 \\
\hline $\begin{array}{l}\text { Feedstock Trans. } \\
\text { With Wood Fuels }\end{array}$ & $\stackrel{8.3}{-}^{-}$ & 56.4 & $\begin{array}{l}5.6 \\
8.4\end{array}$ & $\begin{array}{l}37.0 \\
54.9\end{array}$ & $\begin{array}{l}0.0 \\
8.1\end{array}$ & $\begin{array}{r}0.0 \\
57.2\end{array}$ & $\frac{4.3}{-}$ & $\stackrel{0.14}{-}^{-14}$ & -0.88 & $\begin{array}{l}14.6 \\
12.4\end{array}$ & $\begin{array}{l}96.3 \\
83.2\end{array}$ & 2.4 & $\frac{16.8}{-}$ \\
\hline $\begin{array}{l}\text { Feedstock and Fertiliz } \\
\text { With Wood Fuels }\end{array}$ & izer 9.7 & $\underline{65.8}$ & $\begin{array}{l}16.4 \\
23.7\end{array}$ & $\begin{array}{l}107.9 \\
155.8\end{array}$ & $\begin{array}{r}6.5 \\
22.9\end{array}$ & $\begin{array}{r}46.3 \\
162.0\end{array}$ & $\stackrel{5.8}{-}$ & $\stackrel{4.0}{-}$ & 24.7 & $\begin{array}{r}157.3 \\
25.6\end{array}$ & $\begin{array}{r}1,057.6 \\
236.0\end{array}$ & $\frac{6.9}{-}$ & $\frac{48.7}{-}$ \\
\hline $\begin{array}{l}\mathrm{CH}_{4} \text { Leaks and Flares } \\
\text { With Wood Fuels }\end{array}$ & is 6.7 & 45.3 & $\begin{array}{r}14.3 \\
0.0\end{array}$ & $\begin{array}{r}93.9 \\
0.0\end{array}$ & $\begin{array}{r}15.4 \\
1.6\end{array}$ & $\begin{array}{r}109.0 \\
11.5\end{array}$ & 12.1 & $\stackrel{0.0}{-}$ & $\stackrel{0.0}{-}$ & $\begin{array}{l}0.0 \\
0.0\end{array}$ & $\begin{array}{l}0.0 \\
0.0\end{array}$ & $\begin{array}{l}7.5 \\
-\end{array}$ & 53.3 \\
\hline $\begin{array}{l}\text { Subotal } \\
\text { With Wood Fuels }\end{array}$ & $\stackrel{406.2}{-}$ & $\begin{array}{c}2,078.5 \\
-\end{array}$ & $\begin{array}{r}380.2 \\
96.4\end{array}$ & $\begin{array}{r}2,418.8 \\
559.1\end{array}$ & $\begin{array}{l}304.0 \\
109.8\end{array}$ & $\begin{array}{r}2,001.0 \\
626.5\end{array}$ & $\begin{array}{c}312.9 \\
-\end{array}$ & $\begin{array}{c}107.5 \\
-\end{array}$ & $\begin{array}{c}679.8 \\
-\end{array}$ & $\begin{array}{r}451.3 \\
5.4\end{array}$ & $\begin{array}{r}2,951.8 \\
17.3\end{array}$ & $\stackrel{302.2}{-}$ & $\begin{array}{c}2,058.6 \\
-\end{array}$ \\
\hline $\begin{array}{l}\text { Percent Changes } \\
\text { With Wood Fuels }\end{array}$ & $\overline{-}$ & $\overline{-}$ & $\begin{array}{r}-6.4 \\
-76.3\end{array}$ & $\begin{array}{r}16.4 \\
-73.1\end{array}$ & $\begin{array}{l}-25.1 \\
-73.0\end{array}$ & $\begin{array}{r}-3.7 \\
-69.9\end{array}$ & -23.0 & $\frac{-73.5}{-}$ & -67.3 & $\begin{array}{r}11.1 \\
-98.7\end{array}$ & $\begin{array}{r}42.0 \\
-98.2\end{array}$ & $\begin{array}{l}-25.6 \\
-\end{array}$ & -1.0 \\
\hline $\begin{array}{l}\text { Assembly } \\
\text { Materials }\end{array}$ & $\begin{array}{l}12.4 \\
41.2\end{array}$ & $\begin{array}{r}47.2 \\
142.0\end{array}$ & $\begin{array}{l}12.4 \\
41.2\end{array}$ & $\begin{array}{r}47.2 \\
142.0\end{array}$ & $\begin{array}{l}13.0 \\
46.7\end{array}$ & $\begin{array}{r}49.8 \\
162.9\end{array}$ & $\begin{array}{l}13.4 \\
49.2\end{array}$ & $\begin{array}{l}13.6 \\
53.2\end{array}$ & $\begin{array}{r}55.4 \\
217.6\end{array}$ & $\begin{array}{l}12.4 \\
41.2\end{array}$ & $\begin{array}{r}47.2 \\
142.0\end{array}$ & $\begin{array}{l}12.7 \\
42.1\end{array}$ & $\begin{array}{r}47.6 \\
143.2\end{array}$ \\
\hline $\begin{array}{l}\text { Total } \\
\text { With Wood Fuels }\end{array}$ & $s \stackrel{459.8}{-}$ & $\stackrel{2,267.6}{-}$ & $\begin{array}{l}433.9 \\
150.0\end{array}$ & $\begin{array}{r}2,607.9 \\
748.2\end{array}$ & $\begin{array}{l}363.8 \\
169.5\end{array}$ & $\begin{array}{r}2,213.7 \\
839.2\end{array}$ & $\begin{array}{c}375.5 \\
-\end{array}$ & $\begin{array}{c}174.3 \\
-\end{array}$ & $\begin{array}{c}952.8 \\
-\end{array}$ & $\begin{array}{r}504.9 \\
59.0\end{array}$ & $\begin{array}{r}3,140.9 \\
206.5\end{array}$ & $\begin{array}{c}356.9 \\
-\end{array}$ & $\begin{array}{c}2,249.5 \\
-\end{array}$ \\
\hline $\begin{array}{l}\text { Percent Changes } \\
\text { With Wood Fuels }\end{array}$ & E & - & $\begin{array}{r}-5.6 \\
-67.4\end{array}$ & $\begin{array}{r}15.0 \\
-67.0\end{array}$ & $\begin{array}{l}-20.9 \\
-63.1\end{array}$ & $\begin{array}{r}-2.4 \\
-63.0\end{array}$ & $\frac{-18.3}{-}$ & -62.1 & $\stackrel{-58.0}{-}$ & $\begin{array}{r}9.8 \\
-87.2\end{array}$ & $\begin{array}{r}38.5 \\
-90.9\end{array}$ & -22.4 & -0.8 \\
\hline $\begin{array}{l}\text { LDV + HDV Total } \\
\text { Percent Changes } \\
\text { (w/materials + } \\
\text { assembly) }\end{array}$ & 568.3 & 564.3 & & 474.8 & & & 221.0 & & 663.1 & & 470.5 & & \\
\hline $\begin{array}{l}\text { With Wood Fuels } \\
\text { Percent Changes }\end{array}$ & & $\begin{array}{l}185.9 \\
-67.3\end{array}$ & & $\begin{array}{l}209.7 \\
-63.1\end{array}$ & & & & & & $\begin{array}{r}67.9 \\
-88.1\end{array}$ & & & \\
\hline
\end{tabular}

Notes:

1. Excludes CFCs.

2. "With wood fuels" refers to wood as a feedstock.

3. The first ethanol scenario is ethanol from com.

4. $\mathrm{HD}=$ heavy-duty application (diesel); LD = light-duty application (gasoline).

Table D-6 - Greenhouse Gas Emissions of Industrial Fuels (fuel-cycle $\mathrm{CO}_{2}$-equivalent emissions in grams per million Btu of net final product)

\begin{tabular}{lccccc}
\hline & $\begin{array}{c}\text { Boiler: } \\
\text { Coal }\end{array}$ & $\begin{array}{c}\text { Boiler: } \\
\text { Natural Gas }\end{array}$ & $\begin{array}{c}\text { Boiler: } \\
\text { Fuel Oil }\end{array}$ & $\begin{array}{c}\text { Industrial } \\
\text { Diesel Engines }\end{array}$ & LPG \\
\hline Total & 103,437 & 63,917 & 90,598 & 96,433 & $73,409^{\mathrm{a}}$ \\
\hline
\end{tabular}

a Emissions from combustion (other than $\mathrm{CO}_{2}$ ) are not included. 


\section{REFERENCES}

Delucchi, M.A. 1991. Emissions of Greenhouse Gases from the Use of Transportation Fuels and Electricity 1, no. ANL/ESD/TM-22.

Delucchi, M.A. 1993a. Emissions of Greenhouse Gases from the Use of Transportation Fuels and Electricity 2, no. ANL/ESD/TM-22.

Delucchi, M.A. 1993b. Revisions to the Greenhouse Gas Emissions Model Used in "Emissions of Greenhouse Gases from the Use of Transportation Fuels and Electricity." Draft, no. ANL/ESD/ TM-22.

Martin, D., and L. Michaelis. 1992. Global Warming Due to Transport. Proceedings, 25th ISATA, Silver Jubilee International Symposium on Automotive Technology and Automation (Dedicated Conference on Zero Emission Vehicles-The Electric/Hybrid and Alternative Fuel Challenge, Florence, Italy, June 1-5): Electric/Hybrid Vehicles: An Emerging Global Industry, Automotive Automation Limited, Croydon, England.

Intergovernmental Panel on Climate Change (IPCC) 1992. 1992 IPCC Supplement: Scientific Assessment of Climate Change. World Meteorological Organization and United Nations Environment Program.

Energy Information Administration (EIA). 1994. Supplement to Annual Energy Outlook 1994, no. EIA-0554 (94).

Singh, M. 1994. Analysis Memorandum: Energy Requirements and $\mathrm{CO}_{2}$-Equivalent Emissions of RFG, Argonne National Laboratory Memo (June 6). 


\section{ANNEX: REVISIONS TO THE GREENHOUSE-GAS EMISSIONS MODEL}

This annex describes the changes made by Delucchi to the greenhouse-gas emissions model since the publication of Emissions of Greenhouse Gases from the Use of Transportation Fuels and Electricity (Delucchi 1991). For each described change, the table or appendix affected in that report is indicated in parentheses. The overall effect of all these changes is to make alternative fuels more attractive. Table D-5 in Appendix D presents the base case incorporating these results.

\section{Revisions}

1. The global warming potential factors (GWPs) have been changed on the basis of: (a) recent work done by the Intergovernmental Panel on Climate Change (IPCC) (1992) and Martin and Michaelis (1992), and (b) Delucchi's calculations of emissions of nitrous oxide $\left(\mathrm{N}_{2} \mathrm{O}\right)$ from nitrogen that was deposited in the soil from atmospheric emissions of nitrogen oxides $\left(\mathrm{NO}_{\mathrm{x}}\right)$ (Table 8 ). This set of changes results in a greater change in fuelcycle carbon dioxide $\left(\mathrm{CO}_{2}\right)$-equivalent emissions than does any other change or set of changes described here. Recent estimates of the GWPs, including the ones used here, are summarized in Table DA-1 in this annex.

2. The ability of the model to calculate complete $\mathrm{CO}_{2}$-equivalent fuel-cycle emissions from mixtures of (a) conventional gasoline and reformulated gasoline, (b) gasoline and methanol (from coal, natural gas, or wood), and (c) gasoline and ethanol (from corn or wood) has been expanded. In the previous version of the model, you could specify either all reformulated gasoline or all conventional gasoline, but nothing in between. Now, you can specify any volumetric mixture of reformulated and conventional gasoline. You input the characteristics of conventional gasoline, the characteristics of reformulated gasoline, vehicular emission factors for conventional gasoline, and emissions factors for reformulated gasoline. The model calculates the characteristic of the specified fuel mixture, the fuel economy of a vehicle using the mixture, and emissions from a vehicle using the mixture. Emissions are calculated as grams per mile $(\mathrm{g} / \mathrm{mi})$ emission factors for conventional gasoline multiplied by the fraction of miles driven on conventional gasoline, plus $\mathrm{g} / \mathrm{mi}$ emission factors for reformulated gasoline multiplied by the fraction of miles driven on reformulated gasoline. The mileage fractions are calculated from the specified fuel mix and the thermal efficiency of using each fuel.

The previous version of the model could not estimate emissions from a mixture of biomassderived methanol and petroleum-derived gasoline. Now the model can estimate emissions from any mixture of biomass-derived methanol, or biomass-derived ethanol, with petroleum-derived gasoline. The procedure is as described above for mixtures of conventional gasoline and reformulated gasoline.

3. In this latest version of the model, reformulated gasoline can be characterized in more detail and more accurately than in the previous version. You can specify any volumetric mixture of alkanes, aromatics, olefins, ethyl tertiary-butyl ether (ETBE), methyl tertiarybutyl ether (MTBE), methanol, and ethanol. The model calculates the carbon content, density, and heating value of the specified gasoline. It is assumed that the base-case reformulated gasoline consists of 11.7 percent MTBE, 10.3 percent olefins, 24.6 percent aromatics, and the rest alkanes (Table C-2), on the basis of data presented in Singh and McNutt (1993).

4. The previous version of the model did not deduct from total $\mathrm{CO}_{2}$ emissions any $\mathrm{CO}_{2}$ emitted from the biomass-derived ethanol portion of ETBE additive. This has been corrected.

5. The model now calculates in complete detail the greenhouse-gas impact of oxygenates (ETBE, MTBE, ethanol, or methanol) added to gasoline. The model considers four ultimate components or sources of oxygenates: (a) methanol or ethanol added directly to gasoline, (b) methanol or ethanol made into MTBE or ETBE additive, (c) isobutylene made from field butanes in NGL plants and then made into MTBE or ETBE additive, and (d) isobutylene 


\section{Table DA-1 - Recent Estimates of the Global Warming Potential (GWP) of Non- $\mathrm{CO}_{2}$ Greenhouse Gases}

\begin{tabular}{|c|c|c|c|c|c|c|c|c|c|}
\hline $\begin{array}{l}\text { Time } \\
\text { Horizon } \\
\text { (years) }\end{array}$ & $\begin{array}{l}\mathrm{CH}_{4} \\
\text { Total } \\
\text { GWP }\end{array}$ & $\begin{array}{l}\mathrm{CH}_{4} \\
\text { IPCC } \\
\text { Direct } \\
\text { GWP }\end{array}$ & $\begin{array}{l}\mathrm{N}_{2} \mathrm{O} \\
\text { Total } \\
\text { GWP }\end{array}$ & $\begin{array}{l}\mathrm{N}_{2} \mathrm{O} \\
\text { IPCC } \\
\text { Direct } \\
\text { GWP }\end{array}$ & $\begin{array}{l}\text { CO } \\
\text { Total } \\
\text { GWP }\end{array}$ & $\begin{array}{l}\text { NMHC } \\
\text { Total } \\
\text { GWP }\end{array}$ & $\begin{array}{l}\mathrm{NO}_{2} \\
\text { Total } \\
\text { GWP }\end{array}$ & $\begin{array}{c}\text { CFC-12 } \\
\text { Total } \\
\text { GWP }\end{array}$ & $\begin{array}{l}\text { CFC-12 } \\
\text { IPCC } \\
\text { Total } \\
\text { GWP }\end{array}$ \\
\hline \multicolumn{10}{|c|}{ Intergovernmental Panel on Climate Change ${ }^{\mathrm{a}}$} \\
\hline 20 & 63 & 34 & 270 & 250 & 7 & 31 & $30^{b}$ & 7,100 & 7,000 \\
\hline 100 & 21 & 11 & 290 & 270 & 3 & 11 & $7^{\mathrm{b}}$ & 7,300 & 7,100 \\
\hline 500 & 9 & 4 & 190 & 170 & 2 & 6 & $2^{b}$ & 4,500 & 4,100 \\
\hline \multicolumn{10}{|c|}{ Energy Technology Support Unit } \\
\hline $50^{c}$ & 26.5 & & 270 & & 3 & 8.8 & 3 & 7,350 & \\
\hline \multicolumn{10}{|c|}{ This Project } \\
\hline $100^{d}$ & 21 & & 270 & & 2 & 5 & $4^{f}$ & lot used & \\
\hline
\end{tabular}

a The results for the 20-, 100-, and 500-year time horizons are from the Intergovernmental Panel on Climate Change. The "total GWPs" are the preliminary estimates published by the IPCC in 1990 (Shine et al. 1990). The "IPCC direct GWPs" are updated/revised estimates of direct-warming components of the GWPs; they do not include indirect warming effects (Climate Change 1992 1992). The IPCC now characterizes the indirect-warming effect of $\mathrm{CH}_{4}$ as positive and perhaps of the same order of magnitude as the direct-warming effect; the indirect-warming effect of $\mathrm{N}_{2} \mathrm{O}$ as "uncertain," and the indirect-warming effect of CFC-12 as negative and perhaps equal in magnitude to the positive direct (radiativeforcing) effect (Climate Change 1992 1992).

b The GWPs originally published in Shine et al. (1990) were: 150, 40, and 14, for the 20-, 100-, and 500-year time horizons. However, those values were incorrect due to an error in the calculation of ozone inventory changes (Johnson et al. 1992). The corrected values are shown here (for emissions of $\mathrm{NO}_{x}$ at Earth's surface) (Johnson et al. 1992).

c The results for the 50-year time horizon are from modeling done by Harwell Laboratories of the Energy Technology Support Unit (ETSU) in Great Britain (Martin and Michaelis 1992). The ETSU work appears to improve upon the IPCC work in some respects: it re-estimates the global-warming effect of ground level ozone; it accounts for the effects of $\mathrm{CO}$, $\mathrm{NMHCs}$, and $\mathrm{NO}_{\mathrm{x}}$ emissions on methane concentrations; and it distinguishes between emissions of $\mathrm{NO}_{x}$ at ground level and emissions at higher levels.

d Based on the estimates by IPCC and Martin and Michaelis (1992) cited in this table.

- The GWP for NMHCs is applied to the carbon content of NMHCs only. Thus, NMHCs with a higher carbon content have higher GWP. This is reasonable, because a higher carbon content results in more $\mathrm{CO}_{2}$ production when the NMHC is oxidized and, generally, in greater ozone production.

'This is the sum of a GWP of 2 due to ozone production, and a GWP of 2 due to $\mathrm{N}_{2} \mathrm{O}$ emissions from deposition of atmospheric nitrogen.

made from crude oil in refineries and then made into MTBE or ETBE additive. First, the model calculates the mass (not volume) of crude oil displaced by oxygenates of type (a), (b), or (c), and the corresponding reduction in the mass of crude oil that must be recovered, transported, and refined to make a unit of gasoline. (Chemical properties for alcohols and ethers are from the CRC Handbook of Chemistry and Physics [1975].) This reduction in the amount of crude oil that must be recovered, transported, and refined per unit of gasoline reduces fuel-cycle $\mathrm{CO}_{2}$-equivalent emissions attributable to reformulated gasoline. But the model then adds complete fuel-cycle greenhouse-gas emissions from the production of the components of the oxygenates-alcohol and natural-gas-liquid-derived butane-and from the manufacture of the oxygenates. The model assumes that any methanol or ethanol of types (a) or (b) comes from the same fuel production-and-delivery cycle as the methanol or ethanol that is used directly by alcoholfueled vehicles. The model estimates complete 
fuel-cycle $\mathrm{CO}_{2}$-equivalent emissions from the production of butanes (used to make isobutylene) in natural-gas-liquid plants. (Emissions from the production of butanes in refineries is assumed to be accounted for in the estimate of emissions from the manufacture of hydrocarbons in refineries.) Finally, the model estimates emissions from the manufacture of MTBE or ETBE-that is, from the conversion of butanes and alcohols to MTBE or ETBE.

(This last step might involve some double counting, because the energy required to convert butanes to isobutylene might be included already in the estimates of refinery energy requirements.)

The model incorporates all of the information from Singh and McNutt (1993), and even goes beyond, with three refinements: First, as mentioned above, the model estimates complete fuel-cycle emissions from the production of oxygenates and oxygenate components. For example, it includes emissions from the use of electricity to produce the natural gas from which the butane used to make isobutylene is derived. Second, the model calculates chemical properties of mixtures and components from primary data on characteristics of organic compounds. Third, the model gives an emissions credit for the fuel-gas byproduct of MTBE and ETBE production. It is assumed that this fuel-gas is composed partly of the hydrogen that must be removed from the butane to make isobutylene, and partly of the leftover butane or butane derivatives (more butane is consumed than is needed for the reaction stoichiometry). This suggests that the fuel-gas byproduct, which is considerable, is rather like refinery gas, which is mainly hydrogen. Therefore, it is assumed that the fuel-gas byproduct displaces refinery gas.

Recently, Hesse et al. (1993) have described an integrated plant that produces ethanol, methanol, ETBE, and MTBE from input corn and butane. The butane is made into isobutane and then into isobutylene, and the corn is made into ethanol. The $\mathrm{CO}_{2}$ off-gas from ethanol production and the hydrogen offgas from isobutylene production are combined to make methanol. The methanol and ethanol can be combined with the isobutylene to make
MTBE or ETBE. This process probably results in lower $\mathrm{CO}_{2}$ emissions than the conventional process assumed above because the methanol is made from $\mathrm{CO}_{2}$ from the corn section that otherwise would be vented.

6. The previous version of the model did not account for emissions from the production and transport of the portion of the crude oil that ends up being used as fuel gas or petroleumcoke fuel in refineries (Table A-1). This has been corrected. Refinery gas and petroleum coke have been added to Tables 3,5 , and 7 .

7. In the table showing grams of emissions per million Btu (Table 7), the liquefied petroleum gas (LPG) column has been separated into LPG from natural gas, and LPG from oil.

8. Some assumptions about electric vehicles (EVs) have been changed: the lifetime has been reduced from 153,000 miles to 144,000 miles ( 1.33 times longer than the internal combustion engine vehicle (ICEV) rather than 1.42 times; Table P-2); the battery efficiency has been increased from 75 percent to 80 percent (on the basis of recent test data from Argonne National Laboratory (ANL) for sodium-sulfur batteries); and the ratio of the EV drivetrain efficiency to the ICEV drivetrain efficiency has been increased from 5.7 to 5.9 , on the basis of work published by Delucchi (1992) (Table 2).

9. In Appendix $A$ and Appendix $R$ the following equation was given:

$$
\frac{1}{M_{i}}=\left(1+T_{i}\right)\left(\frac{M P G_{p}}{D_{p}}\right)+\left(1+\frac{W f W_{i}}{W_{p}}\right)
$$

where

$M_{i}=10^{6} \mathrm{Btu} / \mathrm{mi}$ efficiency of AFV $I$,

$T_{i}=$ thermal efficiency advantage (in $\mathrm{mi} / \mathrm{Btu}$ ) or disadvantage of fuel $l$, compared to petroleum fuel $p$,

$W f=$ percent decrease in fuel economy (in $\mathrm{mi} / \mathrm{Btu}$ ) per 1 percent increase in vehicle weight, 
$W_{i}=$ the extra weight of AFV / compared to petroleum-fuel vehicle $p$,

$W_{p}=$ the total driving weight of petroleum-fuel vehicle $p$,

$M P G_{p}=$ the miles-per-gallon fuel economy of petroleum-fuel vehicle $p$, and

$D_{p}=$ the $10^{6} \mathrm{Btu} / \mathrm{gallon}$ density of petroleum fuel $p$.

This equation is wrong. The correct equation is:

$$
\frac{1}{M_{i}}=\left(1+T_{i}\right)\left(\frac{M P G_{p}}{D_{p}}\right)+\left(1-\frac{W f W_{i}}{W_{p}}\right)
$$

This has been corrected in the model.

10. The light-duty-vehicle (LDV)- $\mathrm{N}_{2} \mathrm{O}$ emission factor has been changed to 50 milligrams per mile, on the basis of new data (for example, Dasch, 1992, and other sources), and a reconsideration of the original data (Table B-2).

11. The tailpipe methane $\left(\mathrm{CH}_{4}\right)$ emission rate from natural gas vehicles has been changed from $1.2 \mathrm{~g} / \mathrm{mi}$ to $1.0 \mathrm{~g} / \mathrm{mi}$ (Table B-2), based in part on the data from a medium-duty compressed natural gas (CNG) van that has certified to the California Air Resources Board's (CARB's) ultra-low-emission vehicle (ULEV) standards.

\section{2. "Upstream" nonmethane hydrocarbon} (NMHC) emissions from gasoline marketing (excluding emissions from vehicle refueling, but including emissions from refilling storage tanks at service stations) have been reclassified as "fuel distribution" emissions rather than as "vehicular" emissions (Table 5, Table 9, and Table B-1).

13. In the previous version of the model, the measure of refinery energy use, Btu-refineryenergy per Btu-gasoline, was with respect to Btu of complete gasoline product (including anything produced outside of the refinery, such as MTBE), not just to the refinery-produced hydrocarbon portion of the gasoline.The meaning of the measure has been changed to Btu- refinery-energy per Btu-gasoline-HC, where the denominator includes only the refineryproduced hydrocarbon portion of the gasoline-not, for example, the energy value of any MTBE produced outside of the gasoline (Table $\mathrm{H}-6$ ). Conceptually, it is now being assumed in effect that any methanol or ethanol (as such, or in MTBE or ETBE) is added to the gasoline outside of the refinery gates.

14. A minor mistake in the calculation of vehicular curbweight versus loaded weight has been corrected (Table 2).

15. The estimate of the breakdown of materials that will be used in automobiles in the year 2000 has been changed, on the basis of trends over the past decade toward greater use of plastics and aluminum (Table P-4) (Motor Vehicle Manufacturers Association 1992).

16. Several assumptions regarding natural gas leaks and emissions have been changed to reflect the findings of a recent Environmental Protection Agency (EPA) report to Congress (1992) and other sources. The new values are: 0.20 percent natural gas leakage and release from distribution systems, 0.22 percent leakage and release from transmission, and 0.31 percent leakage and release from production (Table 5); 225 standard cubic feet (SCF)methane per ton of coal mined (Table 5). Also, as discussed below, the split between gasfired pipeline compressor reciprocating engines and gas-fired pipeline compressor turbines has been changed (Appendix $G$ ), as have the emission factors for pipeline compressors (Table A-1).

17. It is now assumed that 10 percent of all vented or flared gas is vented (not flared), and that 90 percent is flared, on the basis of a reexamination of the data, as well as data from other sources (for example, Barns and Edmonds 1990). The original vented fraction was 6 percent (p. M-25).

18. The $\mathrm{CH}_{4}$ rate from petroleum refineries has been increased from 0.4 gram per $106 \mathrm{Btu}$ to 1.2 gram per $106 \mathrm{Btu}$, on the basis of a reexamination of original data (Table A-1). 
19. The $\mathrm{CH}_{4}$ emission rate from natural-gas-tomethanol plants has been increased, on the basis of a reconsideration of the original data, as well as new data from Heath (1991) and Ecotraffic $A B$ (1992) (Table A-1).

20. The compression energy requirement for compressed natural gas (CNG) has been reduced from 0.05 Btu-electric per Btu-CNG to 0.022 , on the basis of calculations of compressor-work requirements using engineering equations and actual energy-use data from CNG stations operated by Pacific Gas and Electric (1993) (Table 3). The requirements for hydrogen compression have been changed from 0.030 to 0.033 , on the basis of calculations of compressor work (Table 3; the value actually shown in Table $3,0.300$, is a misprint; it should have been 0.030).

21. The assumed efficiency of the base-case natural-gas-to-methanol plant has been changed from 65 percent to 66.7 percent (Table 3).

22. The assumed efficiency of wood-tomethanol conversion has been increased from 57 percent to 62.5 percent, but so have the electricity requirements for the wood-tomethanol plant, from 0.02 Btu-electric per Btumethanol to 0.03 (Tables 3 and 4), partly on the basis of data in Stone and Lynd (1993).

23. Some of the assumptions about productivity, fertilizer use, and $\mathrm{N}_{2} \mathrm{O}$ emissions of woodybiomass short-rotation intensive-cultivation (SRIC) systems have been changed. The new assumptions are: 7 tons of wood per acre per year yield; 67 percent of acreage fertilized; 50 pounds of nitrogen, 15 pounds of potassium, and 15 pounds of phosphorous per acre per year; and 0.6 percent of added nitrogen evolved as nitrogen in $\mathrm{N}_{2} \mathrm{O}$. These can be compared with the original assumptions in Appendices $\mathrm{K}$ and $\mathrm{N}$. The new numbers are based in part on Turhollow and Perlack (1991).

24. A review of some of the literature on carbon dioxide emissions from soil found no strong relationship, one way or the other, between the amount of nitrogen fertilizer added and $\mathrm{CO}_{2}$ emissions from soil.
25. The $\mathrm{N}_{2} \mathrm{O}$ emission rate from refineries has been reduced from 1.0 gram per 106 Btu to 0.5 gram per $106 \mathrm{Btu}$, partly on the basis of recent data that indicate that catalytic crackers have low $\mathrm{N}_{2} \mathrm{O}$ emissions (Cooper and Emanuelsson 1992) (Table A-1).

26. In the biomass-to-hydrogen path, 1.30 Btuwood per Btu hydrogen, and 0.065 Btuelectricity per Btu-hydrogen are assumed, partly on the basis of data in Katofsky (1993).

27. Since publication of the 1991 report, EPA has issued two supplements to AP-42, the last one dated October 1992. On the basis of these supplements, the emission factors have been updated for the following:

- Wood-waste combustion in boilers. The $\mathrm{CH}_{4}, \mathrm{NMHC}$, carbon monoxide (CO), and $\mathrm{NO}_{x}$ factors have been updated, using $\mathrm{CO}$ and $\mathrm{NO}_{x}$ emission factors for fluidized-bed combustion and using the $\mathrm{CH}_{4} / \mathrm{NMHC}$ ratio from the previous edition of $A P-42$ (Table $A-1)$.

- Natural-gas turbines for power production. The $\mathrm{CH}_{4}, \mathrm{NMHC}$, and $\mathrm{NO}_{x}$ emission factors have been updated (Table D-4).

- Gas-turbine and gas reciprocating engine pipeline compressors. EPA's updated factors for uncontrolled emissions of $\mathrm{CH}_{4}, \mathrm{CO}$, and nonmethane organic compounds (NMOCs) have been used (Table D-5). It is assumed that $\mathrm{NO}_{x}$ emissions from the population of gas-turbine compressors are 25 percent below uncontrolled levels, and that emissions from the population of reciprocating engines are 50 percent below uncontrolled levels. It is assumed that more reciprocating engines than turbines are controlled because uncontrolled $\mathrm{NO}_{\mathrm{x}}$ emissions from turbines are nearly 10 times lower than uncontrolled emissions from reciprocating engines to begin with.

- Gasoline and diesel industrial engines. The updated factors for uncontrolled emissions have been used (Table D-5).

- Large stationary diesel engines, used primarily in oil and gas fields. The up- 
dated factors for uncontrolled emissions of $\mathrm{CO}, \mathrm{NMOCs}$, and $\mathrm{CH}_{4}$ have been used. It is assumed that $\mathrm{NO}_{x}$ emissions from the population are 20 percent below uncontrolled levels (Table D-5).

28. The October 1992 AP-42 update states that "population statistics show a nearly equal installed capacity of turbines and reciprocating engines" (EPA 1992, 3.2-1). This is not quite consistent with Delucchi's survey and literature review, which indicated that the total installed capacity of reciprocating engines is higher than the total installed capacity of turbines. In any case, in the current version of the model, it is assumed that the installed horsepower-hour capacity of turbines is slightly less than the installed capacity of engines, but that engines use energy more efficiently, so that total energy use by turbines equals total energy use by reciprocating engines. Specifically, it is assumed that 49.4 percent of pipeline energy is used in turbines, 49.4 percent in reciprocating engines, and 1.3 percent in electricity-driven compressors (Table 4). EPA states that "for reciprocating engines, two stroke designs contribute approximately two-thirds of installed capacity" (p. 3.2-1). For the emission model, it is assumed that two-thirds of the energy used by reciprocating engines is used in 2-cycle lean-burn engines, that one-sixth is used in 4cycle lean-burn engines, and that one-sixth is used in 4-cycle rich-burn engines.

\section{References}

Barns, D.W., and J.A. Edmonds. 1990. An Evaluation of the Relationship Between the Production and Use of Energy and Atmospheric Methane Emissions, no. DOE/NBB-088P.

Cooper, D.A., and A. Emanuelsson. 1992. $\mathrm{N}_{2} \mathrm{O}$ emissions from a fluidized bed catalytic cracker. Energy \& Fuels 6:172-175.

Weast, R.C., ed. 1975. CRC Handbook of Chemistry and Physics. 56th ed. Cleveland: CRC Press.

Dasch, J.M. 1992. Nitrous oxide emissions from vehicles. Journal of the Air and Waste Management Association 42:63-67.

Delucchi, M.A. 1991. Emissions of Greenhouse Gases from the Use of Transportation Fuels and Electricity 1, no. ANL/ESD/TM-22.

Delucchi, M.A. 1993. Emissions of Greenhouse Gases from the Use of Transportation Fuels and Electricity 2, no. ANL/ESD/TM-22.

Delucchi, M.A. 1993. Revisions to the Greenhouse Gas Emissions Model Used in "Emissions of Greenhouse Gases from the Use of Transportation Fuels and Electricity." Draft, no. ANL/ESD/ TM-22.

Delucchi, M.A. 1992. Hydrogen Fuel-Cell Vehicles. Institute of Transportation Studies, University of California, Davis. no. UCD-ITS-RR-92-14.

Ecotraffic AB. 1992. The Life Of Fuels: Motor Fuels from Source to End Use. Stockholm: Ecotraffic $A B$.

Environmental Protection Agency (EPA). 1992. Anthropogenic Methane Emissions in the United States: Estimates for 1990, Report to Congress. Review Draft.

EPA. 1985, with supplements to 1992. Compilation of Air Pollutant Emission Factors I, Stationary Sources. 4th ed. Office of Air and Radiation. AP-42. 
Heath, M. 1991. Alternative Transportation Fuels, Natural Gas, Methanol, and Ethanol Compared with Gasoline and Diesel. Study no. 37. Calgary, Canada: Canadian Energy Research Institute.

Hesse, R.J., N.E. Anderson, and D.E. Hallberg. 1993. Showing Commercial Promise: Manufacturing Ethanol, Methanol, and Their Ethers Within the Same Complex. Fuel Reformulation (March/April): 50-57.

Intergovernmental Panel on Climate Change (IPPC). 1992. 1992 IPCC Supplement: Scientific Assessment of Climate Change. World Meteorological Organization and United Nations Environment Program.

Johnson, C., J. Henshaw, and G. Mclnnes. 1992. Impact of Aircraft and Surface Emissions of Nitrogen Oxides on Tropospheric Ozone and Global Warming. Nature 355:69-71.

Katofsky, R.E. 1993. The Production of Fluid Fuels from Biomass. Center for Energy and Environmental Studies, Princeton University. PU/CEES report no. 279.

Martin, D., and L. Michaelis. 1992. Global Warming Due to Transport. Proceedings, 25th ISATA, Silver Jubilee International Symposium on Automotive Technology and Automation (Dedicated Conference on Zero Emission Vehicles-The Electric/Hybrid and Alternative Fuel Challenge, Florence, Italy, June 1-5): Electric/Hybrid Vehicles: An Emerging Global Industry, Automotive Automation Limited, Croydon, England.

Motor Vehicle Manufacturers Association (MVMA).1992. MVMA Facts \& Figures '92. Detroit: MVMA.

Personal Communication from Pacific Gas and Electric to M.A. Delucchi. 1993.

Shine, K.P., R.G. Derwent, D.J. Wuebbles, and J.J. Morcrette. 1990. Radiative forcing of climate. In Climate Change, the IPCC Scientific Assessment. J.T. Houghton, G.J. Jenkins, and J.J. Ephraums, eds. Cambridge, England: Cambridge University Press (pp. 42-68).

Singh, M., and B. McNutt. 1993. Energy and Oil Input Requirements for the Production of Reformulated Gasoline, report no. ANL/ESD-19.

Stone, K., and L.R. Lynd. Analysis of Internal and External Energy Flows Associated with Projected Process Improvements in Biomass Ethanol Production. Paper presented at the 1993 Automotive Technology Contractors' Coordination Meeting, Society of Automotive Engineers.

Turhollow, A.F., and R.D. Perlack. 1991. Emissions of $\mathrm{CO}_{2}$ from Energy Crop Production. Biomass and Bioenergy 1:129-135. 


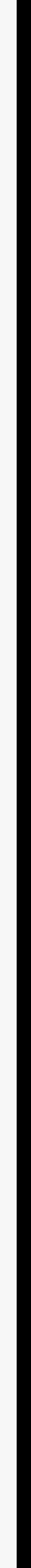

